Luís Mauro Pereira Freitas Jr.

\title{
ESTUDO DA DINÂMICA VERTICAL DE UMA SUSPENSÃO VEICULAR DO TIPO MACPHERSON
}

\begin{abstract}
Dissertação apresentada à Escola de Engenharia de São Carlos da Universidade de São Paulo, como parte dos requisitos para a obtenção do título de Mestre em Engenharia Mecânica
\end{abstract}

ORIENTADOR: Prof. Dr. Luiz Carlos Felício 
Dedico este trabalho e ao meu Pai ("in memoriam") e à minha Mãe ... 


\section{AGRADECIMENTOS}

Gostaria de agradecer ao Prof. Dr. Luiz Carlos Felício pelo seu empenho, dedicação e força em fazer-me atingir meu objetivo.

Também quero agradecer ao Prof. Dr. Álvaro Costa Neto.

Gratidão especial à minha esposa Betânia, pela ajuda, apoio, incentivo e compreensão durante estes dois últimos anos.

Sou grato à Volkswagen do Brasil por permitir-me dedicação a este a trabalho.

À todos os colegas da Volkswagen e da Escola de Engenharia de São Carlos que ajudaram-me de alguma forma.

Obrigado 


\section{Resumo}

Freitas, Luís M. (2005). Estudo da Dinâmica Vertical de uma Suspensão Veicular do Tipo MacPherson. São Carlos, 2006. 122 p. Dissertação (Mestrado) - Escola de Engenharia de São Carlos, Universidade de São Paulo.

O sistema de suspensão de um veículo desempenha papel fundamental na isolação das vibrações provenientes da pista e de outras fontes de excitações e tem como alguns de seus objetivos: melhoria do conforto dos passageiros, manutenção da integridade das cargas e das vias (asfalto), aumento da segurança, proporcionando melhores condições de aderência pneu-piso, etc.

A predição do desempenho de um sistema de suspensão veicular antes da construção de um protótipo físico, permite o dimensionamento prévio dos componentes que o integram com maior precisão, otimizando-se, desta forma, o custo final do produto bem como custos e prazos decorrentes de modificações para solucionar problemas que seriam detectados somente na experimentação do protótipo físico.

Este trabalho apresenta um comparativo entre os resultados analíticos obtidos utilizando-se as funções transferências de um modelo simplificado (ou clássico) linear de uma suspensão automotiva de $1 / 4$ de veículo (quarter-car); dos obtidos através da utilização de um "protótipo virtual" do mesmo modelo simplificado (ou clássico) de 1/4 de veículo e, por fim, dos obtidos utilizando-se um protótipo virtual de um sistema de suspensão do tipo MacPherson, sendo que os protótipos virtuais podem trabalhar com não-linearidades.

São obtidas as respostas dinâmicas no domínio da frequência $(0$ a $30 \mathrm{~Hz})$ e também no domínio do tempo, neste último caso utilizando-se como entrada um "pulso" no pneu, que simula a passagem do veículo sobre um obstáculo a $18 \mathrm{Km} / \mathrm{h}$.

Os resultados são comparados objetivamente e conclui-se sobre as limitações de utilização do modelo simplificado (ou clássico) de 1/4 de veículo.

Palavras-chave: Dinâmica Vertical, Modelagem de Suspensões, Suspensão Macpherson 


\begin{abstract}
Freitas, Luís M. (2006). A Study About the Vertical Dynamic of a MacPherson Vehicle Suspension System. São Carlos, 2006. 122 p. M. Sc. Dissertation Escola de Engenharia de São Carlos, Universidade de São Paulo, 2006.
\end{abstract}

The performance of the suspension system of a vehicle is fundamental to isolate the vibrations from road and from other sources and has the following objetives: improve the comfort of passengers (ride), protect the cargo and the road (asphalt), improve vehicle handling, etc.

The prediction of the performance of a vehicle's suspension system prior to the real prototype construction, allows the previous optimization of the design of the suspension's components, obtaining a low cost product, in a shorter timming, with lower development costs, by solving problems that would be evident only during the tests with the real prototype.

This study presents a comparison between analitycal results obtained by the use of transfers functions of a plain or classical linear model of a automotive suspension system named "quarter-car"; the results obtained from a "virtual prototype" of the same plain or classical model and, finally, the results obtained from a "virtual prototype" of a Macpherson suspension system, considering that the virtuals prototypes are be able to work with non-linearities.

The dynamic response are obtained in the frequency domain $(0 \mathrm{a} 30 \mathrm{~Hz})$ and in the time domain too, in this last case, with a pulse input in the tire, that simulates the car passing over a bump with a speed of $18 \mathrm{Km} / \mathrm{h}$.

Through the comparison of the results is possible to conclude about the limitations of the classical model.

Key words: Ride, Suspension Modeling, Macpherson Suspension 


\section{Sumário}

Resumo

Abstract

Cap. 1 - Introdução

Cap. 2 - Revisão Bibliográfica 4

2.1 - Evolução dos Estudos sobre Dinâmica Vertical 4

2.2 - Principais Tipos de Sistema de Suspensão 21

2.2.1 - Eixos rígidos 21

2.2.2 - Suspensões Independentes 24

2.3 - Principais Componentes dos Sistemas de Suspensão 29

2.3.1 - O componente Mola, tipos e características 31

2.3.1.1 - Mola Semi-elíptica (feixe de molas) 31

2.3.1.2 - Mola Helicoidal $\quad 34$

2.2.1.3 - Mola a Ar ou Pneumática 40

2.3.2 - Batente ou Mola Auxiliar 41

2.3.3 - O componente Amortecedor, tipos e características 42

2.3.3.1 - Amortecimento Dependente do Curso 44

2.3.3.2 -Amortecedor utilizado nas Suspensões MacPherson 46

2.3.4 - Os Isoladores, tipos e características $\quad 49$

2.3.5 - O Pneu, tipos e características $\quad 54$

$\begin{array}{ll}2.4 \text { - Fundamentos } & 57\end{array}$

2.4.1 - Introdução $\quad 57$

2.4.2 - Resposta Dinâmica do Veículo $\quad 59$

2.4.3 - Influência da Rigidez da Suspensão $\quad 62$

2.4.4 - Influência do Amortecimento da Suspensão 65

Cap. 3 - Justificativa e Objetivos $\quad 67$

$\begin{array}{ll}3.1 \text { - Justificativa } & 67\end{array}$

3.2 - Objetivos $\quad 69$ 
$\begin{array}{ll}4.1 \text { - Modelagem } & 70\end{array}$

4.1.1 - Modelo Simplificado (ou Clássico) de 1/4 de Veículo 70

4.1.1.1 - Modelagem Analítica $\quad 70$

4.1.1.2 - Modelagem do Protótipo Virtual relativo ao Modelo Simplificado 75

4.1.2 - Modelagem do Protótipo Virtual da Suspensão Dianteira Macpherson $\quad 77$

4.1.3 - Principais diferenças entre o Modelo Simplificado, o PV MacPherson e o Real 79

4.1.3.1 - Amortecedor com amortecimento dependente do curso ou posição 80

4.1.3.2 - Atrito e carga lateral no amortecedor 81

4.1.3.3 - Mola com Carga Lateral $\quad 82$

4.1.3.4 - Interação Pneu x Solo $\quad 83$

4.2 - Metologia

4.2.1 - Obtenção das respostas dinâmicas no domínio da frequência 85

4.2.1.1 - Metodologia aplicada no Modelo Simplificado (ou Clássico) 85

4.2.1.2 - Protótipo Virtual do Sistema de Suspensão MacPherson 88

4.2.2 - Obtenção das respostas dinâmicas no domínio do tempo 89

Cap. 5 - Resultados e Análises $\quad 91$

5.1 - Resultados $\quad 91$

5.1.1 - Resultados no Domínio da Frequência 91

5.1.1.1 - RF utilizando o Modelo Simplificado Linear e Metódo Analitico 91

5.1.1.2 - RF utilizando o Protótipo Virtual do Modelo Simplificado Linear 95

5.1.1.3 - Considerações sobre as RF's obtidas 96

5.1.1.4 - RF utilizando o Protótipo Virtual MacPherson 97

5.1.1.5 - Análise dos Resultados da RF 100

5.1.1.6 - Influência do Amortecimento Não-linear 104

5.1.1.7 - Conclusão sobre os Resultados no Domínio da Frequência 107

$\begin{array}{ll}\text { 5.1.2 - Resultados no Domínio do Tempo } & 108\end{array}$

5.1.2.1 Deslocamento Vertical da Massa Supensa 108

5.1.2.2 Deslocamento Vertical da Massa Não-suspensa 109

5.1.2.3 Aceleração da Massa Suspensa 111

5.1.2.4 Aceleração da Massa Não-suspensa 112

5.1.2.5 Força no Pneu 113

5.1.2.6 Velocidade de Acionamento do Amortecedor $\quad 114$

5.1.2.7 Curso Utilizado do Amortecedor 116

5.1.2.8 Carga na Mola Auxiliar e Batente 117

5.1.2.9 Influência do Amortecimento Não-linear $\quad 120$

5.1.2.10 Conclusão sobre os Resultados no Domínio do Tempo 125 
Cap. 6 - Conclusões

Referências Bibliográficas 


\section{Capítulo 1 - Introdução}

A dinâmica vertical (ride) trata do comportamento do veículo e dos seus ocupantes quando submetidos a excitações provenientes do piso em que o veículo trafega (externas) ou provenientes do motor, roda, transmissão, etc (internas).

O sistema de suspensão dos veículos desempenha papel fundamental na isolação das vibrações resultantes destas excitações e seus principais objetivos são:

- melhoria do conforto dos passageiros;

- manutenção da integridade das cargas;

- aumento da segurança, proporcionando melhores condições de aderência no contato pneu-piso

A eficiência ou o desempenho de um sistema de suspensão em isolar vibrações e em propiciar o melhor contato possível pneu-solo pode ser avaliado de forma experimental, utilizando-se um protótipo físico, mas também de forma teórica, utilizando-se um modelo dinâmico.

Com o auxílio de um modelo dinâmico é possível a predição do desempenho de um sistema de suspensão antes de sua existência física.

A predição do desempenho de um sistema de suspensão antes da sua construção permite a otimização e o dimensionamento prévio dos componentes que o integram, com maior precisão. São minimizados, desta forma, custos e prazos decorrentes de modificações de componentes para solucionar 
problemas que seriam detectados somente na experimentação do protótipo físico.

A criação de um modelo dinâmico que forneça resultados teóricos mais próximos possíveis da realidade sempre foi um grande desafio para os engenheiros.

A evolução das ferramentas computacionais permite hoje a criação dos chamados "protótipos virtuais" que fornecem predições muito mais precisas e próximas da realidade.

A construção de protótipos virtuais, bem como a execução de testes virtuais, é possível através do programa computacional ADAMS (Automatic Dynamic Analysis of Mechanical Systems) que utiliza simulação de sistemas multi-corpos.

A construção de protótipos virtuais que forneçam predições muito mais precisas e próximas da realidade, apesar das vantagens em relação à prótótipos físicos, demandam recursos financeiros e tempo maiores do que modelos dinâmicos simplificados.

Um modelo dinâmico clássico, simplificado, generalista - pode ser utilizado para variados tipos de suspensão - e bastante conhecido, que representa o sistema de suspensão de um veículo, é o modelo denominado "1/4 de veículo" (quarter-car) com 2 graus de liberdade.

Por ser um modelo dinâmico simplificado e generalista, apresenta resultados cuja congruência com a realidade pode depender de uma série de características específicas e intrínsecas ao tipo de suspensão estudado como atrito, geometria, topologia dos componentes, não-linearidades, etc., as quais são apresentadas no capítulo 2 deste trabalho.

A análise da influência destas características específicas e intrínsecas a cada tipo de suspensão permite delimitar o uso do modelo simplificado (ou clássico) de 1/4 de veículo.

Este trabalho apresenta uma análise da influência de algumas destas características específicas e intrínsecas a uma suspensão do tipo MacPherson de um veículo nacional, através da comparação dos resultados analíticos obtidos utilizando-se as funções transferências do modelo simplificado (ou clássico) de 1/4 de veículo; dos obtidos através de um protótipo virtual do 
mesmo modelo simplificado e, por fim, dos obtidos utilizando-se um protótipo virtual de um sistema de suspensão do tipo MacPherson.

São obtidas as respostas dinâmicas no domínio da frequência $(0$ a $30 \mathrm{~Hz})$ e também no domínio do tempo, neste último caso utilizando-se como entrada um "pulso" no pneu, que simula a passagem do veículo sobre um obstáculo a $18 \mathrm{Km} / \mathrm{h}$.

Os resultados são comparados qualitativa e quantitativamente e concluise sobre a limitação de utilização do modelo simplificado (ou clássico) de 1/4 de veículo. 


\section{Capítulo 2 - Revisão Bibliográfica}

\subsection{Evolução dos Estudos sobre Dinâmica Vertical}

No início do século $X X$ já eram discutidos fenômenos básicos da dinâmica vertical. LANCHESTER, em 1907, aborda aspectos da frequência natural no modo vertical, considerando aceitáveis valores abaixo de $1.50 \mathrm{~Hz}$. A necessidade de dissipar energia de forma a eliminar as oscilações, já era evidente e, como a utilização de amortecedores era recente, LANCHESTER apontava como vantajosa a utilização de feixes de molas, em função deste dissipar de energia devido ao atrito entre as lâminas.

HELE-SHAW ressalta que a importância de uma suspensão macia vai além do conforto gerado, mas também que, por impor menores esforços, melhora a durabilidade do veículo e enfatiza a utilização de amortecedores, considerando que a sua ação deve ser somente na tração.

MAX LAWRENCE também enfatiza a ação do amortecedor somente na tração e considera importante a relação entre massa suspensa e nãosuspensa, sendo que quanto menor a massa não-suspensa, menores os efeitos que esta terá sobre a massa suspensa. Na opinião de LANCHESTER o amortecedor deve atuar tanto na tração como na compressão. Defendia, também, que não era simples a definição do amortecimento.

Ainda no início do século, ARCHIBALD SHARP já fala sobre as vantagens de utilização de uma suspensão a ar para automóveis, obtendo-se desta forma, valores mais baixos para a rigidez vertical.

Por volta de 1910, LITCHFIELD apresenta seu trabalho sobre pneumáticos, mostrando o enorme benefício para o conforto dos passageiros e 
chama J. B. DUNLOP para falar de seu invento. J. B. DUNLOP instalou pneumáticos na bicicleta de seu filho baseado em uma carroça equipada com pneumáticos, que vira quando criança, em torno de 1845 , ano em que R. W. THONSON patenteou o pneumático.

OLLEY da Rolls-Royce of America, por volta de 1921, aborda aspectos sobre as condições das pistas, consideradas de excelente qualidade na Inglaterra, de qualidade diversificada na França e de má qualidade nos Estados Unidos em geral. Com relação às suspensões dos veículos, era predominante a utilização de feixes de molas tanto na Europa quanto nos Estados Unidos.

Ainda no início dos anos 20, ROWELL indica algumas limitações para avaliações de conforto como: determinação deficiente dos critérios de conforto, variação dos tipos de pista, difícil caracterização do pneu e do atrito nas suspensões. Lista também funções para o sistema de suspensão, como: proporcionar conforto aos passageiros, reduzir danos às cargas transportadas, reduzir tensões no chassi e otimizar o contato entre pneu e solo. Para avaliar essas funções, ROWELL utiliza modelos com complexidade crescente, como um modelo de 1 grau de liberdade para mostrar que o comportamento da massa suspensa depende da razão entre a rigidez da mola e a massa suspensa. Com base nesse modelo, REISSNER argumenta que um veículo pequeno pode ser tão confortável quanto um veículo grande.

ROWELL utiliza um modelo plano para representar os movimentos de arfagem e vertical da massa suspensa. É proposto um estudo para entendimento dos modos e freqüências para avaliar a resposta de massa suspensa, pois a diversidade de pistas e a possível variação de velocidade do veículo tornavam difícil a realização de algo mais complexo. Ao escrever as equações de movimento, observou-se a dependência entre os movimentos vertical e de arfagem.

Ainda antes dos anos 20, ROWELL já equaciona o modelo de 2 graus de liberdade na vertical para representar os movimentos de massa suspensa e não-suspensa. Bastante atenção é dada para o modo de massa não-suspensa, avaliando-se a influência dessa massa e da rigidez do pneu. Em seguida inclui mais 1 grau de liberdade para representar o motorista sobre o assento.

ROWELL menciona que, apesar do atrito inerente aos feixes de mola não ser considerado no seu equacionamento, este é de extrema importância no 
comportamento do sistema, pois em algumas situações a rigidez efetiva ou dinâmica da mola pode ser até 10 vezes maior do que a nominal devido ao atrito. Um mínimo de atrito era necessário para dissipação de energia e atenuação das oscilações, porém, não deve ser excessivo. ROWELL apresenta também o componente amortecedor, como uma opção para utilizar molas que possuem atrito interno desprezível, como as helicoidais.

No final dos anos 20, J. F. PURDY e R. B. DAY ressaltam a importância dos pneus para qualidade final de conforto de um veículo e consideravam o valor da amplitude da aceleração vertical como a grandeza adequada para avaliações de conforto, sendo os pneus responsáveis por absorver boa parte dos choques na direção vertical. Isso motivou a construção de um dispositivo para avaliar as propriedades de absorção de choques dos pneus, baseado em valores de aceleração vertical resultante no cubo ao passar por um obstáculo. Como resultado, verificou-se que os maiores choques ocorriam quando o pneu encontrava o obstáculo e quando voltava a tocar o solo, no caso de perda de contato. Verificou-se também que quanto menor a rigidez vertical dos pneus, maior a capacidade de absorção de choques.

Em 1928, ROY W. BROWN explicou a necessidade de medições nos eixos e no chassi para avaliações relativas ao conforto. Utilizou medições de aceleração para mostrar a redução nos picos de aceleração ao diminuir-se a pressão dos pneus (efeito aceito na época). Sugeriu a utilização dessas medições para avaliar a influência das molas, dos assentos e dos amortecedores na sensação de conforto dos passageiros.

Em 1930, MOSS realizou testes com motoristas e passageiros, após passarem com veículos por diferentes percursos e distâncias entre 240 e 480 quilômetros. Após esse período de exposição às vibrações no veículo, os motoristas apresentaram diminuição da velocidade de reação, redução da capacidade de cálculo mental, perda de equilíbrio e redução na capacidade sangüínea em eliminar o dióxido de carbono. MOSS propõe a realização desses testes com os motoristas para quantificar a influência da troca de elementos da suspensão no conforto. Verificou-se que os motoristas apresentavam alterações mais pronunciadas do que os passageiros e que as manifestações subjetivas de desconforto eram maiores do que os indicados pelos resultados dos testes realizados. Sugeriu-se então, como conclusão do 
trabalho, mais estudos para verificar o que mais precisaria ser medido para quantificar de forma mais realista o nível de conforto.

Em 1932, ROY W. BROWN apresenta outros resultados da influência da rigidez do pneu. Estes resultados mostravam que a rigidez do pneu alterava significativamente a freqüência da massa não-suspensa na vertical e pouco influenciava na frequência da massa suspensa. BROWN defendia o uso de avaliações objetivas para verificação de melhorias no conforto do veículo ao trocar os elementos da suspensão. Existiam discussões com relação à melhor grandeza a ser utilizada para essas avaliações. Alguns grupos sugerem a utilização da aceleração, outros do deslocamento. BROWN sugere a contagem dos picos para cada faixa de valores de aceleração.

Em 1933, O. E. KURT apresenta o desbalanceamento e a variação do raio de rolamento de rodas e pneus como formas de excitação do veículo e cita os fatores que podem gerar variação no raio de rolamento, incluindo a excentricidade do cubo e do aro da roda, a variação da rigidez do pneu para cada posição e o próprio desgaste irregular dos pneus. KURT estudou as vibrações resultantes na massa não-suspensa e na massa suspensa.

São apresentados exemplos de veículos com diferentes sensibilidades para os fenômenos, necessitando de valores distintos de desbalanceamento e variação do raio de rolamento para que a vibração seja sensível na massa suspensa.

GEORGES BROULHIET em 1933 apresentou nos EUA a descrição dos trabalhos realizados na França na área de dinâmica vertical e defendeu a importância da aplicação da teoria de vibrações para o entendimento do comportamento do veículo. Tentou-se implantar essa idéia na Peugeot e na Citröen, mas a falta de entendimento por parte dos engenheiros foi um obstáculo para o progresso.

BROULHIET já defendia o uso de uma suspensão dianteira independente com objetivo principal de eliminar vibrações no sistema de direção. Outra vantagem apresentada foi a possibilidade de maior bitola efetiva para as molas deste tipo de suspensão, permitindo redução no valor de rigidez das molas sem comprometer o rolamento do veículo em curvas, por não reduzir a rigidez ao rolamento. ANDRE DUBONNET ressalta outra vantagem das suspensões independentes explicando que, com eixos rígidos, ocorre 
variação lateral significativa no contato entre pneu e pavimento, gerando elevado deslocamento lateral, o que prejudica a aderência pneu-solo.

O modo com movimento vertical da massa suspensa é apresentado como o responsável pelo surgimento de ondulações na pista.

Com relação à suspensão principal, os franceses utilizavam valores de deflexão estática entre 125 e $200 \mathrm{~mm}$ na dianteira e na traseira entre 200 e $280 \mathrm{~mm}$. As limitações para o aumento nos valores de deflexão estática estavam no comprometimento do rolamento do veículo em curvas e as grandes variações de carga dos veículos. Os franceses também defendiam a eliminação do atrito nas suspensões sendo que amortecimento viscoso com maior atuação na tração, indicado para substituir o atrito seco.

O engenheiro MAURICE OLLEY da Cadillac Motor Car Company, descreve em 1934, além dos modos de massa suspensa e não-suspensa, um modo com toda massa do veículo oscilando sobre os pneus, no caso da existência de alto nível de atrito na suspensão. Os valores de freqüência observados para esse modo variam de 4,2 a 5,8 Hz.

OLLEY em 1943, agora atuando na Rolls-Royce da Inglaterra, baseado em sua experiência e também em estudos elementares, verifica que carros de pequeno porte requerem valores menores de deflexão estática nas suspensões. Deflexões semelhantes para um veículo de entre eixos longo e outro de entre eixos curto pode comprometer algumas características desse último, como, por exemplo, mergulho em frenagem.

Essa redução na deflexão estática dos veículos de pequeno porte alterava, mas não comprometia totalmente o conforto do veículo, pois o valor do índice dinâmico desses veículos era próximo da unidade.

Outra vantagem de veículos de maior porte é o fato da variação no número de passageiros ter menor influência na massa total do veículo e, portanto, a variação no conforto com a variação na quantidade de passageiros é menor do que em um veículo de porte menor.

Sobre o conjunto motor-câmbio, o qual tem massa e dimensões significativas, OLLEY considera que aparentemente não existem possibilidades de melhoria em alterar sua localização, entre as rodas dianteiras do veículo. 
No ano seguinte, 1944, OLLEY faz especulações sobre as tendências dos veículos americanos no pós-guerra, além das discussões apresentadas no ano anterior, mencionando que uma redução de massa nesses veículos era algo fácil de ser obtido, em função da grande quantidade de adornos desnecessários existentes.

Em 1946, atuando na Vauxhall Motors, OLLEY apresenta outro trabalho sobre vários aspectos da dinâmica lateral e vertical do veículo. Utilizando um modelo de 2 graus de liberdade, descreve os modos de massa suspensa, nãosuspensa e o modo em que toda massa do veículo oscila sobre os pneus no caso de existência de atrito excessivo no sistema de suspensão.

A ocorrência de "saltos" das rodas do veículo, excitação do modo com movimento predominante vertical da massa não-suspensa, respondia de modo diferente durante a aceleração e a frenagem. A freqüência desse modo era de aproximadamente $10 \mathrm{~Hz}$ para os veículos da época. Durante a aceleração, a amplificação dos valores de aceleração da massa não-suspensa, ocorria próxima a essa freqüência. No entanto, durante uma frenagem, as amplificações persistiam até aproximadamente $7.5 \mathrm{~Hz}$.

A ocorrência de "saltos" das rodas do veículo pode existir em qualquer pista onde as irregularidades excitem o modo de massa não-suspensa. Apesar de tratar separadamente alguns fenômenos de conforto e dirigibilidade, OLLEY considera necessário o veículo apresentar um bom compromisso entre ambos.

BASTOW, em 1951, comenta sobre a mudança de eixo rígido para suspensão independente na dianteira que ocorreu nos últimos 20 anos e acrescenta que há vantangens para uma suspensão independente também na traseira, entre elas a melhoria no conforto do veículo em função da redução na razão entre massa não-suspensa e suspensa. Com a suspensão independente na traseira obtém-se redução na massa não-suspensa pois, o diferencial é fixo à massa suspensa, as molas helicoidais ou barras de torção são mais leves que os feixes e o conjunto de freios pode ser acoplado diretamente ao diferencial. Isso possibilitou uma redução de 50 \% no valor da massa nãosuspensa. Como conseqüência obteve-se melhor conforto e menor variação das forças de contato entre pneu e solo. Outra vantagem da suspensão independente na traseira é a necessidade de menor espaço para instalação do que o requerido pela suspensão de eixo rígido. 
BASTOW menciona a maior liberdade de escolha de amortecedores a partir da redução no valor da massa não-suspensa. Defende também a redução do atrito visando melhorar o conforto em pistas de boa qualidade.

OLLEY participou de discussões defendendo a não necessidade de utilização de suspensões independentes na traseira, acreditando que a suspensão do tipo DeDion seria a melhor opção.

Alguns questionamentos foram feitos como o de J. R. RIX e o de A. DUDLEY sobre a necessidade de amortecimento adicional ao trocar os feixes de molas por molas helicoidais ou barras de torção, o de D. F. WARD sobre a existência de alguma forma para cálculo do valor de amortecimento necessário e o de P. BAILEY que diz não ser possível obter um coeficiente de amortecimento adequado para as condições de veículo carregado e vazio.

BASTOW, no entanto, explica que, segundo sua experiência, o amortecimento é parte necessária em uma suspensão e que melhores resultados eram obtidos com fluído do que com atrito. Como os feixes de molas dissipavam mais energia do que as molas helicoidais, ao introduzir uma suspensão independente com molas helicoidais, o elemento amortecedor torna-se mais crítico, mas não se podia rejeitar esse tipo suspensão por esse motivo.

BASTOW também comenta que existem dúvidas se todo conhecimento sobre a questão está disponível a ponto de se calcular o valor de amortecimento ideal para o sistema de suspensão e que uma das grandes dificuldades, realmente é propiciar uma quantidade de amortecimento que satisfaça todas as condições de carga e variações de rigidez em função do curso de trabalho. No entanto, verifica-se que, se os amortecedores forem inadequados, pode-se comprometer o conforto e o contato entre pneu e solo. BASTOW disse que, com a introdução de uma suspensão independente traseira, ocorre redução na massa não-suspensa e afirma que isso gera uma melhoria no conforto do veículo.

DEN HARTOG discute vários exemplos de sistemas mecânicos que podem ser representados por modelos de poucos graus de liberdade em seu livro sobre vibrações mecânicas, explicando as funções das molas e amortecedores da suspensão de um veículo. HARTOG comenta que não parecem ser racionais as teorias e argumentos dados pelos fabricantes como 
justificativa para a prática de curva de tração dos amortecedores de automóveis mais acentuadas do que a curva de compressão.

Em 1955 COX cita alguns fenômenos considerados complexos para avaliação da dinâmica vertical de veículos como: características não lineares das molas e dos pneus, amortecimento significativo presente nos modos de vibrar, dificuldade de obtenção dos valores de momentos de inércia da massa suspensa e da massa não-suspensa. COX acrescenta que apesar destas dificuldades, é possível entender características globais do comportamento dinâmico na vertical do veículo através de modelos simples, contendo corpos rígidos, molas lineares e amortecimento proporcional à velocidade. COX utiliza um modelo de 2 graus de liberdade para apresentar os efeitos dos modos de vibrar de massa suspensa e não-suspensa na transmissibilidade de vibrações entre pista e veículo.

Também é apresentada a necessidade de amortecimento para atenuar os picos de transmissibilidade próximos às freqüências dos 2 modos e a conseqüência da introdução do amortecimento para freqüências acima de $10 \mathrm{~Hz}$.

COX também apresenta o equacionamento para o modelo plano de 2 graus de liberdade que representa o movimento vertical e o de arfagem da massa suspensa.

As investigações de COX tinham como principal objetivo o entendimento dos esforços impostos sobre a pista durante a passagem por um obstáculo que excitava predominantemente o modo de vibrar da massa não-suspensa. Verificaram-se 2 picos com valores significativos de esforços, quando o pneu encontra o obstáculo e quando o pneu retoma ao solo após a perda de contato. Em ambos os picos os valores de força normal chegaram ao dobro do valor estático. COX sugere um amortecedor com maior atuação na tração do que na compressão visando reduzir esses 2 picos de força.

Com base no trabalho de COX, BASTOW expôe o seguinte: a relação de deflexões entre a suspensão dianteira e a traseira deve ser feita de forma a minimizar o movimento de arfagem. A rigidez deve ser a menor possível sem prejudicar outras características do veículo. O passo seguinte é selecionar o amortecimento que proporcione maior conforto. Após isso pode existir a necessidade de aumentar o amortecimento visando manter os pneus em 
contato com o solo para manter boa aderência durante curvas e frenagens em pavimento irregular. Uma das vantagens da redução da massa não-suspensa é a menor quantidade de amortecimento necessário para manter os pneus em contato com o solo, melhorando o conforto como conseqüência.

OLLEY, atuando na Chevrolet Motor Division, em 1955, apresenta um trabalho sobre suspensões de veículo comerciais, no qual são mostradas vantagens e desvantagens dos feixes de molas, suspensões pneumáticas e suspensões com elementos de borracha.

A maior desvantagem dos feixes de molas refere-se ao fato de que, apesar de ser possível a obtenção do valor adequado de freqüência para a condição de veículo carregado, este valor eleva-se significativamente com a redução da carga do veículo. É apresentada então uma das grandes vantagens da suspensão pneumática sobre a de feixe de molas, que é a de manter o valor de freqüência aproximadamente constante independente da variação da carga do veículo. OLLEY também apresenta alguns conceitos de suspensões dianteiras independentes e traseiras de eixo rígido para ônibus, nas quais utilizavam-se elementos cilíndricos de borracha de grandes dimensões para conectar os elementos da suspensão na estrutura do veículo.

KROTZ, em um trabalho anterior, apresenta valores de freqüência dos modos de massa suspensa de um ônibus, para o qual foram utilizados elementos de borracha nas suspensões. Estes valores são de $1,23 \mathrm{~Hz}$ para a dianteira e de $1,15 \mathrm{~Hz}$ para traseira com o veículo vazio, e $1,03 \mathrm{~Hz}$ e $1,00 \mathrm{~Hz}$ respectivamente para a dianteira e traseira com o veículo carregado. Segundo KROTZ, estes valores característicos para as frequências naturais, somado a baixo nível de atrito no sistema de suspensão, proporciona grande conforto. KROTZ ainda acrescenta que, quando esses elementos de borracha são utilizados também para proporcionar a rigidez longitudinal e lateral das suspensões, consegue-se filtrar efetivamente as vibrações de mais alta freqüência, resultando em um veículo de menor "aspereza" e mais silencioso.

A. E. MOULTON e P. W. TURNER, em 1956, também apresentaram elementos de borracha para servir como o componente elástico principal das suspensões primárias. Diversas configurações construtivas foram apresentadas, com elementos trabalhando em compressão e cisalhamento. Citou-se o exemplo de um veículo leve com elementos de borracha que 
proporcionavam deflexões estáticas de até $127 \mathrm{~mm}$ na dianteira e até $90 \mathrm{~mm}$ na traseira. Os autores consideravam os elementos de borracha apropriados para as suspensões primárias dos automóveis e podiam tomar o lugar das molas de aço. No entanto, surgiram discussões sobre a vida desses elementos e sobre a possibilidade de suportar altas cargas e grandes deflexões simultaneamente.

No final dos anos 50, ELLIS apresenta o conteúdo dos trabalhos realizados por estudantes da ASAE (Advanced School of Automobile Engineering) em Cranfield. Entre outros estava a análise do fenômeno de "salto das rodas" com condições de excitação que resultavam em perda de contato entre pneu e solo. Utilizou-se então um modelo de 2 graus de liberdade de 1/4 de veículo para avaliação deste fenômeno. Os elementos mola e amortecedor eram lineares, no entanto era previsto no modelo o efeito da perda de contato com o solo. Os resultados foram considerados satisfatórios, mas as diferenças entre os resultados fornecidos pela simulação e os experimentais eram perceptíveis. Utilizou-se também um modelo plano de 4 graus de liberdade para representar o movimento vertical e o de arfagem da massa suspensa e os movimentos verticais da massa não-suspensa. Visando validar esse modelo, o veículo foi excitado nas regiões dianteira e traseira, obtendo-se como resultado picos nas freqüências de 2.5, 3.0, 3.5, 5.0, 6.0 e $7.0 \mathrm{~Hz}$. Com base no número maior de picos do que de graus de liberdade do modelo, chegou-se às seguintes explicações:

1- A excitação foi de baixa amplitude podendo não ser suficiente para que as molas trabalhassem durante todo o teste. Desta forma pode-se obter vários modos de vibrar com o veículo oscilando sobre as molas ou sobre os pneus;

2- Foram excitados modos de vibrar com movimento predominante do motor. Como proposta de continuação desse trabalho, sugeriu-se a modelagem com maior número de graus de liberdade, incluindo a movimentação vertical do motor, e a representação dos efeitos de atrito nas suspensões primárias;

Ainda na década de 50 foram apresentados trabalhos importantes relativos à suspensão do conjunto motor e câmbio. Os trabalhos de ANON em 1953, HARRISON em 1956 e HOROVITZ em 1957, deixam clara a importância do conhecimento da teoria de vibrações para facilitar a determinação da coxinização do conjunto. 
Os históricos apresentados por ANON e HARRISON explicam o motivo dos primeiros veículos motorizados apresentarem o motor fixo diretamente à estrutura. Para os motores estacionários tinha-se a prática de fixação mais rígida possível nas fundações (ancoramento) e essa prática foi mantida para nos primeiros veículos motorizados. Porém os resultados indesejáveis de vibração do chassi obtidos com essa prática fizeram surgir fixações mais flexíveis para suportar o motor. ANON defende que as freqüências naturais do motor sobre seus coxins devem ser as mais baixas possíveis, pois o objetivo principal da coxinização é proporcionar isolamento da estrutura do veículo das vibrações provenientes do motor. A introdução dos coxins fez com que o motor deixasse de atuar como um elemento estrutural do chassi, mas essa desvantagem foi mais do que compensada pelo isolamento de vibrações obtido.

HARRISON e HOROVITZ mencionam que existem limites para redução da rigidez, pois os coxins devem suportar excitações provenientes de obstáculos na pista e também do torque do motor.

Em 1961 foram apresentados resultados de um estudo sobre a variação radial dos pneus durante o rolamento. Esse estudo surgiu da necessidade de se prever, durante a produção, características dos pneus relacionadas às vibrações resultantes em veículos, principalmente porque a qualidade das pistas estava melhorando. A variação radial durante o rolamento é causada por variações de dimensões e por variações na rigidez radial ao longo de seu perímetro. Inicialmente, tinha-se a idéia de que a baixa rigidez das suspensões na vertical poderia garantir o isolamento suficiente para freqüências próximas à freqüência de massa não-suspensa, no entanto concluiu-se que, devido ao amortecimento do sistema, a transmissão de vibrações era sensível. Para verificar a variação da altura do centro da roda durante o rolamento do pneu, fez-se necessário construir um dispositivo para medição desta característica. Nesse dispositivo a rotação angular durante as medições possuía freqüência 17 vezes menor do que a primeira freqüência natural do sistema. Como resultado, obteve-se as curvas de variação radial durante o rolamento para pneus de automóveis e também a composição desse sinal em suas primeiras harmônicas. Verificou-se que apenas as 3 primeiras harmônicas apresentavam amplitude significativa. 
As medições foram realizadas para vários conjuntos de pneus, utilizados posteriormente em veículos para avaliações subjetivas. Estabeleceu-se, desta forma, como critério, que a componente de $1^{\mathrm{a}}$. harmônica não devia exceder 0.50mm na produção para evitar o surgimento de vibrações indesejáveis em veículos de passeio.

Em 1984, BEST relata alguns dos aspectos básicos da dinâmica do veículo relativa à dinâmica vertical, principalmente com relação aos modos de vibrar com movimento vertical e de arfagem da massa suspensa. BEST utilizou um modelo computacional que representava o movimento vertical, o de rolagem e o de arfagem da massa suspensa e os movimento verticais da massa não-suspensa. Esse é um dos raros trabalhos da literatura que apresenta resultados relativos ao fenômeno de filtro de entre eixos.

SHARP e CROLLA apresentaram, em 1987, uma revisão bibliográfica sobre a utilização do modelo de $1 / 4$ de veículo para avaliação da suspensão com relação a conforto, redução da variação na força de contato pneu-solo e redução nos esforços transmitidos à carroçaria. Esse modelo proporciona uma boa representação dessas propriedades quando se tem simetria das condições de excitação entre o lado esquerdo e o direito, suspensões longitudinalmente independentes e índice dinâmico igual a um. No entanto, o efeito de filtro de entre eixos não é representado por esse modelo.

Utilizou-se a Densidade Espectral Média Quadrada do deslocamento de um perfil de pista como fonte de excitação. Optou-se pelo modelo de ROBSON com duas inclinações distintas na faixa de 0.01 a 10 ciclos $/ \mathrm{m}$. No entanto, os autores ressaltaram que para uma avaliação completa do sistema de suspensão, seria necessária também a consideração de excitações transientes do tipo de buracos e lombadas, além de excitações regularmente espaçadas, em função da forma construtiva, como emendas em pontes ou em estradas de concreto.

Para uma determinada severidade de pista, o nível de conforto é melhorado ao reduzir a rigidez da suspensão primária. No entanto, para determinado valor de rigidez, o amortecimento para melhor conforto é menor do que o necessário para minimizar a variação de força normal. Portanto, ao reduzir a rigidez, a diferença entre o valor ótimo de amortecimento para conforto e para variação de força normal, aumenta. 
Além das discussões apresentadas existem as restrições quanto ao espaço de trabalho. Se os parâmetros da suspensão forem definidos para uma pista de boa qualidade, essa pode apresentar problemas de espaço de trabalho para pistas ruins.

A linearidade considerada nos cálculos não representa adequadamente as condições de ocorrência de batentes, perda de contato entre pneu e pavimento e as características não lineares de molas e amortecedores. Mesmo para pistas de boa qualidade, a melhor configuração para conforto pode apresentar desvantagens como: rigidez insuficiente para todas as condições de carga, rolamento excessivo em curvas e prejuízos na dirigibilidade.

Em 1988, HROVAT utilizou um modelo 2 graus de liberdade (meio veículo) para avaliar a influência da massa não-suspensa e do amortecimento da suspensão primária, no conforto e no contato pneu solo. Utilizou-se para descrever a pista a Densidade Espectral Média Quadrada da velocidade de ruído branco, multiplicada pela velocidade do veículo, para a obtenção da entrada do modelo.

A rigidez vertical do pneu e da mola primária, bem como o valor da massa suspensa, foram parâmetros mantidos constantes. O valor da massa não-suspensa e o coeficiente de amortecimento foram variados verificando-se suas influências no valor da Raiz Média Quadrada da aceleração da massa suspensa e no deslocamento relativo entre eixo e pista.

HROVAT conclui que fatores de amortecimento entre 0,2 e 0,4 , para o modo de vibrar com movimento predominante de massa suspensa, proporcionam os melhores resultados para os dois critérios, conforto e contato pneu solo.

Ao manter constante o fator de amortecimento, pouca melhoria é obtida no conforto ao reduzir o valor da massa não-suspensa. No entanto, para menores valores de massa não-suspensa, menores valores de fator de amortecimento são necessários para garantir o contato pneu solo. E, ao reduzir o fator de amortecimento, obtém-se melhoria no conforto.

Em 1991, um estudo realizado no Japão entre a Isuzu e a NHK visou o entendimento das propriedades de feixes de molas que influenciam em seu ciclo de histerese. O objetivo principal foi identificar as características que influenciam na rigidez efetiva do feixe quando sujeito a excitações de pequena 
amplitude. Nesse trabalho o valor da rigidez efetiva foi descrito como a inclinação da zona de transição do ciclo de histerese. Utilizando-se feixes trapezoidais com lâminas de mesmo comprimento e contato apenas nas extremidades, foram apresentados resultados de rigidez efetiva 4 vezes maior que a rigidez nominal do feixe. A maior contribuição desse trabalho foi a descoberta de que o valor de rigidez efetiva depende da deformação elástica em regiões próximas ao contato entre as lâminas e não de pequenos escorregamentos entre as lâminas.

Para se chegar a esse resultado foram realizados testes em laboratório com medições da curva de força por deslocamento e de valores de deformação ao longo das faces superior e inferior das lâminas. Esse trabalho apresentou também uma descrição sobre quais tipos de olhais para as extremidades da mola e quais formas construtivas próximas à região de contato propiciam redução no valor de rigidez efetiva do feixe, mesmo sem a eliminação do contato metal-metal. Os feixes testados em laboratório foram implementados em veículo para avaliações de conforto. Comprovou-se que menores valores de rigidez efetiva proporcionavam menores amplitudes da Densidade Espectral Média Quadrada da aceleração da massa suspensa.

SHARP e PILBEAM apresentaram, em 1993, um estudo sobre a resposta da massa suspensa de um veículo, com base em um modelo computacional plano de 4 graus de liberdade, com movimento vertical e o de arfagem da massa suspensa e os movimentos verticais dos eixos.

As métricas utilizadas para avaliação foram o deslocamento angular de arfagem e os valores de aceleração vertical da massa suspensa medidos em seu centro de gravidade. Tomando-se uma configuração de veículo com índice dinâmico igual à unidade e freqüências básicas e fatores de amortecimento iguais nas regiões dianteira e traseira, chegou-se às seguintes conclusões, com base nos valores de amplitude de funções transferência:

- Para velocidades superiores a $10 \mathrm{~m} / \mathrm{s}$, quando a razão entre freqüências básicas traseira e dianteira for maior que 1, reduz-se a resposta em arfagem com pequeno compromisso da resposta vertical no centro de gravidade;

- Para velocidades inferiores a $10 \mathrm{~m} / \mathrm{s}$, a resposta vertical no centro de gravidade melhora quando a razão entre freqüências básicas traseira e 
dianteira for maior que 1, existindo pequena deterioração da resposta de arfagem;

- Realizando-se simulações para diversas velocidades do veículo e alterando-se o valor do momento de inércia de massa em relação ao eixo $Y$ (lyy), constatou-se que valores de razão entre freqüências básicas traseira e dianteira entre 1.1 e 1.25 proporcionam as menores amplitudes de resposta de arfagem da massa suspensa.

Para resposta transiente ao passar por uma onda cossenoidal de duração igual a $0.5 \mathrm{~s}$, visando excitação dos modos de vibrar de massa suspensa, verificou-se que a troca dos amortecedores lineares por bi-lineares, com coeficiente de amortecimento de tração igual ao triplo do da compressão, praticamente não altera o comportamento de resposta da massa suspensa. Os autores enfatizaram, no entanto que, não é a somente amplitude do deslocamento angular em arfagem a responsável pelo desconforto sentido pelos passageiros, mas sim as amplitudes da oscilação longitudinal elevadas que este deslocamento angular gera em passageiros em posição elevada no veículo.

Em 1996 foi apresentado um trabalho, realizado em conjunto pela Ford Motor Company, Ohio State University e S.E.A., sobre a construção de um dispositivo para determinação das propriedades de inércia das massas suspensa e não-suspensa de um veículo. A motivação para esse desenvolvimento foi a necessidade dessas informações para a realização de simulações na área de dinâmica de veículos. Um dos grandes benefícios desse novo dispositivo foi a possibilidade de determinação dessas propriedades sem desmontar o veículo. Os resultados obtidos foram os valores de massa, localização do centro de gravidade, momentos e produtos de inércia. Eram necessárias medições para várias atitudes de suspensão. Os resultados apresentaram maior precisão para as propriedades de massa suspensa.

LEDESMA realizou, em 2002, um comparativo entre 3 tipos de suspensões com relação ao conforto. A principal diferença entre as suspensões eram relativas ao elemento elástico utilizado na vertical:

1) Suspensão com feixe de molas de diversas lâminas;

2) Suspensão com mola de lâmina única; 
3) Suspensão pneumática.

O comparativo foi realizado através de ferramentas de simulação computacional utilizando-se o programa ADAMS (Automatic Dynamic of Mechanical Systems). Como fonte de excitação utilizou-se um perfil de pista e uma excitação singular (impulso simulando a passagem por uma lombada). As respectivas métricas para avaliação do conforto foram valores da Raiz Média Quadrada e valores de pico da aceleração vertical em pontos da massa suspensa. Os resultados mostraram que a suspensão de lâmina única apresentou melhor conforto do que a suspensão com feixe de várias lâminas. A suspensão pneumática proporcionou o melhor conforto quando comparada com as demais.

Em 2003, O. T. PERSEguim, E. PERES e C. G. FERNANDES realizaram avaliações de conforto de um veículo utilitário (camionete) utilizando simulação computacional, medições experimentais e avaliações subjetivas. $\mathrm{O}$ modelo computacional em ADAMS representou as suspensões primárias, as coxinizações de motor e de cabina e a flexibilidade do chassi. Foram elaboradas várias propostas de alterações na suspensão primária do veículo visando reduzir as freqüências e fatores de amortecimento dos modos de massa suspensa. $O$ trabalho também avaliou as características não lineares dos batentes de fim de curso da suspensão primária. Como resultado obtevese melhoria significativa no nível de conforto do veículo tanto objetiva como subjetivamente. 


\section{Conclusões}

A revisão bibliográfica apresentada nesse capítulo permite as seguintes conclusões:

- Apesar da busca por conforto ser antiga (carruagens puxadas por cavalos já possuíam molas para filtrar parte das excitações de pista e melhorar o conforto), somente a partir de 1900, surgiram os primeiros trabalhos que utilizaram equacionamento matemático para avaliação do conforto em um veículo;

- A grandeza aceleração é a mais adequada para quantificação do conforto;

- A teoria de vibrações mecânicas foi amplamente utilizada no desenvolvimento da teoria relativa à dinâmica vertical de veículos;

- Um processo crescente de entendimento da dinâmica vertical e sua influência no conforto, ocorreu durante o século $X X$, sendo acompanhado pelo aumento da complexidade de modelos matemáticos para representação das diversas características do veículo determinantes no conforto do veículo. Os primeiros trabalhos utilizaram modelos de $1 \mathrm{grau}$ de liberdade para avaliar a influência da mola na resposta de aceleração do veículo. Atualmente são utilizados modelos que podem representar características como a flexibilidade e não linearidades de componentes da suspensão. 


\subsection{Principais Tipos de Sistemas de Suspensão}

Considera-se que o conhecimento sobre os sistemas de suspensão e de seus componentes seja fundamental para o estudo da dinâmica vertical dos veículos.

Por esta razão, são apresentados abaixo vários tipos de sistemas existentes, mostrando que o surgimento destes vários tipos de suspensão foi impulsionado pela busca por maior conforto e segurança.

\subsubsection{Eixos Rígidos}

Segundo GILLESPIE, o primeiro sistema de suspensão, usado em carruagens, utilizava molas semi-elípticas (feixe de molas),

Tem como vantagens simplicidade de construção, robustez e baixo custo. Foi utilizada até por volta da década de 60 em veículos de passeio (suspensão traseira) e ainda hoje é usada em veículos comerciais.

Normalmente as molas semi-elípticas eram aplicadas em eixos rígidos sendo que a configuração mais conhecida é a Hotchkiss onde um par de molas semi-elípticas é montado longitudinalmente em um eixo rígido conforme mostra a figura 2.1 .

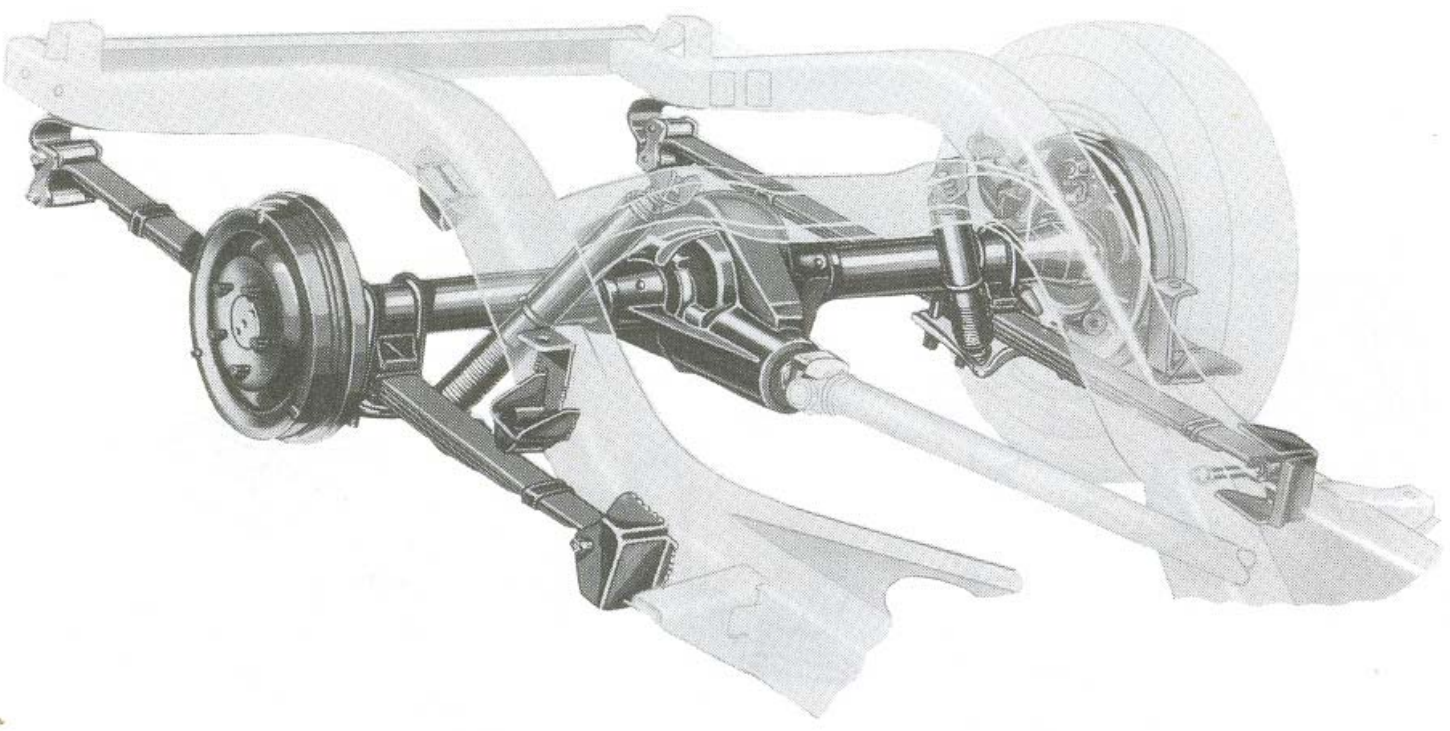

Figura 2.1 - Eixo rígido com molas semi-elípticas 
Suas características (ver detalhes no item 2.3.1.1) dificultavam o uso deste sistema em veículos de passageiros onde o conforto e dirigibilidade são primordiais.

Melhores resultados no aspecto conforto, ruído, vibração e aspereza só começaram a ser obtidos com sistemas que passaram a utilizar molas do tipo helicoidal (ver detalhes no item 2.3.1.2).

Com o advento das molas helicoidais com amortecedor em separado, abriram-se muitas possibilidades de novos tipos de sistemas de suspensão.

Apesar de mais caros que o sistema com molas semi-elípticas, foram criados diversos sistemas de suspensão, onde era possível a utilização de molas helicoidais.

A seguir são descritos alguns destes tipos de suspensão.

A figura 2.2 ilustra uma suspensão de quatro barras, utilizada nas décadas recentes em carros de passageiros de grande porte, com eixos traseiros rígidos.

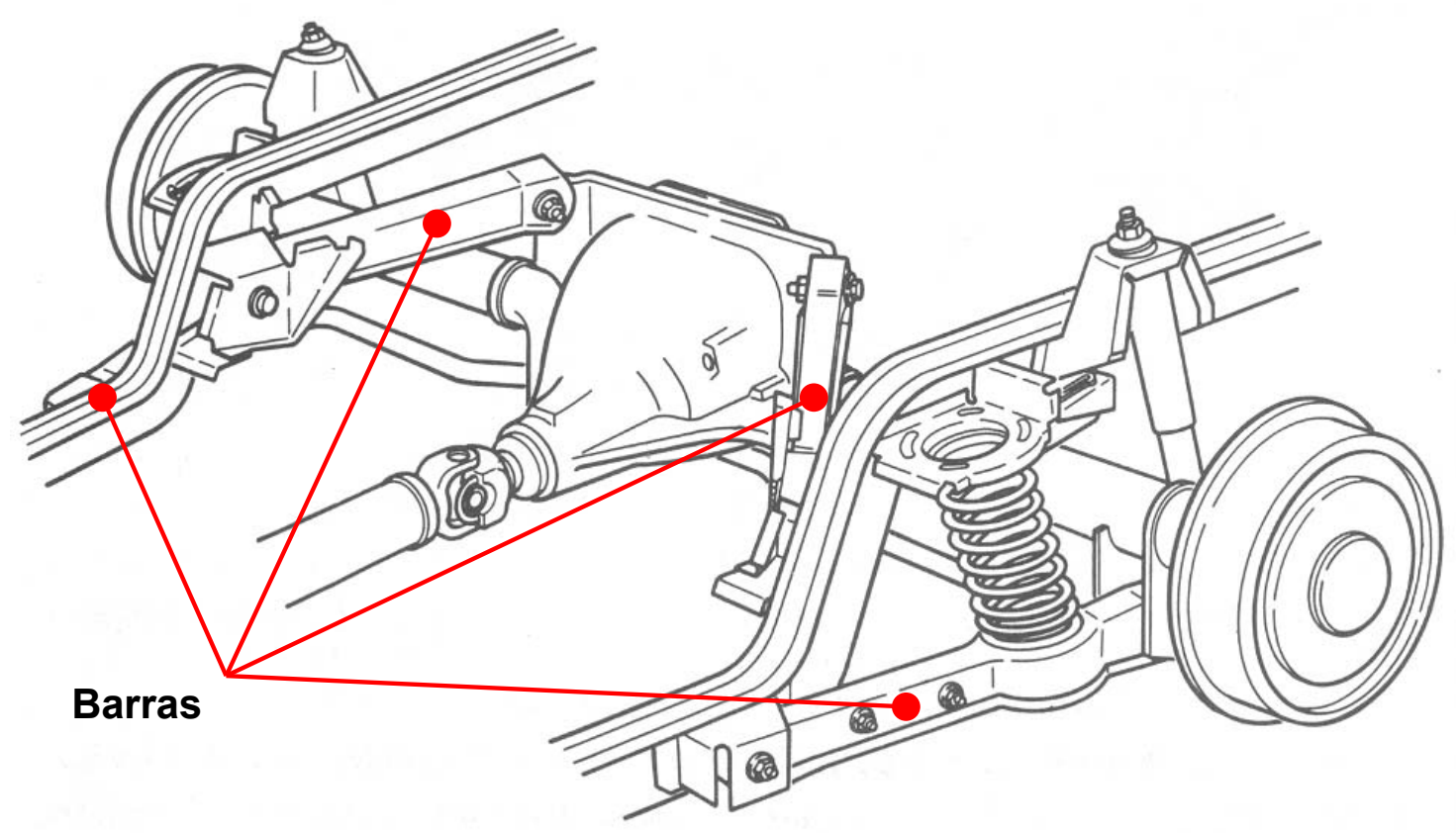

Figura 2.2 - Suspensão de quatro barras

A figura 2.3 ilustra outro esquema chamado de suspensão De Dion. Esta tem a vantagem de diminuir a massa-não-suspensa, pois o diferencial passa a ser massa-suspensa. São possíveis duas configurações: uma com semi-exos com estriados deslizantes e outra com tubo deslizante. 
Segundo GILLESPIE, sua principal desvantagem está no fato de poder haver adição de atrito ao sistema em função da necessidade de haver semieixos com estriados deslizantes ou um tubo deslizante.

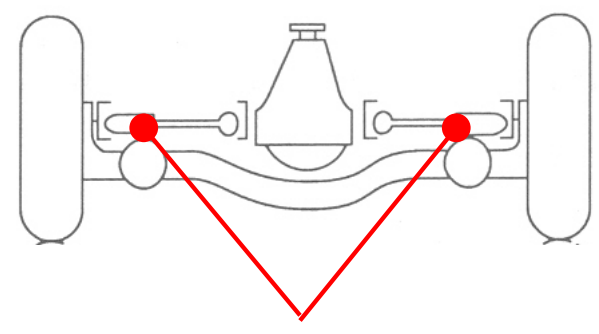

Semi-exos com estriados deslizantes

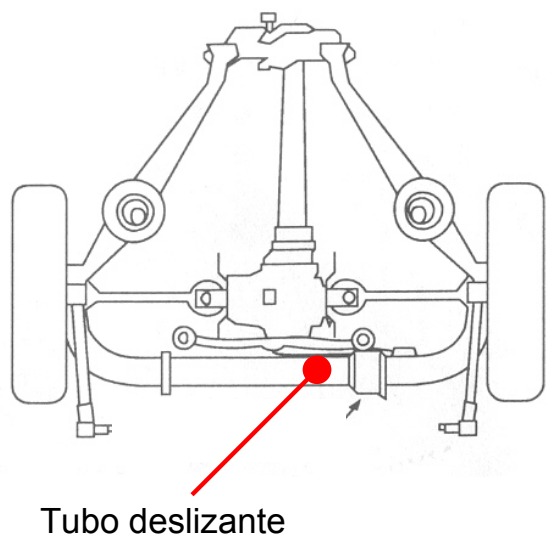

Tubo deslizante

Figura 2.3 - Configurações da Suspensão De Dion 


\subsubsection{Suspensões Independentes}

As suspensões independentes se diferenciam das de eixo rígido pelo fato do movimento vertical de uma roda não interferir no movimento da roda oposta, de um mesmo eixo. Também tem a vantagem de prover maior rigidez à rolagem relativamente à rigidez vertical.

A figura 2.4 mostra um dos mais simples e econômicos projetos de suspensão dianteira independente, foi a "braço-de-arrasto" (trailing-arm) usada pela Volkswagen e Porsche por volta da II Guerra Mundial a qual utilizava dois feixes de molas submetidos à torsão montados transversalmente (GILLESPIE).

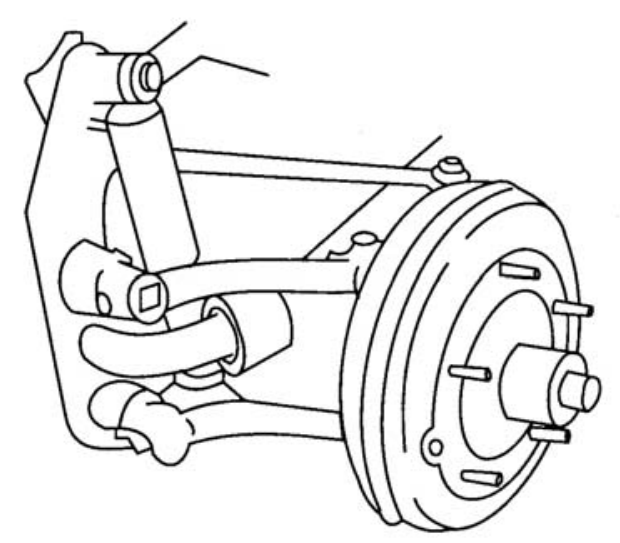

Figura 2.4 - Suspensão Braço-de-Arrasto

A suspensão "braço curto e longo" (Short-Long Arm) ou bandeja dupla em "A" (Double-A-Arm), foi muito utilizada na suspensão dianteira dos veículos americanos após a II Guerra, figura 2.5.

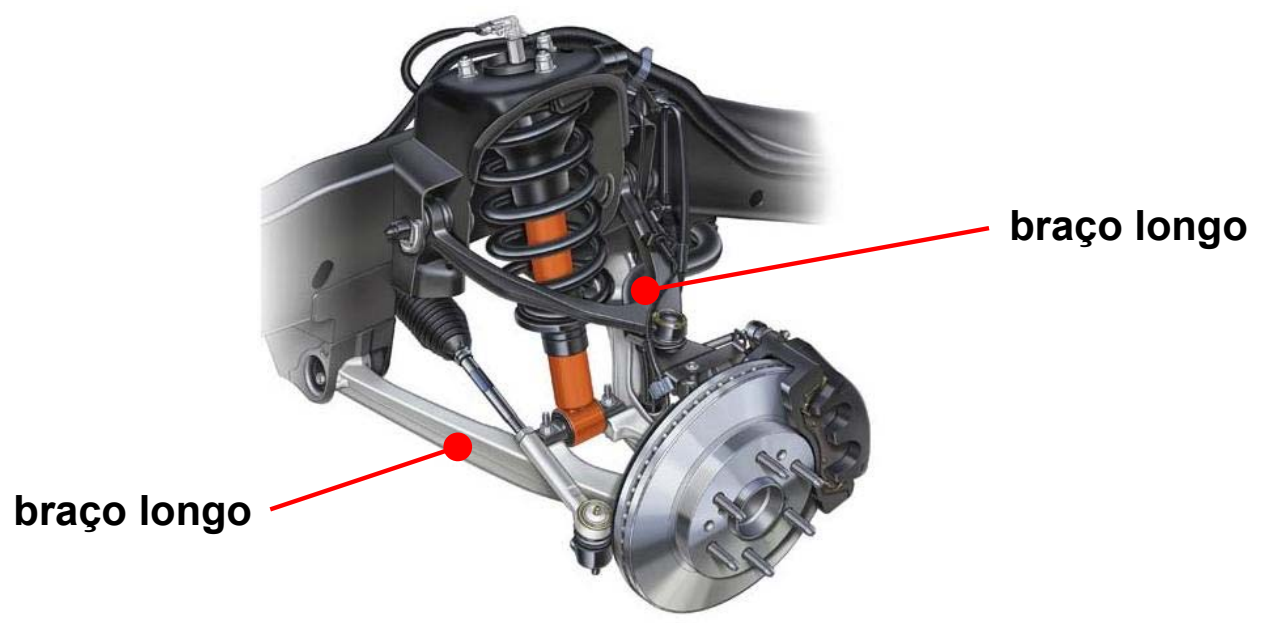

Figura 2.5 - Suspensão Bandeja Dupla em "A" 
A suspensão traseira "multi-barra" (multi-link) caracteriza-se pela utilização de articulações nas conexões existentes nas pontas das barras, o que elimina os momentos fletores, figura 2.6 (GILLESPIE).

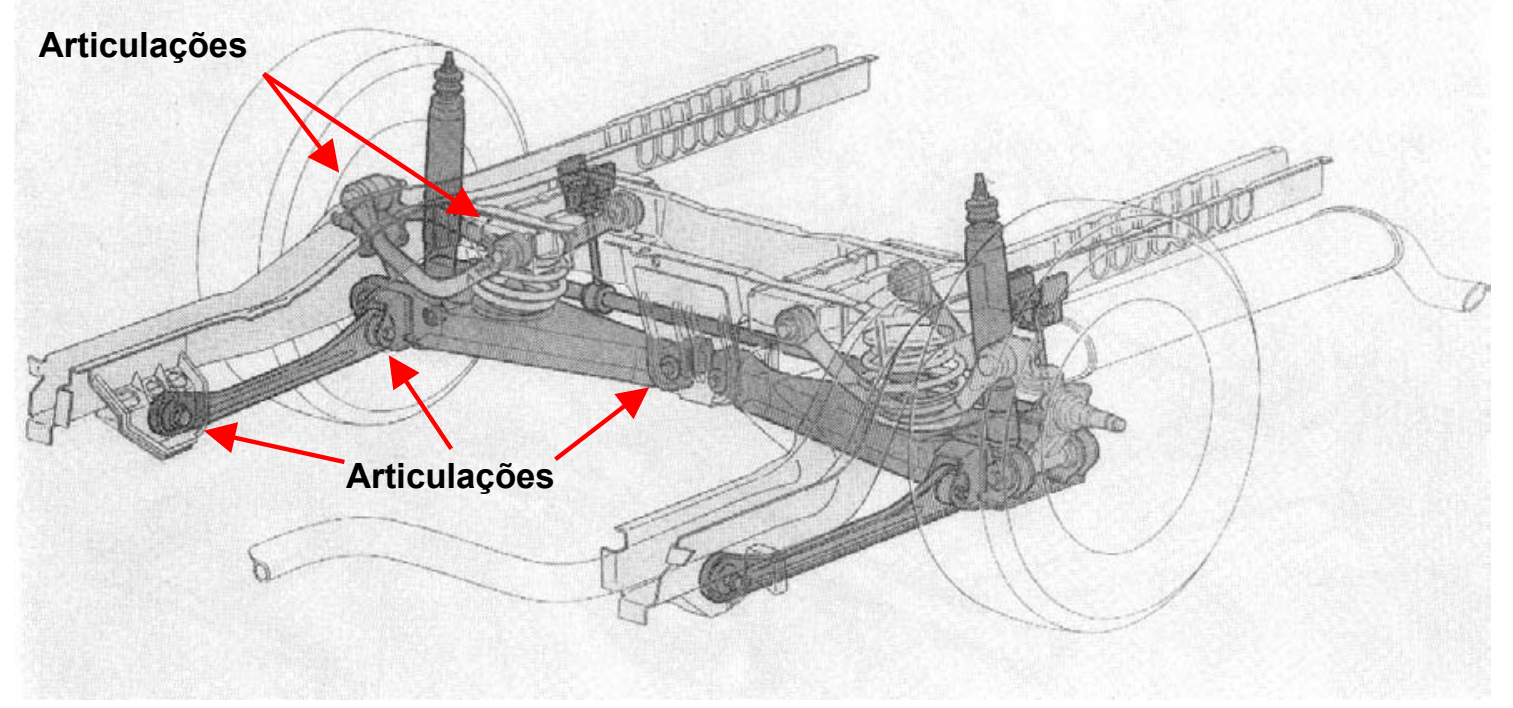

Figura 2.6 - Suspensão traseira multi-barras

A suspensão traseira "braço-de-arrasto" (trailing-arm) foi utilizada em veículos de alta performance e de maior custo como o Corvette americano, figura 2.7 .

O braço-de-arrasto absorve forças longitudinais e momentos de frenagem e aceleração. O semi-eixo serve como um braço de controle superior, além de transmitir torque de tração às rodas e, uma simples barra serve como braço inferior (GILLESPIE).

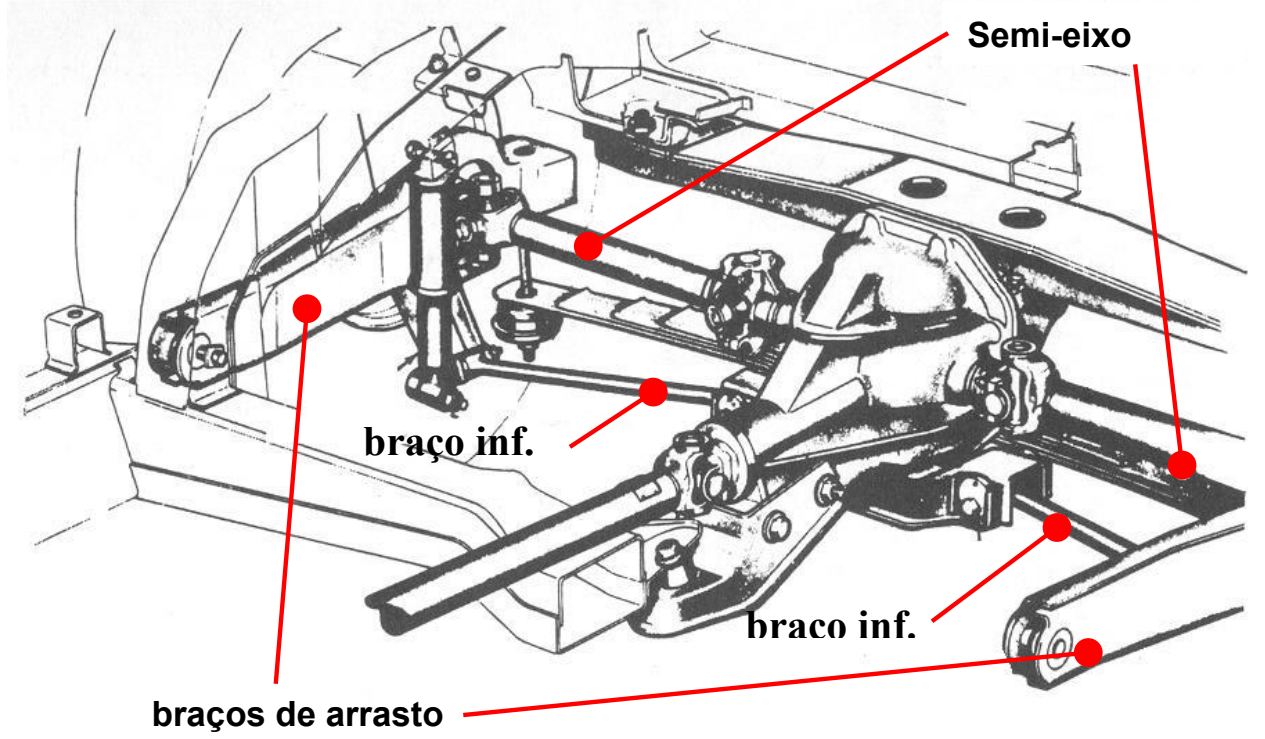

Figura 2.7 - Suspensão traseira Braço-de-Arrasto - Versão com mola semi-elíptica 
Esta suspensão tem a vantagem de reduzir a massa não-suspensa, pois o diferencial faz parte da massa-suspensa.

A suspensão traseira "semi-braço de arrasto" (semi-trailing arm) popularizou-se nos carros da BMW e Mercedez Benz, figura 2.8.

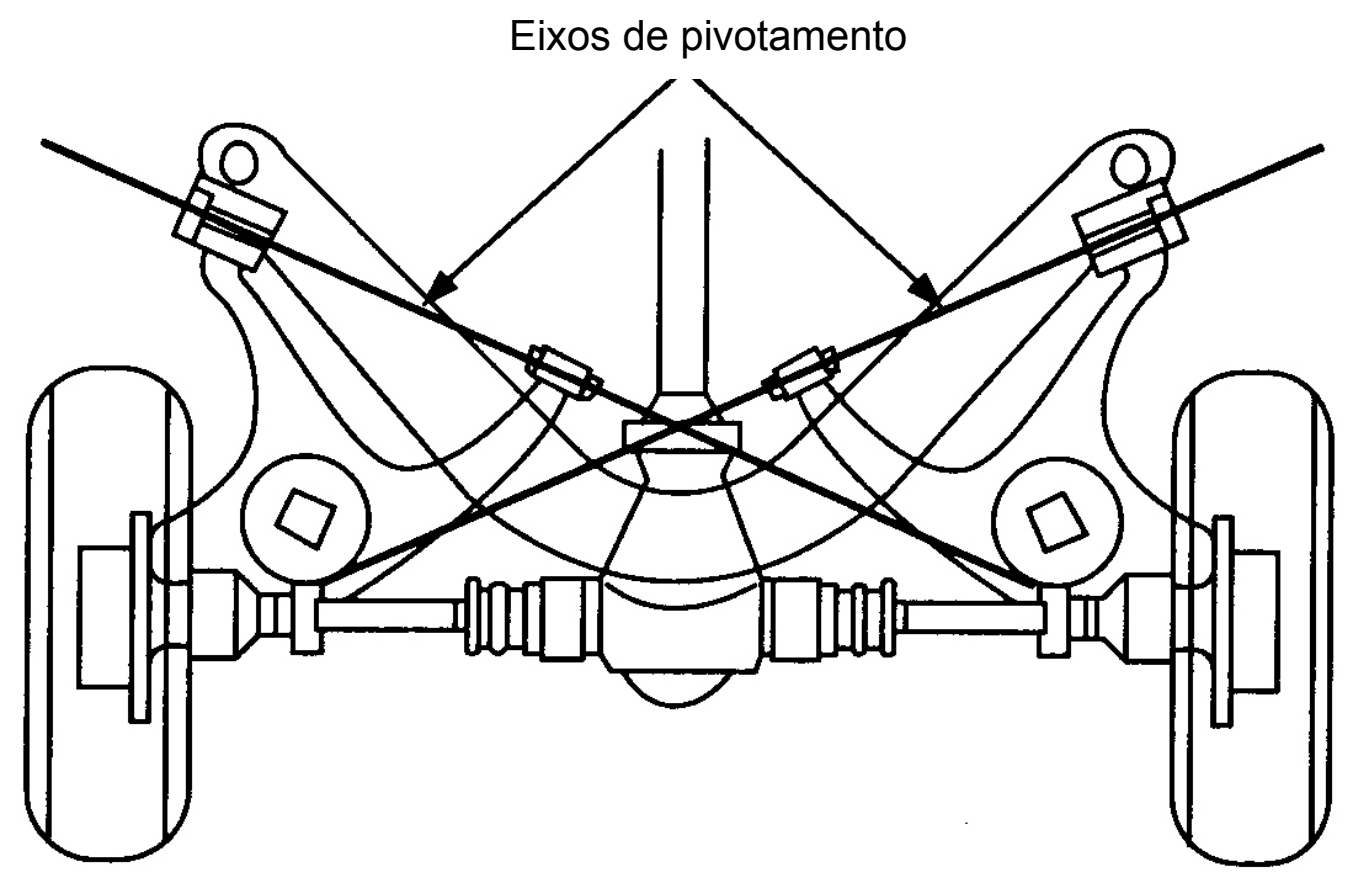

Figura 2.8 - Semi-braço de arrasto

Outro tipo bastante conhecido e muito popular de suspensão, utilizado na traseira pela Volkswagen e Porsche por volta da II Guerra Mundial, foi a "braço oscilante" (Swing-arm) onde as rodas descrevem arcos. As molas são barras de torsão montadas transversalmente, uma para cada lado, figura 2.9.
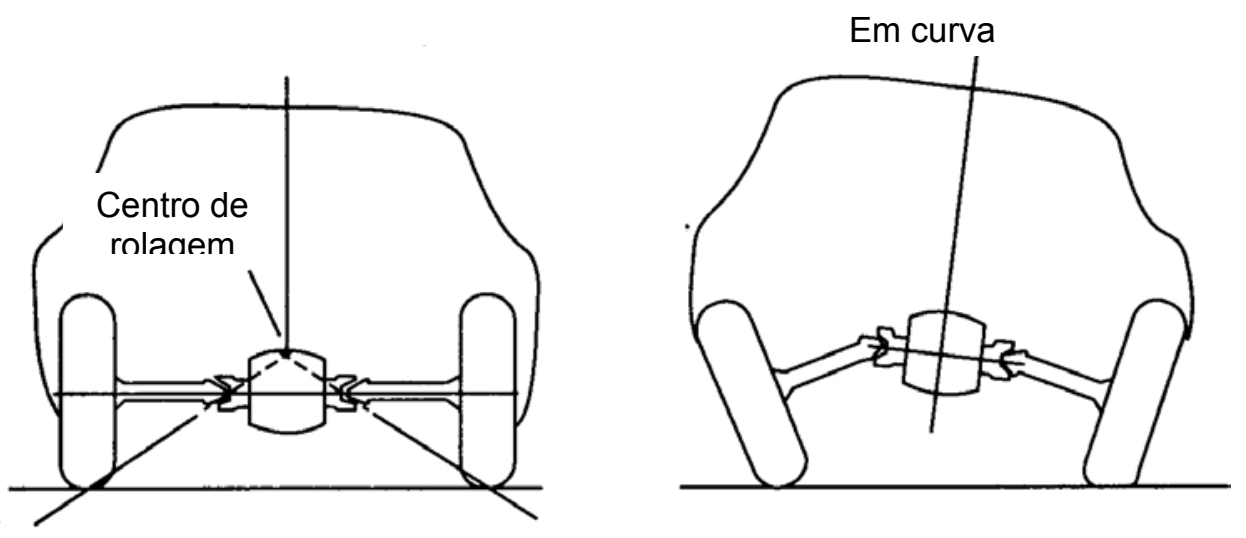

Figura 2.9 - Semi-braço de arrasto 
A suspensão MacPherson é atualmente uma das mais utilizadas na dianteira de veículos de passeio de pequeno e médio porte, com tração dianteira, figura 2.10 .

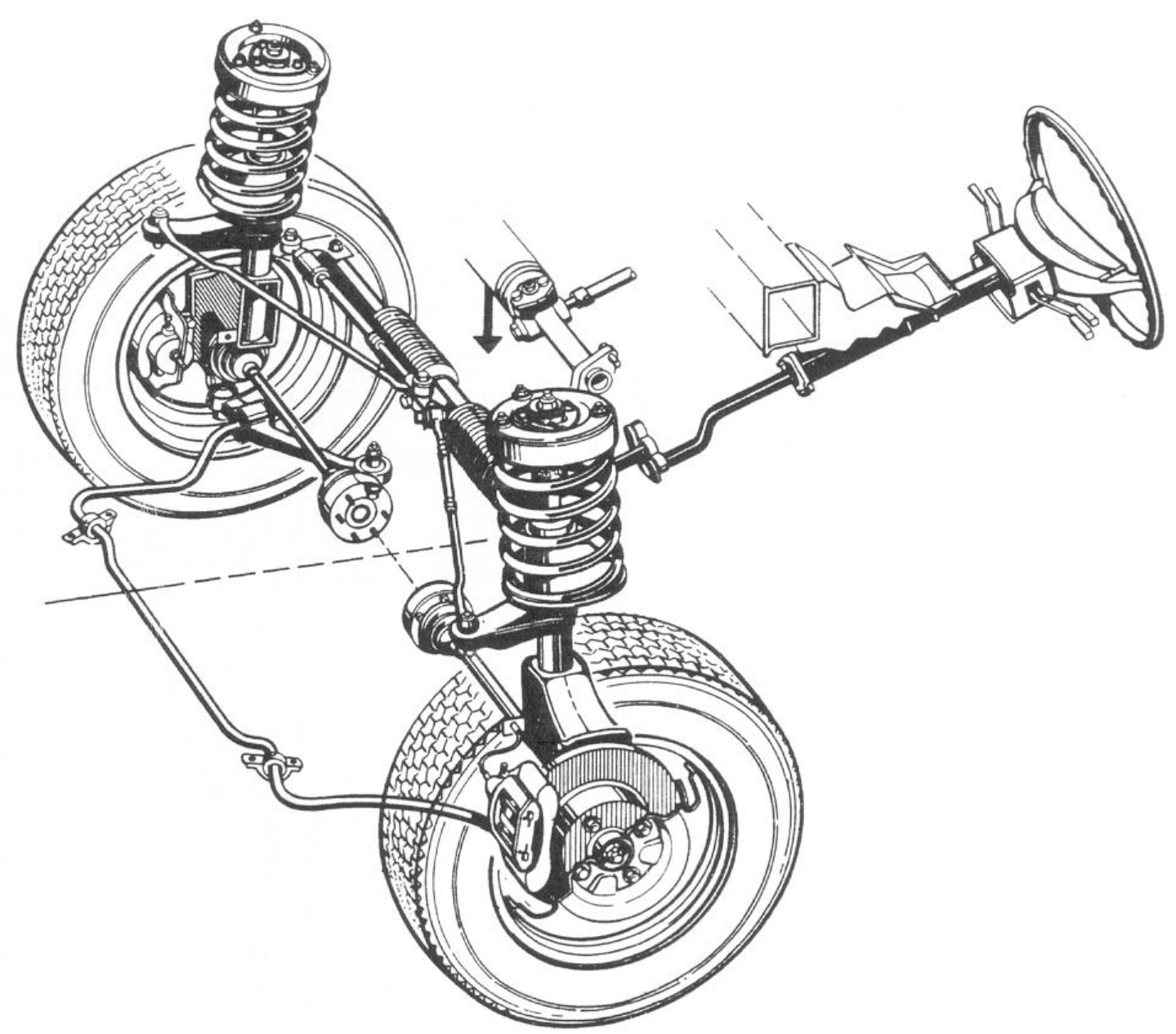

Figura 2.10 - Suspensão Dianteira MacPherson

Idealizada por Earle S. MacPherson é uma derivação da suspensão de bandeja dupla em "A", figura 2.5, na qual a bandeja superior foi eliminada (REIMPELL, STOLL \& BETZLER).

A fixação superior do amortecedor, que é do tipo hidráulico telescópico, é feita direto na carroçaria ou chassi. O amortecedor, além de gerar carga axial de sentido contrário ao da velocidade de oscilação da roda, passa a suportar cargas lateral e longitudinal.

A fixação inferior do amortecedor é feita rigidamente direto na manga de eixo. Segundo GILLESPIE, uma das maiores vantagens da suspensão 
MacPherson é a facilidade de montagem e o espaço livre para o motor quando montado na posição transversal.

Por ter suas fixações no chassi ou na carroçaria separados, este conceito é bem adaptado a veículos com carroçaria monobloco. O sistema possui poucos componentes e distribui bem as cargas da suspensão.

Ainda segundo GILLESPIE, uma desvantagem é a grande altura do conjunto que limita o projetista de carroçaria havendo necessidade de maiores alturas da parte frontal do veículo.

Em uma configuração diferente, pode também ser utilizada na suspensão traseira, figura 2.11 .
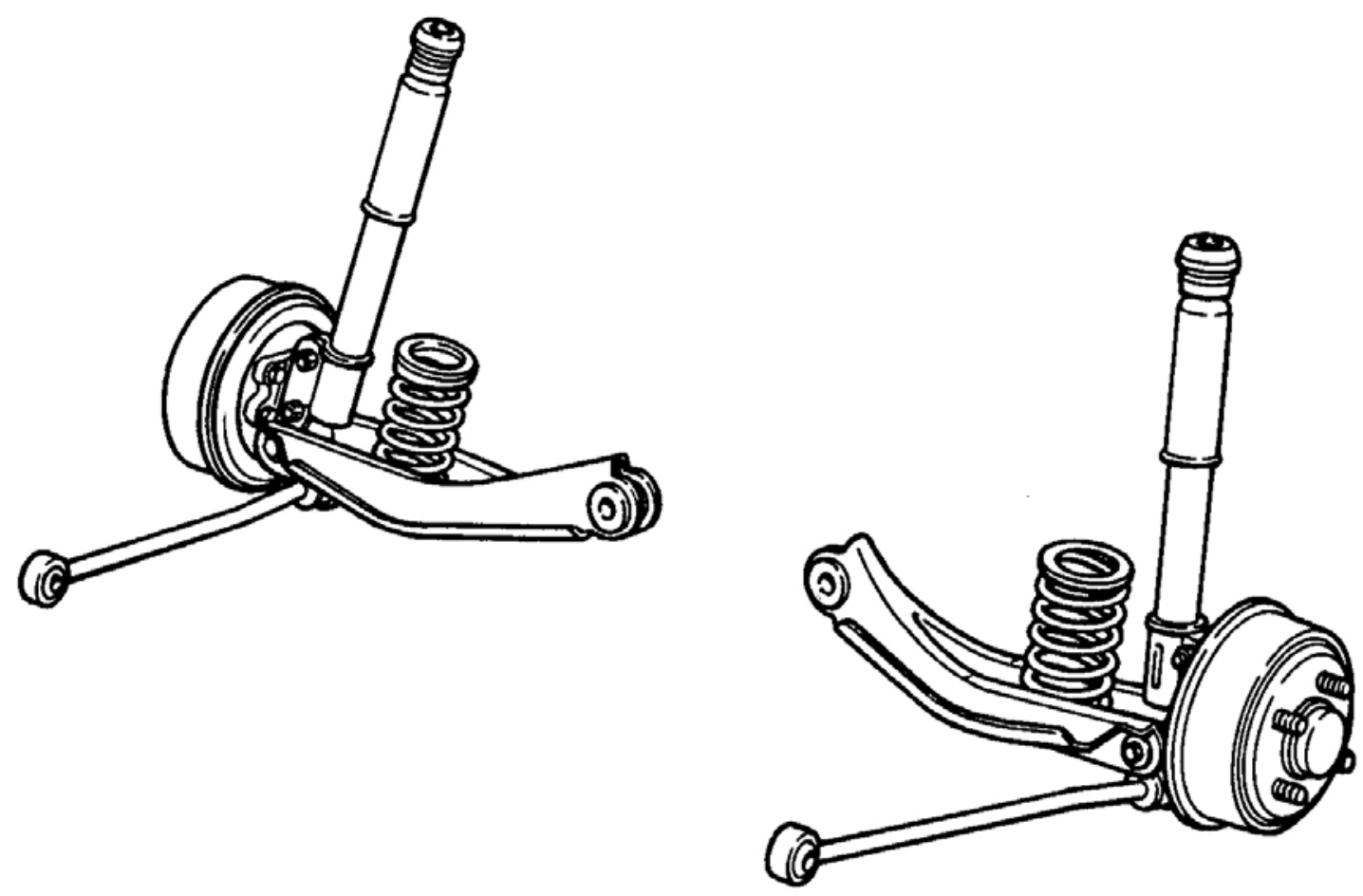

Figura 2.11 - Suspensão Traseira "MacPherson" 


\subsection{Principais Componentes dos Sistemas de Suspensão}

Adicionalmente ao que foi apresentado no item 2.2, é importante uma abordagem sobre os principais componentes dos sistemas de suspensão e suas características, sempre com o foco no estudo da dinâmica vertical.

Não são abordadas somente características de componentes utilizados nas suspensões MacPherson, mas também as de componentes utilizados em outros tipos de suspensão, o que permite melhor conhecimento das características que influenciam no comportamento dinâmico do sistema de suspensão e do veículo.

Os principais componentes de uma suspensão são as molas (principal e auxiliar ou batente), o amortecedor e os isoladores ou coxins, estando estes presentes na maior parte dos sistemas de suspensão atuais.

Como exemplo, na figura 2.12 são mostrados os componentes citados acima de uma suspensão traseira do tipo eixo rígido com molas semi-elípticas:

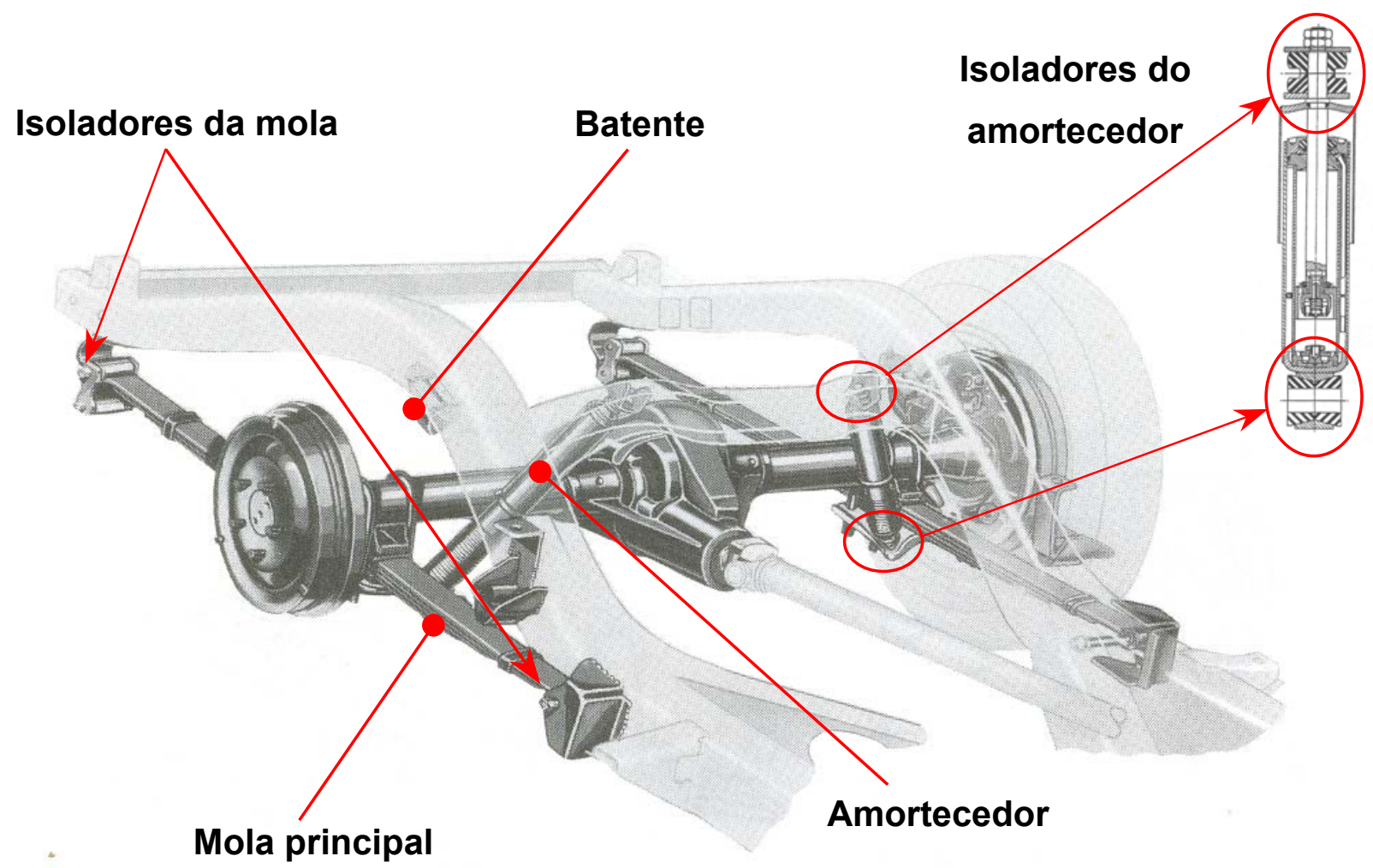

Figura 2.12 - Componentes da suspensão do tipo eixo rígido com molas semielípticas 
Na figura 2.13 são mostrados os componentes citados da parte superior de uma suspensão dianteira do tipo MacPherson:

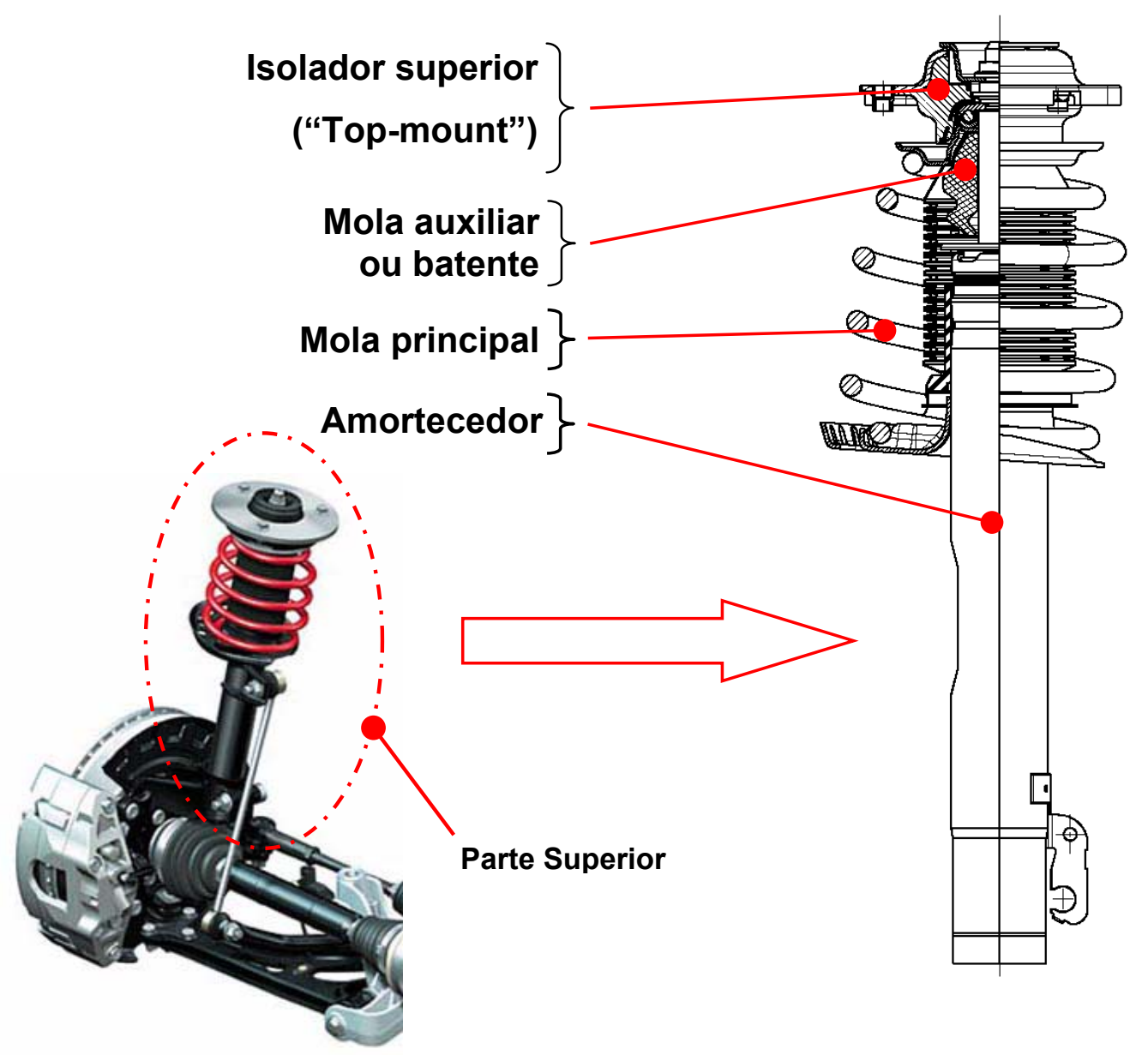

Figura 2.13 - Componentes de uma Suspensão Dianteira MacPherson (parte susperior)

Nos itens seguintes 2.3.1, 2.3.2 e 2.3.3, tratam dos componentes: mola, amortecedor e isoladores respectivamente.

Também será abordado no item 2.3.4, embora de forma bastante superficial, o pneu, cujas características tem importância fundamental no estudo da dinâmica vertical de um sistema de suspensão.

Além da abordagem mais geral, serão apresentadas as características específicas de componentes da suspensão dianteira do tipo MacPherson, objeto de estudo deste trabalho. 


\subsubsection{O componente mola, tipos e características}

\subsubsection{Mola Semi-elíptica (feixe de molas)}

A mola semi-elíptica convencional é composta por várias lâminas sobrepostas, figura 2.14 .

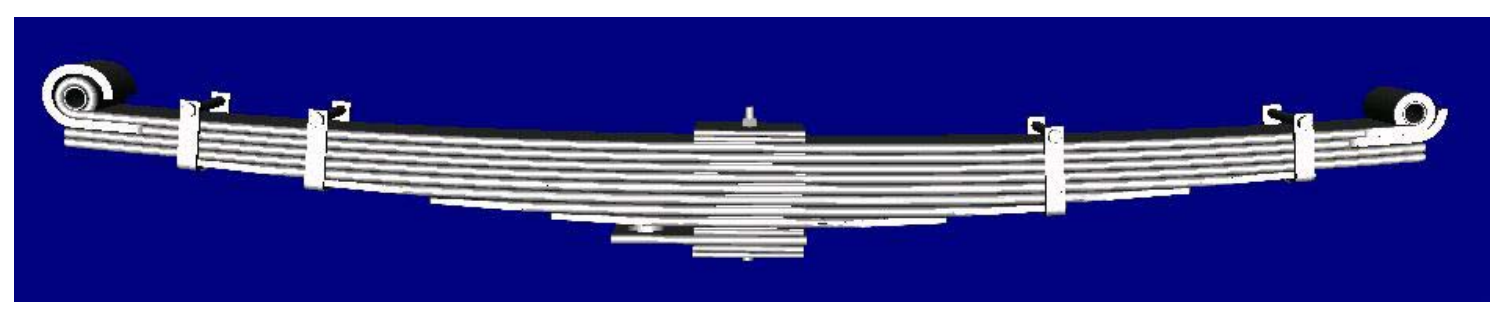

Figura 2.14: Mola Semi-elíptica convencional

Tem como vantagens: simplicidade de construção, robustez e baixo custo. Uma de suas características é o atrito interno gerado pelo escorregamento entre as lâminas, figura 2.15.

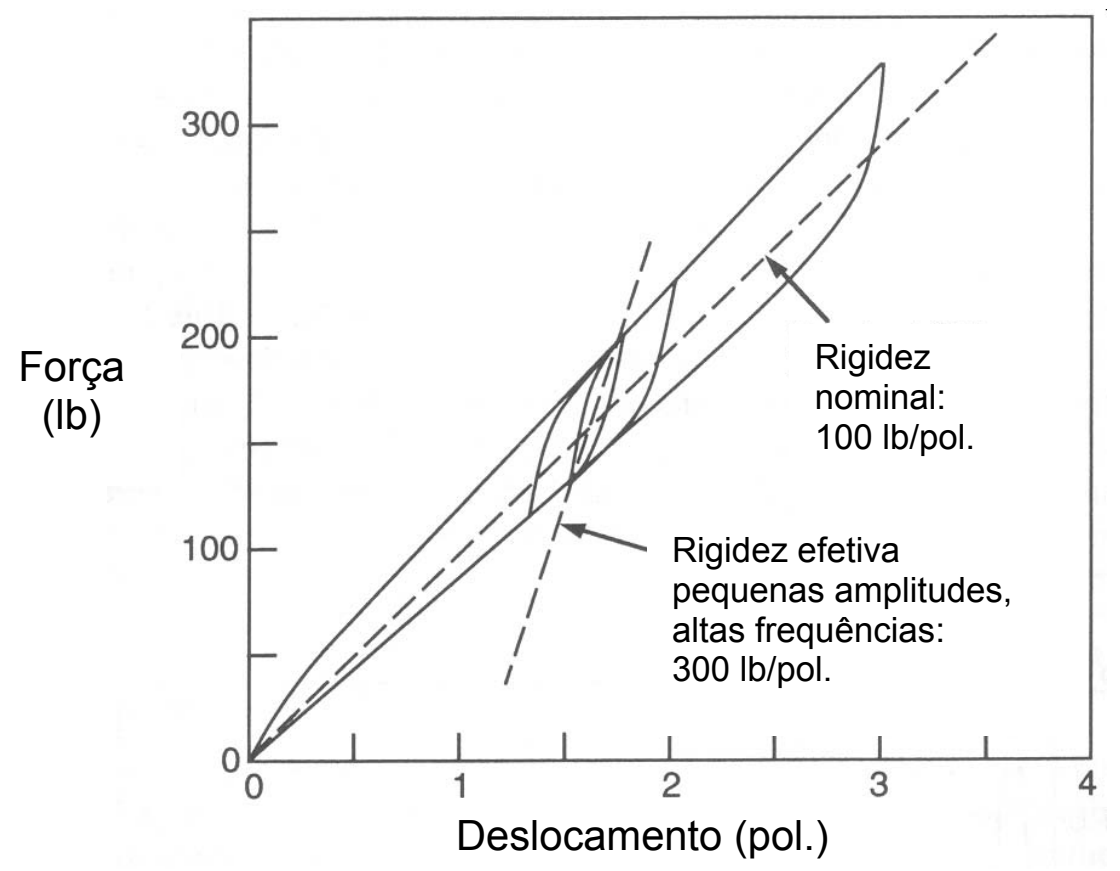

Figura 2.15 - Variação da rigidez vertical das molas semi-elípticas em função da amplitude do curso da suspensão

A alta rigidez, devido à alta histerese deste tipo de mola quando submetida a vibrações de pequenas amplitudes e altas frequências faz com 
que este tipo de mola tenha uma alta transmissibilidade neste modo de operação, com consequente deterioração de conforto.

Segundo GILLESPIE, outra de suas características é a diminuição da rigidez sob carga lateral que tem, como consequência, menor estabilidade lateral, quando são fabricadas mais longas para atingir menor rigidez vertical.

Com molas mais longas também ocorre maior "enrolamento" quando submetida a torques de frenagem ou grandes torques de aceleração, figura 2.16, comum em veículos do pós-guerra. Para absorver estes torques torna-se necessário adicionar um braço tensor, figura 2.17 .

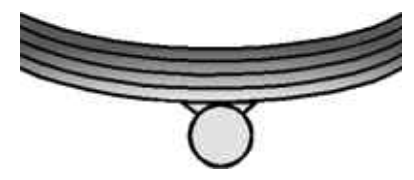

Sem torque

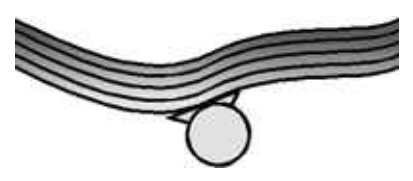

Com torque

Figura 2.16 - "Enrolamento" das molas semi-elípticas quando submetidas à torque
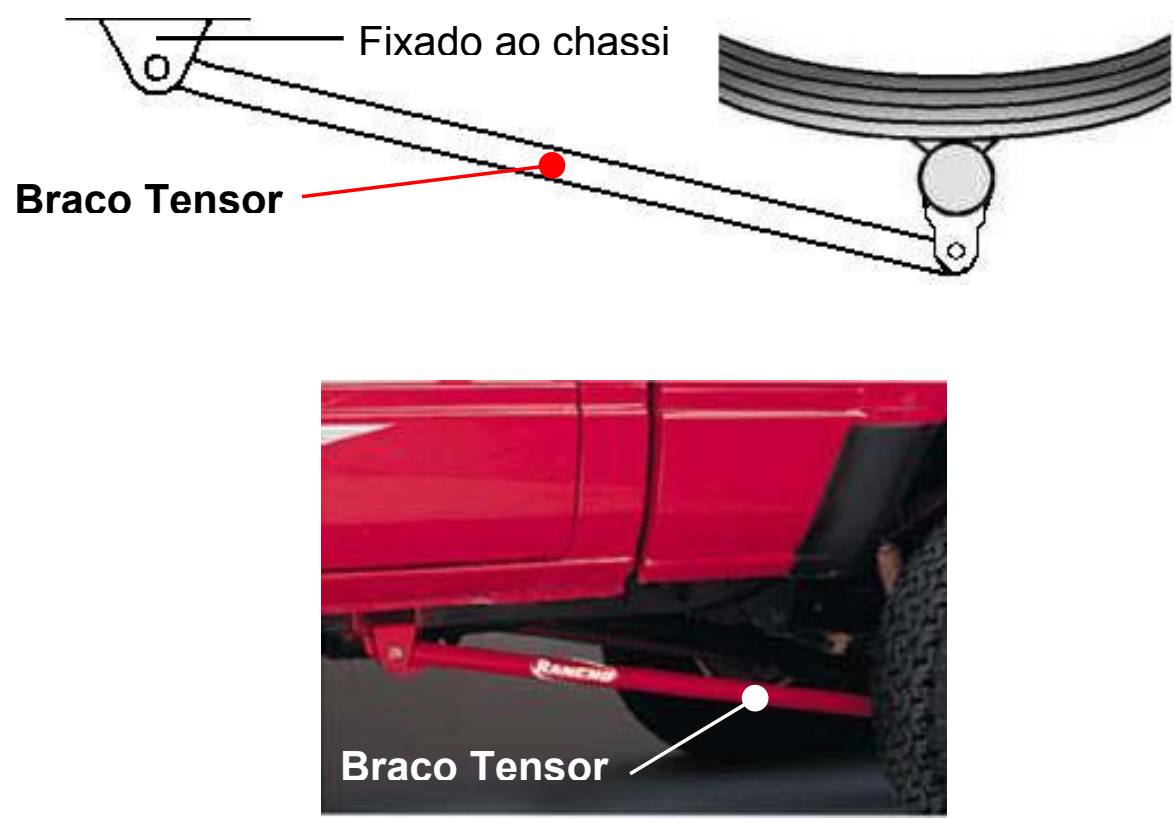

Figura 2.17 - "Braço tensor" para absorver torque e evitar o "enrolamento" das molas semi-elípticas 
Mais recentemente, como forma de reduzir o atrito interno das molas semi-elípticas, foram introduzidas pastilhas redutoras de atrito entre as lâminas, nos pontos onde há contato entre elas, figura 2.18.

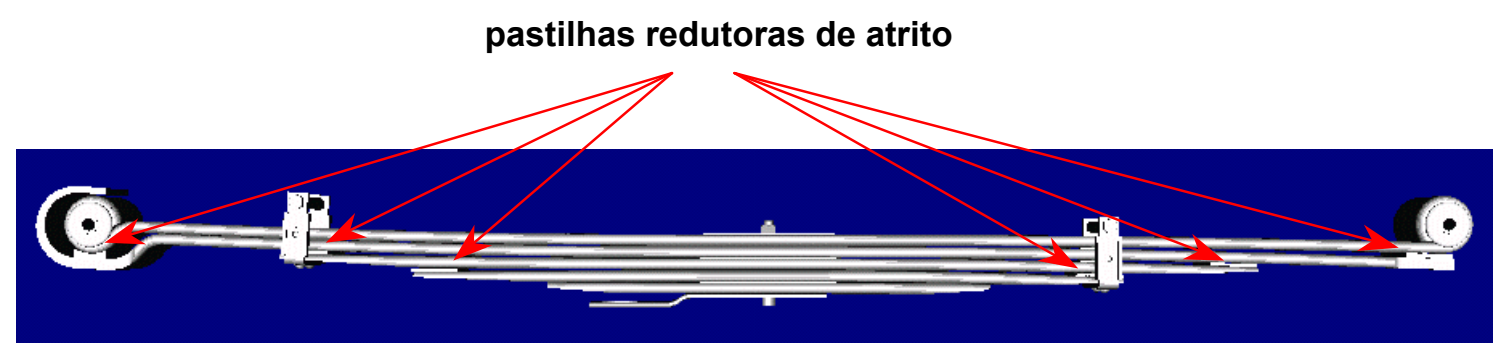

Figura 2.18 - Mola Semi-elíptica com pastilhas para redução de atrito

A mola semi-elíptica do tipo parabólica, figura 2.19, é assim denominada em função de suas lâminas possuírem perfil parabólico.

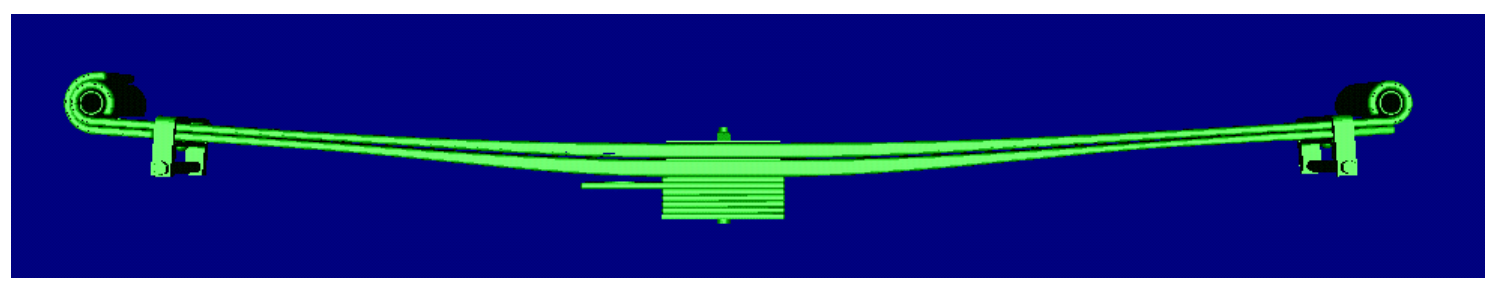

Figura 2.19 - Mola semi-elíptica do tipo parabólica

A mola semi-elíptica do tipo parabólica apresenta como vantagem um menor atrito interno, em função do reduzido número de lâminas e também devido à utilização de pastilhas redutoras de atrito nos pontos de contato entre as lâminas.

Ela pode ter menor rigidez vertical sem comprometimento da rigidez lateral e do "enrolamento". 


\subsubsection{Mola Helicoidal}

A mola helicoidal é fabricada enrolando-se um arame em forma helicoidal, figura 2.20 .

Esta mola possui histerese desprezível, sendo o amortecimento totalmente realizado pelo componente amortecedor. Este tipo de mola é o mais utilizado quando o foco é conforto, pois, melhores resultados são atingidos somente com molas pneumáticas e/ou sistemas ativos de suspensão.

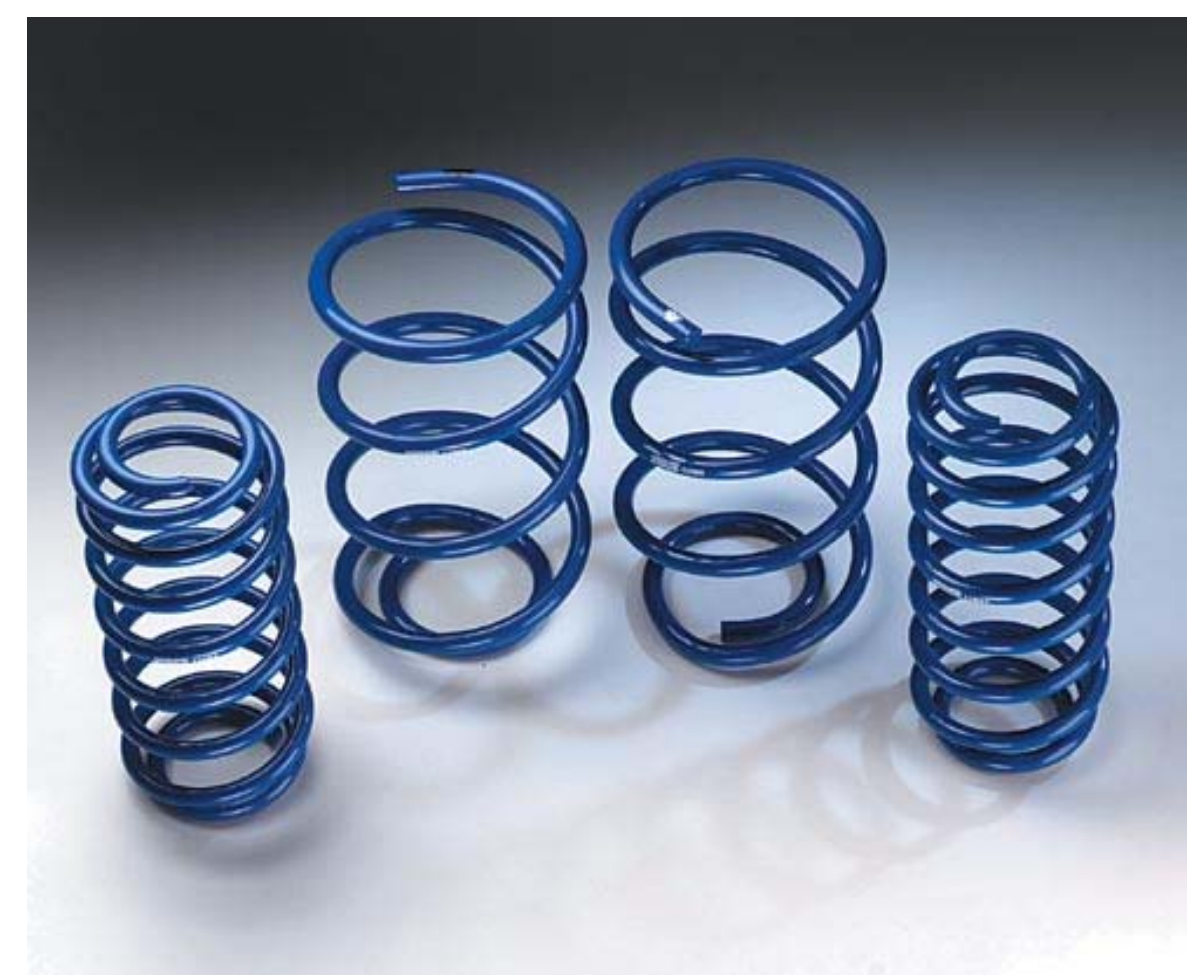

Figura 2.20 - Molas helicoidais

A cilíndrica linear é o tipo mais comum e de menor custo dentre as molas helicoidais. A direção de atuação da carga da mola coincide com o eixo geométrico teórico, figura 2.21.

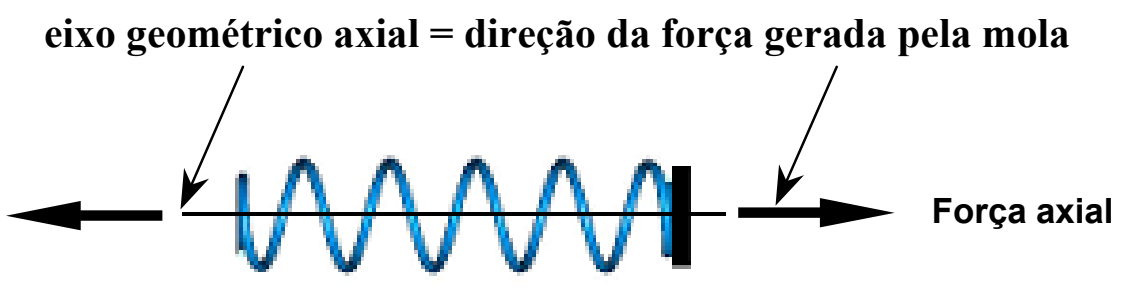

Figura 2.21 - Direção da força gerada nas molas helicoidais convencionais 
A curva de rigidez característica de uma mola é linear obedece à equação:

$$
F=K \cdot x
$$

onde:

$$
\begin{aligned}
& F=\text { carga sobre a mola } \\
& K=\text { constante elástica da mola } \\
& x=\text { deformação da mola }
\end{aligned}
$$

Em veículos equipados com este tipo de mola, portanto, ocorre diminuição da altura do veículo na medida em que é carregado.

A variação da frequência de ressonância de um sistema de suspensão equipado com este tipo de mola também diminui com o carregamento do veículo, figura 2.22:

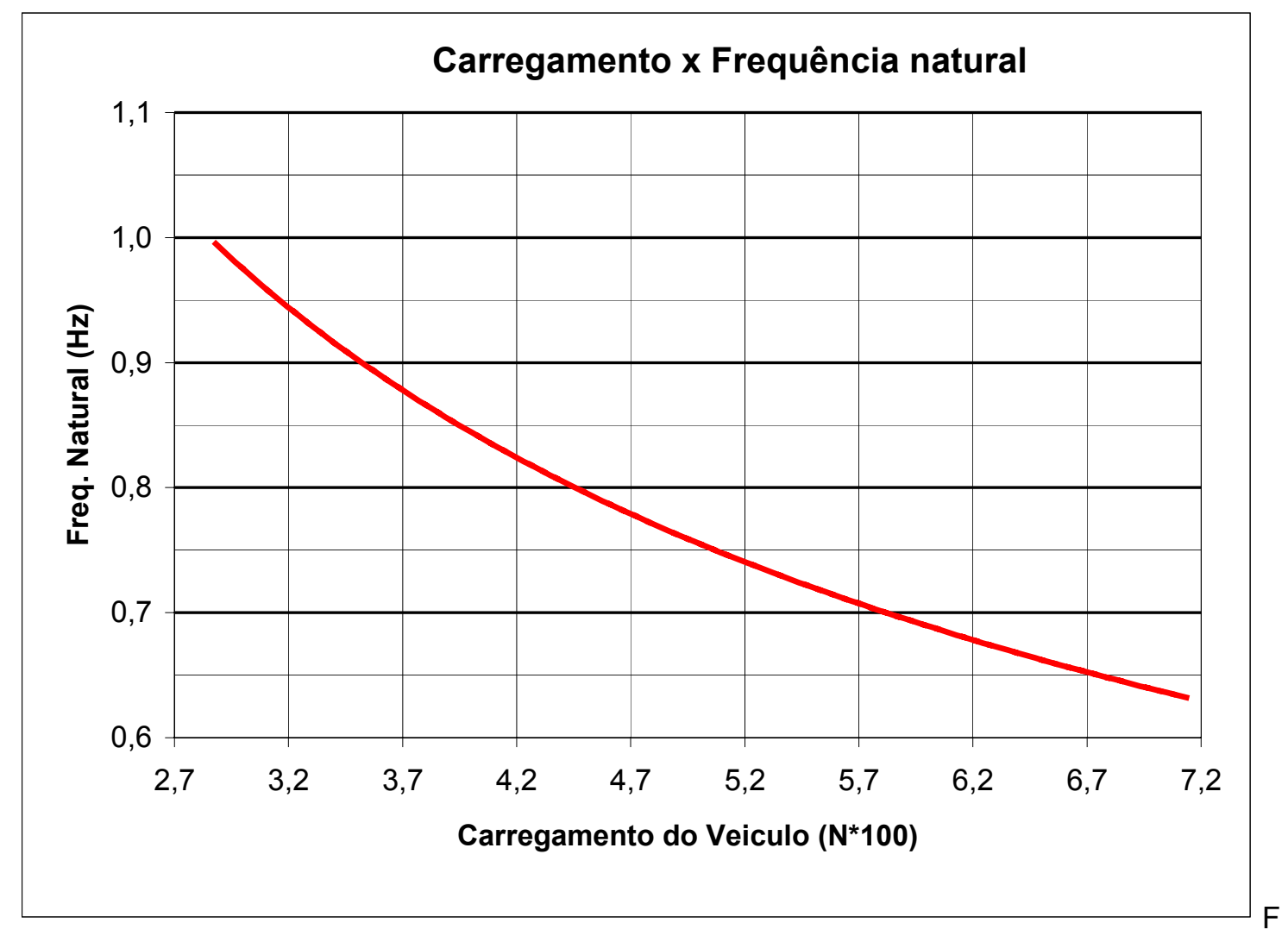

Figura 2.22 - Características dinâmicas do veículo com mola helicoidal linear

A variação da frequência de ressonância e da altura da suspensão é indesejada, pois dificulta o acerto dinâmico do sistema de suspensão de forma a obter-se o mesmo nível de conforto e dirigibilidade, em todas as condições de 
carregamento do veículo. Melhores resultados são obtidos com molas cilíndricas progressivas, as quais são fabricadas partindo-se de um arame cônico. A curva característica "carga x deformação" deste tipo de mola, é progressiva ou não-linear, figura 2.23 .

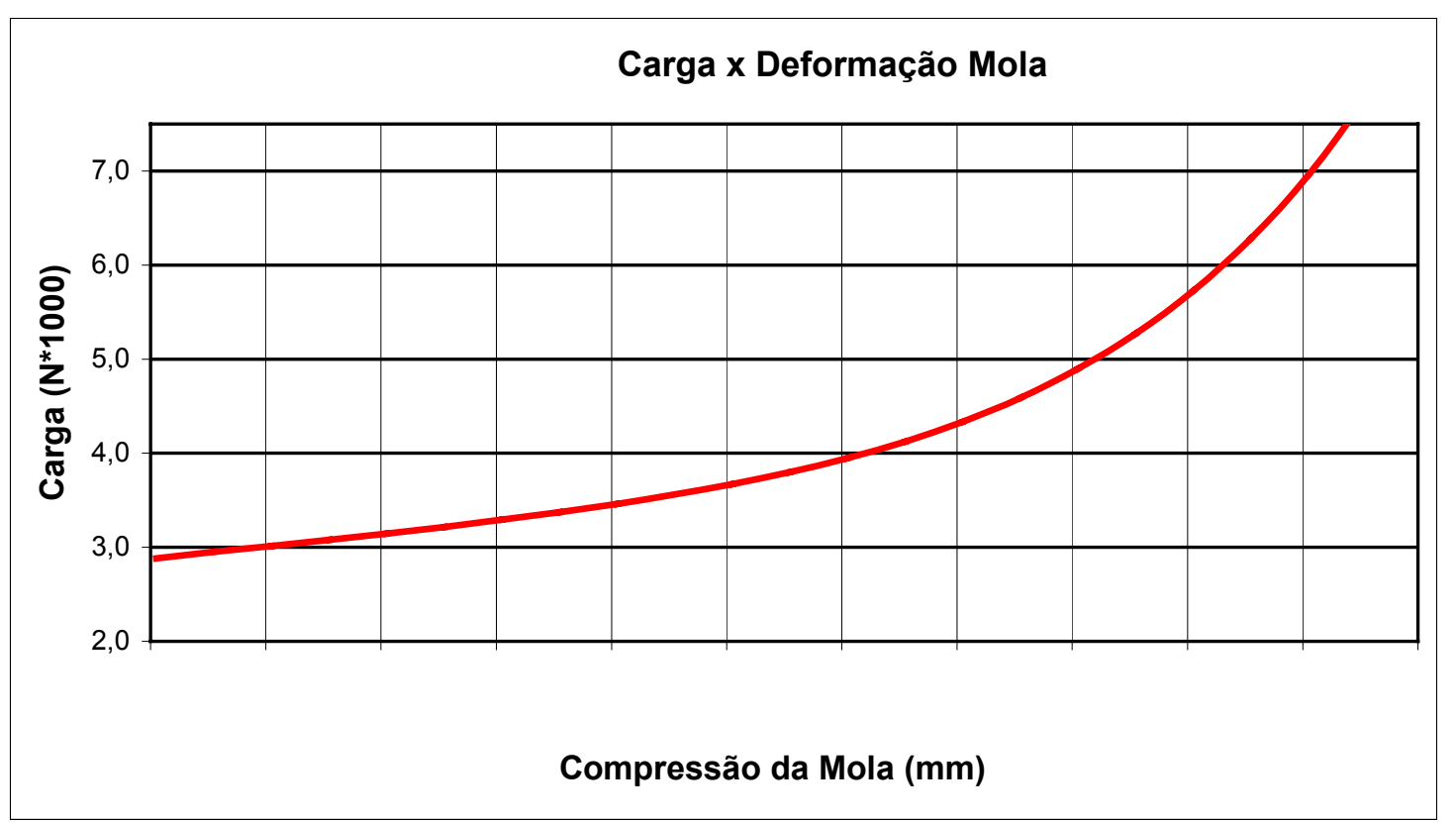

Figura 2.23 - Curva "Carga x Deformação" de uma mola helicoidal progressiva

Uma vantagem do uso deste tipo de mola é que sua frequência de ressonância tem menor variação com a variação do carregamento do veículo, figura 2.24 .

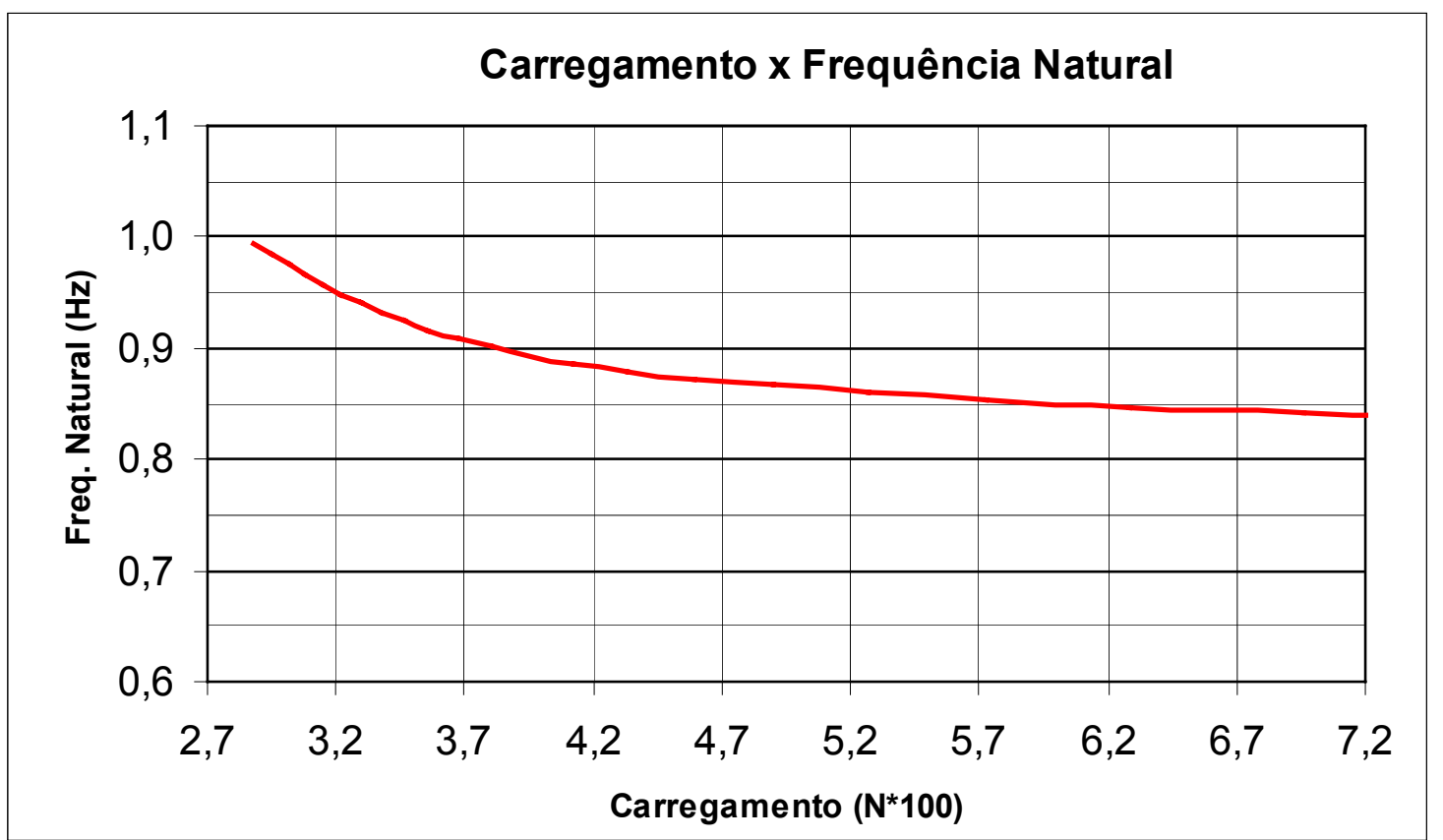

Figura 2.24 - Características dinâmicas de um veículo com mola helicoidal progressiva 
Outra vantagem do uso de molas progressivas é a menor variação de altura do veículo em relação ao equipado com molas lineares, para uma mesma variação de carregamento do veículo.

As molas helicoidais do tipo Barril (Mini-block), figura 2.25, são molas com curva de rigidez progressiva (não-linear) e se diferenciam de uma mola helicoidal progressiva por sua forma de "barril", o que permite que a altura de bloqueio (momento em que todos elos de uma mola helicoidal se tocam) seja menor.

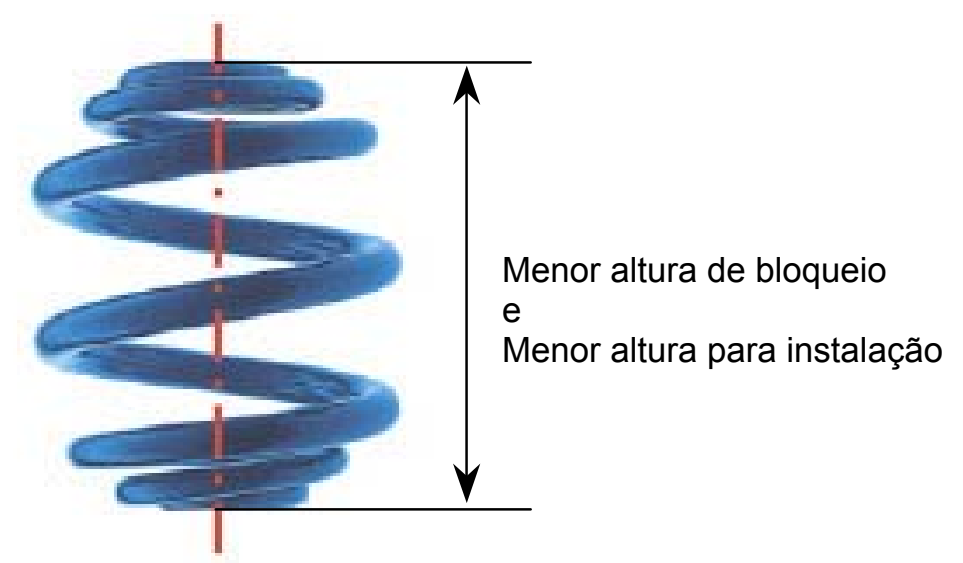

Figura 2.25 - Mola do tipo "Mini-block"

A vantagem deste tipo de mola, além da rigidez progressiva, está no fato de requerer menor espaço para instalação (altura) do que as molas cilíndricas, para um mesmo curso total disponível. 
As molas helicoidais com carga lateral (side-load) diferenciam-se das molas helicoidais cilíndricas lineares convencionais, as quais geram força sempre na mesma direção de seu eixo geométrico. As molas com carga lateral são assim denomindas, pois podem gerar força numa direção que forma um ângulo em relação ao seu eixo axial geométrico, ou seja, além da força na direção de seu eixo geométrico axial, geram também força numa direção perpendicular (radial) a este eixo, figura 2.26.

eixo geométrico axial da mola

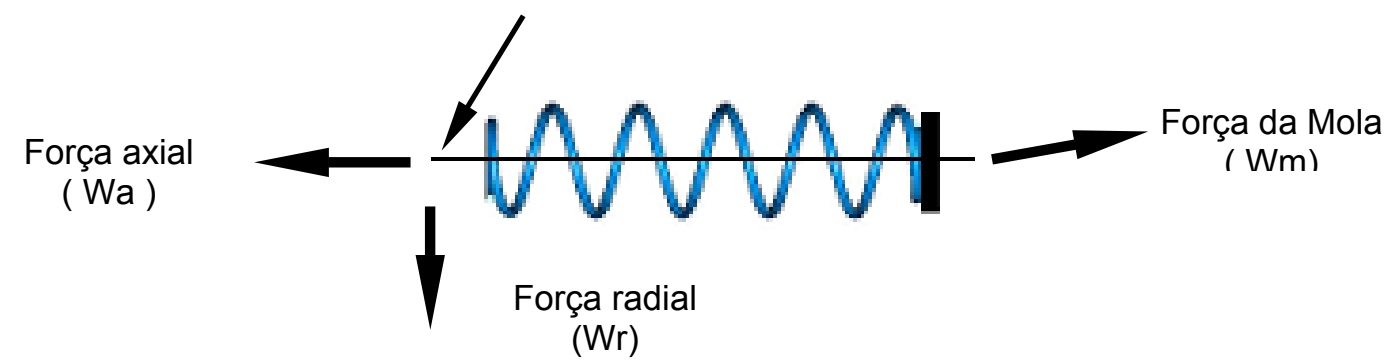

Figura 2.26 - Componente axial e radial da força gerada nas molas helicoidais com carga lateral

Este tipo de mola foi desenvolvido para ser aplicada em suspensões do tipo MacPherson, onde a mola tem a função de anular ou reduzir a força lateral "Ws1" que o amortecedor deste tipo de suspensão recebe em sua haste e buchas ("Ws2" e "Ws3") devido à sua construção e geometria típicas, figura 2.27 .

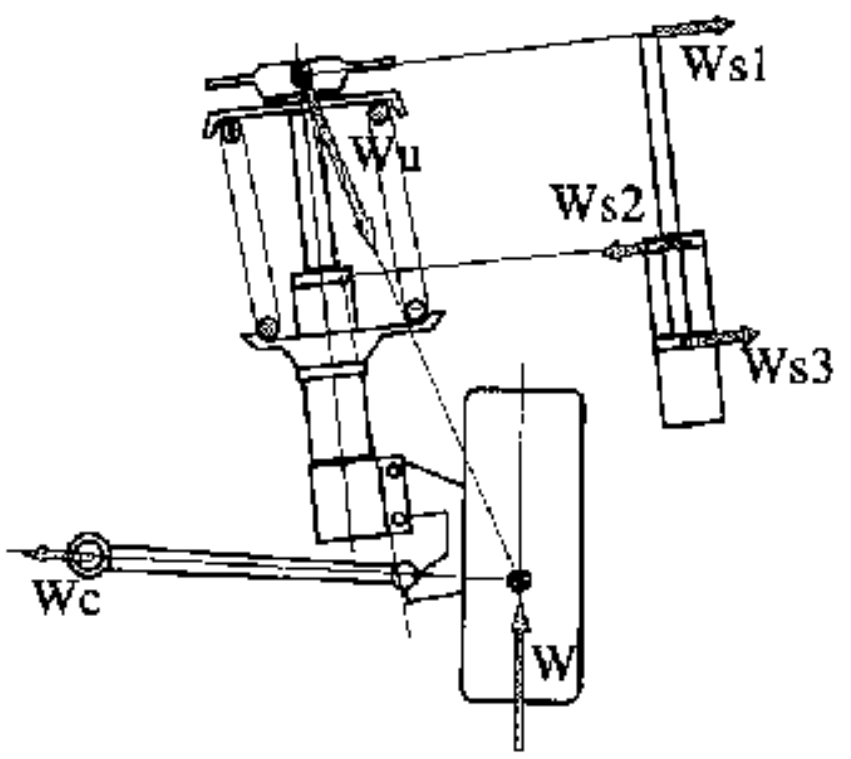

Figura 2.27 - Configuração das forças nas suspensões MacPherson 
A força "Wm" gerada pela mola com carga lateral, figura 2.28, possui uma componente radial que permite melhorar a capacidade da mola em anular a força lateral "Ws1".

Em uma mola convencional, é necessário um grande diâmetro externo, para que a força da mola "Wm", cuja direção coincide com o eixo geométrico da mola, tenha uma componente radial grande suficiente para anular a força lateral "Ws1".

A mola com carga lateral substitui com vantagens a mola convencional, pois seu diâmetro externo pode ser menor, o que a torna mais leve e compacta que a mola convencional, para um mesmo efeito de anulação da força lateral "Ws1".

A figura 2.28 mostra a configuração de forças com uma mola convencional e com uma mola com carga lateral as quais tem as mesmas dimensões geométricas. A força lateral "Ws1" pode ser totalmente anulada quando é utilizada uma mola com carga lateral.

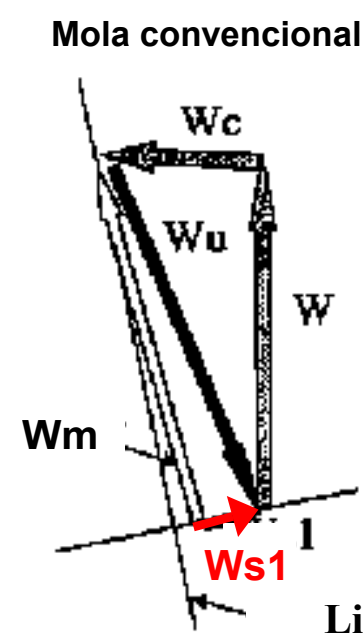

Linha centro geométrica

\section{Mola com carga lateral}

do amortecedor

Figura 2.28 - Configuração de forças nas suspensões MacPherson

Efeito da mola "side-load" 


\subsubsection{Mola a ar ou pneumática}

A mola a ar ou pneumática é o tipo que oferece as melhores características dinâmicas sob variadas condições de carga entre todas as acima descritas, substituindo a mola helicoidal com vantagens, figura 2.29.

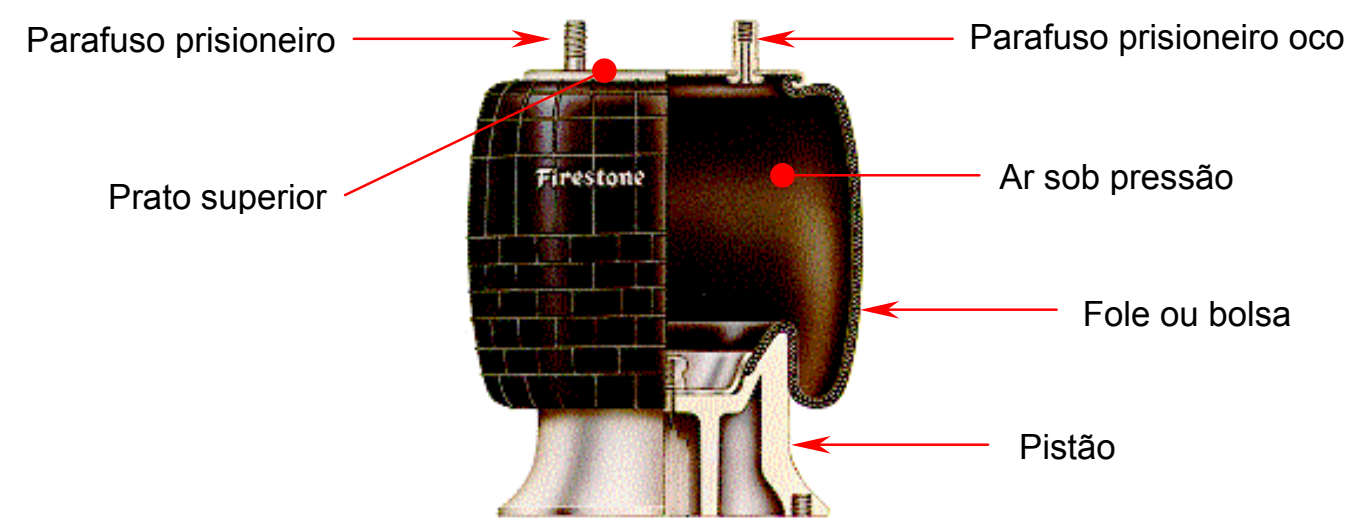

Figura 2.29 - Mola a ar ou pneumática (cortesia Firestone)

Quando associada a um sistema de controle de altura da suspensão, mantém as características dinâmicas próximas do ideal sob qualquer condição de carregamento, tabela 2.1 É a melhor opção em situações onde há uma grande diferença de carga entre as condições do veículo vazio e carregado, onde há necessidade de manter-se a altura do veículo constante e também onde o conforto tem grande importância.

\begin{tabular}{|c|c|c|c|}
\hline \multicolumn{5}{|c|}{ Características Dinâmicas } \\
a uma altura de 18,5 polegadas (projeto) \\
\hline \multicolumn{4}{|c|}{ Volume da bolsa @ 100 PSI = 1,330 pol. $^{3}$} \\
\hline $\begin{array}{c}\text { Pressão } \\
\text { (PSI) }\end{array}$ & $\begin{array}{c}\text { Carregamento } \\
\text { (Ibs) }\end{array}$ & $\begin{array}{c}\text { Rigidez } \\
\text { (Ibs/pol.) }\end{array}$ & $\begin{array}{c}\text { Freq. Natural } \\
(\mathrm{Hz})\end{array}$ \\
\hline 40 & 2.780 & 287 & 1,01 \\
\hline 60 & 4.250 & 425 & 0,99 \\
\hline 80 & 5.680 & 546 & 0,97 \\
\hline 100 & 7.120 & 659 & 0,95 \\
\hline \multicolumn{4}{|c|}{ Pressões em valores relativos } \\
\hline
\end{tabular}

Tabela 2.1 - Características dinâmicas mola a ar Firestone 1T15M-9 


\subsubsection{Batente ou mola auxiliar}

Trata-se de uma mola de rigidez não-linear, fabricada normalmente em poliuretano (PU) microcelular sendo que a geometria e a densidade da peça definem a rigidez característica.

$\mathrm{Na}$ figura 2.30 é mostrada a rigidez característica e a geometria de um batente de uma suspensão dianteira MacPherson:
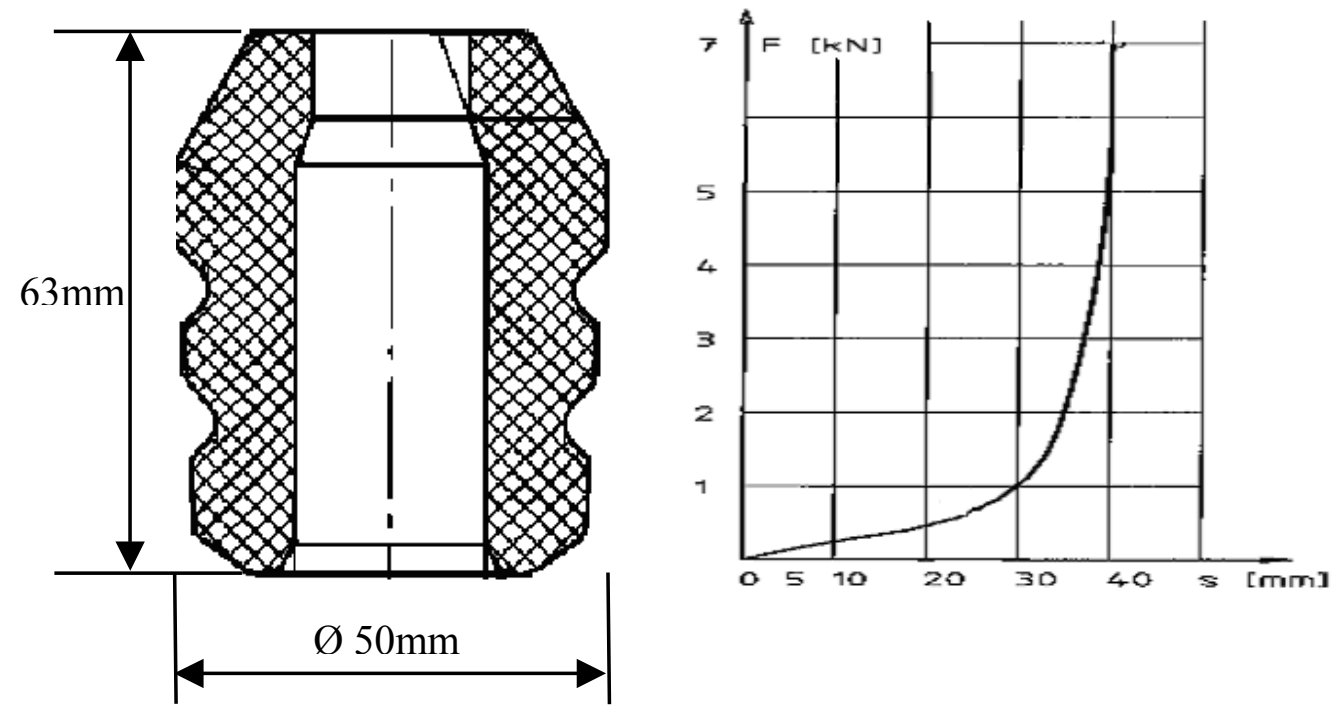

Figura 2.30 - Geometria e rigidez típica de um batente

Pode-se dizer que uma mola auxiliar diferencia-se de um batente pelo fato de os batentes terem caracteríticas de rigidez com menor progressividade e de o início de sua atuação ocorrer mais perto do final de curso de compressão ou de extensão da suspensão. A mola auxiliar tem a característica de rigidez mais progressiva e sua atuação ocorre na compressão durante um maior curso da suspensão. Alta histerese neste tipo de componente compromete a sua eficiência dinâmica e o bom desempenho do sistema de suspensão.

Em suspensões traseiras é mais frequente o uso de mola auxiliar devido ser maior a variação de carga do veículo de vazio para carregado. 


\subsubsection{O componente amortecedor, tipos e características}

Segundo DIXON os amortecedores podem ser divididos em dois tipos: o de atrito seco com elementos sólidos e o hidráulico com elementos fluídos.

Pode-se citar dois tipos de amortecedor de atrito seco com elementos sólidos: o com discos deslizantes (Truffault-Hartford), mostrado na figura 2.31 e o com cinta enrolada (Gabriel Snubber), mostrado na figura 2.32.

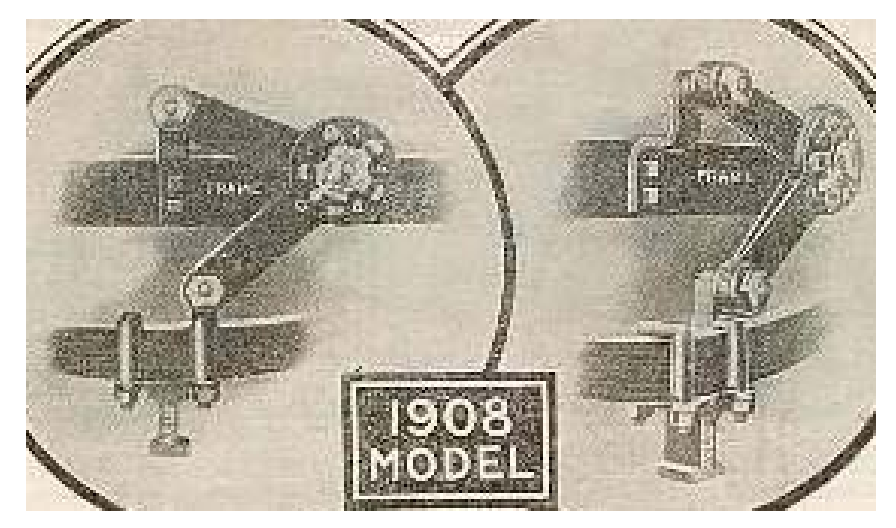

Figura 2.31 - Truffault-Hartford

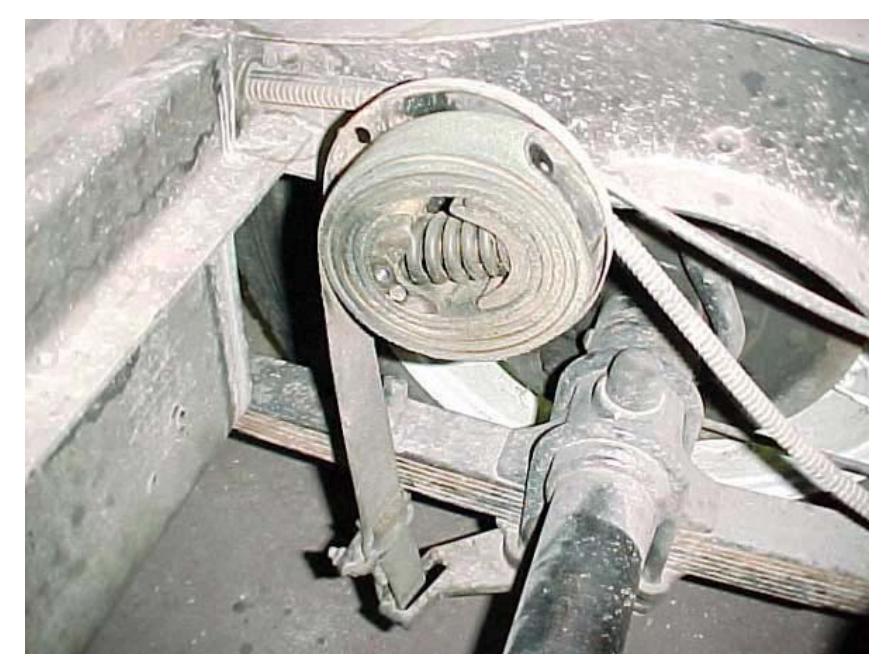

Figura 2.32 - Gabriel Snubber 
Pode-se citar ainda dois tipos de amortecedores hidráulicos com elementos fluídicos: o amortecedor com alavanca (Houdaille), mostrado na figura 2.33 e o telescópico, mostrado na figura 2.34.

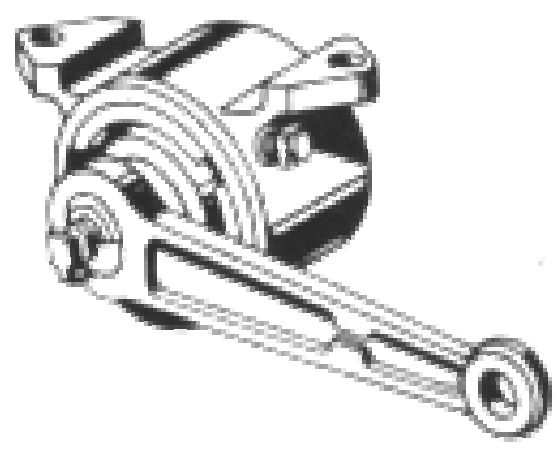

Figura 2.33 - Alavanca (Houdaille)

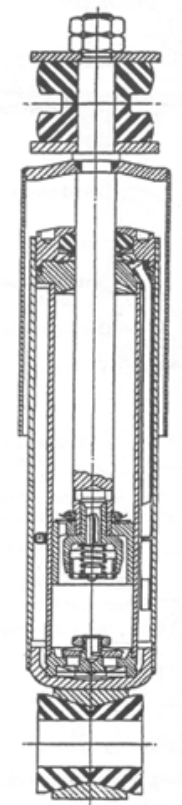

Figura 2.34 - Telescópico

Atualmente os tipos mais comuns de amortecedores são os hidráulicos telescópicos.

Existem dois tipos de amortecedores hidráulicos telescópicos no que diz respeito à acomodação do volume inserido da haste: o de tubo simples e o de tubo duplo, figura 2.35:

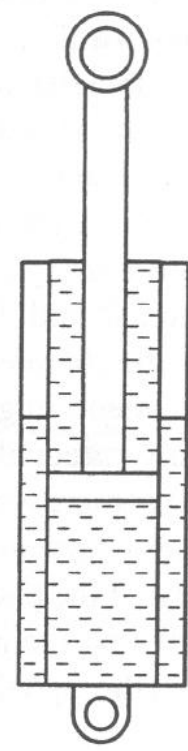

Tubo duplo

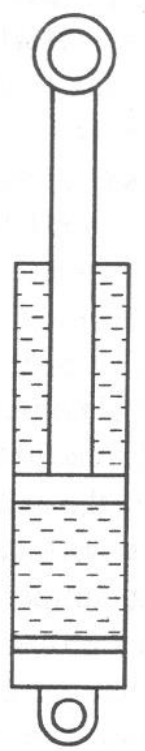

Tubo simples
Figura 2.35 - Tipos mais comuns de amortecedores hidráulicos 
Quanto às características de dissipação de energia, os tipos progressivos (não-lineares), são os mais comuns atualmente.

A figura 2.36 mostra um diagrama "força x velocidade de acionamento" com características progressiva e não-linear.

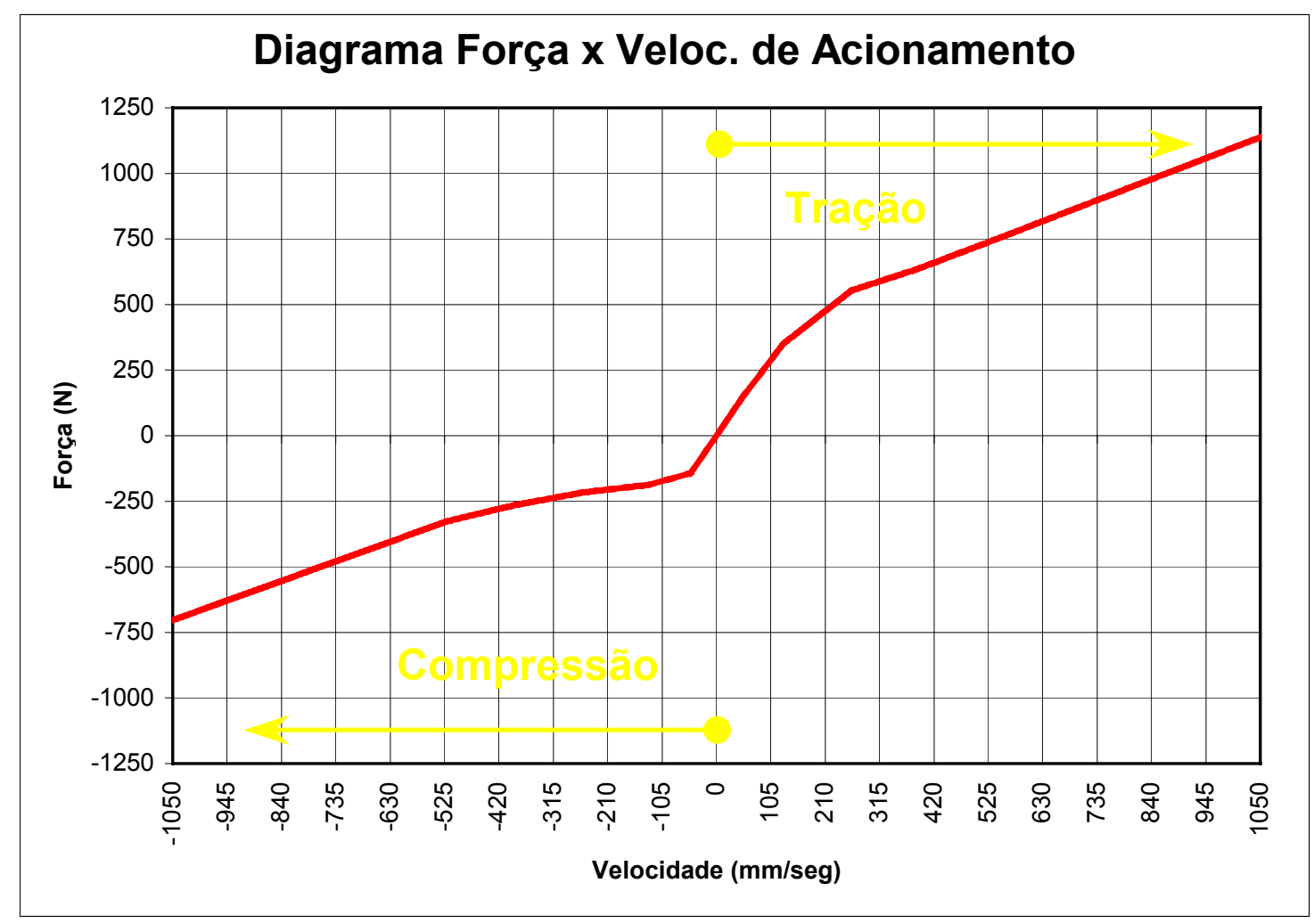

Figura 2.36 - Diagrama "força x velocidade de acionamento" de um amortecedor hidráulico telescópico progressivo

\subsubsection{Amortecimento dependente do curso ou posição}

O amortecimento dependente do curso é possível com a ajuda de cavidades de controle.

Estas cavidades são conformadas mecanicamente no tubo de pressão dos amortecedores de tubo duplo, obtendo-se, desta forma, uma passagem do fluído hidráulico que depende da posição relativa da haste e do tubo de pressão, figura 2.37. Com isto, a força, que é função da velocidade de acionamento, passa a ser também função também do curso ou posição da haste. 


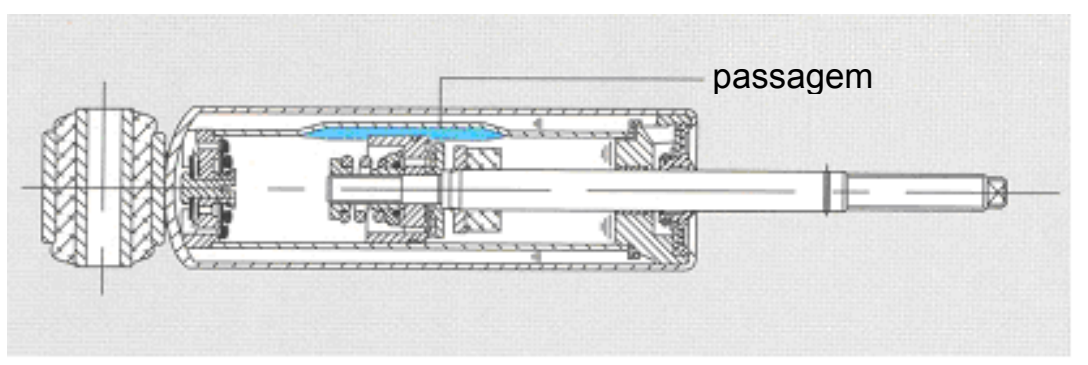

Figura 2.37 - Cavidades conformadas no tubo de pressão formam passagens

Na configuração mostrada na figura 2.37, a curva de amortecimento é alterada somente na região central do curso do amortecedor. As cavidades existentes nesta região permitem a passagem do fluído hidráulico, o que diminui a resistência hidráulica oferecida ao movimento da haste do amortecedor, alterando-se assim a curva de amortecimento (relação força $x$ velocidade).

A configuração das cavidades é feita de tal forma que haja uma transição suave na curva de amortecimento.

$\mathrm{Na}$ figura 2.38 é mostrada a alteração da característica de amortecimento conforme a posição da haste ou pistão do amortecedor e a configuração das cavidades.

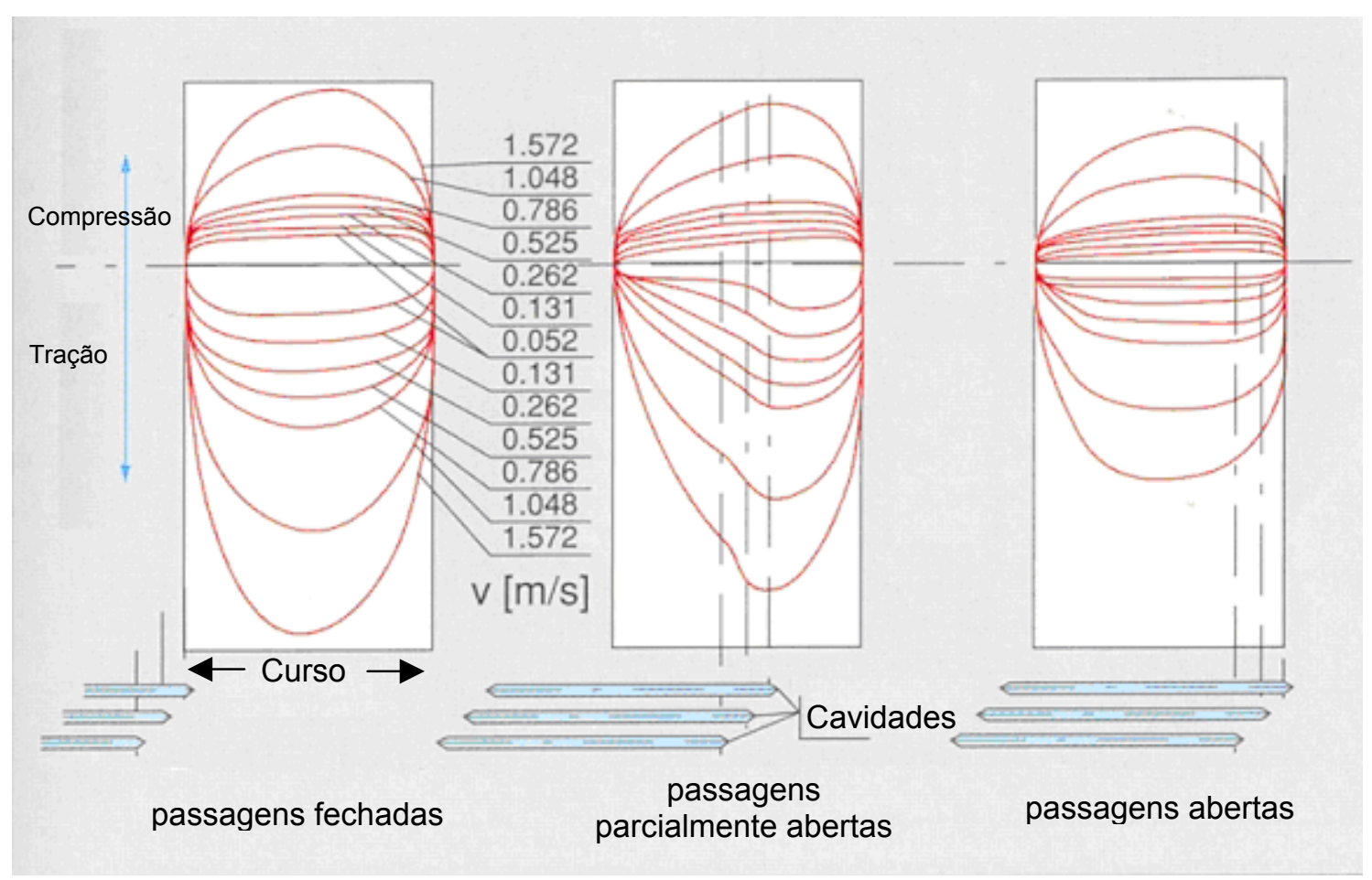

Figura 2.38 - Característica de amortecimento x configuração das cavidades 
$\mathrm{Na}$ figura 2.39 são mostradas algumas configurações possíveis de cavidades específicas para uma finalidade ou aplicação.

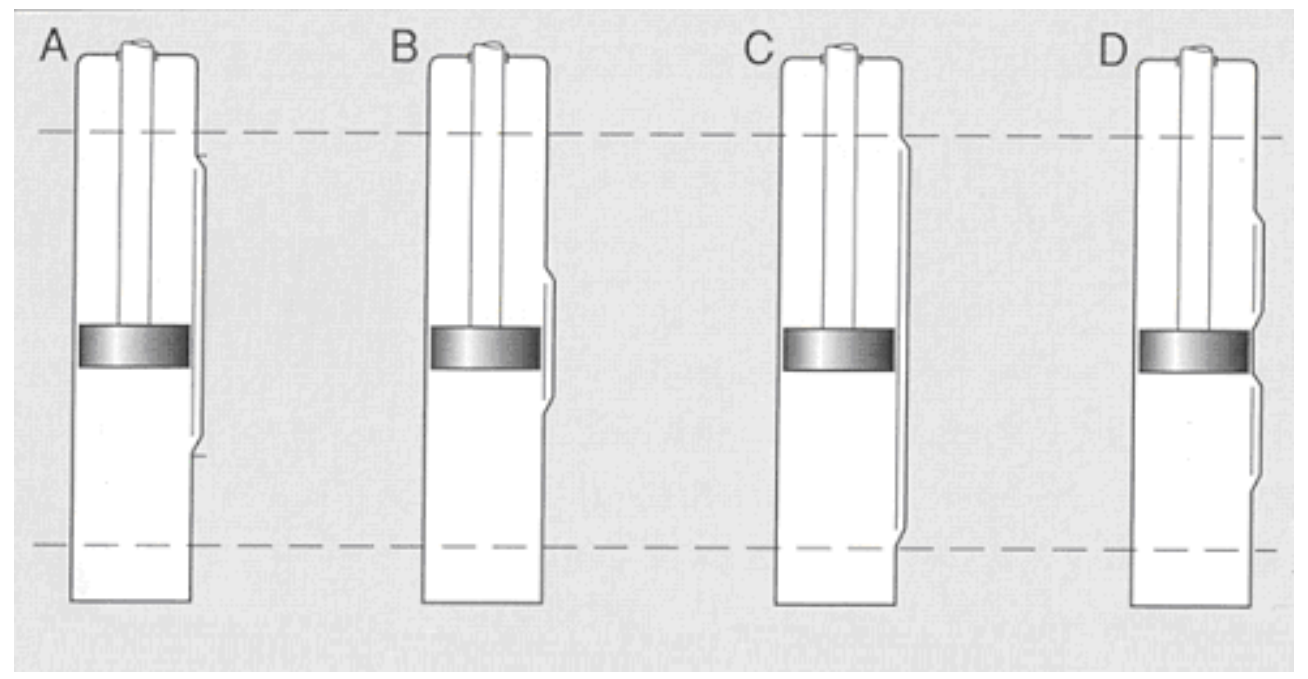

Figura 2.39 - Configuração das cavidades para variadas finalidades e aplicações

A execução "A" diminue a resistência hidráulica oferecida ao deslocamento do pistão em grande parte do curso da região central do amortecedor.

A execução "B" também diminue a resistência hidráulica oferecida ao deslocamento do pistão, porém somente em um pequeno curso em torno da região central.

A execução "D" aumenta a resistência hidráulica oferecida ao deslocamento do pistão em um pequeno curso em torno da região central e também em regiões perto dos finais de curso do amortecedor.

Com a execução "C", apenas nos finais de curso da suspensão existe a ação de um "freio hidráulico" não permitindo desta forma impactos, principalmente quando ocorre abertura total do amortecedor.

\subsubsection{O amortecedor utilizado nas suspensões MacPherson}

Normalmente são utilizados amortecedores do tipo hidráulico telescópico progressivo (não-linear) com tubo duplo e tem como característica funcional específica, a incidência de significativas forças radiais (normais ao seu eixo 
axial). As forças radiais são bem maiores do que as incidentes em amortecedores utilizados em outros tipos de suspensão.

Conforme detalhado no item 2.3.1.2, molas com carga lateral, estas forças radiais são resultantes da geometria da suspensão MacPherson e das forças que nela atuam.

Em função da incidência de forças radiais significativas, em relação às axiais, o amortecedor MacPherson tem características peculiares como maior diâmetro da haste (cerca de duas vezes o diâmetro da haste dos amortecedores convencionais) e tubo reservatório mais reforçado, figura 2.40.

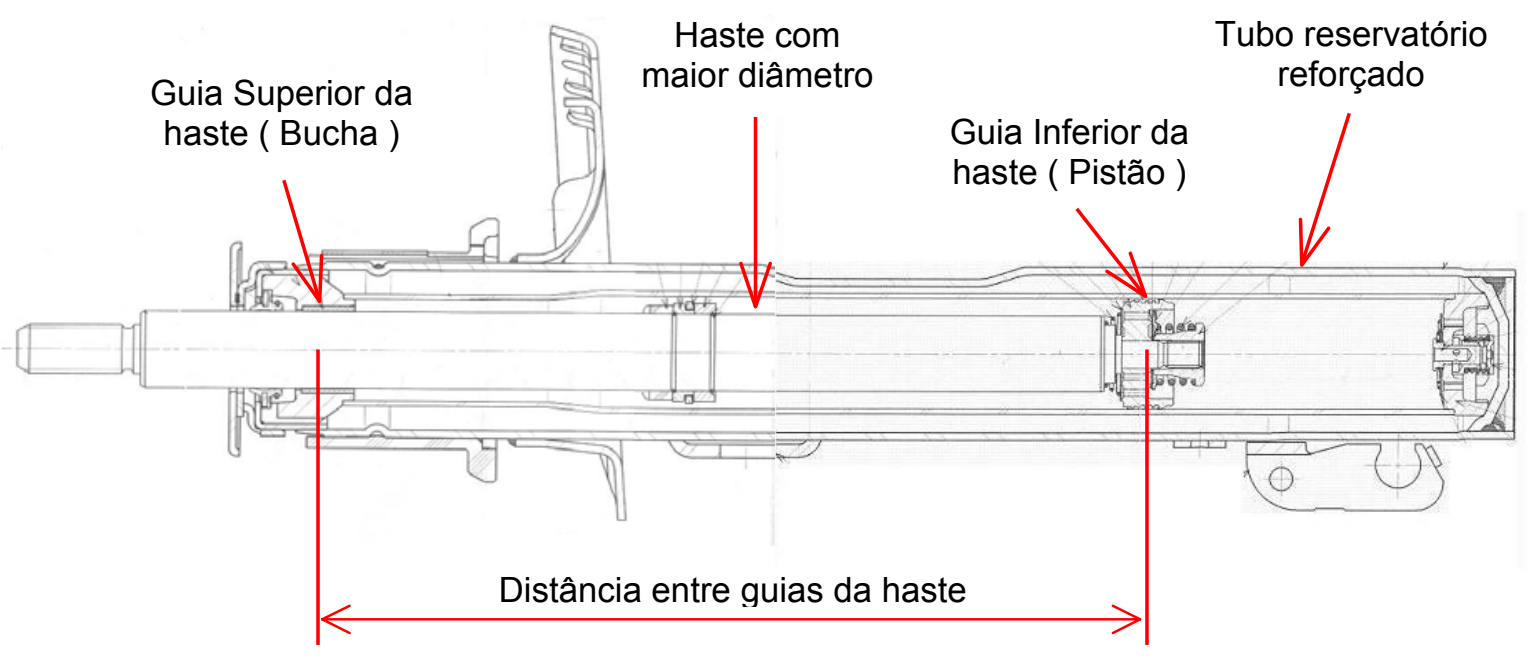

Figura 2.40 - Características dos amortecedores para suspensões MacPherson

Especial atenção deve ser dada aos apoios ou guias da haste, à distância entre elas e ao atrito gerado nestas guias, figura 2.40.

A força normal nas guias da haste depende da distância entre as guias e também da força lateral que o amortecedor recebe.

Esta e outras relações de dependência entre variáveis importantes dos amortecedores para suspensões MacPherson podem ser observadas na tabela mostrada na figura 2.41 . 


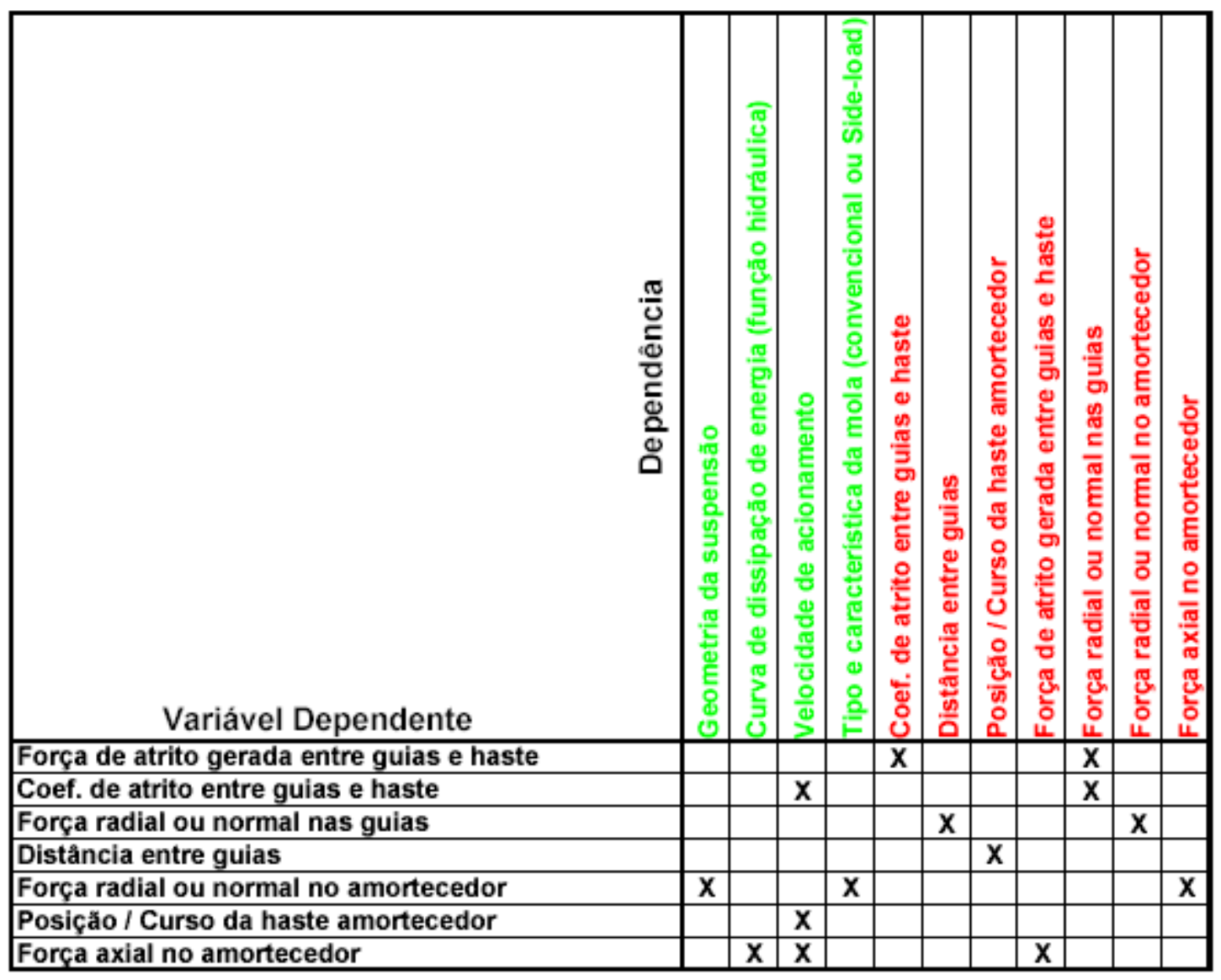

Figura 2.41 - Dependência entre variáveis dos amortecedores nas suspensões MacPherson

$\mathrm{Na}$ tabela mostrada na figura 2.41 considera-se como variáveis independentes as assinaladas em verde sendo, as demais, dependentes.

A análise acima é importante na medida em que mostra que a caracterização do atrito em amortecedores utilizados em suspensões do tipo MacPherson é bastante complexa.

A importância em caracterizar-se o atrito em suspensões do tipo MacPherson está no fato de que o atrito interno gerado em amortecedores utilizados nestas suspensões, segundo MUHR \& BENDER, causa deterioração do conforto quando o veículo trafega com velocidade baixa e constante, em linha reta, em estradas de boa qualidade e passa por pequenos degraus na pista (cerca de $1 \mathrm{~cm}$ ), situação bem conhecida por pilotos de testes de várias indústrias automobilísticas. 


\subsubsection{Os isoladores, tipos e características}

Os isoladores ou coxins de um sistema de suspensão têm como principal função, procurar isolar vibrações cujas frequências e amplitudes não foram eficientemente isoladas por outros componentes do sistema de suspensão.

Normalmente são componentes metal-borracha sendo que sua forma e características funcionais variam conforme a aplicação.

Abordaremos aqui apenas os isoladores ou coxins de um sistema de suspensão dianteira do tipo MacPherson, que é o objeto de estudo deste trabalho.

Na figura 2.42 estão indicadas as posições dos três isoladores ou coxins comumente utilizados em um sistema de suspensão do tipo MacPherson.

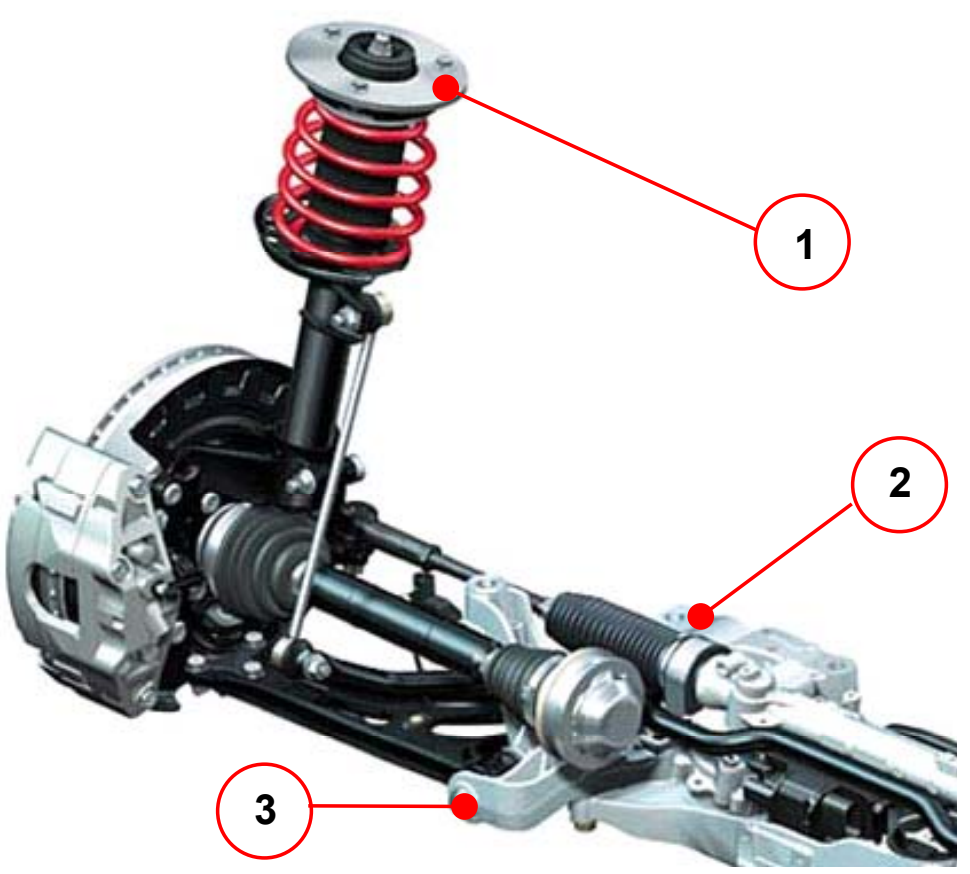

Figura 2.42 - Isoladores ou Coxins de uma Suspensão Dianteira do tipo MacPherson

Os isoladores nas posições (2) e (3) desempenham papel importante na dinâmica lateral e longitudinal do veículo, porém tem menor influência na dinâmica vertical.

Já as características funcionais do isolador da posição (1) são determinantes nos movimentos verticais da suspensão, e, portanto, na dinâmica vertical do veículo. 
Como o foco é a dinâmica vertical, não serão abordados aspectos funcionais dos isoladores (2) e (3).

O isolador na posição (1) da figura 2.42, denominado de isolador superior da suspensão ou ainda coxim superior da suspensão (Top-mount), geralmente é composto de partes metálicas (em aço ou alumínio) que estruturam um composto elastomérico, figura 2.43a e 2.43b.

Possui dois tipos: o desacoplado, figura 2.43a, e o não-desacoplado, figura 2.43b:

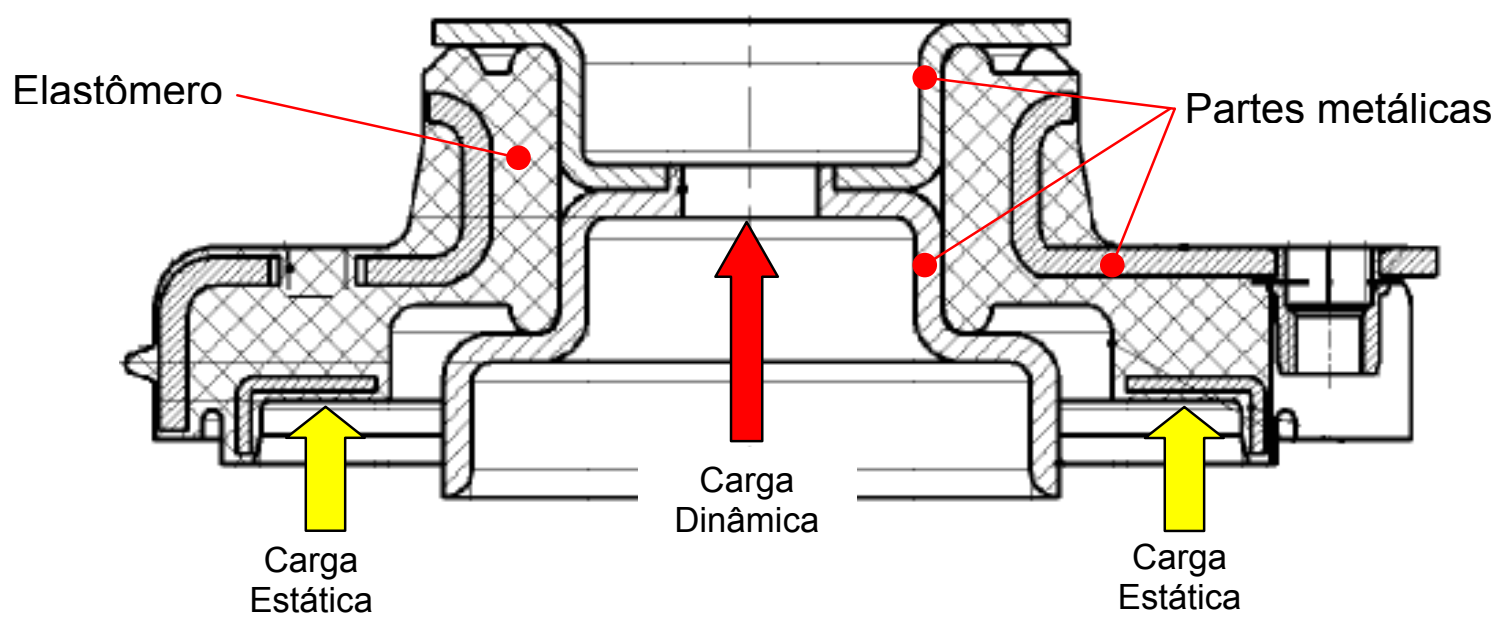

Figura 2.43a - Isolador ou coxim superior do tipo desacoplado

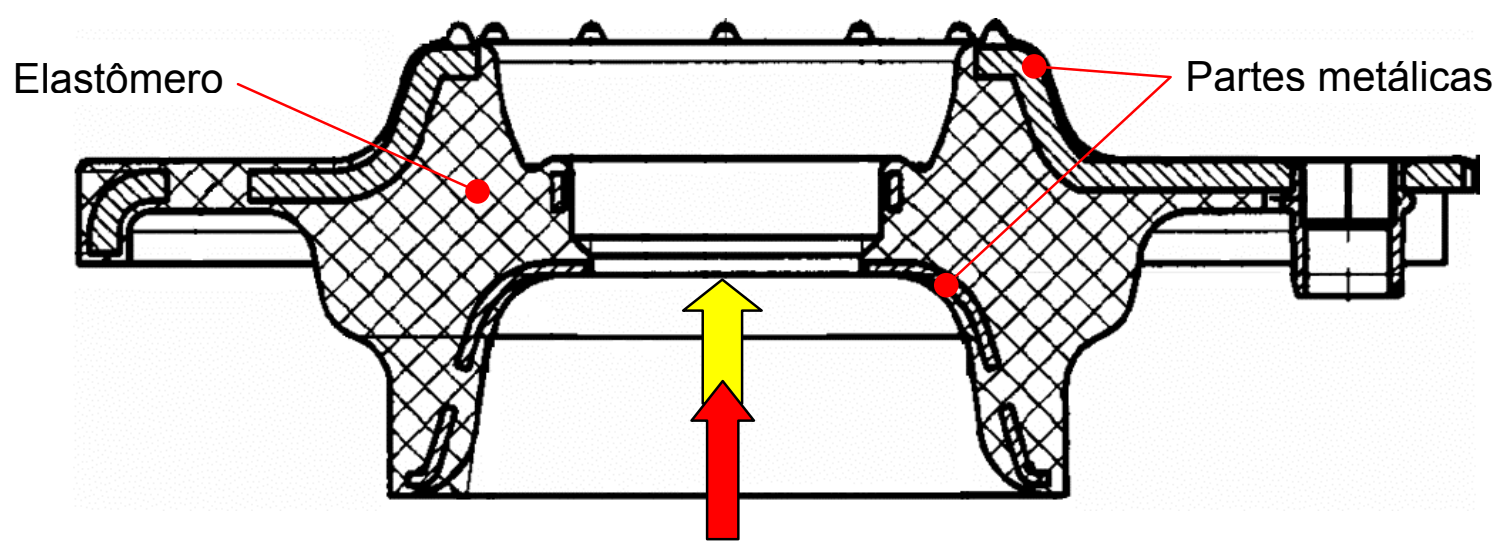

Cargas Estática e Dinâmica

Figura $2.43 \mathrm{~b}$ - Isolador ou coxim superior do tipo não-desacoplado

A principal diferença entre o tipo desacoplado e o tipo não-desacoplado é a forma como as cargas verticais estáticas e dinâmicas são absorvidas por eles. 
No tipo não-desacoplado as cargas verticais estáticas e dinâmicas são absorvidas no mesmo ponto. Por este motivo, neste tipo de isolador ou coxim superior, é necessária uma maior rigidez vertical para que se possa absorver a carga estática com deslocamentos compatíveis e ainda serem possíveis deslocamentos adicionais para absorção das cargas dinâmicas.

A rigidez na região de oscilação das cargas dinâmicas para pequenas amplitudes (da ordem de $+/-1$ a $2 \mathrm{~mm}$ e frequências mais altas) é determinante na transmissibilidade vertical deste tipo de coxim e ainda se altera com a variação da massa suspensa.

Estes aspectos são mostrados no gráfico da figura 2.44:

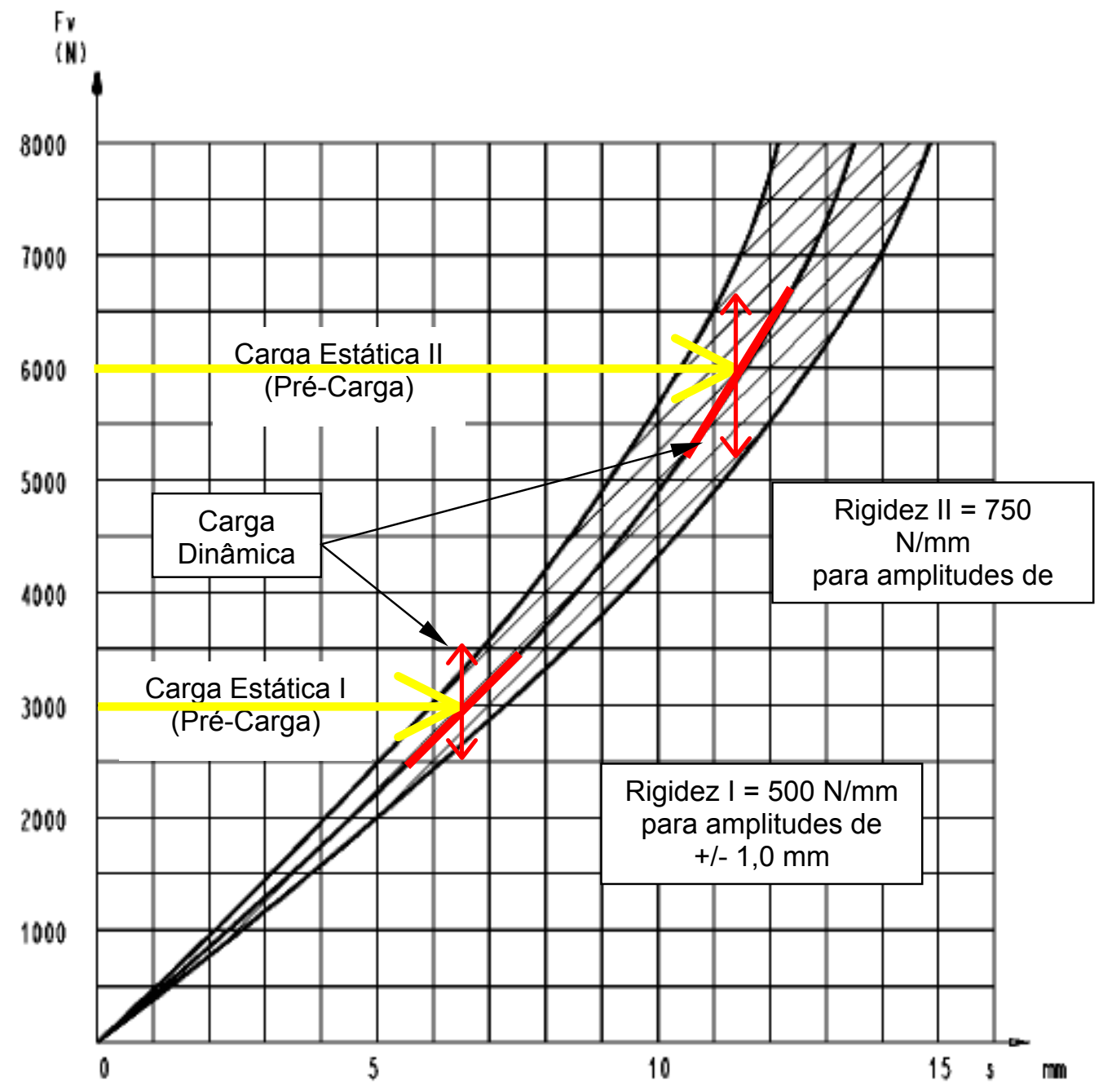

Figura 2.44 - Rigidez vertical do isolador não-desacoplado

O tipo não-desacoplado sofre de outro problema: com o envelhecimento do composto elastomérico ocorre aumento da rigidez e variação da suspensão (cedimento). 
O tipo desacoplado, por trabalhar em separado com as cargas estática e dinâmica, permite a otimização da rigidez para as cargas dinâmicas e particularmente para condições de maiores frequências e pequenas amplitudes conforme mostrado na figura 2.45 .

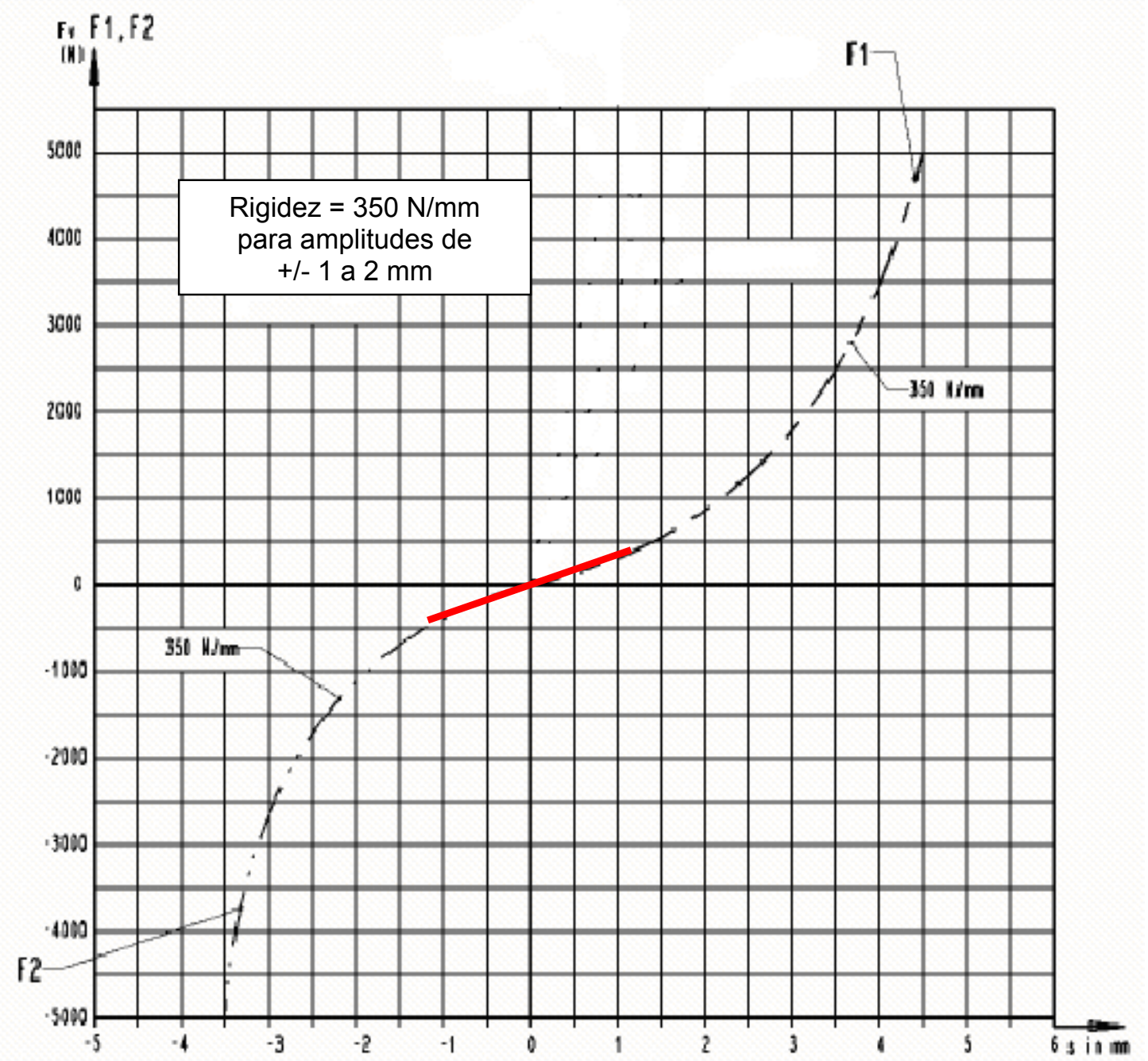

Figura 2.45 - Rigidez vertical do isolador desacoplado

As curvas F1 e F2 representam a rigidez do coxim desacoplado onde são absorvidas as cargas dinâmicas, figura 2.43a. Estas curvas representam a deformação em função da carga, aplicada conforme mostrado na figura 2.46. A curva F1 representa a rigidez na direção vertical no sentido de "Z" positivo (de baixo para cima) e a curva F2 representa a rigidez também na direção vertical, porém no sentido de " $Z$ " negativo (de cima para baixo). 


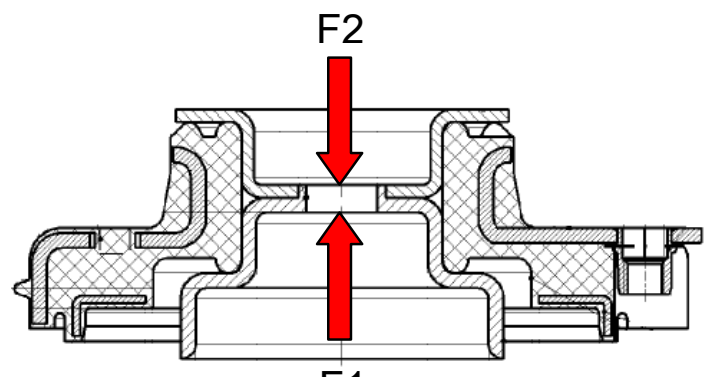

$\mathrm{F} 1$

Figura 2.46 - Esquema de aplicação de carga para levantamento das curvas F1 e F2

O tipo desacoplado também possui outras vantagens sobre o tipo nãodesacoplado como a não variação da rigidez com o aumento da massa suspensa ou com o envelhecimento do composto elastomérico.

Outra característica importante é a rigidez dinâmica que permite quantificar o nível de histerese presente em peças deste tipo.

A tabela 2.2 mostra requisitos da rigidez dinâmica que devem ser atendidos em função da frequência para um isolador superior do tipo desacoplado:

\begin{tabular}{|l|c|c|c|}
\hline & \multicolumn{3}{|c|}{ Caracteristicas Dinâmicas } \\
\hline Temp. Teste & \multicolumn{3}{|c|}{$20+/-2^{\circ} \mathrm{C}$} \\
\hline Pré-Carga & $+300 \mathrm{~N}$ \\
\hline Frequência & $300 \mathrm{~Hz}$ & $15 \mathrm{~Hz}$ & $1 \mathrm{~Hz}$ \\
\hline Amplitude & $0,1+/-0,01 \mathrm{~mm}$ & $0,5+/-0,02 \mathrm{~mm}$ & $1+/-0,05 \mathrm{~mm}$ \\
\hline Tempo de excitação & $30 \mathrm{~s}$ & $30 \mathrm{~s}$ & $15 \mathrm{~s}$ \\
\hline Rigidez Dinâmica & $<900 \mathrm{~N} / \mathrm{mm}$ & $<700 \mathrm{~N} / \mathrm{mm}$ & $<650 \mathrm{~N} / \mathrm{mm}$ \\
\hline
\end{tabular}

Tabela 2.2 - Rigidez Dinâmica Vertical do isolador desacoplado

Percebe-se que a rigidez dinâmica aumenta com o aumento da frequência e a diminuição da amplitude.

O correto casamento das características dos pneus e amortecedores utilizados com as do isolador superior são determinantes na absorção de vibrações com frequências entre 25 e $100 \mathrm{~Hz}$ (aspereza), pelo sistema de suspensão do veículo.

Em deslocamentos de maiores amplitudes e altas velocidades que atuam no amortecedor, como a passagem do veículo em alta velocidade por um degrau 
na pista, a progressão da curva de rigidez estática é determinante na sensação de conforto dos passageiros.

\subsubsection{O pneu, tipos e características}

Segundo Dr. G. HILL, considerando-se somente a dinâmica vertical do veículo, as características de interesse do pneu são a sua deflexão radial (estática) e a velocidade de deflexão (dinâmica) que resultam em força vertical.

A força vertical imposta pelo pneu assume somente valores positivos, em função da possibilidade do pneu perder contato com o solo.

A parcela estática da força vertical $\left(F_{V}^{S}\right)$ segue aproximadamente a equação (2.2):

$$
F_{V}^{S}=a_{1} \Delta z+a_{2}(\Delta z)^{2}
$$

onde:

$$
F_{V}^{S}=\text { carga estática vertical; }
$$

$a_{1}$ e $a_{2}=$ constantes que podem ser obtidas através de cálculo utlizando medições experimentais da deformação utilizando-se a carga nominal do pneu e o dobro deste valor; $\Delta z=$ deformação vertical do pneu devido à carga estática $F_{V}^{S}$

Medições da rigidez radial estática $\left(F_{V}^{S}=\right.$ Carga $\times \Delta z=$ Deflexão) podem ser feitas em dispositivos conforme o mostrado na figura 2.47. 


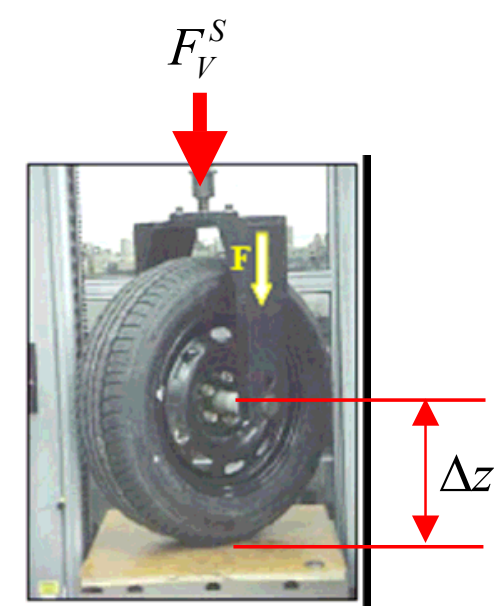

Figura 2.47 - Dispositivo de medição de rigidez radial estática

Para pneus com perfil 70 ou maior é admissível o uso de rigidez radial linear, figura 2.48a, porém para pneus com perfil 60 ou menor deve ser considerada que a rigidez radial é não-linear, figura $2.481 \mathrm{~b}$.
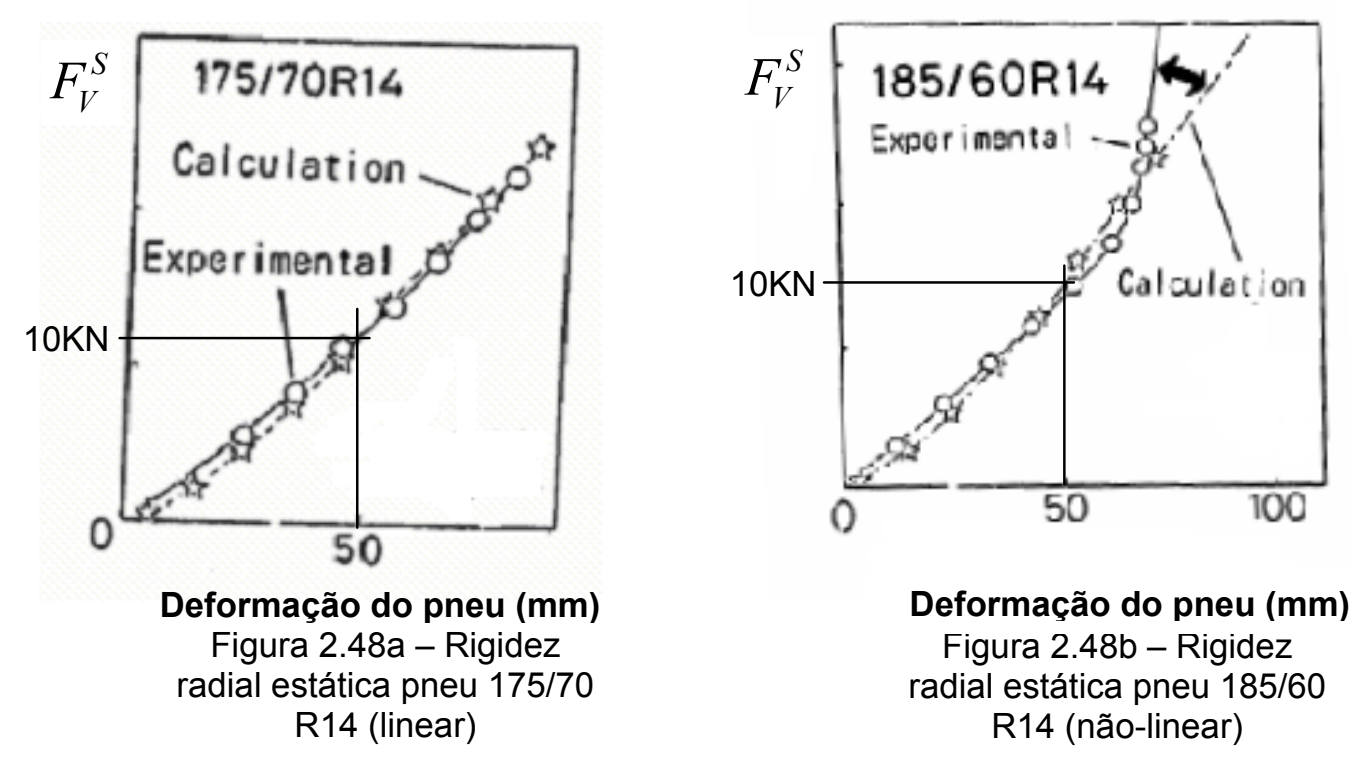

Deformação do pneu (mm)

Figura 2.48b - Rigidez radial estática pneu $185 / 60$ R14 (não-linear)

O valor da rigidez radial dos pneus de carros de passeio varia entre 150 e $250 \mathrm{~N} / \mathrm{mm}$.

A parcela dinâmica da força vertical $\left(F_{V}^{D}\right)$ segue aproximadamente a equação (2.3):

$$
F_{V}^{D}=d r \Delta \dot{z}
$$

onde:

$$
F_{V}^{D}=\text { carga dinâmica vertical; }
$$




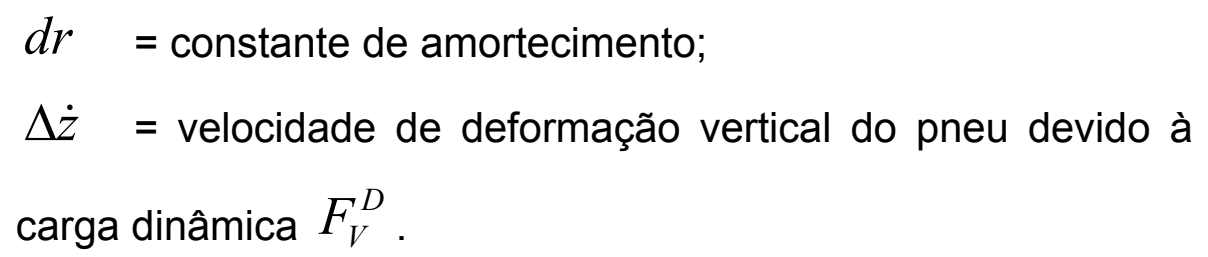

Muitas vezes o amortecimento vertical dos pneus pode ser desprezado, pois seu valor é pequeno quando comparado ao valor do amortecimento do amortecedor principal do sistema de suspensão.

Pode ser adicionado também algum amortecimento ao sistema devido ao escorregamento relativo entre pneu e solo e ao atrito existente entre eles. Este escorregamento relativo é devido à geometria do sistema de suspensão. Quando a suspensão movimenta-se verticalmente, direção "Z", ocorre a chamada variação da bitola na direção " $Y$ ", transversal ao veículo e no plano do solo, cuja amplitude depende fundamentalmente da geometria do sistema de suspensão utilizado.

A movimentação relativa entre pneu e solo, descrita acima, e o atrito existente entre eles, geram forças cujas amplitudes dependem de diversos parâmetros como velocidade do veículo, velocidade e amplitude da movimentação da suspensão, tipo de pneu, pressão de enchimento, etc. 


\subsection{Fundamentos}

Os fundamentos da dinâmica vertical (ride) apresentados nesta seção foram extraídos levando-se em consideração o conteúdo das obras de autores como GILLESPIE, J. REIMPELL, DIXON, W. F. MILLIKEN e D. L. MILLIKEN, H. B. PACEJKA e Dr. G. HILL que abordam o tema de forma semelhante, parcial, e/ou complementar.

É importante ressaltar que estão aqui apresentados apenas os fundamentos necessários e relacionados ao tema da dissertação, com maior ou menor ênfase, suprimindo-se os considerados não necessários e não relacionados com o tema.

\subsubsection{Introdução}

Como já citado anteriormente, a dinâmica vertical estuda o comportamento do veículo e de seus ocupantes quando submetidos a excitações.

Um veículo locomovendo-se a uma determinada velocidade é excitado por uma ampla gama de vibrações externas ou internas. Estas vibrações são filtradas pelo sistema de suspensão e chegam aos passageiros na forma de sensações tácteis, visuais e/ou audíveis.

Segundo A. COSTA, as vibrações, quanto às frequências, podem ser divididas em 3 faixas: até $25 \mathrm{~Hz}$, a sensação dos passageiros é somente táctil, em função do ouvido humano geralmente ter capacidade de ouvir somente fequências acima de $25 \mathrm{~Hz}$. Na faixa de $25 \mathrm{~Hz}$ até $20.000 \mathrm{~Hz}$, a sensação dos ocupantes é de ruído (audível), e, entre 25 e 100Hz, a sensação é de aspereza (táctil).

Segundo GILLESPIE, a vibração é um dos mais importantes critérios, embora de natureza subjetiva, pelo qual as pessoas julgam a qualidade de contrução e o do projeto de um veículo.

Conforme A. COSTA, a dinâmica vertical pode ser dividida em 3 subproblemas, figura 2.49 : 
a) Modelagem e caracterização das fontes de excitação

b) Resposta dinâmica do veículo

c) Tolerância e percepção às vibrações dos passageiros

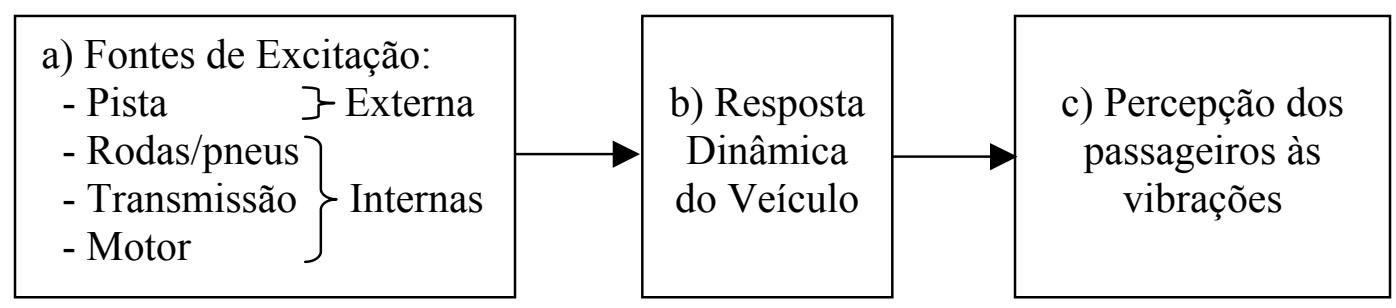

Figura 2.49 - Subproblemas da dinâmica vertical

São de interesse da dinâmica vertical as seguintes grandezas: deslocamento do centro de gravidade das massas suspensa e não-suspensa do veículo na direção vertical (z); a rotação em torno do eixo transversal (y) denominada arfagem; a rotação em torno do eixo longitudinal $(x)$, denominada rolamento ou rolagem (roll); o deslocamento do centro da roda; e, deslocamento e velocidade da suspensão, figura 2.50 .

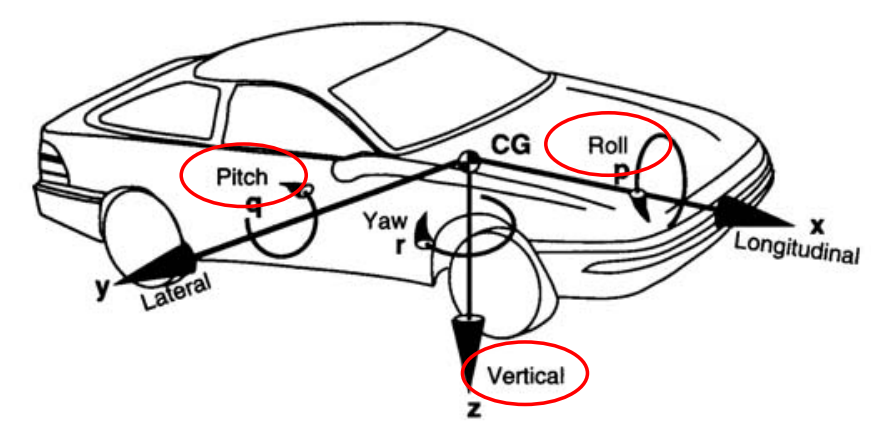

Figura 2.50 - Grandezas de interesse

De uma forma geral, neste trabalho são abordados os seguintes aspectos da dinâmica vertical:

- Resposta dinâmica das massas supensa e não-suspensa do veículo (no domínio da frequência e do tempo);

- Deslocamento e aceleração das massas supensa e não-suspensa do veículo na direção vertical; 
- Deslocamentos e velocidades de algumas partes da suspensão.

Não são abordados:

- As fontes de excitação internas (rodas/pneus, transmissão, e motor);

- A rotação em torno do eixo transversal (y) denominada arfagem;

- A rotação em torno do eixo longitudinal $(x)$, denominada rolamento ou rolagem.

A pista como fonte de excitação externa é abordada de forma simplificada.

\subsubsection{Resposta Dinâmica do Veículo}

A resposta dinâmica de um veículo pode ser caracterizada pelas relações das entradas e das saídas. As entradas são as excitações geradas pelas fontes apresentadas na figura 2.49. A saída de maior interesse geralmente é a vibração na carroceria. A relação entre as amplitudes da saída e da entrada, em função da frequência, é neste trabalho chamado de "ganho" que é associado ao termo "transmissibilidade".

O modelo simplificado (ou clássico) de $1 / 4$ de veículo, figura 2.51, consiste de uma massa suspensa " $M$ " ( $M$ = massa da carroceria completa) suportada por uma suspensão primária que a conecta com uma massa "m" não-suspensa, onde $m=$ (massa do eixo) + (massa da roda).

Esta suspensão primária possue rigidez (Ks) e amortecimento (Cs) como propriedades básicas. $\mathrm{O}$ pneu é representado na maior parte das vezes por uma mola simples $\left(\mathrm{K}_{\mathrm{t}}\right)$, em certos estudos um amortecedor é incluído para representar o pequeno amortecimento inerente à natureza visco-elástica dos pneus. 


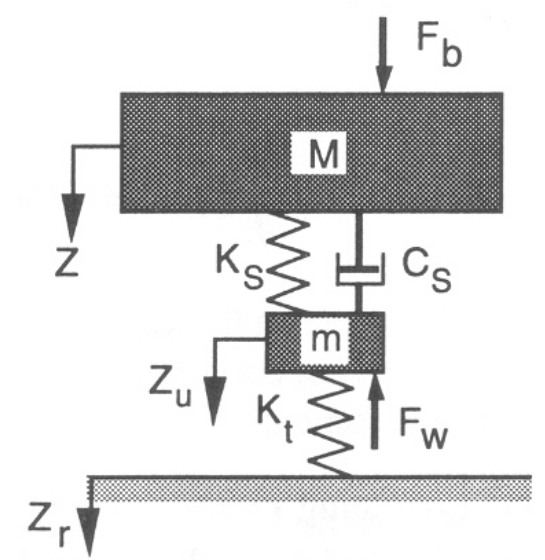

Figura 2.51 - Modelo simplificado (ou clássico) de 1/4 de veículo

$$
\text { onde: } \quad \begin{aligned}
& F_{b}=\text { Força atuante na massa suspensa "M" } \\
& F_{W}=\text { Força atuante na massa não-suspensa "m" } \\
& Z=\text { Deslocamento da massa suspensa "M" ( Saída ) } \\
& Z_{u}=\text { Deslocamento da massa não-suspensa "m" ( Saída ) } \\
& Z_{r}=\text { Deslocamento do solo ou pista ( Entrada ) } \\
& K_{S}=\text { Rigidez da mola principal da suspensão } \\
& C_{S}=\text { Coeficiente de amortecimento da suspensão } \\
& K_{t}=\text { Rigidez do pneu }
\end{aligned}
$$

Trata-se de um sistema com dois graus de liberdade, sendo que, se o sistema for linear, a primeira frequência natural, não-amortecida $\left(f_{n}\right)$ e também a amortecida $\left(f_{d}\right)$ da massa suspensa "M" são dadas pelas equações (2.4) (2.5), apresentadas abaixo:

$$
f_{n}=\frac{1}{2 \pi} \sqrt{\frac{R R}{M}}
$$

$$
\text { onde: } \quad \begin{aligned}
R R & =\frac{K s \cdot K t}{K s+K t} \\
R R & =\text { Rigidez equivalente da suspensão } \\
M & =\text { Massa suspensa }
\end{aligned}
$$




$$
f_{d}=f_{n} \sqrt{1-\zeta_{S}^{2}}
$$

onde: $\quad \zeta_{S}=C_{S} / \sqrt{4 . K S . M}$

$\zeta_{S}=$ Relação de amortecimento

$C_{S}=$ Coeficiente de amortecimento da suspensão

Segundo GILLESPIE, para um bom nível de conforto, a relação de amortecimento, $\zeta_{s}$ geralmente fica entre 0,2 e 0,4. Também HROVAT, em 1988, conclui que fatores de amortecimento entre 0,2 e 0,4, para o modo de vibrar com movimento predominante de massa suspensa, proporcionam os melhores resultados para os dois critérios, conforto e contato pneu solo. Com estes valores da relação de amortecimento observa-se nas expressões acima que a frequência natural e a frequência amortecida ficam muito próximas e, por este motivo, somente a frequência natural não-amortecida $\left(f_{n}\right)$ é comumente utilizada para caracterização do veículo.

A relação $W / K_{S}$, onde $W$ é o peso da massa suspensa e $K_{S}$ a constante elástica, representa a deflexão estática da suspensão devido ao peso do veículo e é um indicativo da capacidade da suspensão de isolar a massa suspensa de vibrações, Considerando que quanto menor a frequência natural melhor será este isolamento, os valores de $K_{S}$ devem ser os menores possíveis e, consequentemente, maior será a deflexão estática $\left(W / K_{S}\right)$.

Baixas frequências naturais requerem maiores cursos de suspensão para que as acelerações da pista sejam absorvidas sem atingir o batente ou o fim de curso da suspensão. O curso da suspensão depende do espaço disponível sendo que normalmente veículos maiores comportam maiores cursos de suspensão do que veículos menores e, portanto, tem condições de serem mais confortáveis.

Conforme a $2^{\mathrm{a}}$. Lei de Newton as equações do modelo simplificado de um quarto de veículo, apresentado na figura 2.54 , podem ser escritas conforme abaixo: 
Para a massa $M$ (massa suspensa):

$$
M \ddot{Z}=F_{b}-K_{S}\left(Z-Z_{u}\right)-C_{S}\left(\dot{Z}-\dot{Z}_{u}\right)
$$

Para a massa $m$ (massa não-suspensa):

$$
m \ddot{Z}_{u}=-F_{W}-K_{t}\left(Z_{u}-Z_{r}\right)-K_{S}\left(Z_{u}-Z\right)-C_{S}\left(\dot{Z}_{u}-\dot{Z}\right)
$$

onde: $\quad Z=$ Deslocamento vertical da massa suspensa

$Z_{u}=$ Deslocamento vertical da massa não-suspensa

$Z_{r}=$ Deslocamento da pista

$F_{b}=$ Força que age na massa suspensa

$F_{W}=$ Força que age na massa não-suspensa

As equações (2.6) e (2.7) permitem obter as funções transferência entre as diversas entradas e saídas bem como a resposta no domínio da frequência correspondente do sistema.

O modelo simplificado (ou clássico) de 1/4 de veículo ora apresentado é limitado para estudos de dinâmica somente na direção vertical.

Outra limitação diz respeito à obtenção da resposta do sistema no domínio da frequência, que só é possível com relativa simplicidade quando $K_{t}$, $K_{s}$ e $C_{S}$ são lineares.

\subsubsection{Influência da Rigidez da Suspensão}

Em um projeto clássico de veículos automotores, a constante elástica da mola é fixada de forma que a frequência natural não-amortecida da massa suspensa fique em torno de $1 \mathrm{~Hz}$.

A razão pela qual buscam-se valores baixos da frequência natural da massa suspensa pode ser percebida pelo exposto nos próximos parágrafos. 
A isolação característica da suspensão, fornecida pelo modelo simplificado (ou clássico) de 1/4 de veículo, combinada com o espectro típico da aspereza da estrada (entrada), resulta no espectro da aceleração da massasuspensa (saída), a qual pode ser calculada através da equação (2.8) abaixo para um modelo linear:

$$
G_{z s}(f)=\left|H_{v}(f)\right|^{2} G_{z r}
$$

onde: $\quad G_{z s}(f)=$ Densidade Espectral Média Quadrada (PSD = Power Spectral Density) da Aceleração da massa suspensa;

$H_{v}(f)=$ Ganho, resposta do sistema (veículo);

$G_{z r}=$ Densidade Espectral Média Quadrada (PSD = Power Spectral Density) da Aceleração da entrada (pista).

Na figura 2.52 estão representados graficamente valores típicos típicos de $H_{v}(f), G_{z r}$ e o resultado da combinação entre eles calculado através da equação (2.8):
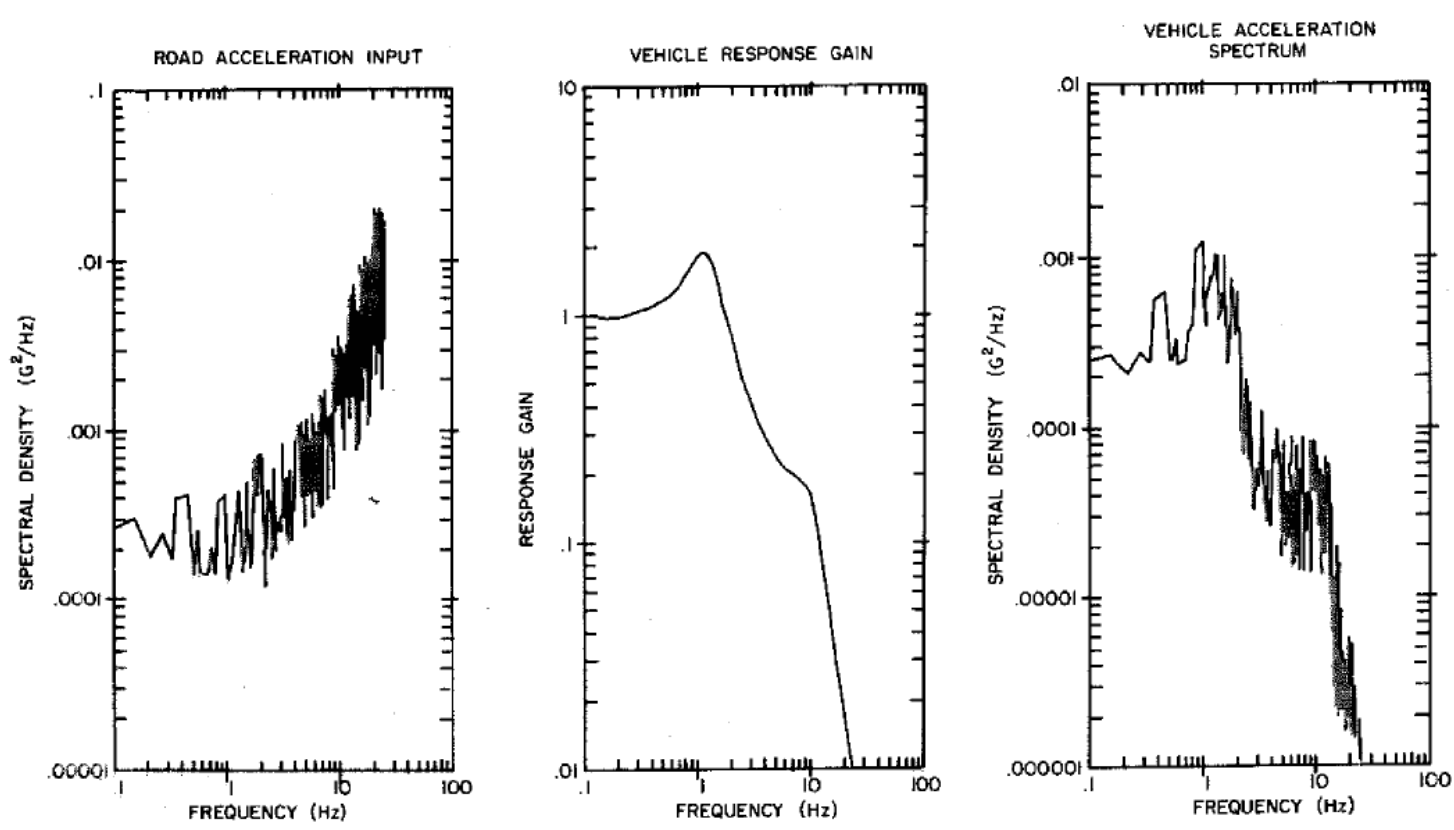

Figura 2.52 - Isolação da aceleração da estrada por um modelo simplificado (ou clássico) de $1 / 4$ de veículo 
Observa-se que embora o espectro da aceleração da pista aumente com a frequência, as características de isolação do sistema de supensão neste caso compensam este aumento e há um decréscimo no espectro da aceleração da massa suspensa.

A aceleração da pista (entrada) pode ser representada analiticamente (aproximadamente) por uma função que aumenta com o quadrado da frequência.

Utilizando-se tal função para representar a entrada da pista e calculando-se através da equação (2.8) a aceleração transmitida para a massa suspensa para várias frequências naturais da massa suspensa, percebe-se o aumento significativo do espectro da aceleração da massa suspensa, figura 2.53

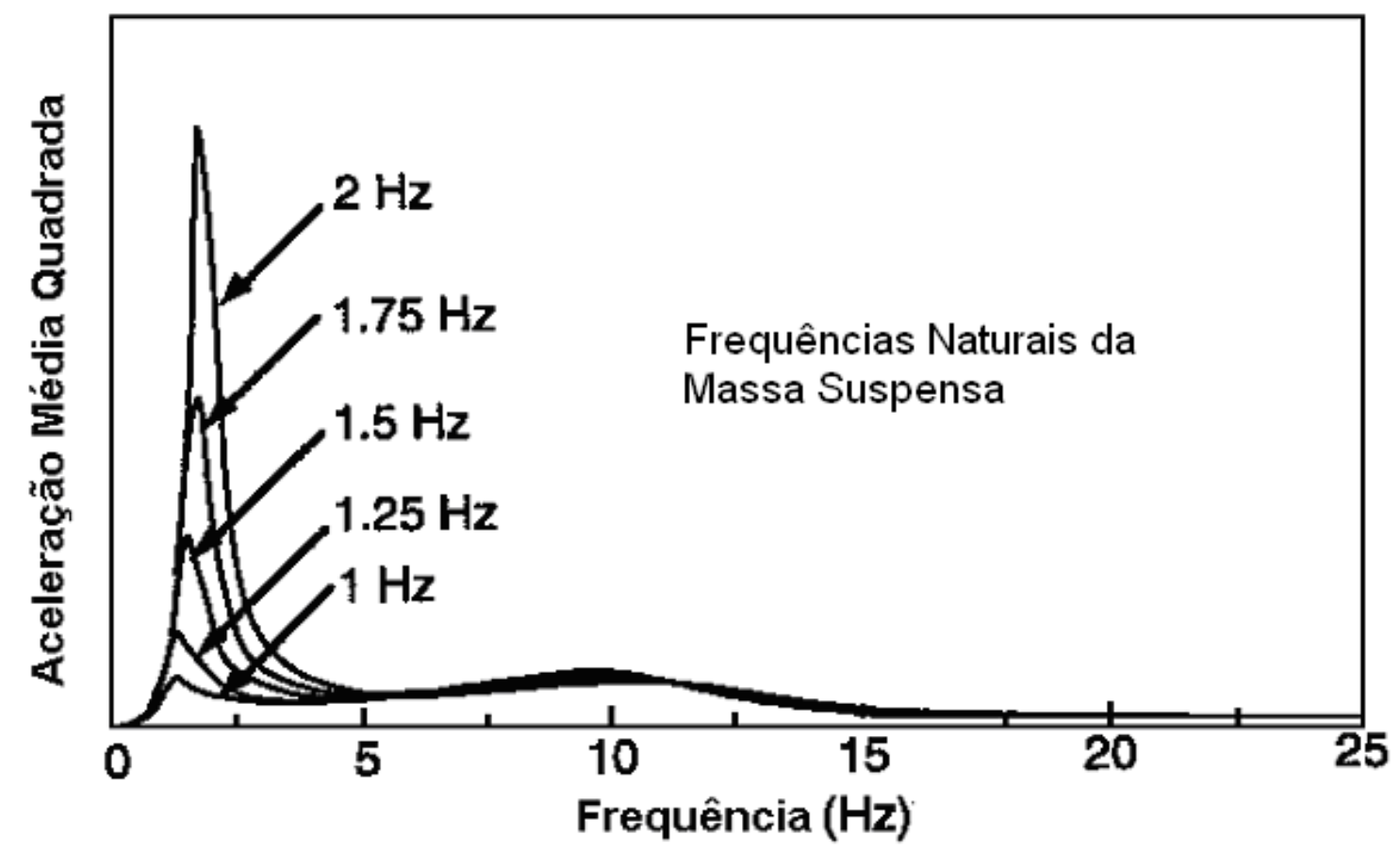

Figura 2.53 - Espectro da aceleração da massa suspensa considerando diferentes frequências naturais da massa suspensa

A análise feita acima demonstra claramente os benefícios de se manter baixos os valores da frequência natural da massa suspensa. 


\subsubsection{Influência do Amortecimento da Suspensão}

Como já afirmado anteriormente, o valor da frequência natural amortecida é praticamente a mesma da não-amortecida para valores de amortecimentos $\zeta_{S}$ entre 0,2 e 0,4 , porém o valor máximo da relação de amplitude no pico (na frequência de ressonância) é muito sensível ao nível de amortecimento e pode variar de 1,5 a 3,0 em veículos de passageiros.

A função do amortecimento nos sistemas de suspensão vem normalmente da ação de um amortecedor hidráulico e sua função é dissipar a energia armazenada no sistema devido à passagem por um obstáculo.

Segundo GILLESPIE, a relação de amortecimento da suspensão $\zeta_{S}$ apresenta um valor ótimo por volta de $40 \%$ para a maior parte dos veículos. Valores menores ou maiores deterioram o desempenho do sistema aumentando a sua transmissibilidade como pode ser visto no gráfico da figura 2.54:

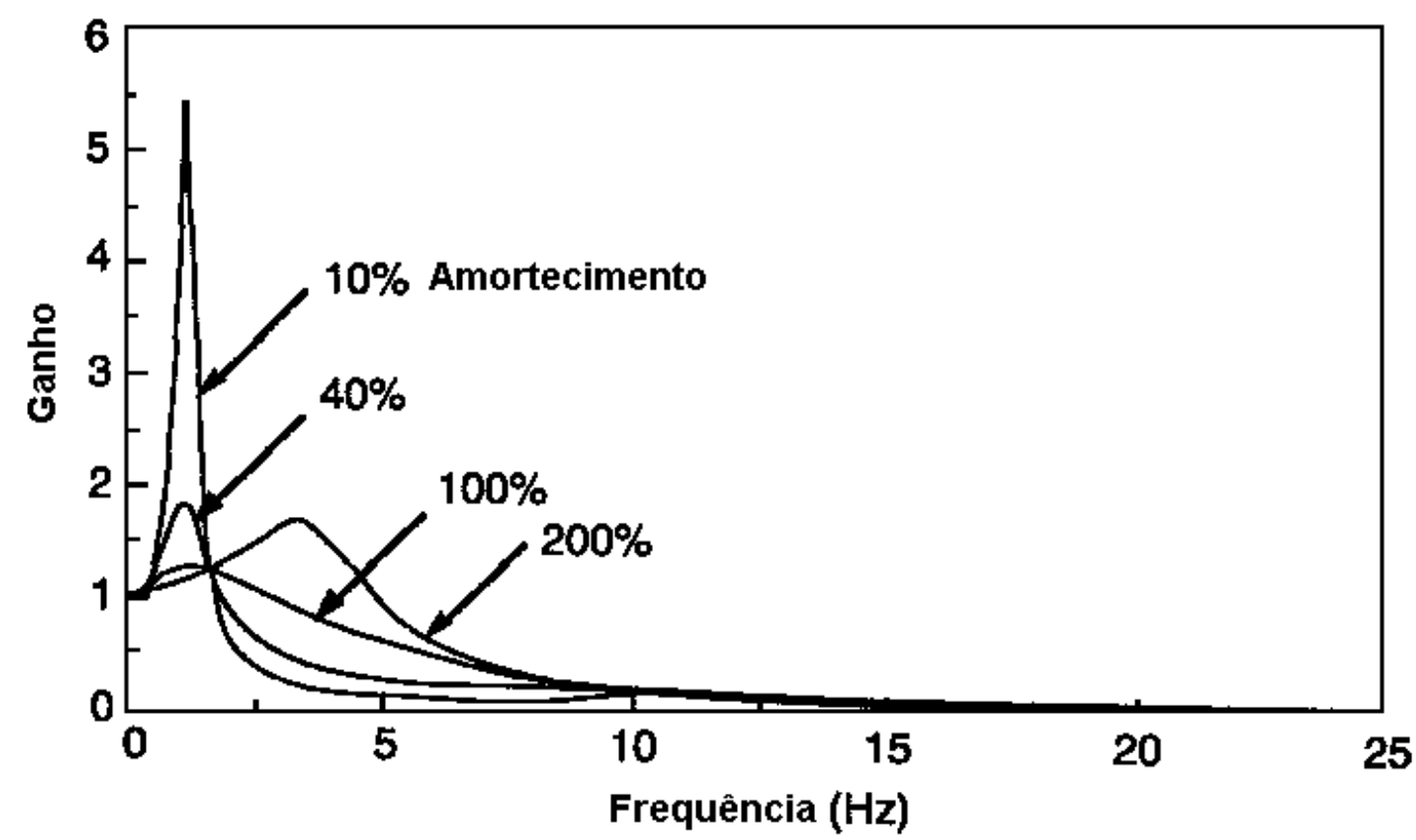

Figura 2.54 - Efeito do amortecimento na capacidade de isolação da suspensão

O tratamento analítico apresentado acima tem somente caráter ilustrativo, pois não representa a realidade. A característica de amortecimento 
para se atingir uma ótima performance é bastante complexa nos veículos modernos e são moldadas objetivando-se não só conforto como também segurança e dirigibilidade na medida em que é determinante na manutenção do contato pneu-solo. Também é importante ressaltar que a característica de amortecimento não é linear como assumida acima.

Tipicamente, os amortecedores utilizados nos veículos atuais são bilineares, ou seja, tem uma característica de amortecimento na compressão e outra diferente na tração sendo que a relação entre o amortecimento na tração e o amortecimento na compressão é de 3 para 1.

Fica claro, portanto, que os amortecedores utilizados em sistemas de suspensão devem ser tratados como elementos com características não lineares.

Geralmente buchas de material elastomérico (isoladores) são associadas em série com os amortecedores, o que muda significativamente sua característica nos movimentos de pequena amplitude e alta frequência. 


\section{Capítulo 3 - Justificativa e Objetivos}

\subsection{Justificativa}

Baseado no conteúdo sumário e predominantemente qualitativo exposto nos itens 2.2 e 2.3 do capítulo 2, podem ser enumeradas algumas limitações que podem influenciar nos resultados oferecidos pelo modelo simplificado (ou clássico) de 1/4 de veículo, figura 3.1, como por exemplo:

- não contempla geometria;

- não contempla alguns componentes;

- não contempla não-linearidades;

- contempla parcialmente topologia dos componentes

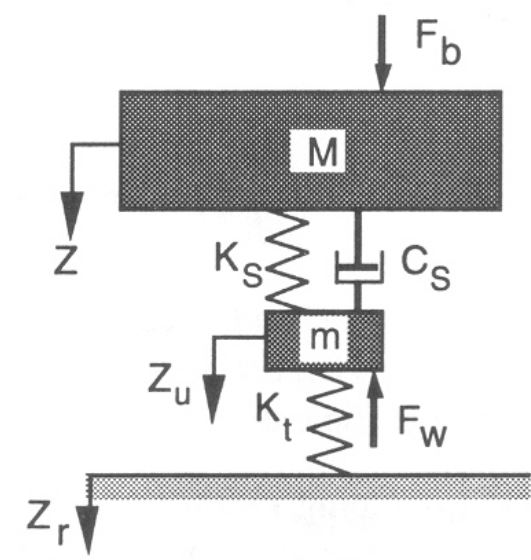

Figura 3.1 - Modelo simplificado (ou clássico) de 1/4 de veículo 
Além de respostas no domínio da frequência, são necessárias também respostas no domínio do tempo para o estudo da dinâmica vertical das suspensões e dos veículos. Situações específicas como a passagem por um obstáculo ou a rodagem em pista de testes, as quais são determinantes no dimensionamento do sistema de suspensão e de seus componentes, também podem enfatizar as limitações do modelo simplificado (ou clássico) de 1/4 de veículo.

A passagem por um obstáculo ou a rodagem em pista de testes pode exigir muito dos batentes de final de curso da suspensão, o que pode induzir a maiores erros nos resultados oferecidos pelo modelo simplificado (ou clássico) de $1 / 4$ de veículo, o qual não os contempla. Neste caso para obter-se resultados mais representativos da realidade, são necessários modelos mais elaborados e que levem em consideração as caracterísiticas dos batentes de final de curso da suspensão, entre outras descritas nos itens 2.2 e 2.3 .

Alguns destes modelos mais elaborados são frequentemente chamados de protótipos virtuais por exigir etapas análogas à de um protótipo físico, como construção, instalação de sensores e atuadores, especificação e execução de testes, etc., reforçando o fato destas etapas serem todas virtuais.

A criação de protótipos virtuais, bem como a execução de testes virtuais é possível graças a programas computacionais como o ADAMS que utiliza simulação de sistemas multi-corpos. Também o programa Matlab/Simulink pode ser usado para contrução de protótipos e simulações virtuais.

Através de um estudo comparativo entre o modelo simplificado (ou clássico) de 1/4 de veículo e um portótipo virtual de uma suspensão real, é possível identificar algumas das limitações do modelo simplificado (ou clássico) de $1 / 4$ de veículo.

Este trabalho apresenta um estudo comparativo entre os resultados fornecidos pelo modelo simplificado (ou clássico) de 1/4 de veículo e um protótipo virtual de um sistema de suspensão do tipo MacPherson de um veículo real, estudo cujos objetivos são apresentados com maiores detalhes no item 3.2 , a seguir. 


\subsection{Objetivos}

Objetivando-se um estudo que visa um comparativo básico entre os resultados oferecidos pelo modelo simplificado (ou clássico) de 1/4 de veículo e os oferecidos pelo protótipo virtual de um sistema de suspensão MacPherson, foram estabelecidos os seguintes procedimentos:

(1) Obter as respostas dinâmicas da massa suspensa e da massa nãosuspensa de um veículo, utilizando:

- um modelo simplificado (ou clássico) de 1/4 de veículo, representado por um sistema massa-mola com dois graus de liberdade;

- um protótipo virtual, mais complexo e específico de um sistema de suspensão dianteira do tipo MacPherson de um veículo nacional, construído com o auxílio de uma ferramenta computacional de simulação de sistemas multicorpos (ADAMS);

(2) Avaliar os resultados da resposta fornecidos pelo modelo simplificado (ou clássico) de 1/4 de veículo, usando como base os fornecidos pelo protótipo virtual da suspensão MacPherson, considerados mais próximos da realidade;

(3) Analisar as limitações de utilização do modelo simplificado (ou clássico) de $1 / 4$ de veículo no estudo de suspensões veiculares; 


\section{Capítulo 4 - Modelagem e Metodologia}

\subsection{Modelagem}

\subsubsection{Modelo simplificado (ou clássico) de 1/4 de veículo}

\subsubsection{Modelagem Analítica}

Para o levantamento analítico da resposta no domínio da frequência, a modelagem será desenvolvida utilizando a "Transformada de Laplace" para se obter as funções transferência necessárias do modelo simplificado (ou clássico) de 1/4 de veículo, com "Ks", "Cs" e "Kt" lineares (vide item 2.4.2 do capítulo 2), conforme mostra a figura 4.1.

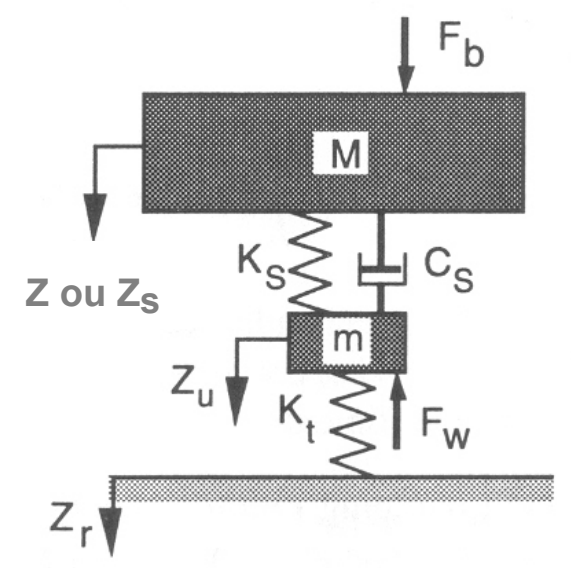

Figura 4.1 - Modelo simplificado (ou clássico) de 1/4 de veículo 
onde:

$$
\begin{aligned}
& F_{b}=\text { Força atuante na massa suspensa "M" } \\
& F_{W}=\text { Força atuante na massa não-suspensa "m" } \\
& Z \text { ou } Z_{S}=\text { Deslocamento da massa suspensa "M" ou "Ms" } \\
& Z_{u}=\text { Deslocamento da massa não-suspensa "m" ou "Mu" } \\
& Z_{r}=\text { Deslocamento do solo ou pista } \\
& K_{S}=\text { Rigidez da mola principal da suspensão } \\
& C_{S}=\text { Coeficiente de amortecimento do amortecedor } \\
& K_{t}=\text { Rigidez do pneu }
\end{aligned}
$$

As funções transferência a serem obtidas são as seguintes:

$$
\begin{aligned}
& \frac{\ddot{Z} s}{\ddot{Z} r}=\text { transmissibilidade entre pista e massa suspensa } \\
& \text { e } \\
& \frac{\ddot{Z} u}{\ddot{Z} r}=\text { transmissibilidade entre pista e massa não-suspensa }
\end{aligned}
$$

A seguir está apresentada a modelagem e, consequentemente, a obtenção das funções transferência desejadas.

Aplicando a Lei de Newton às duas massas, considerando $F_{b}$ e $F_{W}$ iguais a zero, obtem-se as seguintes equações:

$$
\begin{aligned}
& M_{S} \ddot{Z}_{S}+K_{S}\left(Z_{S}-Z_{U}\right)+C_{S}\left(\dot{Z}_{S}-\dot{Z}_{U}\right)=0 \\
& M_{U} \ddot{Z}_{U}+K_{S}\left(Z_{U}-Z_{S}\right)+C_{S}\left(\dot{Z}_{U}-\dot{Z}_{S}\right)+K_{t}\left(Z_{U}-Z_{R}\right)=0
\end{aligned}
$$

Escrevendo as equações em função de $\ddot{Z}_{S}, \ddot{Z}_{U}$ e $\ddot{Z}_{R}$ fica:

$$
\begin{gathered}
M_{S} \ddot{Z}_{S}+K_{S} \iint\left(\ddot{Z}_{S}-\ddot{Z}_{U}\right) d t^{2}+C_{S} \int\left(\ddot{Z}_{S}-\ddot{Z}_{U}\right) d t=0 \\
M_{U} \ddot{Z}_{U}+K_{S} \iint\left(\ddot{Z}_{U}-\ddot{Z}_{S}\right) d t^{2}+C_{S} \int\left(\ddot{Z}_{U}-\ddot{Z}_{S}\right) d t+K_{T} \iint\left(\ddot{Z}_{U}-\ddot{Z}_{R}\right) d t^{2}=0
\end{gathered}
$$


Agora, fazendo a Transformada de Laplace das equações obtem-se:

$$
\begin{gathered}
M_{S} \ddot{Z}_{S}(s)+K_{S}\left(\frac{\ddot{Z}_{S}(s)-\ddot{Z}_{U}(s)}{s^{2}}\right)+C_{S}\left(\frac{\ddot{Z}_{S}(s)-\ddot{Z}_{U}(s)}{s}\right)=0 \\
M_{U} \ddot{Z}_{U}(s)+K_{S}\left(\frac{\ddot{Z}_{U}(s)-\ddot{Z}_{S}(s)}{s^{2}}\right)+C_{S}\left(\frac{\ddot{Z}_{U}(s)-\ddot{Z}_{S}(s)}{s}\right)+K_{T}\left(\frac{\ddot{Z}_{U}(s)-\ddot{Z}_{R}(s)}{s^{2}}\right)=0
\end{gathered}
$$

Desenvolvendo as equações 4.5 e 4.6 vem:

$$
\begin{aligned}
& \left(M_{S} s^{2}+C_{S} s+K_{S}\right) \ddot{Z}_{S}(s)-\left(C_{S} s+K_{S}\right) \ddot{Z}_{U}(s)=0 \\
& -\left[\frac{\left(C_{S} s+K_{S}\right)}{K_{T}}\right] \ddot{Z}_{S}(s)+\left\{\frac{\left[M_{U} s^{2}+C_{S} s+\left(K_{T}+K_{S}\right)\right]}{K_{T}}\right\} \ddot{Z}_{U}(s)=\ddot{Z}_{R}(s)
\end{aligned}
$$

Escrevendo 4.7 e 4.8 na forma de matriz fica:

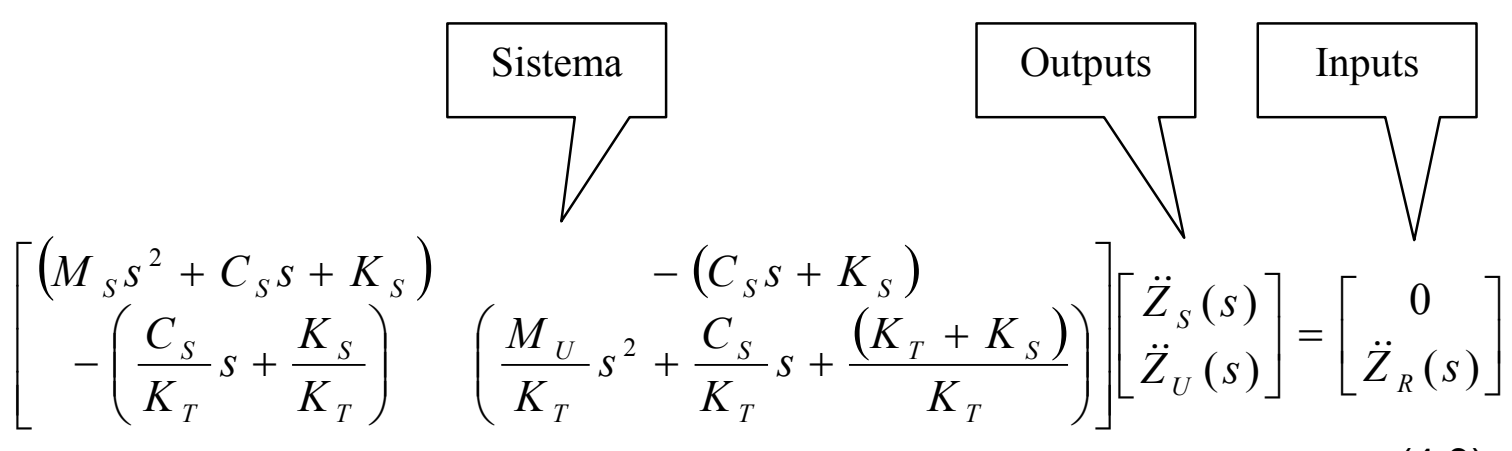

Chamando a matriz do sistema como sendo $[D E N]$; isto é:

$$
\left[\begin{array}{cc}
\left(M_{S} s^{2}+C_{S} s+K_{S}\right) & -\left(C_{S} s+K_{S}\right) \\
-\left(\frac{C_{S}}{K_{T}} s+\frac{K_{S}}{K_{T}}\right) & \left(\frac{M_{U}}{K_{T}} s^{2}+\frac{C_{S}}{K_{T}} s+\frac{\left(K_{T}+K_{S}\right)}{K_{T}}\right)
\end{array}\right]=[D E N]
$$


Com a ajuda do MatLab pode-se encontrar o determinante da matriz através do código:

>> syms s MS MU CS KS KT

$>>\mathrm{DEN}=\left[\left(\mathrm{MS}^{*} \mathrm{~S}^{\wedge} 2+\mathrm{CS}^{*} \mathrm{~S}+\mathrm{KS}\right)-\left(\mathrm{CS}^{*} \mathrm{~S}+\mathrm{KS}\right) ;-\left((\mathrm{CS} / \mathrm{KT})^{*} \mathrm{~S}+(\mathrm{KS} / \mathrm{KT})\right)\right.$

$\left.\left((\mathrm{MU} / \mathrm{KT})^{*} \mathrm{~S}^{\wedge} 2+(\mathrm{CS} / \mathrm{KT})^{*} \mathrm{~S}+((\mathrm{KT}+\mathrm{KS}) / \mathrm{KT})\right)\right]$

$\mathrm{DEN}=$

$\left[\begin{array}{c}M S^{*} S^{\wedge} 2+C S^{*} S+K S, \\ -C S / K T^{*} S-K S / K T, \quad M U / K T^{*} S^{\wedge} 2+C S / K T^{*} S+(K T+K S) / K T\end{array}\right]$

$>>\mathrm{DETDEN}=\operatorname{det}(\mathrm{DEN})$

DETDEN $=$

$\left(M^{*} s^{\wedge} 4^{*} M U+M S^{*} S^{\wedge} 3^{*} C S+M S^{*} S^{\wedge} 2^{*} K T+M S^{*} S^{\wedge} 2^{*} K S+C S^{*} S^{\wedge} 3^{*} M U+C S^{*} S^{*} K T+K S\right.$ $\left.{ }^{*} M U^{*} \mathrm{~S}^{\wedge} 2+\mathrm{KS}{ }^{*} \mathrm{KT}\right) / \mathrm{KT}$

Agora, aplicando a Regra de Cramer pode-se determinar a função transferência $\frac{\ddot{Z}_{S}(s)}{\ddot{Z}_{R}(s)}$; assim:

$\ddot{Z}_{S}(s)=\frac{\left|\begin{array}{cc}0 & -\left(C_{S} s+K_{S}\right) \\ \ddot{Z}_{R}(s) & \left(\frac{M_{U}}{K_{T}} s^{2}+\frac{C_{S}}{K_{T}} s+\frac{\left(K_{T}+K_{S}\right)}{K_{T}}\right)\end{array}\right|}{|D E N|}$

A função transferência de $\frac{\ddot{Z}_{S}(s)}{\ddot{Z}_{R}(s)}$ fica:

$\frac{\ddot{Z}_{S}(s)}{\ddot{Z}_{R}(s)}=\frac{\left(C_{S} s+K_{S}\right)}{\left(M_{S} C s+\left(M_{S} \frac{C_{S}}{K_{T}}+C_{S} \frac{M_{U}}{K_{T}}\right) s^{3}+\left(M_{S} \frac{\left(K_{T}+K_{S}\right)}{K_{T}}+K_{S} \frac{M_{U}}{K_{T}}\right) s^{2}+C_{S}\left(\frac{\left(K_{T}+K_{S}\right)}{K_{T}}-\frac{K_{S}}{K_{T}}\right) s+K_{S}\left(\frac{\left(K_{T}+K_{S}\right)}{K_{T}}-\frac{K_{S}}{K_{T}}\right)\right)}$ 
Repetindo o processo para a função transferência $\frac{\ddot{Z}_{U}(s)}{\ddot{Z}_{R}(s)}$, temos:

$$
\ddot{Z}_{S}(s)=\frac{\left|\begin{array}{cc}
\left(M_{S} s^{2}+C_{S} s+K_{S}\right) & 0 \\
-\left(\frac{C_{S}}{K_{T}} s+\frac{K_{S}}{K_{T}}\right) & \ddot{Z}_{R}(s)
\end{array}\right|}{|D E N|}
$$

que resulta:

$$
\left.\frac{\ddot{Z}_{U}(s)}{\ddot{Z}_{R}(s)}=\frac{\left(M_{S}{ }^{2}+C_{S} s+K_{S}\right)}{\left(M_{S} C S^{4}+\left(M_{S} \frac{C_{S}}{K_{T}}+C_{S} \frac{M_{U}}{K_{T}} s^{3}+\left(M_{S} \frac{\left(K_{T}+K_{S}\right)}{K_{T}}+K_{S} \frac{M_{U}}{K_{T}}\right) s^{2}+C_{S}\left(\frac{\left(K_{T}+K_{S}\right)}{K_{T}}-\frac{K_{S}}{K_{T}}\right) s+K_{S}\left(\frac{\left(K_{T}+K_{S}\right)}{K_{T}}-\frac{K_{S}}{K_{T}}\right)\right)\right.}\right)
$$

As equações 4.12 e 4.14 representam o modelo simplificado (ou clássico) de 1/4 de veículo com 2 graus de liberdade, analítico e linear. 


\subsubsection{Modelagem do protótipo virtual relativo ao modelo simplificado (ou clássico) de 1/4 de veículo}

Com base no modelo simplificado (ou clássico) de 1/4 de veículo, foi construído, com o auxílio da ferramenta computacional de simulação de sistemas multicorpos ADAMS, o protótipo virtual mostrado na figura 4.2.

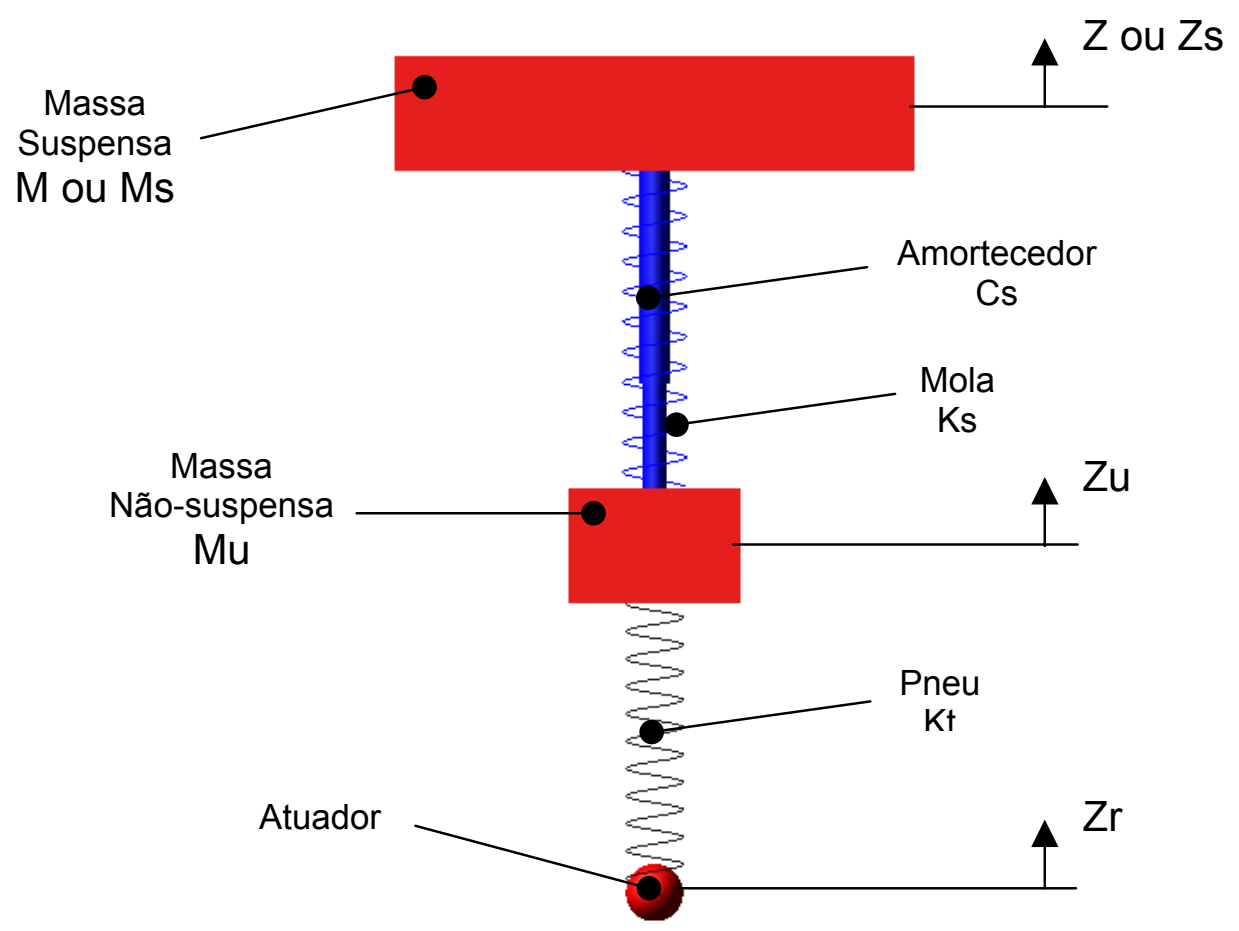

Figura 4.2 - Protótipo Virtual do modelo simplificado (ou clássico) de 1/4 de veículo

onde: $\quad Z$ ou $Z_{S}=$ Deslocamento da massa suspensa "M" ou "Ms"

$$
\begin{aligned}
& Z_{u}=\text { Deslocamento da massa não-suspensa "m" ou "Mu" } \\
& Z_{r}=\text { Deslocamento do solo ou pista } \\
& K_{S}=\text { Rigidez da mola principal da suspensão } \\
& C_{S}=\text { Coeficiente de amortecimento do amortecedor } \\
& K_{t}=\text { Rigidez do pneu }
\end{aligned}
$$

Também pode ser utilizado o programa computacional Matlab/Simulink para este modelamento. 
A topologia simplificada do protótipo virtual do modelo simplificado (ou clássico) de 1/4 de veículo é apresentada na tabela da figura 4.3:

\begin{tabular}{|c|c|c|}
\hline $\begin{array}{c}\mathbf{1}^{\mathbf{0}} \text { Corpo ou } \\
\text { componente }\end{array}$ & Tipo de conexão & $\begin{array}{c}\mathbf{2}^{\mathbf{0}} \text { Corpo ou } \\
\text { componente }\end{array}$ \\
\hline $\mathrm{Ms}$ & $\begin{array}{c}\text { Junta } \mathrm{n}^{\circ} 1-1 \text { Grau de Liberade (GL) } \\
\text { Translação em Z (vertical) }\end{array}$ & Solo \\
\hline $\mathrm{Ms}$ & Mola linear, Ks & $\mathrm{Mu}$ \\
\hline $\mathrm{Ms}$ & $\begin{array}{c}\text { Junta } \mathrm{n}^{\circ} \mathbf{2}-1 \mathrm{GL} \\
\text { Translação em Z (vertical) }\end{array}$ & Solo \\
\hline $\mathrm{Mu}$ & $\begin{array}{c}\text { Mola linear, Kt } \\
\text { Mu }\end{array}$ & Atuador \\
\hline Atuador & Translação em $\mathrm{Z}$ (vertical) & Solo \\
\hline Atuador & Sinal de excitação & Solo \\
\hline
\end{tabular}

Figura 4.3 - Topologia simplificada do protótipo virtual do modelo simplificado (ou clássico) de 1/4 de veículo

É importante ressaltar que este protótipo virtual procura representar fielmente o modelo simplificado (ou clássico) de 1/4 de veículo e foi construído para demonstrar a equivalência entre os resultados obtidos através de um protótipo virtual e os obtidos através da modelagem clássica analítica desenvolvida no item 4.1.1.1. 


\subsubsection{Modelagem do protótipo virtual da Suspensão Dianteira Macpherson}

O protótipo virtual mostrado na figura 4.4 também foi construido com 0 auxílio do programa de simulação de sistemas multicorpos ADAMS, e representa uma suspensão do tipo MacPherson dianteira esquerda de um veículo nacional.

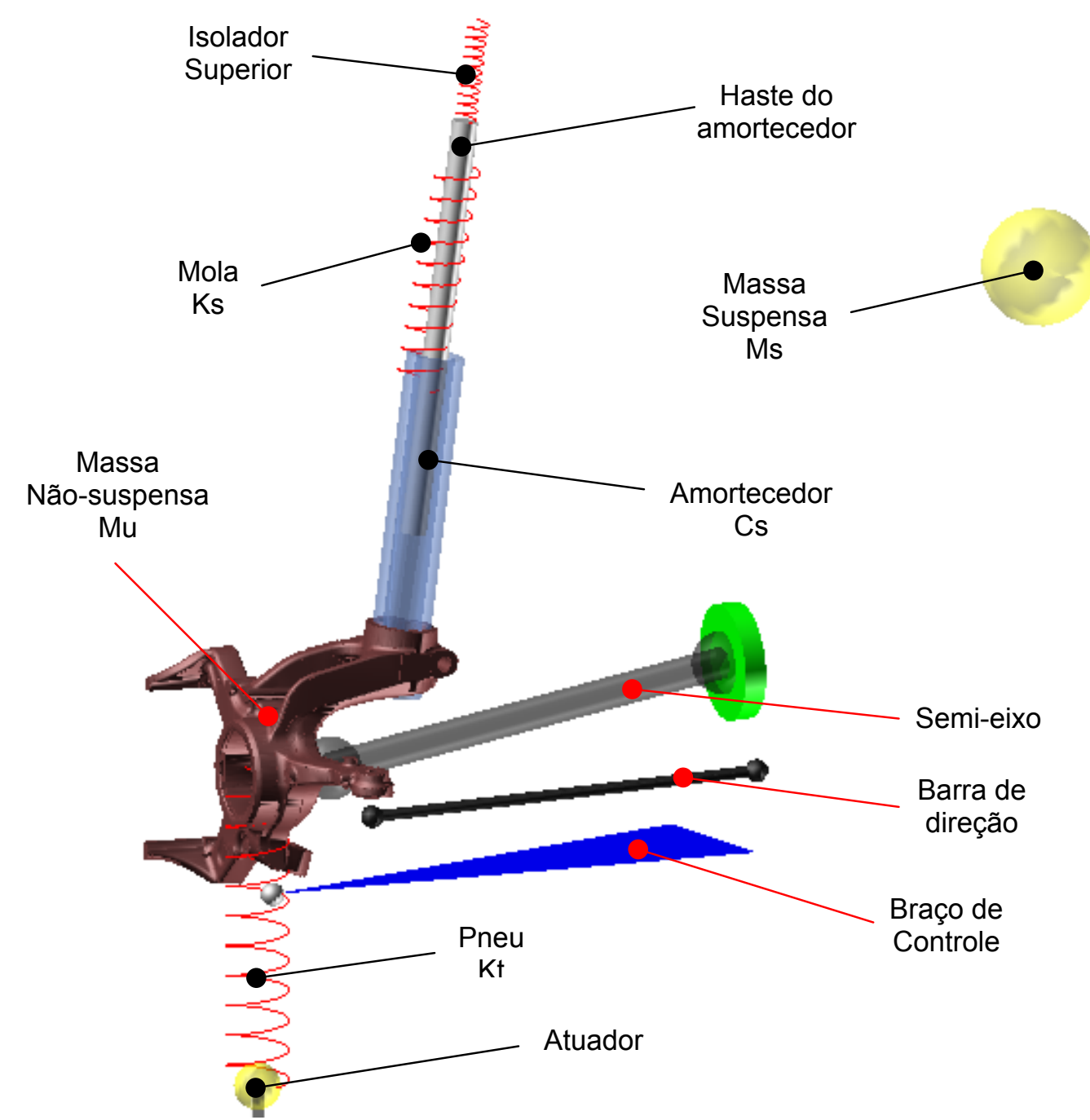

Figura 4.4 - Protótipo virtual da suspensão MacPherson dianteira esquerda de um veículo nacional

O protótipo virtual mostrado na figura 4.4 procura representar o mais fielmente possível a suspensão MacPherson real, possuindo características similares como: topologia dos componentes, geometria da suspensão, distribuição de massas e inércias, curva de absorção de energia do amortecedor não-linear (Cs), mola auxiliar e batente de final de curso. 
Também pode ser utilizado o programa computacional Matlab/Simulink para este modelamento. Neste caso, como a geometria do modelo é mais complexa em função da similaridade com a geometria do sistema de suspensão MacPherson real, a modelagem em Matlab/Simulink fica mais simples com a utilização da livraria "SimMechanics" disponível no Simulink.

A topologia simplificada do protótipo virtual da suspensão dianteira MacPherson, para estudos no domínio da frequência (pneu não se separa do solo), é apresentada na tabela da figura 4.5:

\begin{tabular}{|c|c|c|}
\hline $1^{\text {a }}$ Corpo ou componente & Tipo de conexão & $2^{\text {a }}$ Corpo ou componente \\
\hline \multirow{7}{*}{ Ms } & $\begin{array}{c}\text { Junta } n^{\circ} 1 \text { - } 1 \mathrm{GL} \\
\text { Transl. em Z (vertical) }\end{array}$ & Solo \\
\hline & $\begin{array}{c}\text { Junta } n^{\circ} 3 \text { - } 3 \mathrm{GL} \\
\text { Esférica (Rot. em X, Y e Z) }\end{array}$ & $\begin{array}{l}\text { Braço de controle } \\
\text { (Mancal dianteiro) }\end{array}$ \\
\hline & $\begin{array}{c}\text { Junta } n^{\circ} 4 \text { - } 3 \mathrm{GL} \\
\text { Esférica (Rot. em X, Y e Z) }\end{array}$ & $\begin{array}{l}\text { Braço de controle } \\
\text { (Mancal traseiro) }\end{array}$ \\
\hline & $\begin{array}{c}\text { Junta } \mathrm{n}^{\circ} 6-2 \mathrm{GL} \\
\text { Cilíndrica, Transl. e Rot.em Y }\end{array}$ & $\begin{array}{l}\text { Anel externo da Junta } \\
\text { Móvel da homocinética }\end{array}$ \\
\hline & $\begin{array}{c}\text { Junta } n^{\circ} 8 \text { - } 3 \mathrm{GL} \\
\text { Esférica (Rot. em X, Y e Z) }\end{array}$ & $\begin{array}{c}\text { Barra de direção } \\
\text { (articulador interno) }\end{array}$ \\
\hline & Mola linear, Ks & Corpo do amortecedor \\
\hline & $\begin{array}{c}\text { Coxim superior Rigidez não-linear } \\
\text { em: } \\
\text { Tx, Ty, Tz, Rx, Ry e Rz }\end{array}$ & Haste do amortecedor \\
\hline \multirow{6}{*}{$\mathrm{M}_{U}$} & $\begin{array}{l}\text { Junta } n^{\circ} 9 \text { - } 3 \mathrm{GL} \\
\text { Esférica (Rot. em X, Y e Z) }\end{array}$ & $\begin{array}{l}\text { Junta homocinética } \\
\text { (Junta Fixa) }\end{array}$ \\
\hline & $\begin{array}{c}\text { Junta } n^{\circ} 10-3 \mathrm{GL} \\
\text { Esférica (Rot. em X, Y e Z) }\end{array}$ & $\begin{array}{c}\text { Barra de direção } \\
\text { (articulador externo) }\end{array}$ \\
\hline & $\begin{array}{c}\text { Junta } n^{\circ} 11 \text { - } 3 \mathrm{GL} \\
\text { Esférica (Rot. em X, Y e Z) }\end{array}$ & $\begin{array}{c}\text { Braço de controle } \\
\text { (articulador da suspensão) }\end{array}$ \\
\hline & $\begin{array}{c}\text { Junta } \text { n }^{\circ} 15-0 \mathrm{GL} \\
\text { Fixa }\end{array}$ & Corpo do amortecedor \\
\hline & Pneu, Mola rigidez linear, $\mathrm{Kt}$ & ponto contato pneu-solo \\
\hline & $\begin{array}{c}\text { Junta } n^{\circ} 22 \text { - } 2 \mathrm{GL} \\
\text { Cilíndrica, Transl. e Rot.em Z }\end{array}$ & ponto contato pneu-solo \\
\hline $\begin{array}{l}\text { Junta homocinética } \\
\text { (Junta Móvel) }\end{array}$ & $\begin{array}{c}\text { Junta } n^{\circ} 7 \text { - } 3 \mathrm{GL} \\
\text { Esférica (Rot. em X, Y e Z) }\end{array}$ & $\begin{array}{l}\text { Anel externo da Junta } \\
\text { Móvel da homocinética }\end{array}$ \\
\hline \multirow[t]{2}{*}{ Corpo do amortecedor } & $\begin{array}{c}\text { Junta } n^{\circ} 17 \text { - } 2 \mathrm{GL} \\
\text { Cilíndrica, Transl. e Rot.em Z }\end{array}$ & Haste do amortecedor \\
\hline & Amortecedor, Não-linear, Cs & Haste do amortecedor \\
\hline \multirow{3}{*}{ Atuador } & $\begin{array}{c}\text { Junta Planar - } 5 \text { GL } \\
\text { Transl X e Y, Rot X, Y e Z }\end{array}$ & ponto contato pneu-solo \\
\hline & $\begin{array}{l}\text { Junta } \mathrm{n}^{\circ} 20-1 \mathrm{GL} \\
\text { Transl. em Z (vertical) }\end{array}$ & Solo \\
\hline & Sinal de excitação & Solo \\
\hline
\end{tabular}

Figura 4.5- Topologia simplificada do protótipo virtual

da Suspensão Dianteira MacPherson 


\subsubsection{Principais diferenças entre o modelo simplificado (ou clássico) de 1/4 de veículo, o protótipo virtual MacPherson e a MacPherson real}

O quadro mostrado na figura 4.6a apresenta as principais caracteríticas do modelo simplificado (ou clássico) de 1/4 de veículo e do protótipo virtual MacPherson:

\begin{tabular}{|l|c|c|}
\hline \multicolumn{1}{|c|}{ Característica } & $\begin{array}{c}\text { Modelo simplificado } \\
\text { (ou clássico) de 1/4 } \\
\text { de veículo }\end{array}$ & $\begin{array}{c}\text { Protótipo virtual } \\
\text { MacPherson }\end{array}$ \\
\hline 1) Geometria da Suspensão & Não & Sim \\
\hline 2) Topologia dos componentes & Parcial & Total \\
\hline 3) Não-linearidades & Não & $10^{(*)}$ \\
\hline 4) Graus de liberdade ou GL & 2 & \\
\hline
\end{tabular}

Figura 4.6a - Quadro comparativo das principais características do

modelo simplificado (ou clássico) de 1/4 de veículo do protótipo virtual da suspensão

MacPherson

Cabe aqui um esclarecimento sobre os 10 graus de liberdade do protótipo virtual MacPherson, conforme assinalado com $\left(^{*}\right)$ no quadro da figura 4.6: como este protótipo virtual foi modelado de forma a representar fielmente a suspensão MacPherson real, possui componentes com massa, momentos de inércia, topologia e também graus de liberdade reais. Abaixo, na figura $4.6 \mathrm{~b}$, é apresentado um quadro resumo com os componentes (ilustrados na figura 4.4.) e o número de graus de liberdade que cada um possui:

\begin{tabular}{lll} 
Componente & $N^{\circ} \mathrm{GL}$ & Graus de Liberdade (GL) \\
\hline Barra de direção & $2 \mathrm{GL}$ & $(\mathrm{Rx}$ e Rz) \\
Braço de controle (bandeja) & $1 \mathrm{GL}$ & $(\mathrm{Rx})$ \\
Semi-eixo ou homocinética & $3 \mathrm{GL}$ & $(\mathrm{Ty}, \mathrm{Rx}$ e Rz) \\
Haste do amortecedor & $1 \mathrm{GL}$ & $(\mathrm{Tz})$ \\
Massa Suspensa & $1 \mathrm{GL}$ & $(\mathrm{Tz})$ \\
Massa não-suspensa & $2 \mathrm{GL}$ & $(\mathrm{Tz}, \mathrm{Rz})$
\end{tabular}

Figura 4.6b - Quadro resumo de componentes e graus de liberdade Protótipo Virtual da suspensão MacPherson 


\subsubsection{Amortecedor com amortecimento dependente do curso ou posição, conforme descrito no item 2.3.3.1}

A caracterísitica do amortecedor nos modelos apresentados considera somente a velocidade de acionamento como variável independente, ou seja:

$$
F_{A}=f(V)
$$

onde:

$$
\begin{aligned}
& F_{A}=\text { Força gerada pelo amortecedor } \\
& V=\text { Velocidade de acionamento ou velocidade relativa } \\
& \text { entre haste e corpo }
\end{aligned}
$$

Para a reprodução do efeito de amortecimento dependente do curso ou posição, os modelos deveriam ser construídos de forma a considerar como variável independente, além da velocidade relativa entre a haste e corpo do amortecedor, também a posição relativa entre eles, ou seja:

$$
F_{A}=f(V, P)
$$

onde:

$$
\begin{aligned}
& F_{A}=\text { Força gerada pelo amortecedor } \\
& V=\text { Velocidade de acionamento ou velocidade relativa } \\
& \text { entre haste e corpo do amortecedor } \\
& P=\text { Posição relativa entre haste e corpo do amortecedor }
\end{aligned}
$$

Considerando que o amortecedor utilizado na suspensão do veículo real estudado possui esta característica e que nenhum dos modelos aqui apresentados a considera, concluí-se que os resultados obtidos de qualquer dos modelos provavelmente terão diferenças em relação aos resultados reais.

Este fato, porém, não invalida a análise comparativa entre o modelo simplificado (ou clássico) de 1/4 de veículo e o protótipo virtual da suspensão MacPherson. 
No caso do amortecedor real, na região próxima ao final de curso de tração, há um acréscimo de amortecimento que não foi considerado no protótipo virtual. Como a região afetada é conhecida, há condições de indicar os resultados que são afetados pela inexistência deste amortecimento adicional.

\subsubsection{Atrito e carga lateral no amortecedor, conforme descrito no item}

\subsubsection{2}

Conforme já descrito no item 4.1.3.1, a característica do amortecedor nos modelos aqui apresentados considera somente a velocidade de acionamento como variável independente, ou seja:

$$
F_{A}=f(V)
$$

onde:

$$
\begin{aligned}
& F_{A}=\text { Força gerada pelo amortecedor; } \\
& V=\text { Velocidade de acionamento ou velocidade } \\
& \text { relativa entre haste e corpo. }
\end{aligned}
$$

Para a reprodução do efeito do atrito interno dos amortecedores utilizados nas suspensões MacPherson, conforme descrito no item 2.3.3.2, o protótipo virtual MacPherson deveria ser construído de forma a considerar também a parcela de força gerada pelo atrito, ou seja:

$$
F_{A}=F_{V}+F_{\text {atrito }}
$$

onde:

$$
\begin{aligned}
& F_{A}=\text { Força gerada pelo amortecedor; } \\
& F_{V}=\text { Força gerada pela função hidráulica do } \\
& \text { amortecedor a qual é função da velocidade de }
\end{aligned}
$$


acionamento ou velocidade relativa entre haste $\mathrm{e}$ corpo do amortecedor;

$F_{\text {atrito }}=$ Força gerada devido ao atrito interno no amortecedor e à carga lateral que este recebe.

O protótipo virtual MacPherson não considera o amortecimento adicional que existe no sistema de suspensão real imposto pela força devida ao atrito gerado internamente no amortecedor.

Considerando que o amortecedor utilizado na suspensão do veículo real estudado possui atrito interno e que o protótipo virtual MacPherson não o considera, pode-se dizer que os resultados obtidos utilizando-se o protótipo virtual tem menor congruência com os resultados reais. Apesar disto, não são feitas neste trabalho, considerações sobre o atrito interno do amortecedor.

Segundo MUHR \& BENDER, 0 atrito gerado internamente nos amortecedores utilizados nas suspensões do tipo MacPherson tem influência mais significativa quando o veículo trafega com velocidade baixa e constante, em linha reta, em estradas de boa qualidade e passa por pequenos degraus na pista (cerca de $1 \mathrm{~cm}$ ), situação bem conhecida por pilotos de testes de várias indústrias automobilísticas.

\subsubsection{Mola com carga lateral}

A mola utilizada na suspensão MacPherson do veículo estudado possui carga lateral, característica que é descrita detalhadamente no item 2.3.1.2.

Da mesma forma que para o item anterior, não são feitas considerações sobre a influência da mola com carga lateral sobre $o$ atrito interno do amortecedor. 


\subsubsection{Interação Pneu x Solo}

\subsection{No plano X-Y (solo)}

O atrito entre pneu e solo no plano X-Y, plano do solo (horizontal), foi considerado nulo.

Porém, conforme já descrito no item 2.3.5, devido à movimentação relativa entre pneu e solo e ao atrito existente entre eles, é adicionado amortecimento ao sistema de suspensão.

Sendo assim, a ausência de atrito entre pneu e solo faz com que o amortecimento do sistema de suspensão do protótipo virtual MacPherson seja menor que o amortecimento do sistema MacPherson real.

Considerando-se o veículo andando em linha reta, a movimentação relativa entre pneu e solo no plano $X-Y$ ocorre nas suspensões em geral em função de sua geometria e da movimentação na direção Z. Como no caso estudado a amplitude do movimento no plano X-Y é pequeno, os efeitos de amortecimento adicional gerados por ele também são pequenos, quando comparados ao amortecimento principal, e por isto podem ser desprezados.

Neste estudo consideramos inexistente o atrito entre pneu e solo, hipótese esta, aceitável considerando o exposto no parágrafo anterior e também que tem sido adotada por autores como GILLESPIE e Dr. G. HILL.

\subsection{Na direção vertical (Z)}

Para o modelo simplificado (ou clássico) de 1/4 de veículo, em todos os casos estudados, considera-se que o pneu não se separa do solo.

Para o protótipo virtual MacPherson, e ainda referente ao pneu, são possíveis duas situações:

(i) Para obtenção das respostas dinâmicas no domínio da frequência, assim como no modelo simplificado (ou clássico) de 1/4 de veículo, também foi considerado que o pneu não se separa do solo; 
(ii) Já para obtenção das respostas dinâmicas no domínio do tempo, o pneu pode separar-se do solo, como pode ocorrer no caso real.

Em todos os casos o pneu foi representado por uma mola linear com rigidez igual a $200 \mathrm{~N} / \mathrm{mm}$ e o seu amortecimento não foi considerado.

Neste estudo - vide item 2.3.5 - o amortecimento do pneu foi desprezado, pois seu valor é pequeno quando comparado ao valor do amortecimento do amortecedor principal do sistema de suspensão. 


\subsection{Metodologia}

Neste item 4.2 são descritas apenas as metodologias. Os resultados obtidos são apresentados no capítulo 5.

4.2.1 Metodologia para obtenção das respostas dinâmicas no domínio da frequência

4.2.1.1 Metodologia aplicada no modelo simplificado (ou clássico) de 1/4 de veículo

4.2.1.1 Para o modelo simplificado (ou clássico) de 1/4 de veículo, linear

Para este modelo a resposta em frequência foi obtida utilizando-se as funções transferências obtidas pelo método analítico da "Transformada de Laplace" (vide item 4.1.1.1) e a função "Bode" do programa computacional MatLab.

4.2.1.1.2 Protótipo virtual do modelo simplificado (ou clássico) de 1/4 de veículo, linear

A resposta em frequência foi obtida excitam-se o modelo mostrado na figura 4.7 através de um atuador: 


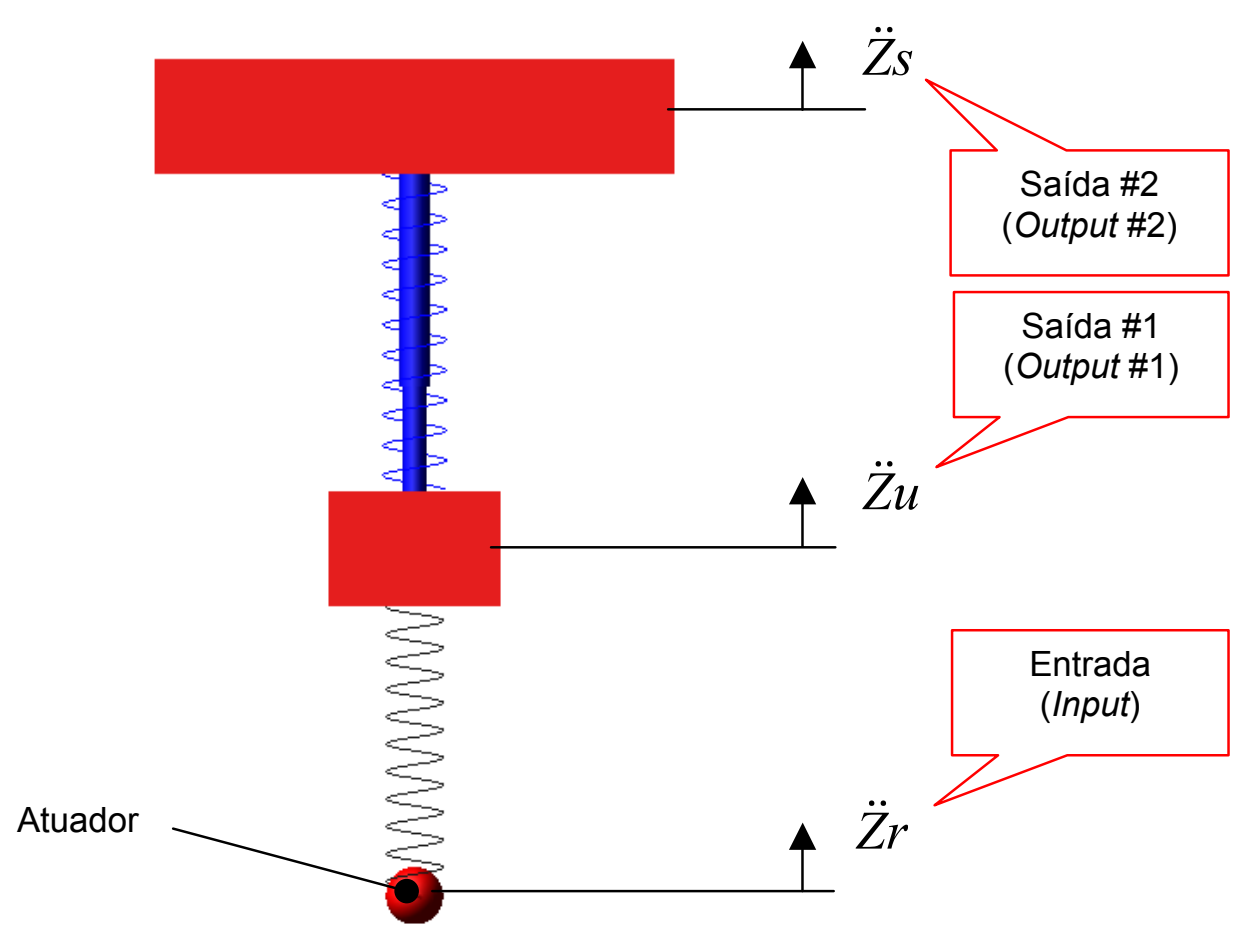

Figura 4.7 - Entradas e saídas no

protótipo virtual do modelo simplificado (ou clássico) de 1/4 de veículo

O sinal gerado para excitação do modelo através do atuador foi uma varredura senoidal da aceleração da pista ( $\ddot{Z} r$ = aceleração da pista) com amplitude igual a $\pm 0,1 \mathrm{~g}$ e frequência variando de 0 (zero) a $30 \mathrm{~Hz}$.

A Densidade Espectral Média Quadrada (PSD) da entrada $\ddot{Z} r$, conforme mostrado no gráfico da figura 4.8 é plana dentro da faixa de frequência de interesse.

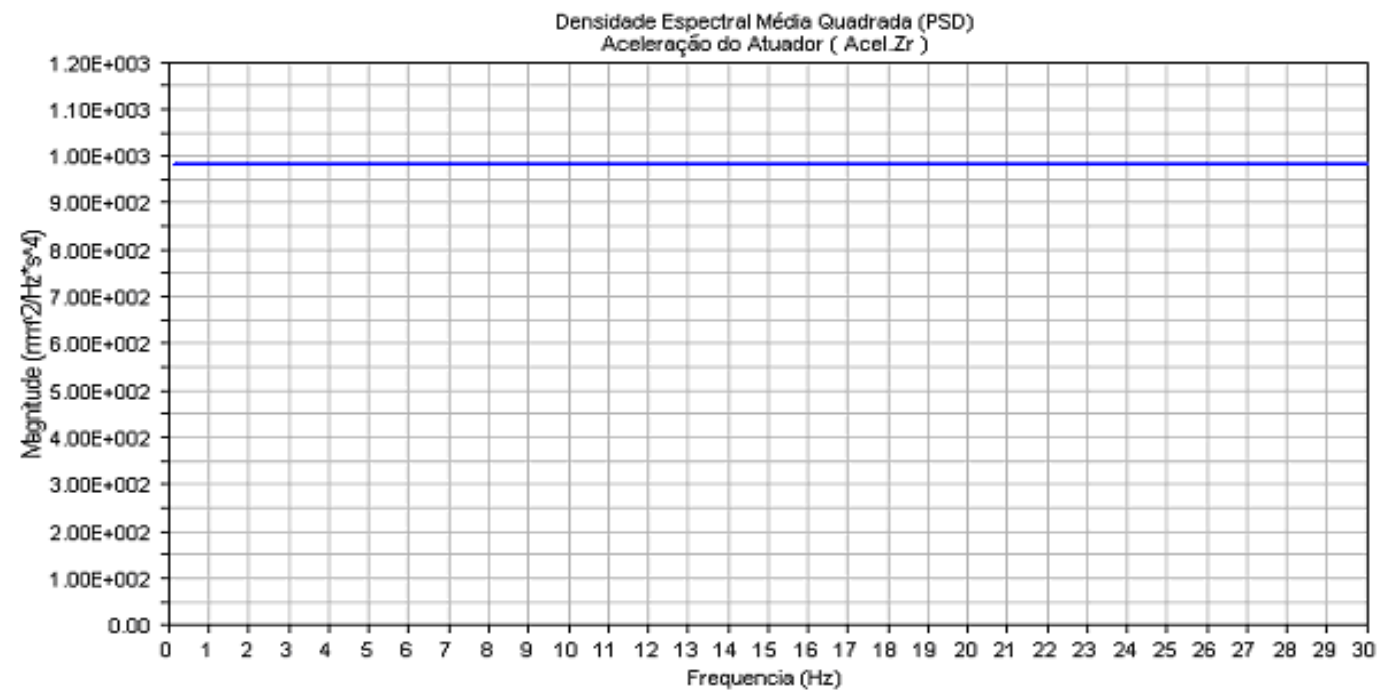

Figura 4.8 - Densidade Espectral Média Quadrada (PSD) de $\ddot{Z} r$ usada como entrada no protótipo virtual do modelo simplificado (ou clássico) de 1/4 de veículo 
A resposta em frequência foi obtida através do módulo Vibration do programa computacional ADAMS, tendo como de entrada a aceleração da pista $(\ddot{Z} r)$ e como saídas a aceleração da massa suspensa ( $\ddot{Z} s)$ e a aceleração da massa não-suspensa ( $\ddot{Z} u)$.

O método utilizado pelo programa é o da "linearização em torno do ponto de operação".

Foram obtidas as respostas em frequência das seguintes relações entre entrada e saídas:

$$
\frac{\ddot{Z} s}{\ddot{Z} r}=\text { transmissibilidade entre pista e massa suspensa }
$$

e

$$
\frac{\ddot{Z} u}{\ddot{Z} r}=\text { transmissibilidade entre pista e massa não-suspensa }
$$




\subsubsection{Para o protótipo virtual do sistema de suspensão dianteira MacPherson}

A resposta em frequência foi obtida com a mesma metodogia descrita no item anteriror (4.2.1.1.2) considerando as entradas e saídas conforme mostradas na figura 4.9 .

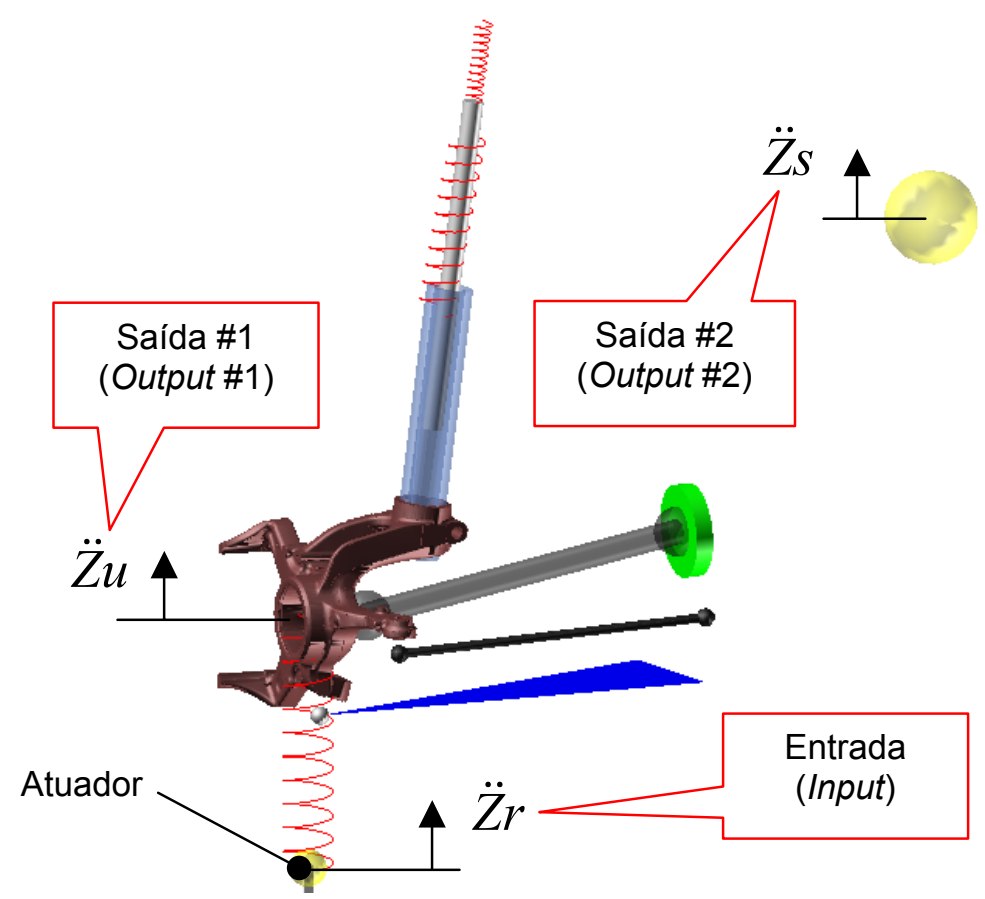

Figura 4.9 - Entradas e saídas no protótipo virtual da Suspensão MacPherson 


\subsubsection{Obtenção das respostas dinâmicas no domínio do tempo}

Inúmeras são as situações em que é necessária a avaliação da resposta dinâmica do veículo e da suspensão no domínio do tempo.

Aqui será avaliada uma única situação, porém muito importante na análise do comportamento dinâmico do veículo e de sua suspensão: a passagem por um obstáculo com as dimensões mostradas na figura 4.10, a uma velocidade de $18 \mathrm{Km} / \mathrm{h}(5 \mathrm{~m} / \mathrm{s})$.

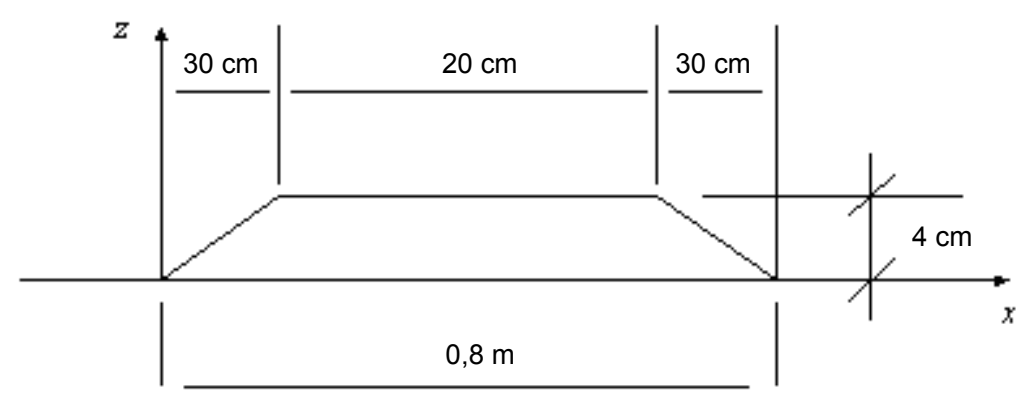

Figura 4.10 - Dimensões do obstáculo utilizado na simulação

O sinal da entrada "pulso" em $Z r$ que representa a passagem pelo obstáculo da figura 4.10 tem, no domínio do tempo, as características mostradas na figura 4.11 .

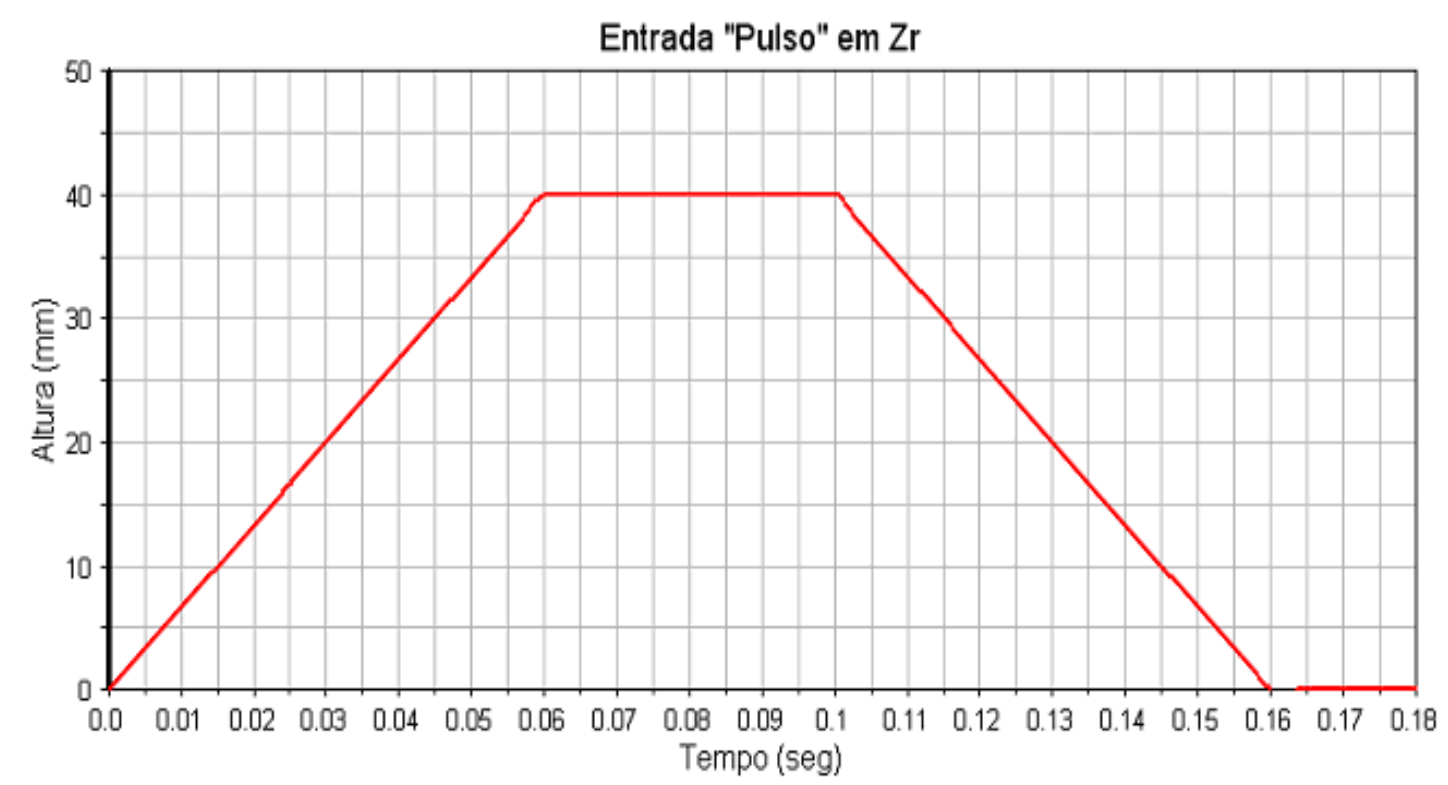

Figura 4.11 - Caracterísitcas da entrada "pulso" em $\operatorname{Zr}(18 \mathrm{Km} / \mathrm{h}$ ou $5 \mathrm{~m} / \mathrm{s}$ ) no domínio do tempo 
O pulso mostrado na figura 4.11 representa teoricamente a leitura vertical do obstáculo da figura 4.10, no domínio do tempo, considerando as condições já mencionadas.

Na prática, o obstáculo da figura 4.10 tem uma forma um pouco diferente devido principalmente à fatores como a interação geométrica entre o obstáculo e o pneu e à ação dos isoladores dianteiro e traseiro do braço de controle da suspensão.

Serão analisados, comparativamente, os resultados do modelo simplificado (ou clássico) de 1/4 de veículo e do protótipo virtual MacPherson, através das seguintes grandezas:

- Deslocamento vertical da massa supensa $(Z s)$

- Deslocamento vertical da massa não-suspensa $(Z u)$

- Aceleração da massa suspensa $(\ddot{Z} s)$

- Aceleração da massa não-suspensa ( $\ddot{Z} u)$

- Força no pneu

- Velocidade de acionamento do amortecedor

- Curso utilizado do amortecedor

- Carga na mola auxiliar e batente da suspensão

Os resultados e análises são apresentados no próximo capítulo. 


\section{Capítulo 5 - Resultados e Análises}

\subsection{Resultados}

\subsubsection{Resultados no Domínio da Frequência}

5.1.1.1 Resposta no domínio da frequência obtida utilizando-se o modelo simplificado (ou clássico) de 1/4 de veículo linear e metódo analitico

Os dados de entrada abaixo (vide figura 4.1) foram tabulados de forma a obter a máxima similaridade possível entre o modelo simplificado (ou clássico) de 1/4 de veículo e a suspensão MacPherson real, escolhida para este estudo.

Dentro deste encaminhamento, os valores obtidos foram:

$$
\begin{aligned}
& \mathrm{Ms}=319 \mathrm{Kg} \quad \text { (Massa suspensa) } \\
& \mathrm{Mu}=39 \mathrm{Kg} \quad \text { (Massa não-suspensa) } \\
& \mathrm{Ks}=23 \mathrm{~N} / \mathrm{mm} \quad \text { (Rigidez da mola principal) } \\
& \mathrm{Kt}=200 \mathrm{~N} / \mathrm{mm} \quad \text { (Rigidez do pneu) } \\
& \text { Cs }=1,20 \mathrm{Ns} / \mathrm{mm} \quad\left(\zeta_{s}=0,22\right) \\
& \mathrm{Cs}=2,17 \mathrm{Ns} / \mathrm{mm} \quad\left(\zeta_{s}=0,40\right)
\end{aligned}
$$

Conforme GILLESPIE:

$$
C_{S}=\zeta_{S} \cdot \sqrt{4 \cdot K s \cdot M s}
$$




$$
\text { onde: } \quad \begin{aligned}
\zeta_{S} & =\text { Relação de amortecimento (damping ratio) } \\
C_{S} & =\text { Coeficiente de amortecimento da suspensão }
\end{aligned}
$$

Ainda, conforme GILLESPIE, para um bom nível de conforto, a relação de amortecimento $\left(\zeta_{S}\right)$ normalmente fica entre 0,2 e 0,4.

Utilizando as funções tranferência obtidas no item 4.1.1.1 (equações 4.12 e 4.14), foram obtidos os gráficos da resposta no domínio da frequência de $\frac{\ddot{Z} s}{\ddot{Z} r}$, figura 5.1 , para amortecimentos de $20 \%$ e $40 \%$, e, de $\frac{\ddot{Z} u}{\ddot{Z} r}$, figura 5.2 , também para amortecimentos de $20 \%$ e $40 \%$. 



Figura 5.1 - Gráfico da Resposta em Frequência de $\ddot{Z} s / \ddot{Z} r$ do modelo simplificado (ou clássico) de 1/4 de veículo - método analítico 

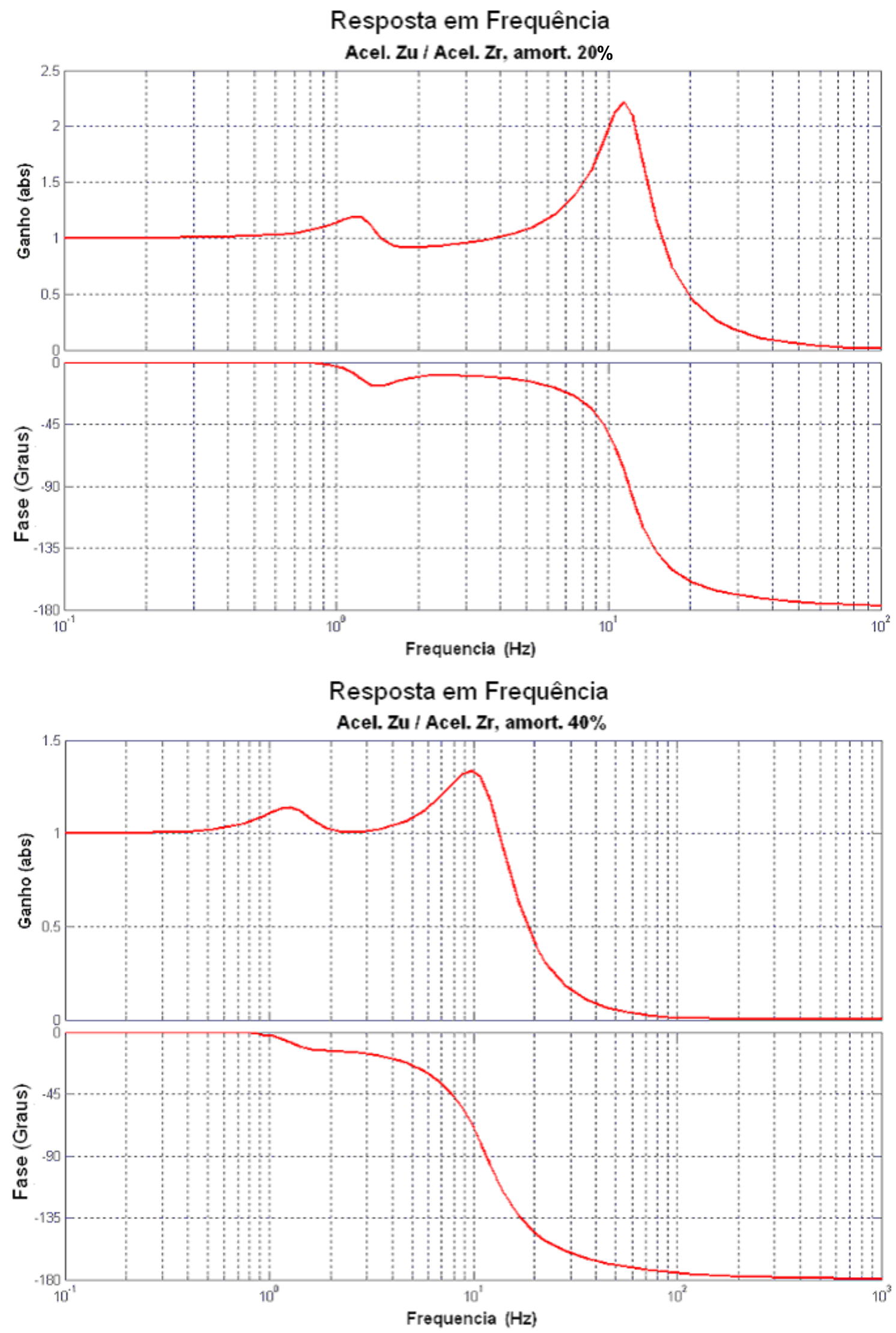

Figura 5.2 - Gráfico da Resposta em Frequência de $\ddot{Z} u / \ddot{Z} r$ do modelo simplificado (ou clássico) de 1/4 de veículo - método analítico 
5.1.1.2 Resposta no domínio da frequência obtida utilizando-se o protótipo virtual do modelo simplificado de $1 / 4$ de veículo linear

Os gráficos a seguir, mostrados nas figuras 5.3 e 5.4 apresentam os resultados obtidos utilizando-se o protótipo virtual do modelo simplificado (ou clássico) de $1 / 4$ de veículo e também os resultados obtidos pelo método analítico (item 5.1.1.1):

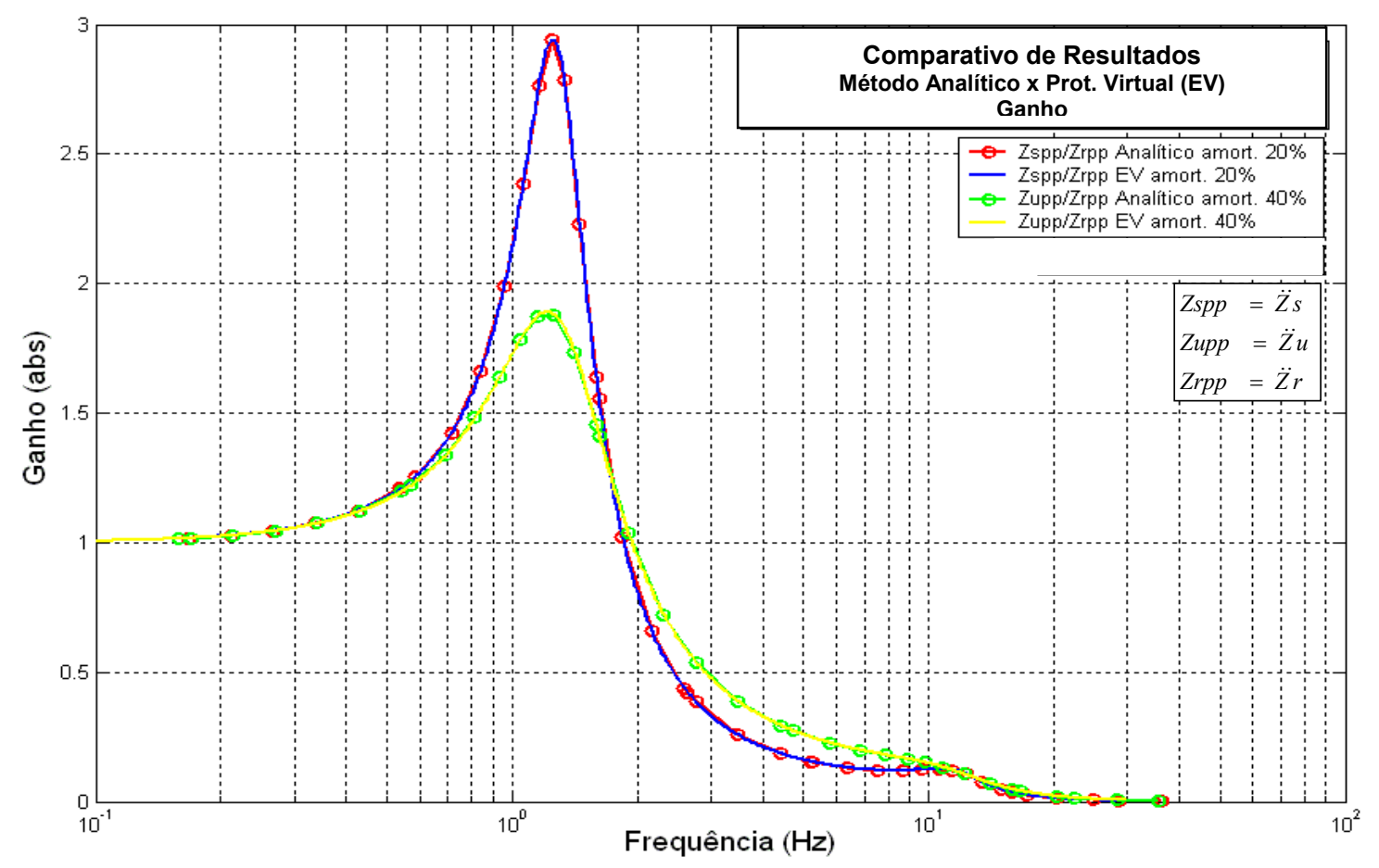

Figura 5.3 - Comparativo de Resultados para o Modelo Simplificado de $1 / 4$ de veículo Ganho: Método Analítico x Protótipo Virtual 


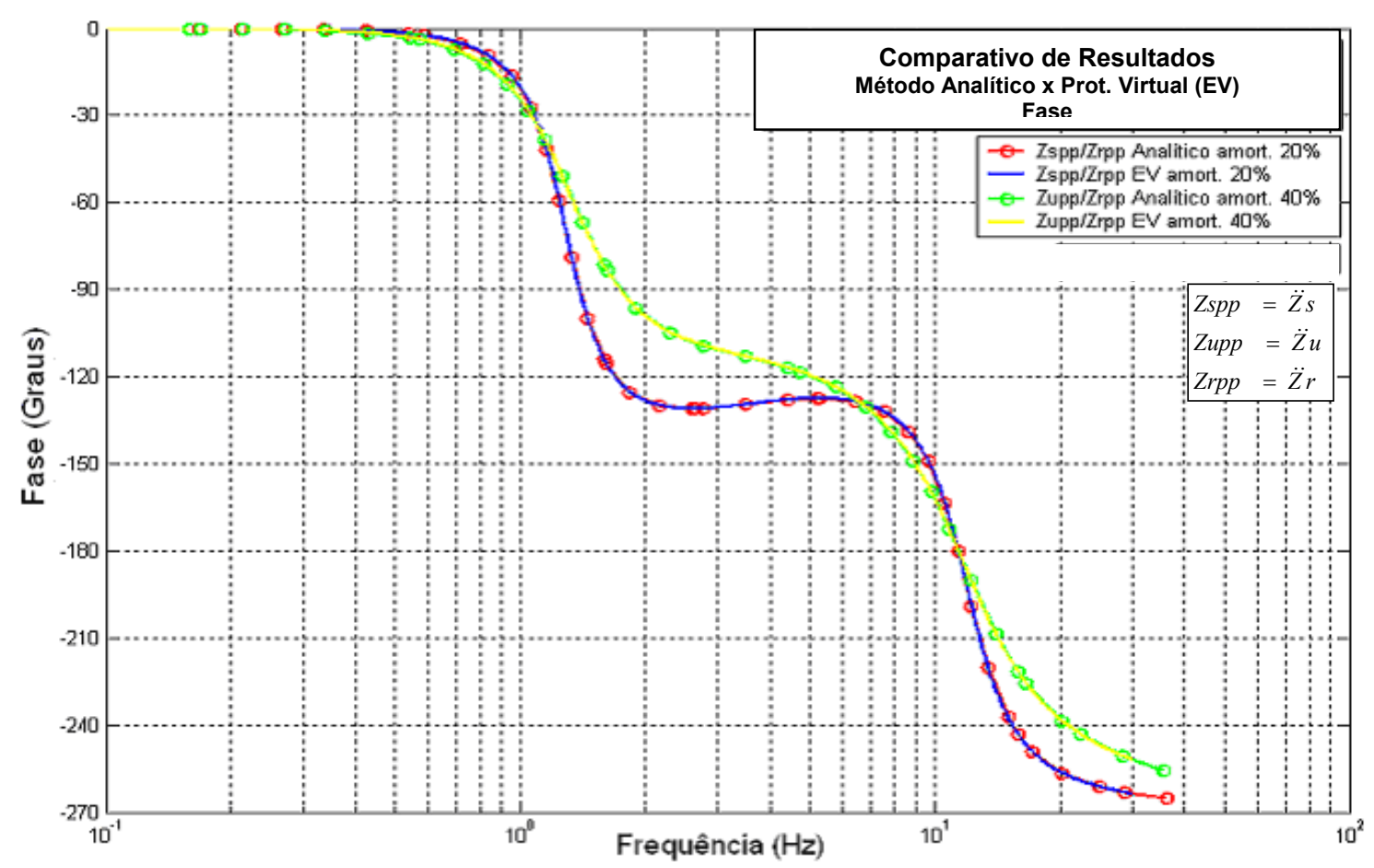

Figura 5.4 - Comparativo de Resultados para o Modelo Simplificado de $1 / 4$ de veículo Fase: Modelo Analítico x Protótipo Virtual

\subsubsection{Considerações sobre a respota no domínio da frequência do modelo simplificado (ou clássico) de $1 / 4$ de veículo obtida através do método analítico e através do protótipo virtual}

A análise comparativa dos resultados apresentada no item 5.1.1.2 mostra que o protótipo virtual do modelo simplificado (ou clássico) de 1/4 de veículo (que utiliza o método da "linearização em torno do ponto de operação") fornece os mesmos resultados que o método analítico, como já era esperado.

Feita esta consideração, pode-se seguir para a fase seguinte que apresenta os resultados obtidos através de simulações utilizando um protótipo virtual de uma suspensão dianteira MacPherson de um veículo nacional, considerados mais próximos da realidade. 
5.1.1.4 Resposta no domínio da frequência obtida utilizando-se o protótipo virtual do sistema de suspensão dianteira MacPherson

Os gráficos a seguir, mostrados nas figuras 5.5 e 5.6 das próximas páginas, apresentam:

- A resposta no domínio da frequência obtida utilizando-se o protótipo virtual da suspensão MacPherson;

- A resposta no domínio da frequência obtida utilizando-se o modelo simplificado (ou clássico) de $1 / 4$ de veículo, já apresentada anteriormente nos itens 5.1.1.1 e 5.1.1.2. 

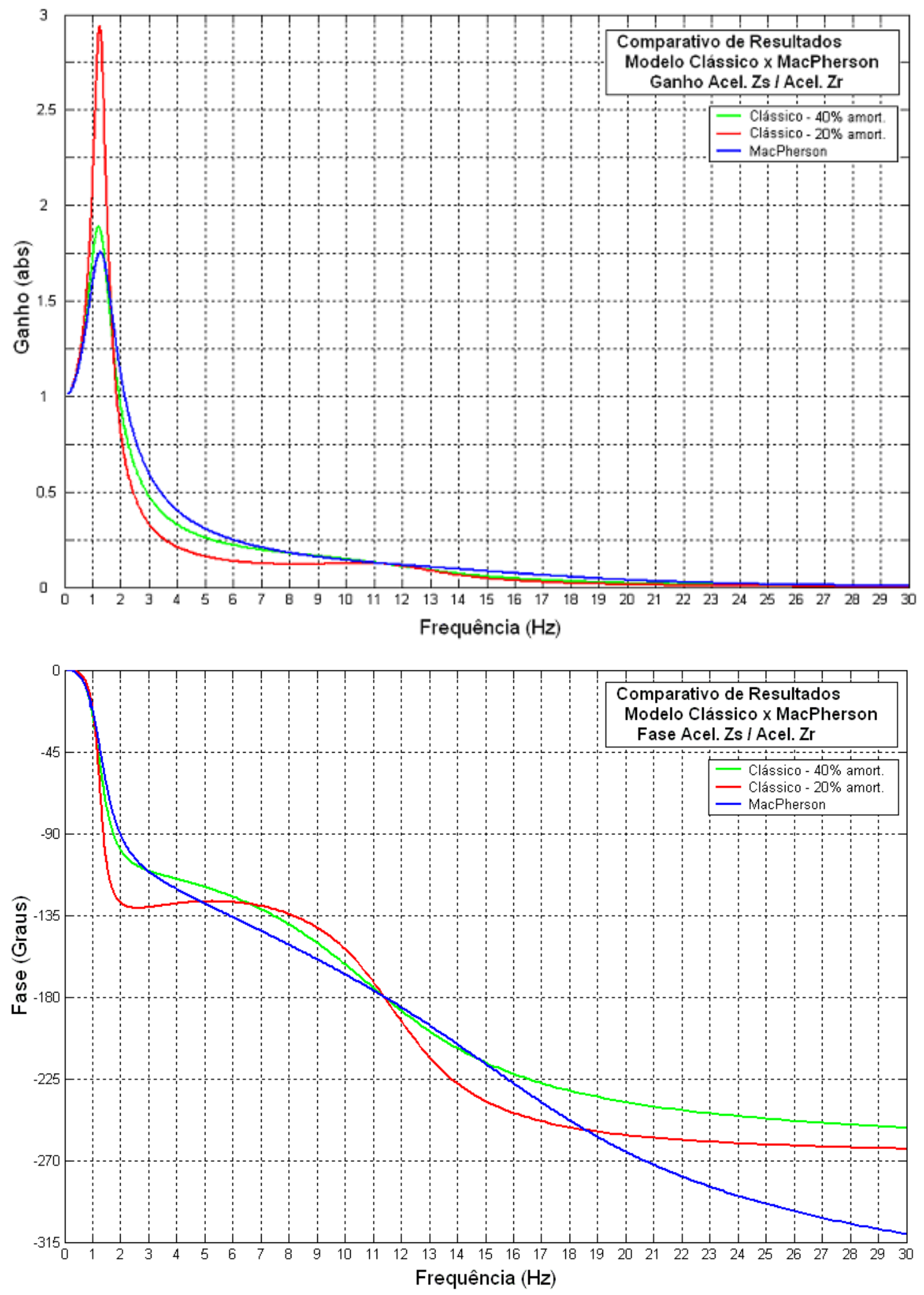

Figura 5.5 - Comparativo de Resultados - Ganho e Fase de $\frac{\ddot{Z} s}{\ddot{Z} r}$

Modelo simplificado (ou clássico) de $1 / 4$ de veículo $X$

Protótipo Virtual da suspensão MacPherson 

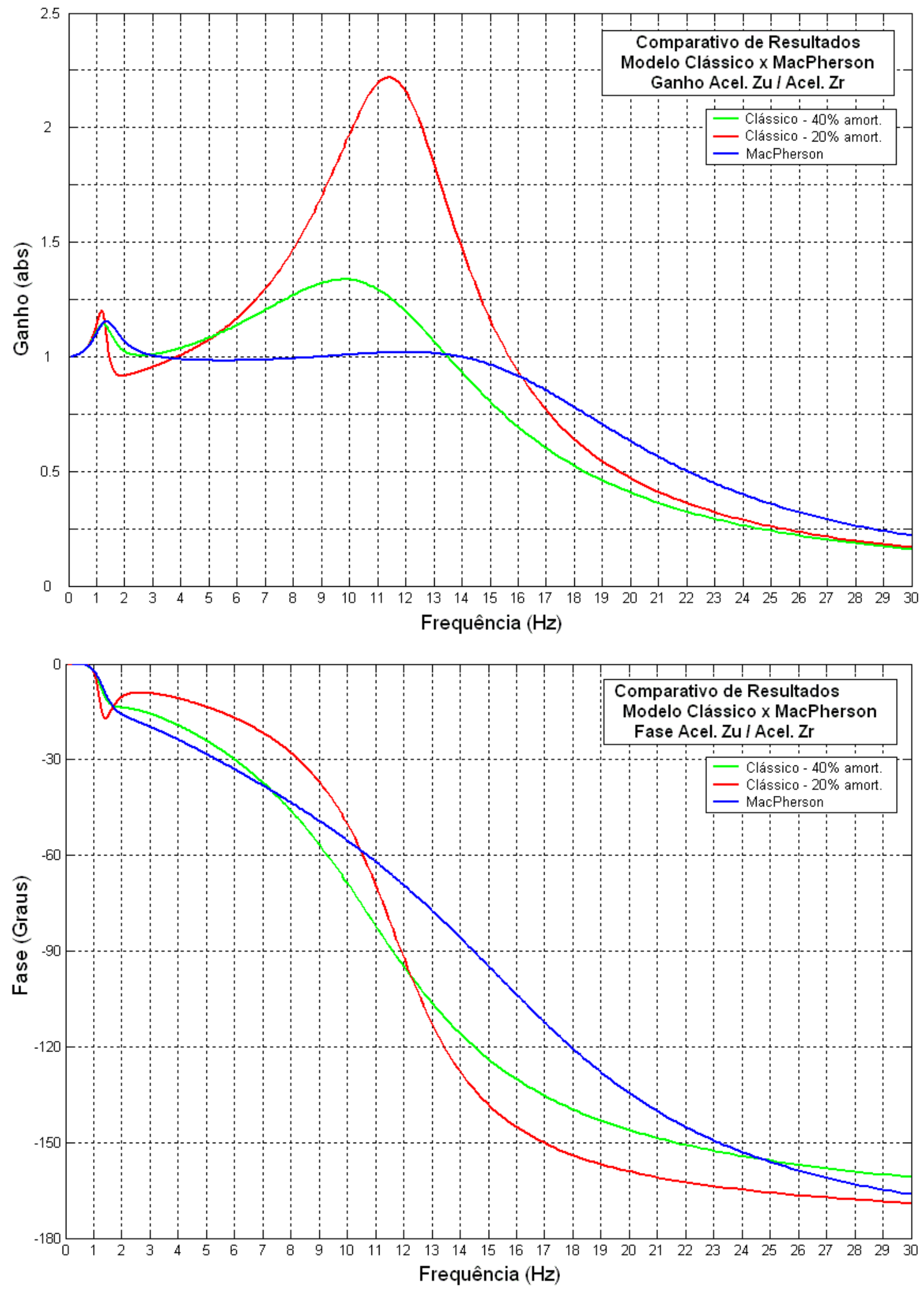

Figura 5.6 - Comparativo de Resultados - Ganho e Fase de $\frac{\ddot{Z} u}{\ddot{Z} r}$

Modelo simplificado (ou clássico) de $1 / 4$ de veículo $X$

Protótipo Virtual da suspensão MacPherson 


\subsubsection{Análise dos resultados da Resposta no Domínio da Frequência}

A tabela mostrada na figura 5.7 apresenta um comparativo dos resultados para a frequência de pico, retirados dos gráficos das figuras $5.5 \mathrm{e}$ 5.6 bem como a diferença percentual entre eles.

Adotou-se como base para cálculo da diferença percentual, os resultados obtidos através do Protótipo Virtual MacPherson. $O$ cálculo foi efetuado utilizando a expressão geral (5.2):

$$
\operatorname{Dif}(\%)=\frac{(\text { VC }- \text { Vbase })}{\text { Vbase }} \cdot 100
$$

onde:

Dif $(\%)$ = Diferença percentual em relação ao valor base;

$V C=$ Neste caso são todos os valores exceto o valor base;

Vbase $=$ Valor em relação ao qual quer se achar a diferença percentual. Neste caso o valor base é cada um dos resultados do Protótipo Virtual Macpherson.

\begin{tabular}{|c|r|ccc|}
\hline \multirow{2}{*}{ Referência } & \multirow{2}{*}{ Modelo } & \multicolumn{4}{|c|}{ Frequência de Pico } \\
\cline { 3 - 5 } & & Valor (Hz) & Ganho (abs) & Fase ( $)$ \\
\hline \multirow{2}{*}{ Massa } & PV MacPherson & $\mathbf{1 , 2 8}$ & $\mathbf{1 , 7 6}$ & $-\mathbf{4 4 , 0 0}$ \\
suspensa & Modelo Clássico 40\% & 1,22 & 1,89 & $-47,00$ \\
(Ms) & Diferença (\%) & $-4,7 \%$ & $+7,4 \%$ & $+6,8 \%$ \\
& Modelo Clássico 20\% & 1,25 & 2,94 & $-59,00$ \\
& Diferença (\%) & $-2,0 \%$ & $+67,0 \%$ & $+34,1 \%$ \\
\hline \multirow{2}{*}{ Massa } & PV MacPherson & $\mathbf{1 2 , 3 5}$ & $\mathbf{1 , 0 2}$ & $-\mathbf{7 2 , 0 0}$ \\
não-suspensa & Modelo Clássico 40\% & 9,90 & 1,34 & $-68,00$ \\
(Mu) & Diferença (\%) & $-19,8 \%$ & $+31,4 \%$ & $-5,6 \%$ \\
& Modelo Clássico 20\% & 11,35 & 2,22 & $-77,00$ \\
& Diferença (\%) & $-8,1 \%$ & $+117,6 \%$ & $+6,9 \%$ \\
\hline
\end{tabular}

Figura 5.7 - Comparativo Analítico dos Resultados

Modelo simplificado (ou clássico) de 1/4 de veículo x Protótipo Virtual MacPherson

Observa-se, pelos gráficos das figuras 5.5 e 5.6 e pela tabela da figura 5.7, que os resultados do modelo simplificado (ou clássico) de 1/4 de veículo que mais se aproximam dos da MacPherson são os que utilizam 
amortecimento igual a 40\%, para a frequência de pico das massas suspensa e não-suspensa.

Para a massa suspensa, os erros de $-4,7 \%$ para a frequência, $+7,4 \%$ para o ganho e $+6,8 \%$ para a fase, são satisfatórios, considerando as limitações do modelo simplificado (ou clássico) de 1/4 de veículo.

A mesma observação é válida para a massa não-suspensa com erros de $-19,8 \%$ para a frequência de pico, $+31,4 \%$ para o ganho e $-5,6 \%$ para a fase.

O gráfico mostrado na figura 5.8, apresenta a velocidade de acionamento do amortecedor em função da frequência para um sinal de excitação do sistema $\ddot{Z} r= \pm 0,1 g$, com a frequência variando de 0 a $30 \mathrm{~Hz}$ linearmente com o tempo.

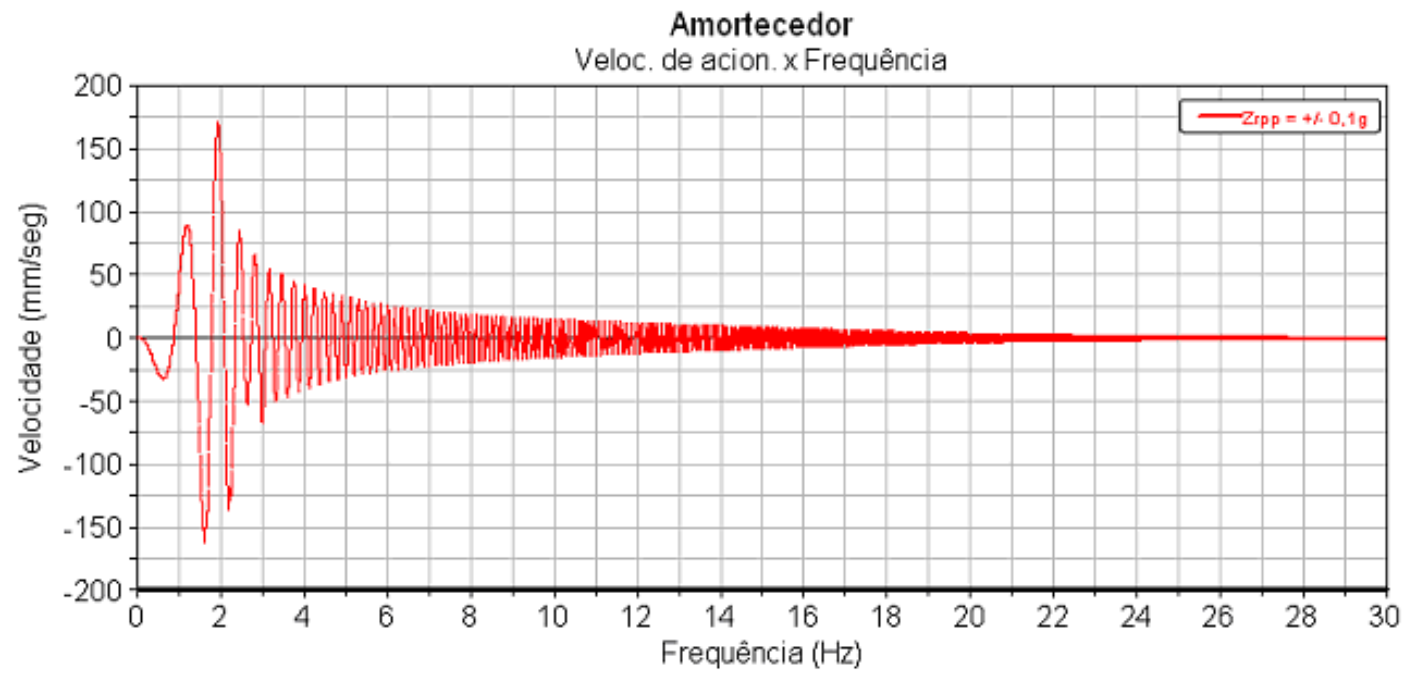

Figura 5.8 - Velocidade de Acionamento do Amortecedor x Frequência para $\ddot{Z} r= \pm 0,1 \mathrm{~g}$

Analisando o gráfico mostrado na figura 5.8, observa-se que as velocidades impostas ao amortecedor chegam a um máximo de $150 \mathrm{~mm} / \mathrm{s}$ na região da frequência de pico da massa suspensa, $1 \mathrm{~Hz}$, e estão abaixo de 60 $\mathrm{mm} / \mathrm{s}$ no restante da faixa.

Através do gráfico mostrado na figura 5.9, que apresenta o detalhe " $X$ " do gráfico mostrado na figura 5.10, percebe-se que, para velocidades entre 60 e $150 \mathrm{~mm} / \mathrm{s}$, a curva real do amortecedor tem maior congruência com a curva de amortecimento linear igual a 40\%, excetuando-se a região de compressão para velocidades acima de $60 \mathrm{~mm} / \mathrm{s}$. 
Para velocidades abaixo de $60 \mathrm{~mm} / \mathrm{s}$, o mesmo gráfico demonstra que a curva de amortecimento linear 40\% (em amarelo) tem completa congruência com a curva real do amortecedor (em vermelho).

A análise descrita acima pode explicar a maior compatibilidade dos resultados do modelo simplificado (ou clássico) de 1/4 de veículo que utiliza amortecimento de $40 \%$.

O gráfico da figura 5.9, no entanto, mostra apenas o comportamento do amortecedor em velocidades muito baixas, representando apenas o detalhe "X", mostrado no gráfico da figura 5.10 , da faixa total de velocidade de acionamento prevista para o amortecedor.

O gráfico mostrado na figura 5.10 permite analisar que, a curva real do amortecedor (em vermelho), para velocidades de acionamento do amortecedor entre $150 \mathrm{~mm} / \mathrm{s}$ e $1050 \mathrm{~m} / \mathrm{s}$, tem maior compatibilidade com a curva do amortecimento linear de $20 \%$ (em azul), ou até mesmo amortecimento menores que $20 \%$.

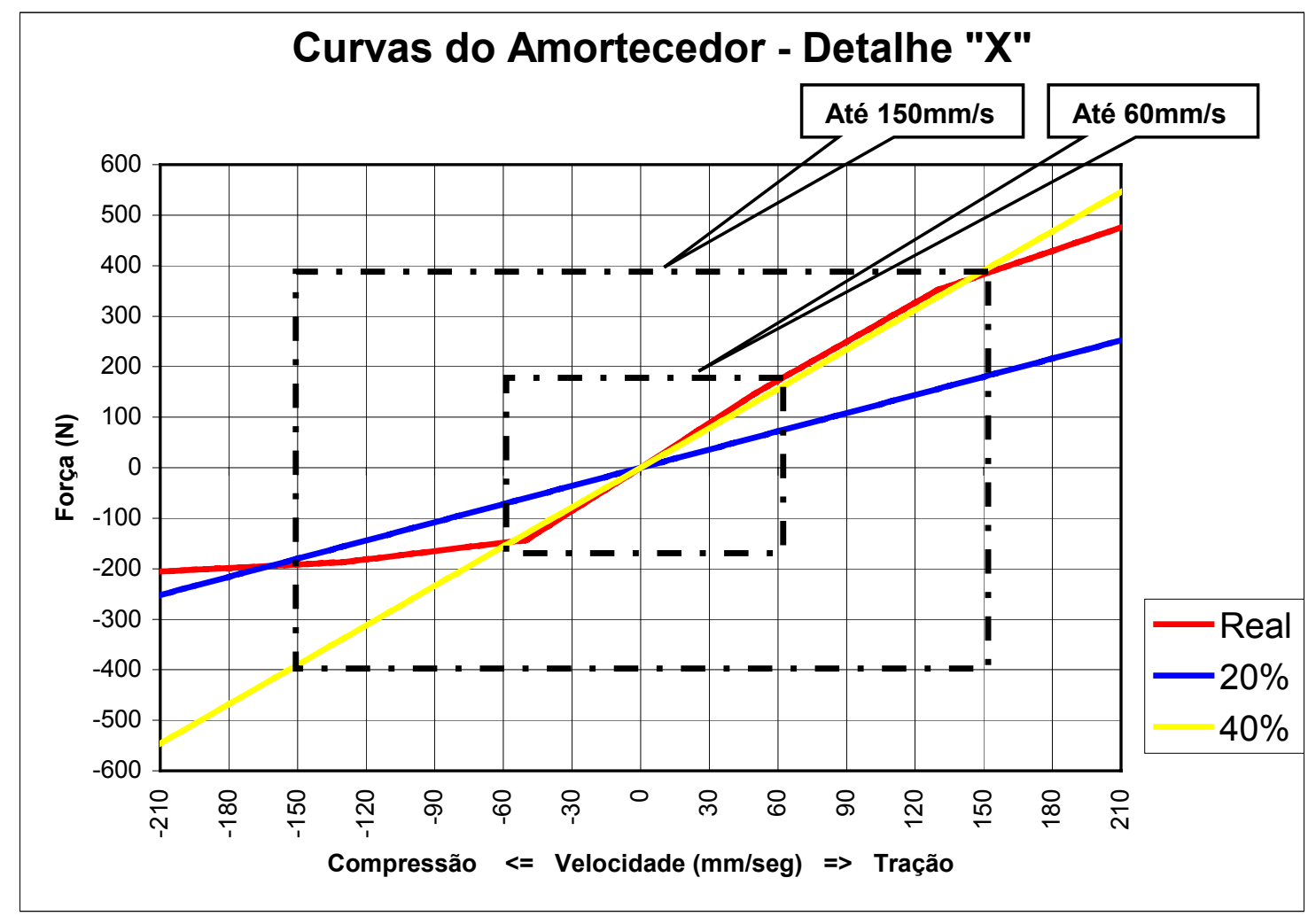

Figura 5.9 - Comparativo das curvas do amortecedor considerando velocidades até $210 \mathrm{~mm} / \mathrm{s}$ (detalhe " $X$ ") 


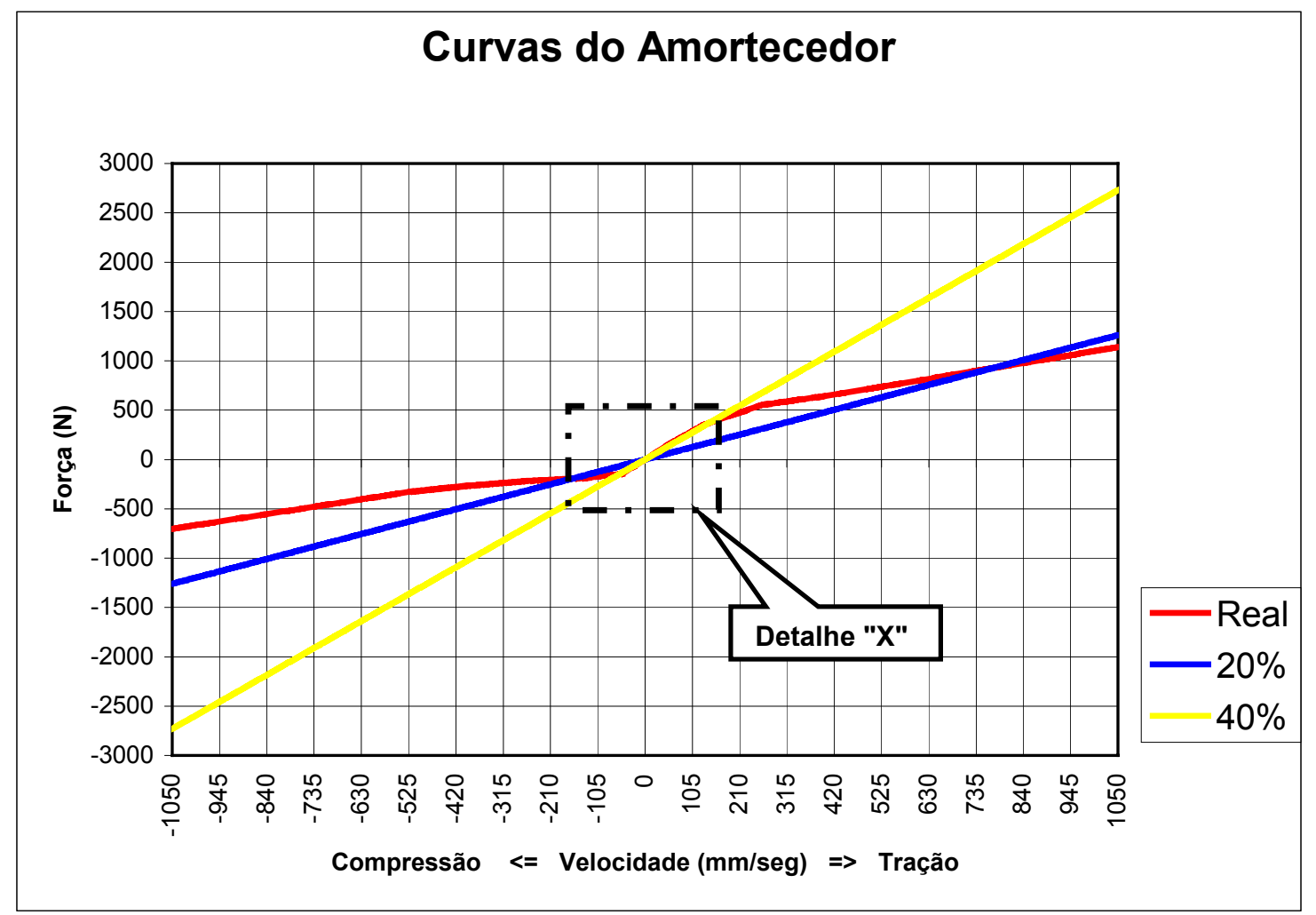

Figura 5.10 - Comparativo das curvas do amortecedor considerando a faixa total de velocidades

O ganho $\frac{\ddot{Z} s}{\ddot{Z} r}$ na frequência de ressonância (pico) da massa suspensa são importantes características, pois demonstram a eficiência do sistema de suspensão em isolar vibrações (provenientes das fontes citadas no item 2.3.1), uma de suas principais funções. O ganho, neste caso, deve ser o menor possível em toda a faixa de frequências.

A importância do valor do ângulo de fase de $\frac{\ddot{Z} s}{\ddot{Z} r}$ está no fato de que, juntamente com a frequência de ressonância, determina o acoplamento das frequências de ressonância dos quatro sistemas de suspensão que compõe o veículo e determinam os modos de vibração vertical, de arfagem e de rolagem. 


\subsubsection{Influência do Amortecimento não-linear}

A dificuldade em avaliar a curva de amortecimento correto pode ser contornada se a curva do amortecedor não-linear real fôr incorporada ao modelo simplificado (ou clássico) de 1/4 de veículo.

Os resultados do modelo simplificado (ou clássico) de 1/4 de veículo com a curva do amortecedor não-linear real são apresentados nos gráficos das figuras 5.11 e 5.12, junto com resultados anteriores para facilitar a comparação visual.
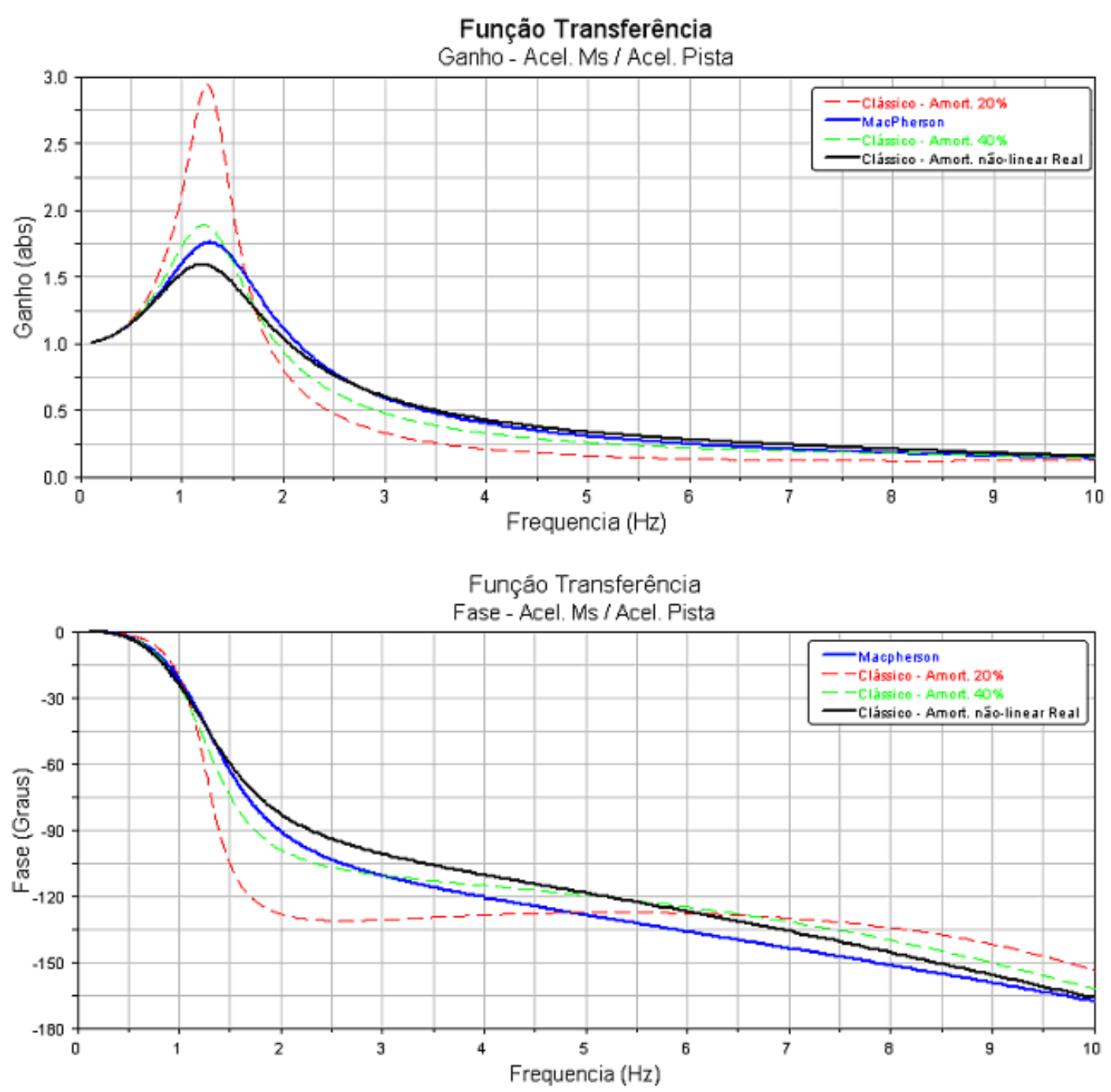

Figura 5.11 - Comparativo de Resultados - Ganho e Fase de $\ddot{Z} s / \ddot{Z} r$ Modelo simplificado (ou clássico) de 1/4 de veículo x Protótipo Virtual MacPherson 


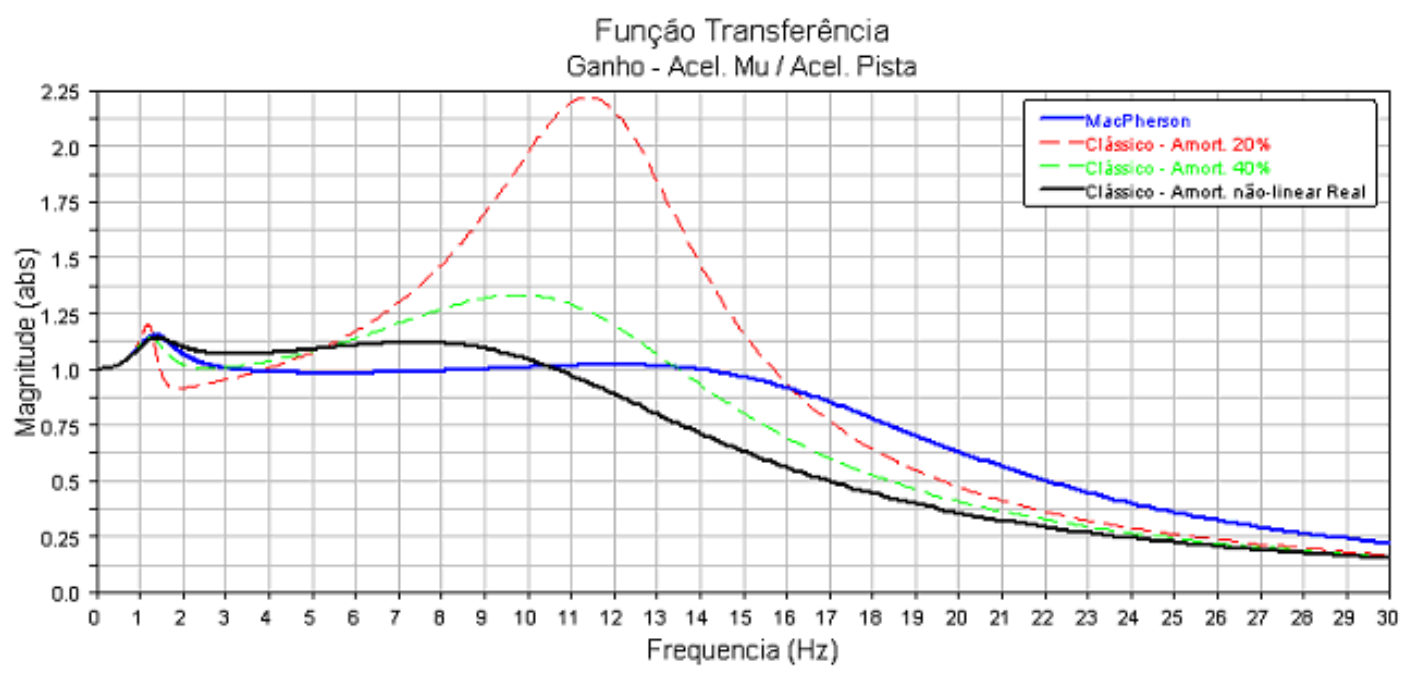

Funçăo Transferência

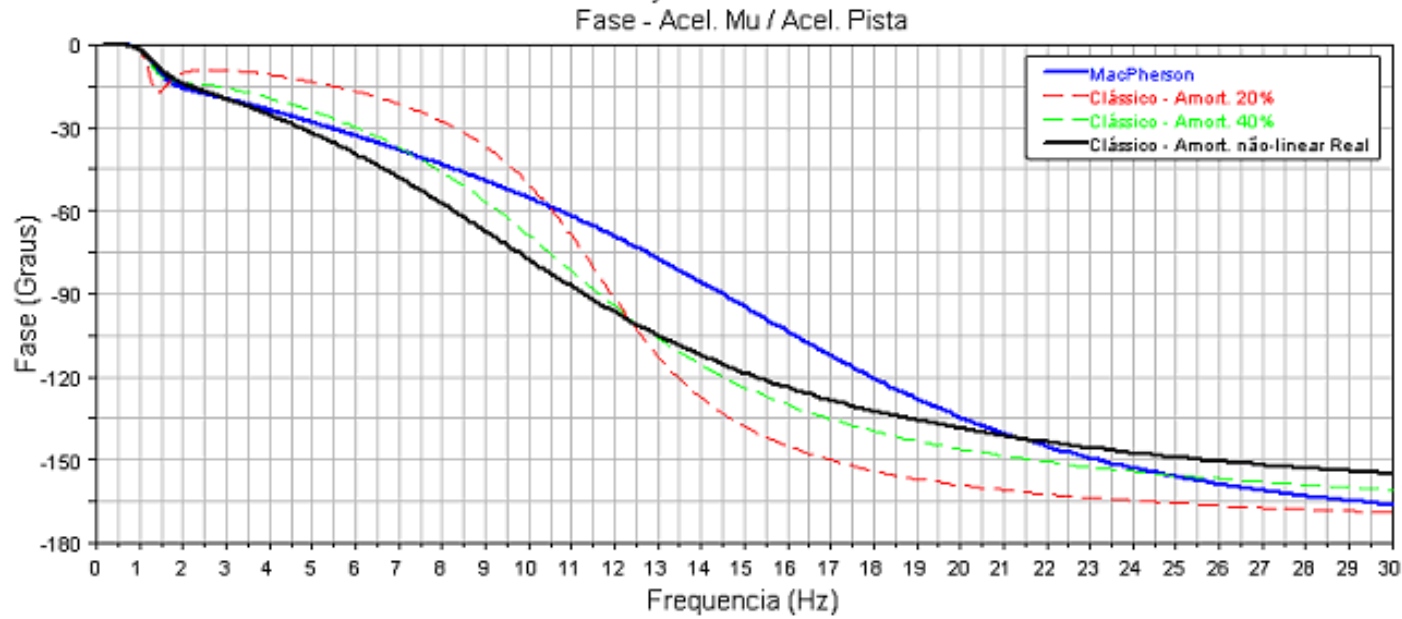

Figura 5.12 - Comparativo de Resultados - Ganho e Fase de $\ddot{Z} u / \ddot{Z} r$

Modelo simplificado (ou clássico) de 1/4 de veículo x Protótipo Virtual MacPherson

A mesma tabela, já apresentada na figura 5.7, é novamente mostrada na figura 5.13, porém com os resultados do modelo simplificado (ou clássico) de 1/4 de veículo com curva do amortecedor não-linear real.

Adotou-se como base para cálculo da diferença percentual, os resultados obtidos através do Protótipo Virtual MacPherson. O cálculo foi efetuado utilizando como base a expressão (5.2). 


\begin{tabular}{|c|r|ccc|}
\hline \multirow{2}{*}{ Referência } & \multirow{2}{*}{ Modelo } & \multicolumn{3}{|c|}{ Frequência de Pico } \\
\cline { 3 - 5 } & & Valor (Hz) & Ganho (abs) & Fase ( ${ }^{\circ}$ ) \\
& PV MacPherson & 1,28 & 1,76 & $-44,00$ \\
Massa & Modelo Clássico 40\% & 1,22 & 1,89 & $-47,00$ \\
suspensa & Diferença (\%) & $-4,7 \%$ & $7,4 \%$ & $6,8 \%$ \\
(Ms) & Modelo Clássico 20\% & 1,25 & 2,94 & $-59,00$ \\
& Diferença (\%) & $-2,0 \%$ & $67,0 \%$ & $34,1 \%$ \\
& Modelo Clássico não-linear & 1,19 & 1,59 & $-37,50$ \\
& Diferença (\%) & $-6,7 \%$ & $-9,7 \%$ & $-14,8 \%$ \\
\hline & PV MacPherson & $\mathbf{1 2 , 3 5}$ & $\mathbf{1 , 0 2}$ & $-\mathbf{7 2 , 0 0}$ \\
Massa & Modelo Clássico 40\% & 9,90 & 1,34 & $-68,00$ \\
não-suspensa & Diferença (\%) & $-19,8 \%$ & $31,4 \%$ & $-5,6 \%$ \\
(Mu) & Modelo Clássico 20\% & 11,35 & 2,22 & $-77,00$ \\
& Diferença (\%) & $-8,1 \%$ & $117,6 \%$ & $6,9 \%$ \\
& Modelo Clássico não-linear & 7,57 & 1,12 & $-53,00$ \\
& Diferença (\%) & $-38,7 \%$ & $9,8 \%$ & $-\mathbf{2 6 , 4} \%$ \\
\hline
\end{tabular}

Figura 5.13 - Comparativo Analítico dos Resultados

Modelo simplificado (ou clássico) de 1/4 de veículo x Protótipo Virtual MacPherson

Pode-se dizer que a incorporação da curva não-linear do amortecedor traz como benefício, eliminar a dificuldade de avaliar o valor do amortecimento linear mais adequado a ser utilizado no amortecedor.

De uma forma geral, as diferenças entre os resultados oferecidos pelo modelo simplificado (ou clássico) de 1/4 de veículo com curva de amortecedor não-linear em relação aos oferecidos pelo Protótipo Virtual MacPherson, são maiores do que as diferenças entre os oferecidos pelo modelo simplificado (ou clássico) de 1/4 de veículo com curva de amortecedor linear e amortecimento $40 \%$ em comparação com os oferecidos pelo Protótipo Virtual MacPherson, considerando-se a frequência de pico.

São consideradas satisfatórias as diferenças percentuais para a massa suspensa, de $-6,7 \%$ para a frequência, $-9,7 \%$ para o ganho e $-14,8 \%$ para a fase, entre os resultados oferecidos pelo modelo simplificado (ou clássico) de $1 / 4$ de veículo com curva de amortecedor não-linear e o Protótipo Virtual MacPherson. 


\subsubsection{Conclusão sobre os resultados no domínio da frequência}

Baseado no exposto acima, pode-se considerar viável o uso do modelo simplificado (ou clássico) de 1/4 de veículo para análises preliminares da resposta no domínio da frequência, apenas para a massa suspensa e como referência. O que nos permite fazer esta afirmação são os erros estimados dos resultados fornecidos pelo modelo simplificado (ou clássico) de 1/4 de veículo com amortecimento não-linear, para a frequência de pico da massa suspensa, de cerca de $-7 \%$ para frequência, $-10 \%$ para o ganho e $-15 \%$ para a fase.

A correta avaliação do amortecimento linear a ser utilizado no amortecedor é de suma importância.

Este conclusão é válida única e exclusivamente para um sistema de suspensão MacPherson que tenha características similares ao da MacPherson aqui estudada. Não é possível afirmar que o mesmo cenário se repetirá para outra suspensão, com características diferentes, mesmo que seja do tipo MacPherson.

O fato de características como atrito, entre outras descritas no item 4.1.3, não serem consideradas, pode aumentar os erros em relação aos resultados reais. 


\subsubsection{Resultados no domínio do tempo}

A seguir são apresentados os resultados da resposta dinâmica no domínio do tempo tendo como entrada o pulso mostrado na figura 4.11.

Os resultados obtidos utilizando-se o modelo simplificado (ou clássico) de $1 / 4$ de veículo e o Protótipo Virtual da suspensão MacPherson são apresentados juntos, para facilitar a comparação.

Importante salientar que os resultados apresentados em todos os gráficos a seguir, foram obtidos através da utilização do modelo simplificado (ou clássico) de $1 / 4$ de veículo ou do Protótipo Virtual da suspensão MacPherson e, portanto, tratam-se de resultados teóricos. Nenhum destes gráficos apresenta resultados obtidos experimentalmente.

\subsubsection{Deslocamento vertical da massa supensa ( $Z s$ )}

Conforme o gráfico mostrado na figura 5.21, até o final do primeiro ciclo de compressão $(t=0.4 \mathrm{~s}$ ) nenhum dos resultados do modelo simplificado (ou clássico) de 1/4 de veículo apresentam boa congruência com o comportamento dinâmico do Protótipo Virtual da suspensão MacPherson. 
Clássico $\times$ MacPherson

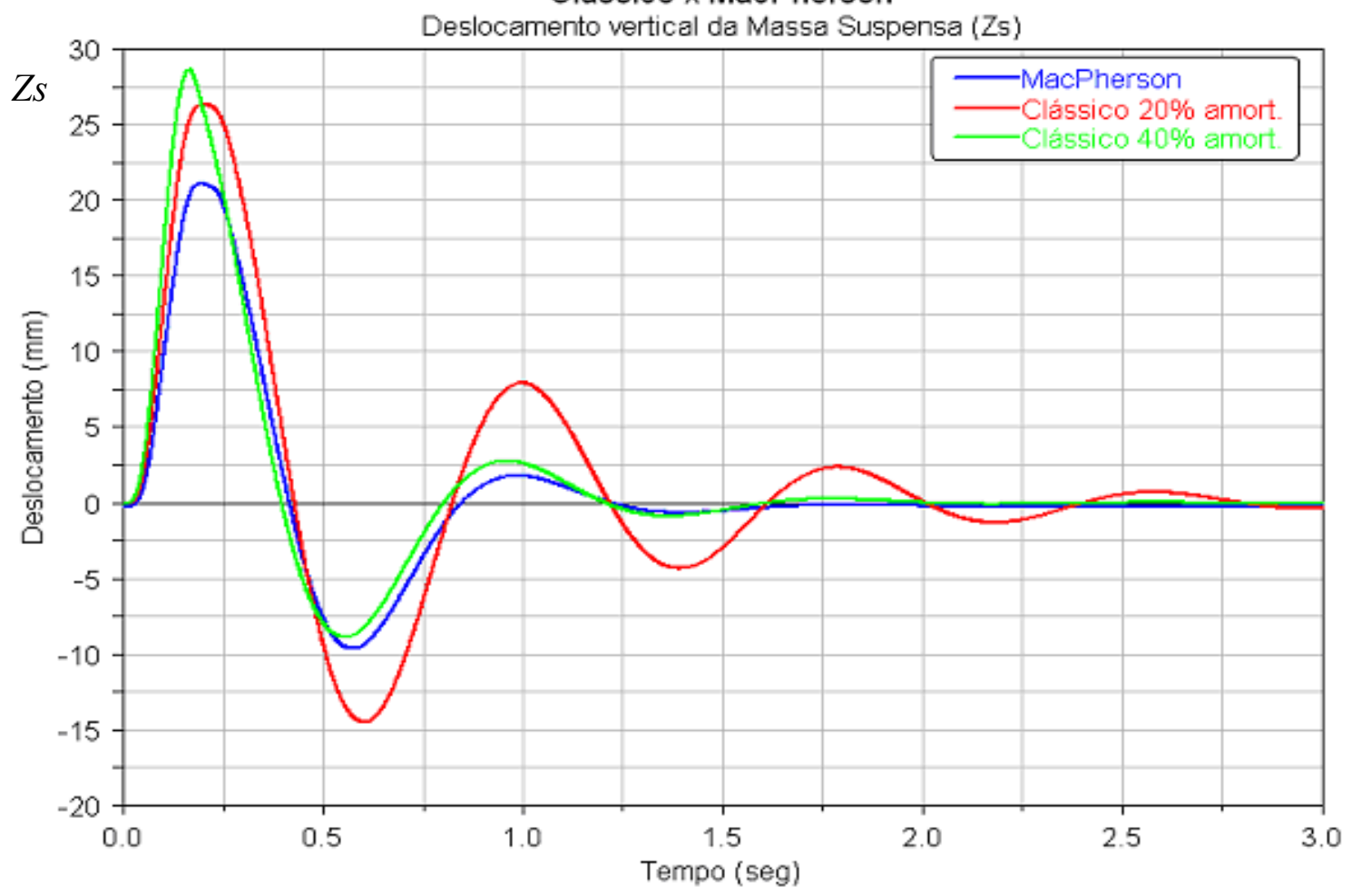

Figura 5.21 - Comparativo entre o modelo simplificado (ou clássico) de 1/4 de veículo e o Protótipo Virtual da suspensão MacPherson considerando o deslocamento vertical da massa suspensa $(Z s)$

A partir de 0,4s o comportamento dinâmico do modelo simplificado (ou clássico) de $1 / 4$ de veículo com amortecimento de $40 \%$ é o que melhor se aproxima dos resultados do Protótipo Virtual da suspensão MacPherson.

\subsubsection{Deslocamento vertical da massa não-suspensa $(Z u)$ :}

O gráfico da figura 5.22 mostra pouca compatibilidade entre os resultados fornecidos pelo modelo simplificado (ou clássico) de 1/4 de veículo e pelo Protótipo Virtual da suspensão MacPherson. Esta, no entanto, pode ser considerada uma característica que tem importância secundária na análise de suspensões. 
Clássico $\times$ MacPherson

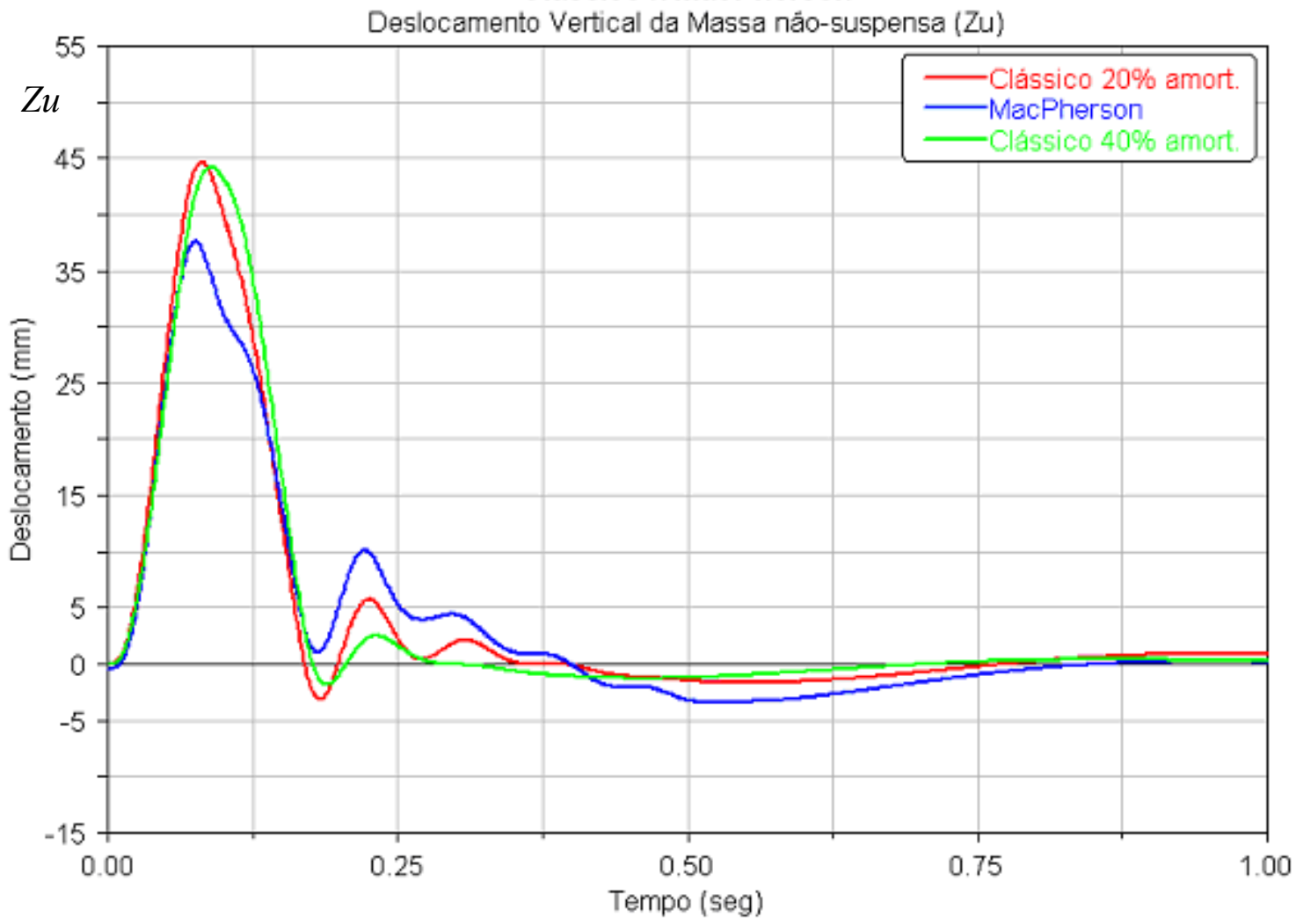

Figura 5.22 - Comparativo entre o modelo simplificado (ou clássico) de 1/4 de veículo e o Protótipo Virtual da suspensão MacPherson considerando o deslocamento vertical da massa não-suspensa $(Z u)$ 


\subsubsection{Aceleração da massa suspensa ( $\ddot{Z} s)$ :}

Esta característica tem grande importância na análise do conforto, juntamente com com a relação do ganho $\ddot{Z} s / \ddot{Z} r$ apresentada na análise no domínio da frequência (item 5.1.1.4).

O gráfico da figura 5.23 mostra que, para esta característica, a melhor coerência ocorre entre o protótipo virtual da suspensão MacPherson e o modelo simplificado (ou clássico) de $1 / 4$ de veículo com $20 \%$ de amortecimento.

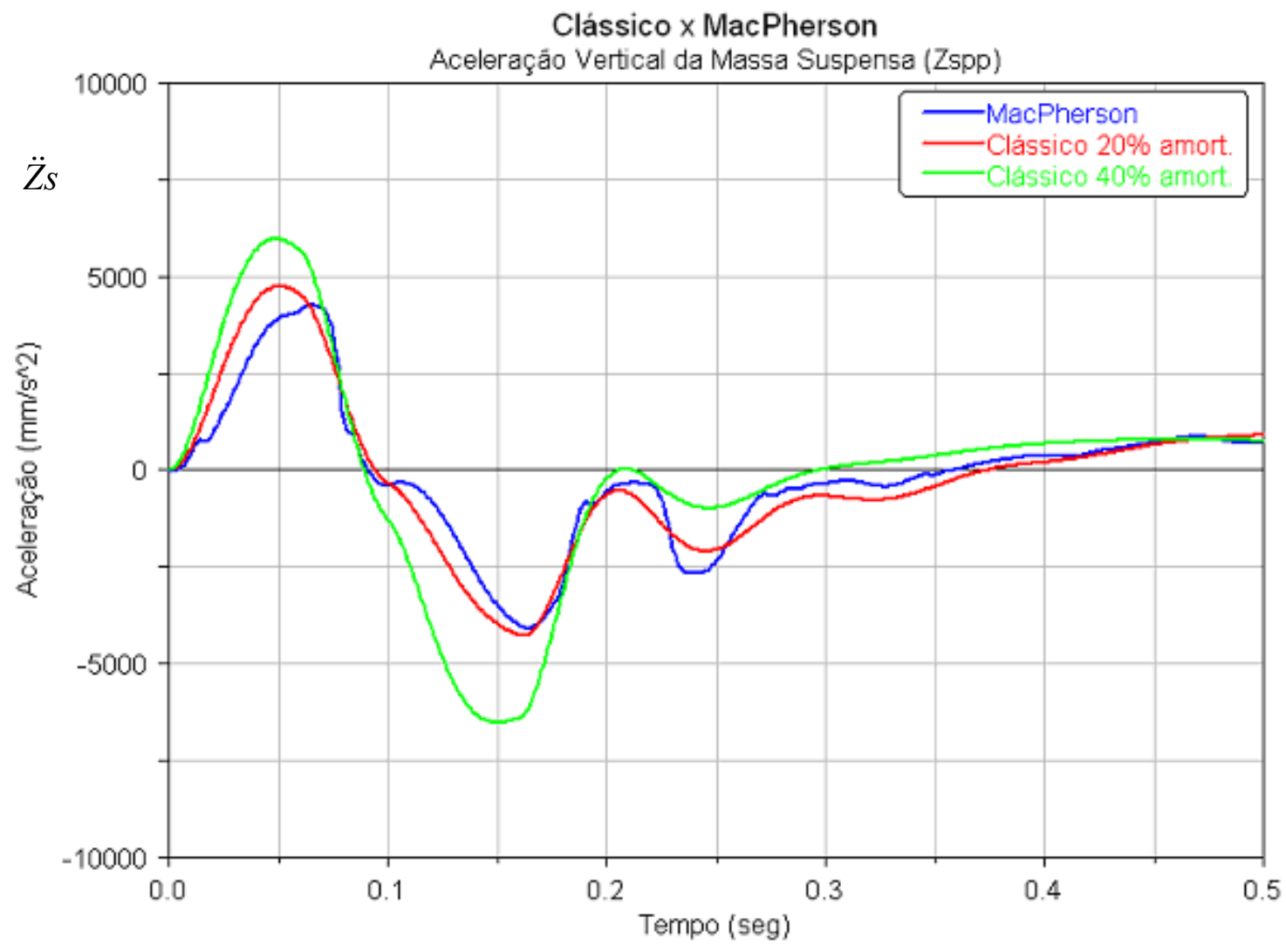

Figura 5.23 - Comparativo entre o modelo simplificado (ou clássico) de 1/4 de veículo e o protótipo virtual da suspensão MacPherson considerando a aceleração vertical da massa suspensa $(\ddot{Z} s)$

A maior amplitude entre picos, observada no modelo simplificado (ou clássico) de $1 / 4$ de veículo com amortecimento de $40 \%$, deve-se ao fato da força gerada pelo amortecedor ser maior neste caso que nos demais. Como a força gerada pelo amortecedor é maior, tanto no ciclo de compressão como no 
ciclo de tração, gera-se, como consequência, maior aceleração da massa suspensa.

\subsubsection{Aceleração da massa não-suspensa ( $\ddot{Z} u$ )}

O gráfico da figura 5.24 mostra que, novamente, a melhor coerência entre o protótipo virtual da suspensão MacPherson e o modelo simplificado de $1 / 4$ veículo ocorre com $20 \%$ de amortecimento.

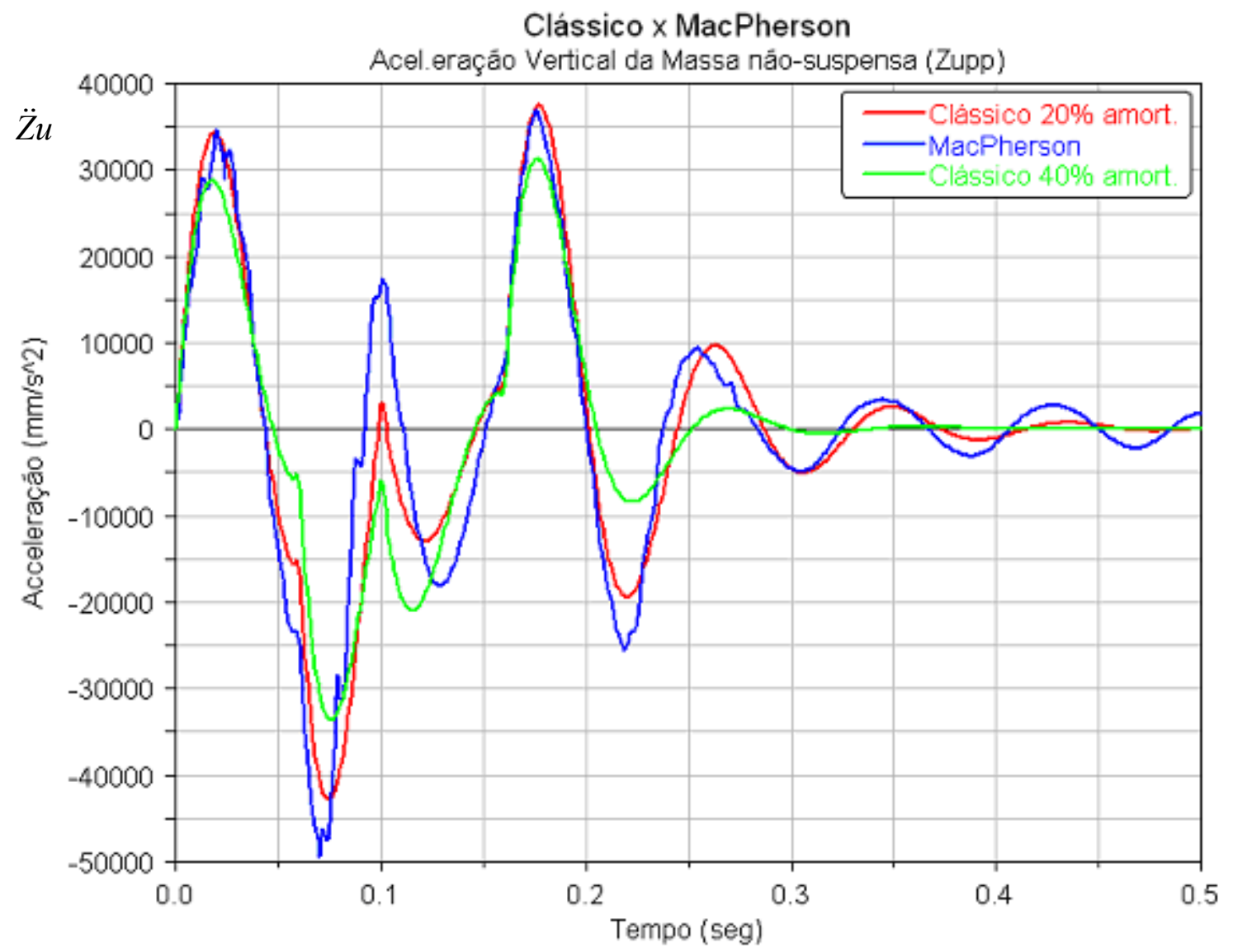

Figura 5.24 - Comparativo entre o modelo simplificado (ou clássico) de 1/4 de veículo e o protótipo virtual da suspensão MacPherson considerando a aceleração vertical da massa não-suspensa $(\ddot{Z} u)$ 


\subsubsection{Força no pneu}

Esta é uma característica de muita importância para a análise da simulação.

A rigidez característica do pneu utilizado, tanto no modelo simplificado (ou clássico) de 1/4 de veículo quanto no protótipo virtual MacPherson, foi considerada linear e com constante igual a $200 \mathrm{~N} / \mathrm{mm}$.

Esta hipótese representa uma boa aproximação somente até um determinado limite de carga radial, limite este que varia conforme as caracterísiticas de cada pneu, as quais podem ser obtidas experimentalmente (vide item 2.3.5).

Neste estudo, foi considerado que até o limite de carga radial de 6000N o pneu tem rigidez com comportamento linear (pneu real). O gráfico da figura 5.25 mostra que a carga radial ou vertical incidente no pneu permanece dentro dos limites em todos os casos estudados.

Mais uma vez o modelo simplificado (ou clássico) de 1/4 de veículo com $20 \%$ de amortecimento apresenta maior compatibilidade com o protótipo virtual da suspensão MacPherson. 


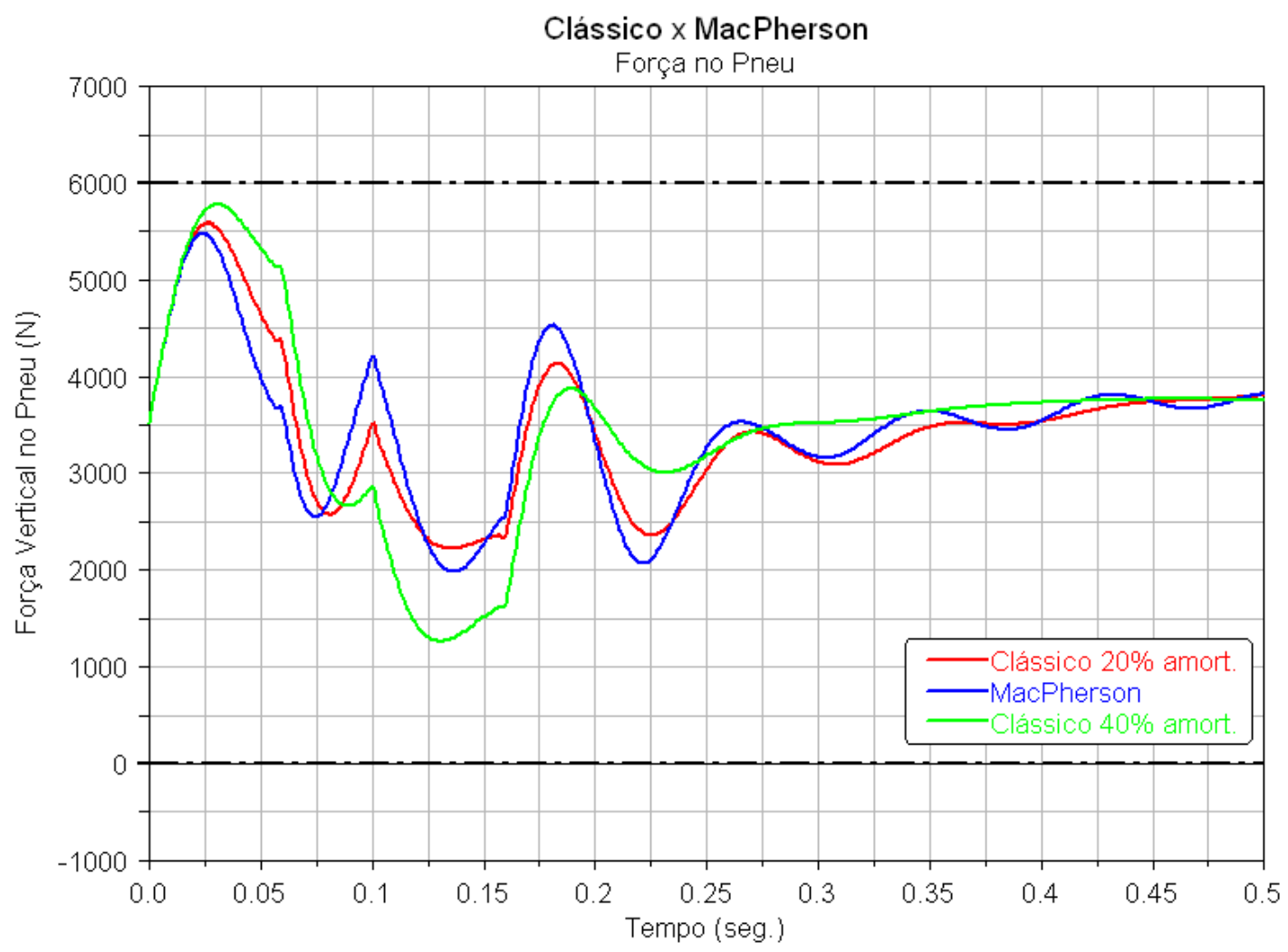

Figura 5.25 - Comparativo entre o modelo simplificado (ou clássico) de $1 / 4$ de veículo e o Protótipo virtual da suspensão MacPherson considerando a força radial (vertical) no pneu

É importante ressaltar que o protótipo virtual da suspensão MacPherson contempla o caso real, ou seja, a possibilidade do pneu perder o contato com o solo, transmitindo, desta forma, somente forças maiores que zero. O modelo simplificado (ou clássico) de 1/4 de veículo não considera esta possibilidade.

\subsubsection{Velocidade de acionamento do amortecedor}

$\mathrm{Na}$ análise do gráfico mostrado na figura 5.26 verifica-se que os limites assinalados por linhas traço-ponto de 1050 e $-1050 \mathrm{~mm} / \mathrm{s}$ não são ultrapassados em nenhum dos casos estudados.

Estes limites indicam a faixa em que foram medidas ou especificadas as caracterísitcas do amortecedor real. Quando estes limites são ultrapassados, entra-se em uma região em que o comportamento da característica de absorção de energia do amortecedor não é conhecida. Para simulações onde estes limites são ultrapassados é necessário conhecer o comportamento do 
amortecedor nesta condição de trabalho para garantir que os resultados fornecidos pelos modelos sejam confiáveis.

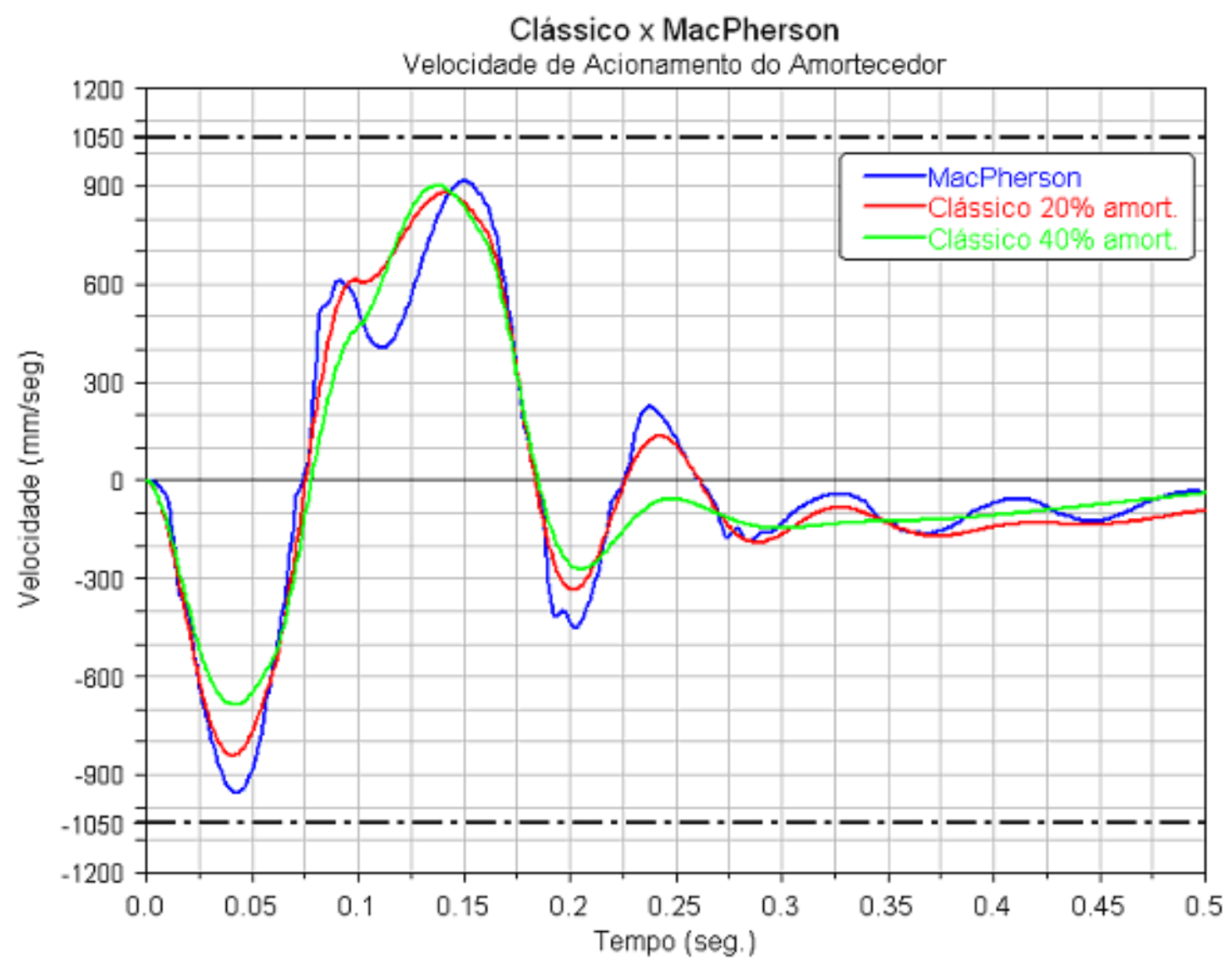

Figura 5.26 - Comparativo entre o modelo simplificado (ou clássico) de 1/4 de veículo e o Protótipo Virtual da suspensão MacPherson considerando a velocidade de acionamento do amortecedor

Ainda pela análise do gráfico da figura 5.26 percebe-se que a velocidade de acionamento do amortecedor permanece maior do que $150 \mathrm{~mm} / \mathrm{s}$ durante a maior parte da simulação em todos os casos. Por este fato e pelo exposto no item 5.1.1.5 e ilustrados pelos gráficos das figuras 5.9 e 5.10 , que analisa a similaridade das curvas lineares do amortecedor $20 \%$ e $40 \%$ com a não-linear real, pode-se explicar ser, o comportamento dinâmico do modelo simplificado (ou clássico) de $1 / 4$ de veículo com amortecimento de $20 \%$, mais similar ao do protótipo virtual da suspensão MacPherson na maior parte dos casos analisados. 


\subsubsection{Curso utilizado do amortecedor}

Os resultados do modelo simplificado (ou clássico) de 1/4 de veículo com amortecimento de $20 \%$ são os mais coerentes com o resultado do protótipo virtual MacPherson conforme mostrado no gráfico da figura 5.27.

Os valores 47 e -106 em evidência no gráfico, linhas traço-ponto, mostram os limites de curso do amortecedor. A observação destes limites tem grande importância conforme exposto no próximo item.

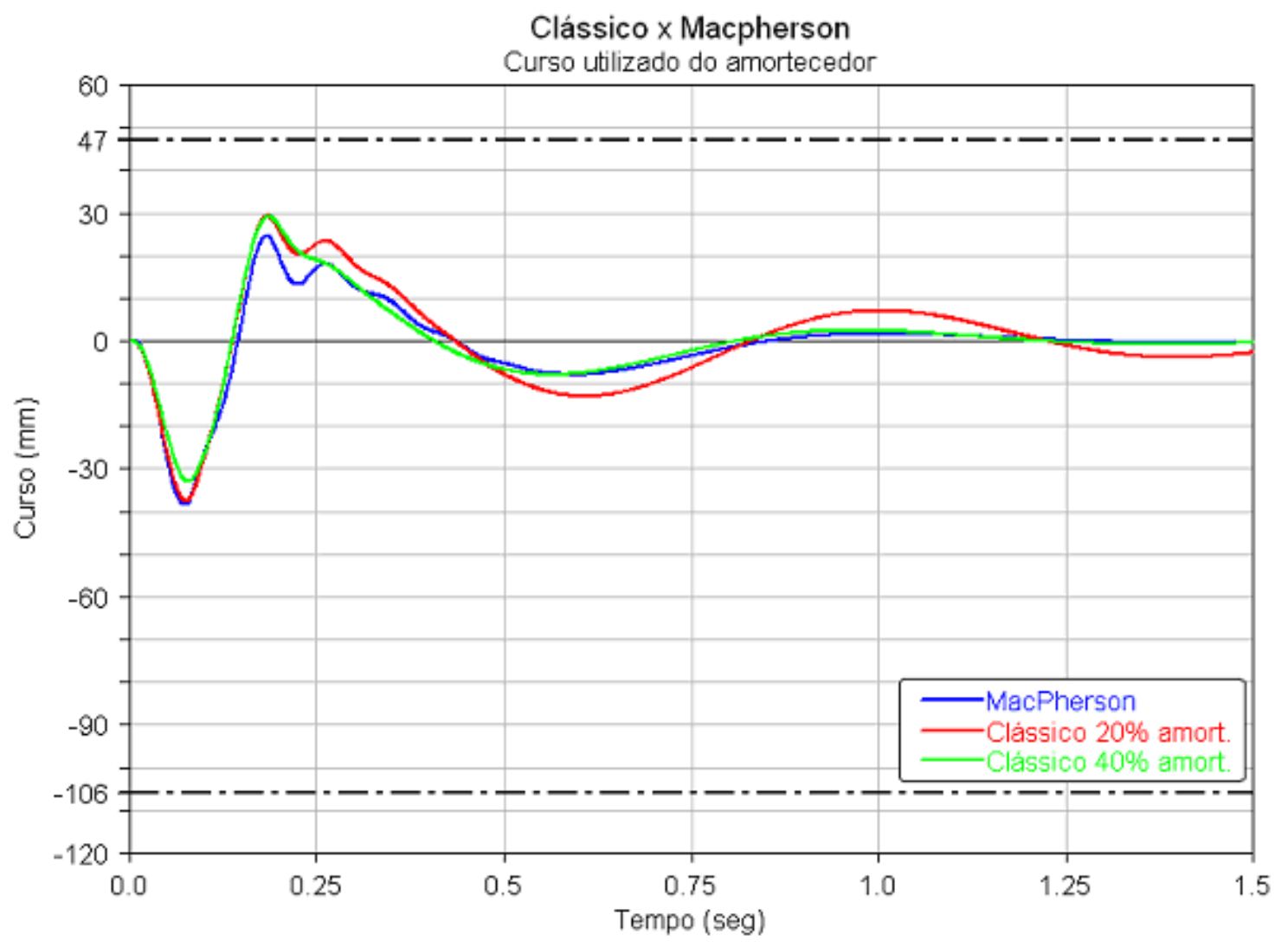

Figura 5.27 - Comparativo entre o modelo simplificado (ou clássico) de 1/4 de veículo e o protótipo virtual da suspensão MacPherson considerando o curso utilizado do amortecedor 


\subsubsection{Carga na mola auxiliar e batente}

Esta é uma característica importante na análise de suspensões, pois é determinante nos seguintes aspectos:

Limitação do curso: em nenhuma suspensão existe disponibilidade total de curso. Segundo GILLESPIE, suspensões que possuem baixas frequências naturais requerem maiores cursos para que as acelerações da pista sejam absorvidas sem atingir os batentes ou os finais de curso da suspensão.

O curso da suspensão depende do espaço disponível, sendo que normalmente veículos maiores comportam maiores cursos de suspensão do que veículos menores e, portanto, tem condições de serem mais confortáveis.

A limitação do curso da suspensão é sempre necessária e evita, por exemplo, a interferência do pneu com a caixa de roda e/ou mantém a variação da geometria da suspensão dentro de limites aceitáveis e conhecidos.

$\mathrm{Na}$ maior parte das situações, a mola auxiliar limita o curso da suspensão na compressão (fechamento) e evita "batentes metálicos", como o toque entre elos da mola principal ou interferências indesejáveis entre as partes internas do amortecedor.

A limitação do curso de extensão da supensão (abertura) é feita por um batente interno no amortecedor (batente de tração).

O correto acerto das características dos componetes citados acima permite otimização do conforto e das cargas que incidem no sistema de suspensão e no veículo.

Conforto: um bom acerto do sistema de suspensão em geral e também das caracteríticas da mola auxiliar e dos batentes de finais de curso, propicia progressividade ao sistema de suspensão.

Uma boa progressividade gera sensação de conforto para os passageiros, de forma que, em situações de solicitação extrema, a sensação de "impacto" ou "batida" na suspensão que os passageiros podem ter, é minimizada. 
Cargas que incidem no sistema: a sensação de "impacto" ou "batida", citada acima, está relacionada com a amplitude da força que o sistema recebe, ou seja, maior sensação de "impacto" ou "batida" refere-se a picos maiores de força.

O gráfico mostrado na figura 5.28 mostra a força gerada pela mola auxiliar e pelo batente em função do curso do amortecedor.

A mola auxiliar atua no fechamento ou compressão da suspensão a partir de $-28 \mathrm{~mm}$ (linha traço-ponto) tendo, característica não-linear e progressividade média.

$\mathrm{Na}$ outra extremidade ou na extensão do amortecedor, para cursos a partir de 40mm (linha traço-ponto), atua o batente localizado na parte interna do amortecedor (batente de tração), que tem característica não-linear e nãoprogressiva. Em função destas características, deve-se evitar ao máxmo o acionamento do batente de tração do amortecedor, ou, se inevitável, a energia a ser absorvida por ele deve ser a menor possível.

A curva mostrada no gráfico da figura 5.28 foi obtida através do protótipo virtual da suspensão MacPherson, comprimindo a suspensão em aproximadamente $78 \mathrm{~mm}$ e extendendo-a em $42 \mathrm{~mm}$ a partir do ponto de equilíbrio estático inicial $(X=0)$. No eixo "X" do gráfico está registrado o curso da suspensão e, no eixo "Y", a força estática necessária.

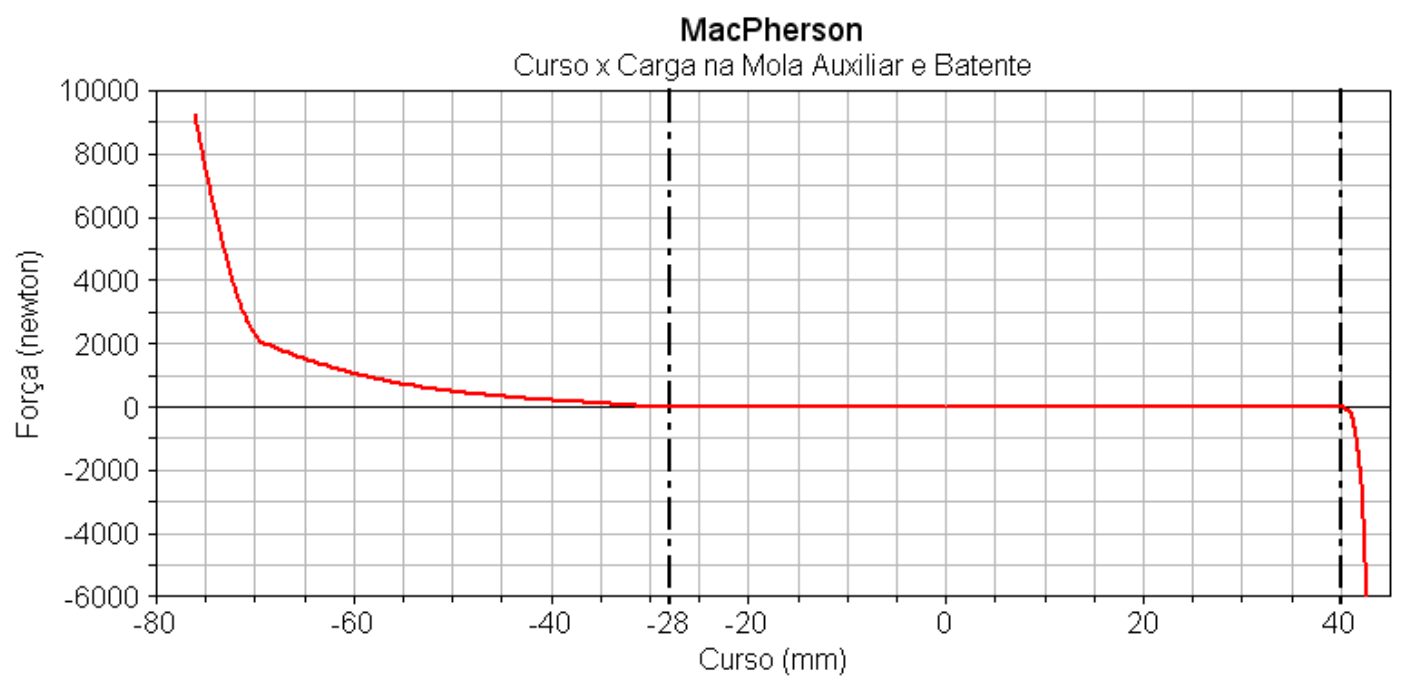

Figura 5.28 - Diagrama Carga x Deformação da Mola auxiliar de compressão e do batente de extensão da Suspensão MacPherson 
Os gráficos das figuras 5.29 e 5.30 , mostram o quanto foi utilizado do curso da suspensão durante a simulação com a entrada "pulso" que está sendo estudada aqui. É possível conlcuir que uma força foi aplicada na suspensão pela mola auxiliar, com amplitude maxima de cerca de $180 \mathrm{~N}$, no primeiro ciclo de compressão do amortecedor e também que o batente que limita a abertura ou extensão da suspensão não foi acionado.

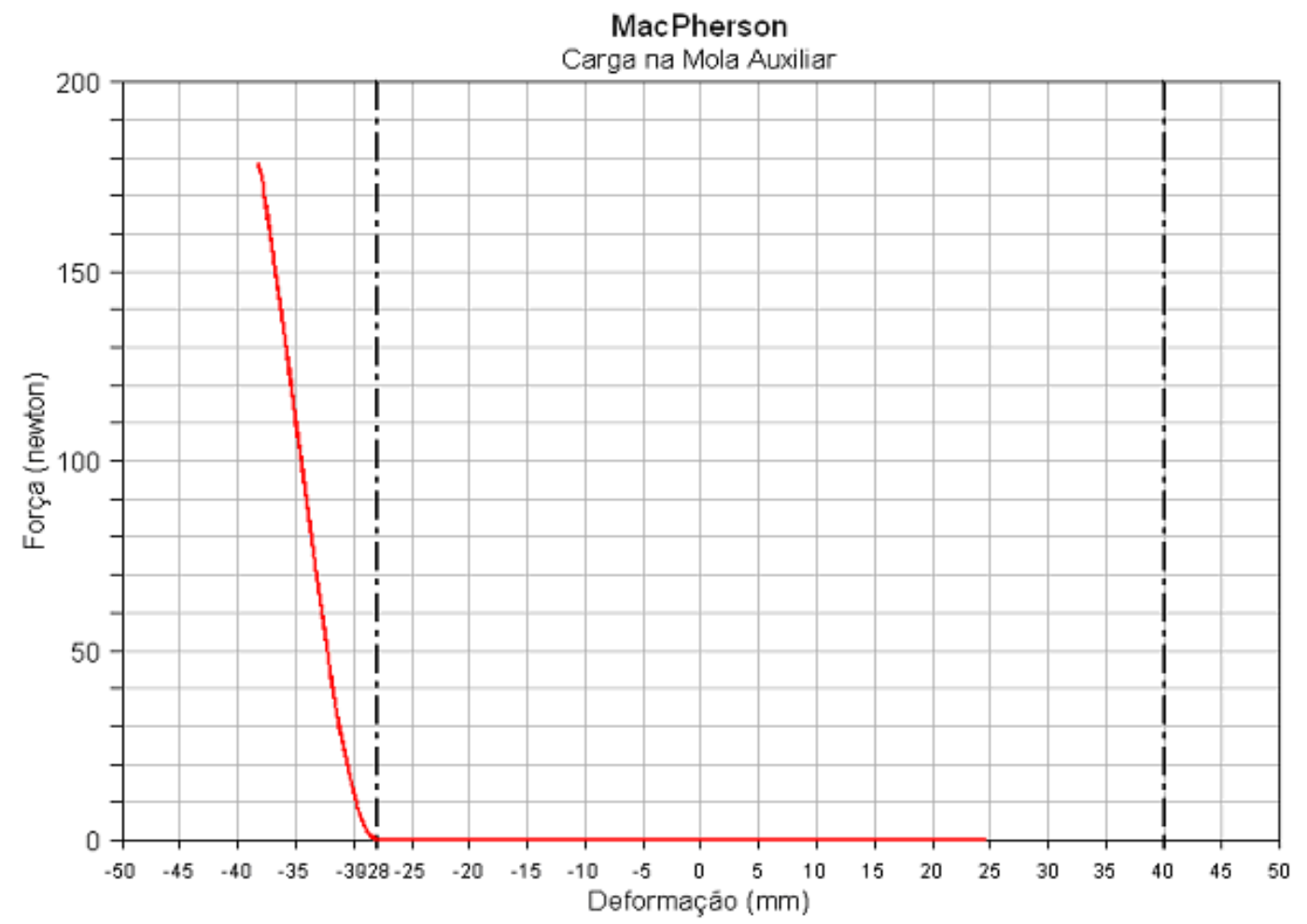

Figura 5.29 - Carga aplicada pela Mola auxiliar na simulação com entrada "pulso" 


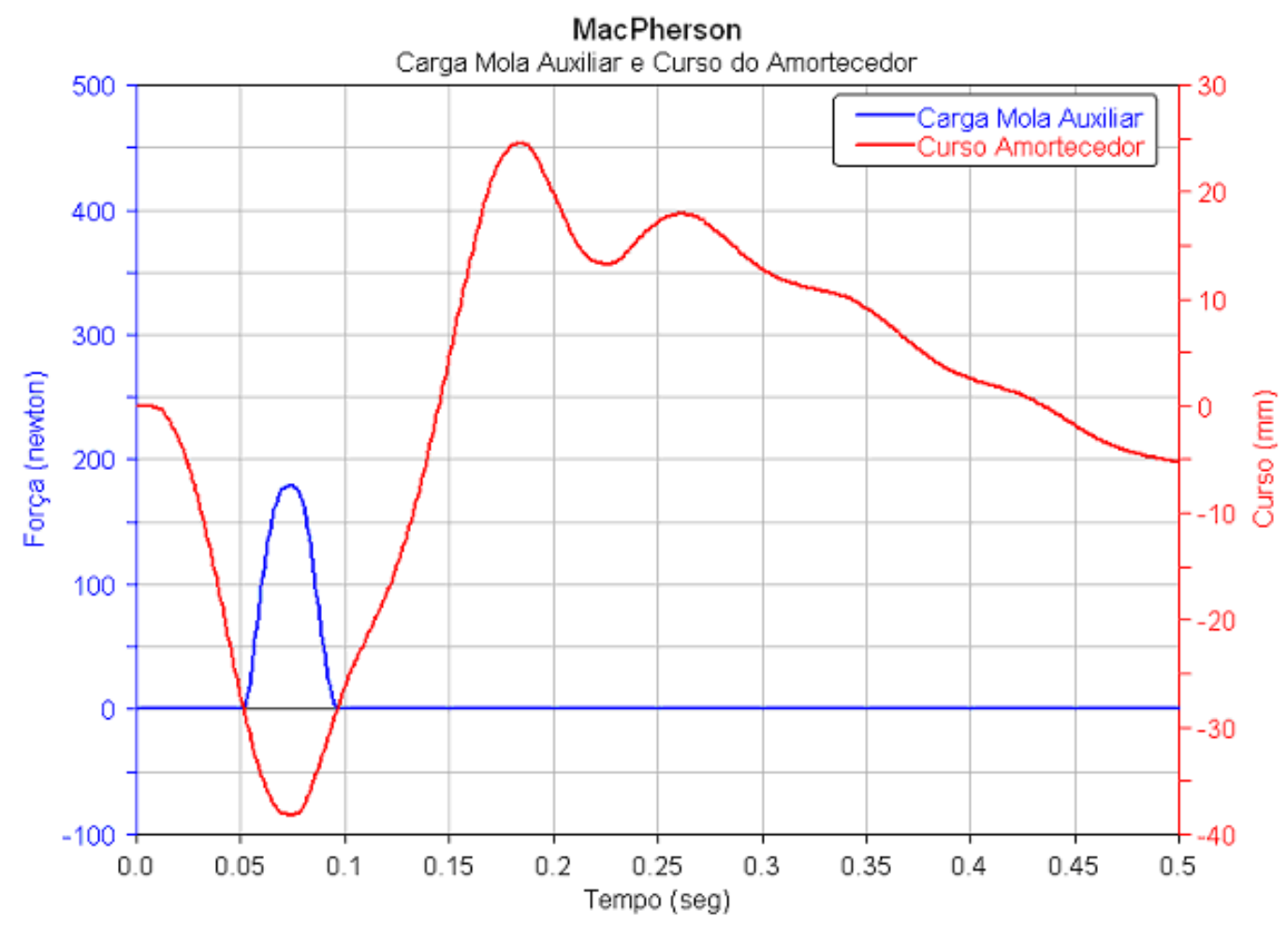

Figura 5.30 - Carga aplicada pela Mola auxiliar e Curso do amortecedor na simulação com entrada "pulso"

Os aspectos expostos acima significam uma limitação do modelo simplificado (ou clássico) de 1/4 de veículo, pois estes componentes da suspensão não estão contemplados neste modelo.

\subsubsection{Influência do Amortecimento não-linear:}

Como já citado no item 5.1.1.6, a dificuldade em avaliar a curva de amortecimento correto para o amortecedor pode ser contornada se a curva do amortecedor não-linear real for incorporada ao modelo simplificado (ou clássico) de $1 / 4$ de veículo, o que é possível se utilizarmos o protótipo virtual deste modelo.

Os resultados do modelo simplificado (ou clássico) de 1/4 de veículo com a curva do amortecedor não-linear real são apresentados na sequência de gráficos mostrados nas figuras 5.31 a 5.37 , junto com resultados do protótipo virtual da suspensão MacPherson para facilitar a comparação visual. 


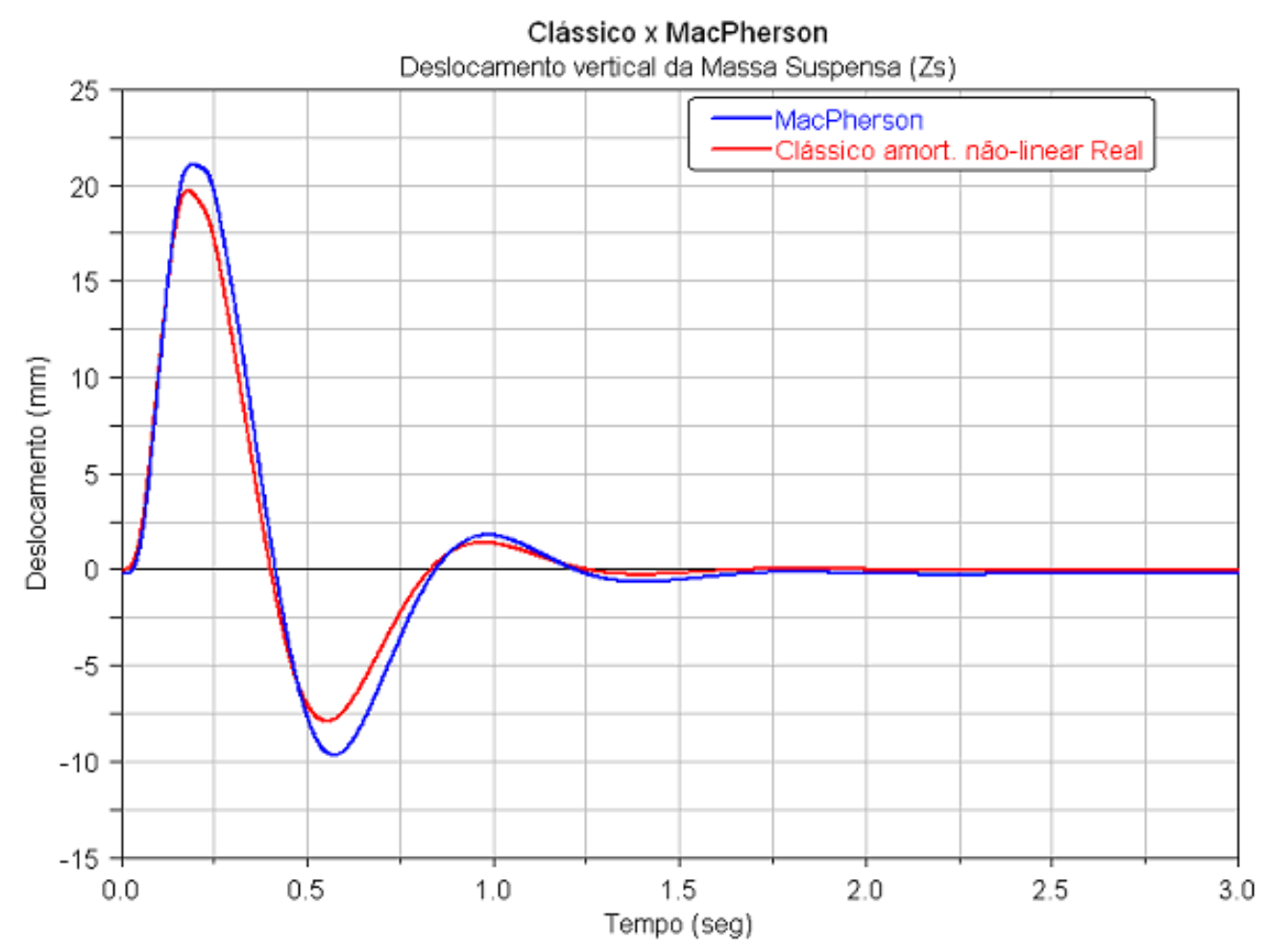

Figura 5.31 - Comparativo entre o Modelo simplificado (ou clássico) de 1/4 de veículo e o protótipo virtual da suspensão MacPherson considerando o deslocamento vertical da massa suspensa $(Z s)$

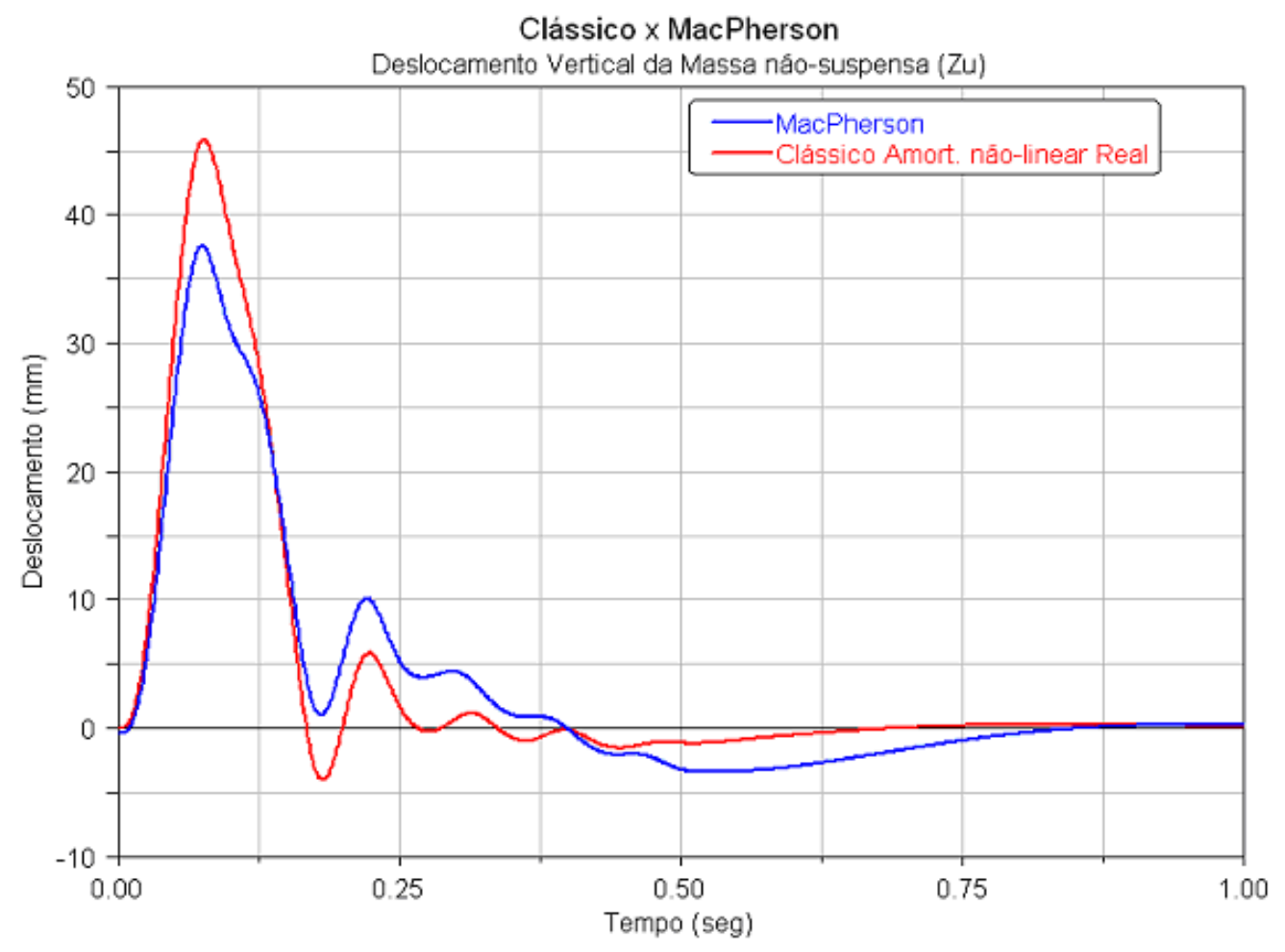

Figura 5.32 - Comparativo entre o Modelo simplificado (ou clássico) de $1 / 4$ de veículo e o protótipo virtual da suspensão MacPherson considerando odeslocamento vertical da massa não-suspensa $(Z u)$ 


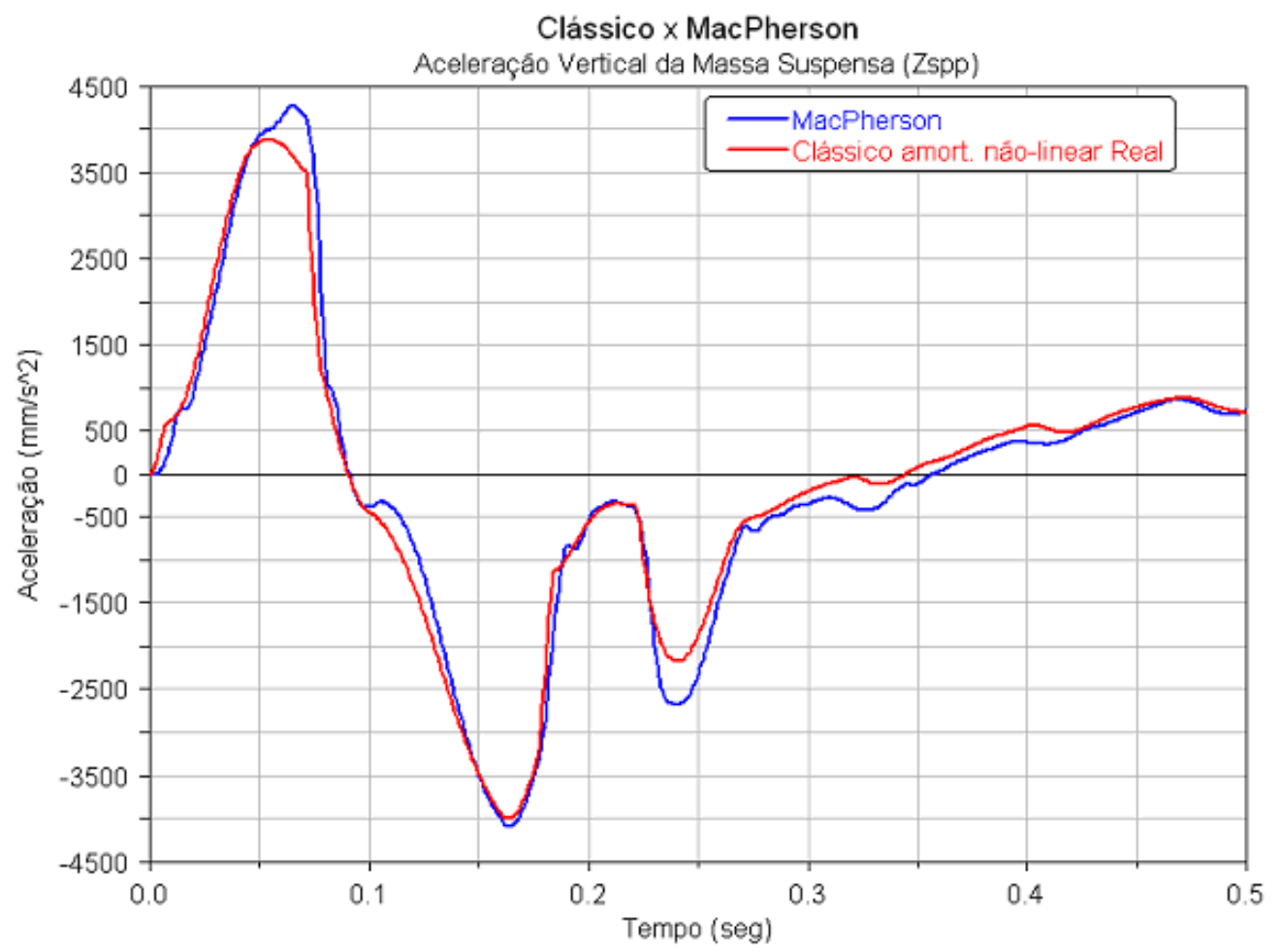

Figura 5.33 - Comparativo entre o Modelo simplificado (ou clássico) de $1 / 4$ de veículo e o protótipo virtual da suspensão MacPherson considerando a aceleração vertical da massa suspensa ( $\ddot{Z} s$ )

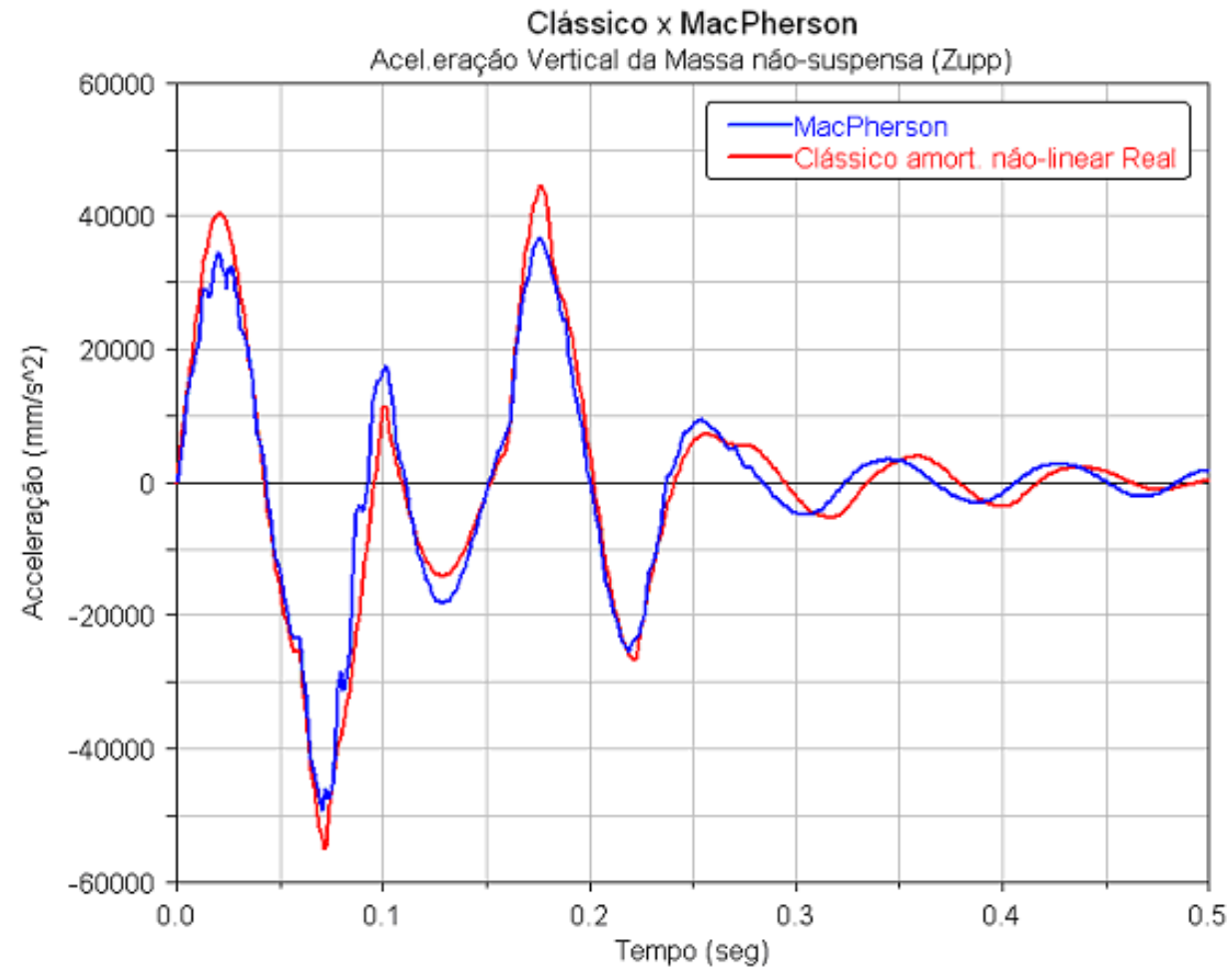

Figura 5.34 - Comparativo entre o Modelo simplificado (ou clássico) de 1/4 de veículo e o protótipo virtual da suspensão MacPherson considerando a aceleração vertical da massa não-suspensa $(\ddot{Z} r)$ 


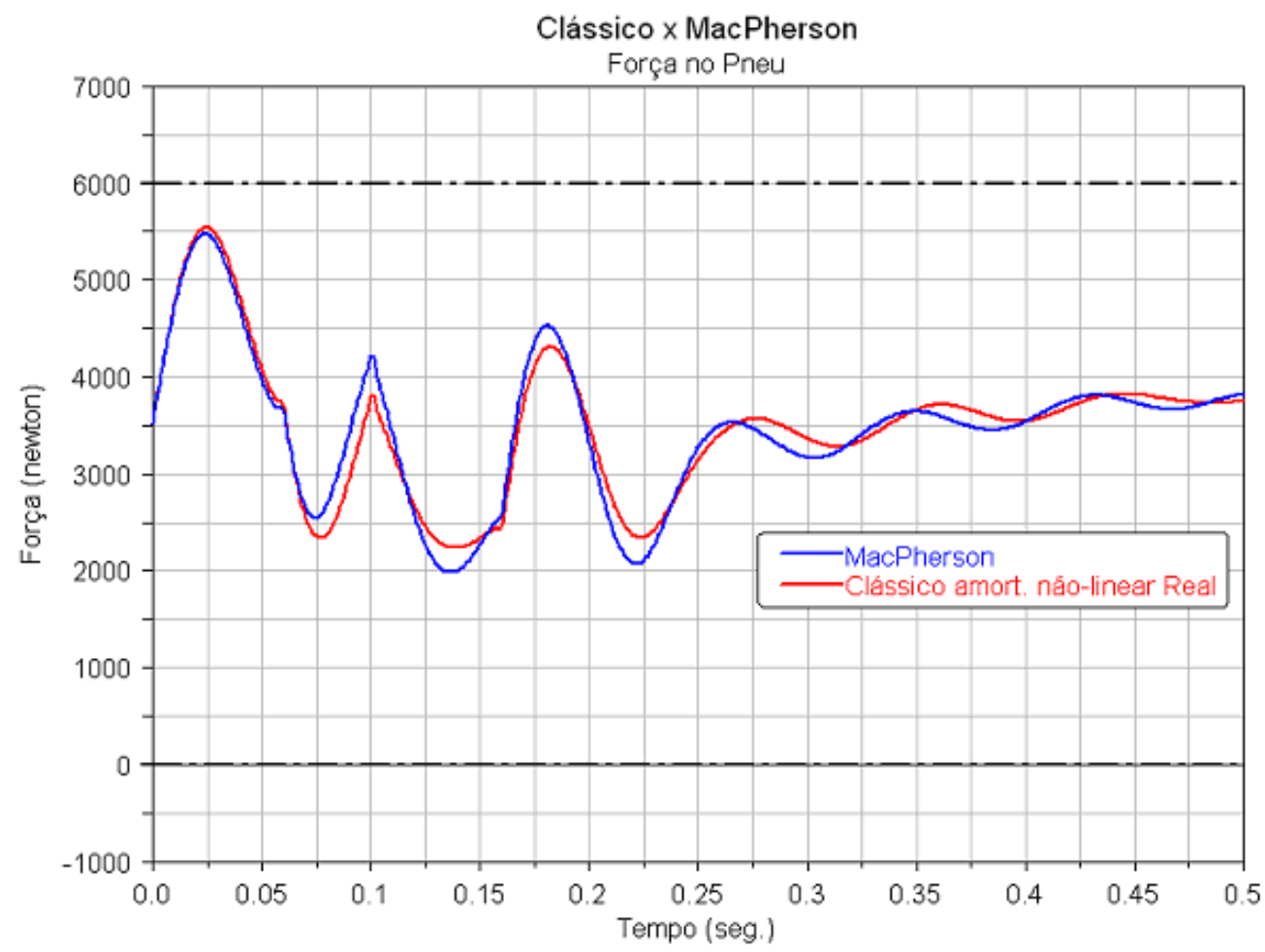

Figura 5.35 - Comparativo entre o Modelo simplificado (ou clássico) de $1 / 4$ de veículo e o protótipo virtual da suspensão MacPherson considerando a força radial (vertical) no pneu

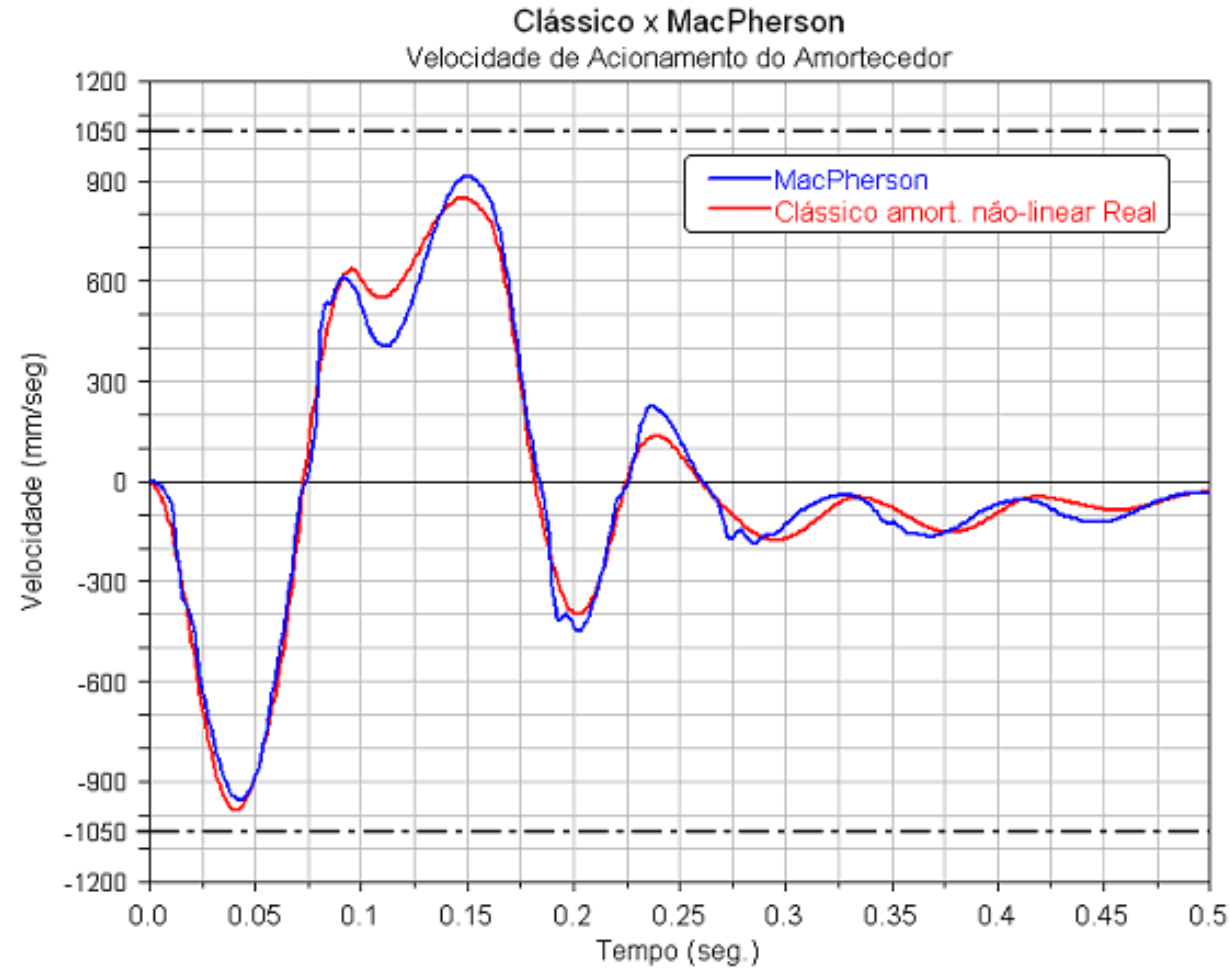

Figura 5.36 - Comparativo entre o Modelo simplificado (ou clássico) de 1/4 de veículo e o protótipo virtual da suspensão MacPherson considerando a velocidade de acionamento do amortecedor 


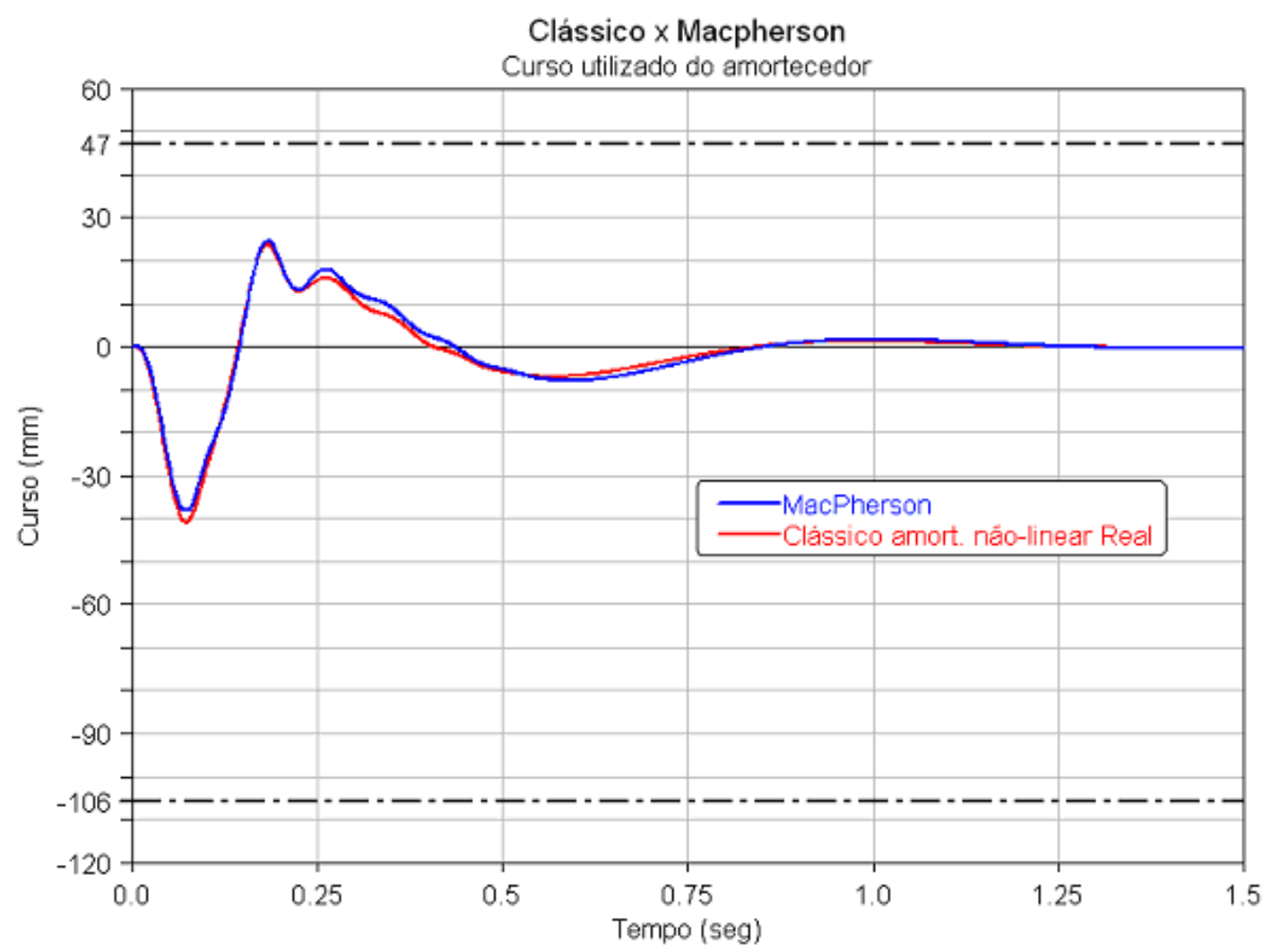

Figura 5.37 - Comparativo entre o Modelo simplificado (ou clássico) de 1/4 de veículo e o protótipo virtual da suspensão MacPherson considerando o curso utilizado do amortecedor

Através da análise visual, qualitativa e subjetiva dos gráficos apresentados pelas figuras 5.31 a 5.37 , verifica-se grande aumento da congruência entre os resultados do modelo simplificado (ou clássico) de 1/4 de veículo e do protótipo virtual da suspensão MacPherson com a simples adoção da mesma curva não-linear do amortecedor nos dois casos.

Este fato demonstra que a influência do amortecimento, neste caso particular de tipo de suspensão e simulação, é preponderante sobre as demais características apresentadas no item 4.1.3, que trata das principais diferenças entre o modelo simplificado (ou clássico) de 1/4 de veículo, o protótipo virtual da suspensão MacPherson e o real.

Especificamente, para o caso estudado, os finais de curso da suspensão não são atingidos, houve pouca influência da mola auxiliar, conforme pode ser constato pelo gráfico da figura 5.30, o pneu não perde contato com o solo, conforme pode ser constatado pelo gráfico da figura 5.35, entre outros fatos. Nem sempre, no entanto, isto ocorre. 
A maior ocorrência, no entanto, de situações como as citadas acima, pode aumentar bastante a diferença entre os resultados fornecidos pelo modelo simplificado (ou clássico) de 1/4 de veículo e pelo protótipo virtual da suspensão MacPherson.

\subsubsection{Conclusão sobre os resultados no domínio do tempo}

Pelo exposto acima, podemos concluir que é possível utilizar o modelo simplificado (ou clássico) de 1/4 de veículo para simulações no domínio do tempo, porém, com restrições.

Esta conclusão leva em consideração que são bastante frequentes neste tipo de análise e em função de seu objetivo, situações onde são atingidos os finais de curso da suspensão e/ou a ação da mola auxiliar é significativa e/ou ainda, há perda de contato do pneu com o solo, o que não ocorreu na situação estudada. Quando, no entanto, isto ocorre, a diferença entre os resultados oferecidos pelo modelo simplificado (ou clássico) de $1 / 4$ de veículo e os oferecidos pelo protótipo virtual da suspensão MacPherson podem ser maiores do que os observados aqui.

Neste caso, muitas vezes é possível "adaptar" o modelo simplificado (ou clássico) de 1/4 de veículo para que forneça resultados mais próximos da realidade. Assim como a utilização da curva não-linear, por exemplo, outras "adaptações", como a adição de finais de curso e da mola auxiliar, podem ser feitas.

Estas "adaptações", no entanto, não tem muito sentido na medida em que o modelo simplificado (ou clássico) de 1/4 de veículo começa a perder a simplicidade, que é um de seus aspectos mais positivos, e, muitas vezes, estas adaptações, podem ser mais trabalhosas do que a construção de um protótipo virtual, como o da suspensão MacPherson utilizado neste estudo. 


\section{Capítulo 6 - Conclusões}

Conforme a conclusão sobre os resultados no domínio da frequência, item 5.1.1.7, considera-se viável a utilização do modelo simplificado (ou clássico) de 1/4 de veículo para análises preliminares da resposta no domínio da frequência, apenas para massa suspensa e como referência. Esta conclusão vale somente para suspensões do tipo MacPherson que tenham características similares às da estudada neste trabalho.

A conclusão sobre os resultados no domínio do tempo, item 5.1.2.10, conclui que é possível utilizar o modelo simplificado (ou clássico) de 1/4 de veículo para simulações no domínio do tempo, porém com restrições, as quais são em função deste estudo ter abordado uma única situação particular passagem por um obstáculo a $18 \mathrm{Km} / \mathrm{h}$ - e não ter abordado inúmeras outras.

Como sugestão, pode-se simular outras situações reais, visando comparar os resultados oferecidos pelo modelo simplificado (ou clássico) de $1 / 4$ de veículo e os oferecidos pelo protótipo virtual da suspensão MacPherson.

Não são recomendadas "adaptações" no modelo simplificado (ou clássico) de 1/4 de veículo visando melhorar a congruência dos resultados oferecidos por ele com a realidade, em função destas adaptações serem trabalhosas e por não garantirem resultados mais confiáveis.

Deve-se considerar que, dependendo das necessidades a médio e longo prazo, é melhor investir tempo na construção de um protótipo virtual. Se o objetivo for a análise e otimização estrutural dos componentes da suspensão ou ainda a dirigibilidade do veículo (handling), por exemplo, que não foram abordadas aqui, vale a pena optar pela construção de um protótipo virtual. 
Consideram-se atingidos os objetivos e a expectativa é de que este trabalho represente uma contribuição para o desenvolvimento tecnológico brasileiro e seja particularmente útil para iniciantes em estudos dinâmicos de veículos automotores. 


\section{Referências Bibliográficas}

Ordem cronológica

LANCHESTER, F. W. (1907/1908). Some problems peculiar to the design of the automobile, Proceedings of the Institution of Automobile Engineers, vol.2, p.197 -287

SHARP, A. (1909). Pneumatic springs for road vehicles, Proceedings of the Institution of Automobile Engineers, vol. 4

LITCHFIELD, P. W. (1913). Pneumatic tires, SAE Transactions, vol. 8

OLLEY, M. (1921). European and American automobile practice compared, Transactions of the Society of Automotive Engineers, vol. 16

ROWELL, H. S. (1922/1923). Principles of vehicle suspension, Proceedings ofthe Institution of Automobile Engineers, vol. 17

PURDY, J. F. \& DAY, R. B. (1927). A method of measuring the cushioning quality of tires, SAE Transactions, vol. 22

BROWN, R. W. (1928). The measurement of riding-qualities, SAE Transactions, vol. 23

MOSS, F. A. (1931). Measurement of comfort in automobile riding, SAE Transactions, vol. 25-26

BROWN, R. W. (1932). The tire factor in automobile riding-quality, SAE Transactions, vol. 27

KURT, O. E. 1933. An analysis of tires and wheels as causes of tramp, SAE Transactions, vol.28, 
BROULHIET, G. (1933). Independent wheel suspension, SAE Transactions, vol. 28

OLLEY, M. (1934). Independent wheel suspension - its whys and wherefores, SAE Transactions, vol. $34, \mathrm{n}^{\circ} 3$

OLLEY, M. (1943). Notes on light motor cars, SAE paper 430083

OLLEY, M. (1944). Speculations on post war cars, SAE paper 440052

OLLEY, M. (1946/1947). Road manners of the modern car, Proceedings of the Institution of Automobile Engineers, vol. 51

OLLEY, M. (1955). Report on suspensions for commercial vehicles, SAE paper 550125

COX, H. L. (1955/1956). The riding qualities of wheeled vehicles, Proceeding of I.Mech.E., Automobile Division, $n^{\circ} 10$

(1961). The effects of loaded radial runout on tire roghness and shake, SAE paper 610545

ELLIS, J.R. (1962). Experimental confirmation of ride theory, Proceedings of a Symposium on Vehicle Ride, Advanced School of Automobile Engineering, Cranfield

DEN HARTOG, J. P. (1984). Mechanical vibrations, Dover Publications, New York, 436p.

BEST, A. (1984). Vehicle ride - stages in comprehension, Phys. Technology, Northern Ireland, vol. 15 
SHARP, R. S.; PILBEAM, C. (1993). Achievability and value of passive suspension designs for minimum pitch response, Proceedings I.Mech.E., Conference on Vehicle Ride and Handling, p. 243-259

LEDESMA, R. (2002). Ride performance comparison of trailer suspension systems using computational methods, SAE paper 2002-01-3103, Intemational Truck \& Bus Meeting and Exposition

PERSEGUIM, O.T.; PERES, E.; FERNANDES, C.G. (2003). Pickups vehicle dynamics: ride and skate, SAE paper 2003-01-3588, Congresso SAE Brasil 2003, São Paulo

GILLESPIE, T. D. (1992). Fundamentals of Vehicle Dynamics, Society of Automotive Engineers, p. 237-247

REIMPELL, J. S. (2001). The Automotive Chassis: Engineering Principals, Society of Automotive Engineers, p. 307-385

DIXON, J. C. (1999). The Shock Absorber Handbook, Society of Automotive Engineers, p. 1-138

MUHR \& BENDER (1993). Side load springs as a solution to minimize adverse side loads acting on the MacPherson strut, SAE paper 940862

HILL, Dr. G. (2003). Vehicle Dynamics Lecture notes, FACHHOCHSCHULE REGENSBURG UNIVERSITY OF APPLIED SCIENCES, p. 25, p. 79-109

MILLIKEN, W. F. (1995). Race Car Vehicle Dynamics, Society of Automotive Engineers, p. 755-786

PACEJKA, H. B. (2002). Tire and Vehicle Dynamics, Society of Automotive Engineers, p. 1-138 
NETO, Á. COSTA (2005). Dinâmica Veicular, Universidade de São Paulo, São Carlos, BR, p. 65-115 